\title{
Puntas de flecha orientalizantes en contextos urbanos del Sureste de la Península Ibérica: Peña Negra, La Fonteta y Meca Early Iron Age arrowheads in urban contexts from the Southeast of the Iberian Peninsula: Peña Negra, La Fonteta and Meca
}

\author{
Alberto J. Lorrio*, Sara Pernas ${ }^{* *}$, Mariano Torres Ortiz***
}

Recibido 15/05/2016

Aceptado 19/09/2016

\section{Resumen}

Se analiza un conjunto de puntas de flecha orientalizantes de bronce, en su mayoría del tipo de doble filo y arpón lateral, procedentes de tres destacados núcleos urbanos: Herna/Peña Negra y La Fonteta, en el Sureste peninsular, y El Castellar de Meca en los rebordes de la Meseta Sur. Se realiza la clasificación tipológica del medio centenar de piezas catalogadas, identificando nuevas variantes, se analizan las huellas de impacto y roturas así como el análisis metalográfico de algunas de ellas. A continuación se estudian los contextos de hallazgo, repasando posibles evidencias de inestabilidad, al tiempo que se revisa la presencia de este tipo de armas en contextos orientalizantes contemporáneos del cuadrante suroriental de la Península Ibérica. Finalmente se revisa la presencia de este tipo de puntas en contextos de la Segunda Edad del Hierro de la zona

Palabras clave. Puntas de flecha, Período Orientalizante, Primera Edad del Hierro, Cultura lbérica, Sureste de la Península lbérica.

\begin{abstract}
A collection of Orientalizing bronze arrowheads, mainly of the one-barb, double edge, socketed type, are analyzed in this paper. They were found in three outstanding urban settlements: Herna/Peña Negra and La Fonteta in Southeastern Iberia, and Castellar de Meca, in the eastern limits of the Southern Plateau. A typological classification is also made, defining new subtypes. Impact traces, breakings and metallographic studies are also analyzed. Next their finding contexts are studied, revising possible contexts of instability and the appearance of this kind of weapon in contemporary Orientalizing contexts in Southeastern Iberia. Finally, the presence of this arrowhead type in Late Iron Age contexts of the area is reviewed.
\end{abstract}

Key words: Arrowheads, Orientalizing period, Early Iron Age, Iberian culture, Southeastern Iberia.

\section{INTRODUCCIÓN}

El hallazgo en los últimos años de numerosas puntas de flecha de bronce en algunos destacados yacimientos protohistóricos del cuadrante suroriental de la Península Ibérica nos ha llevado a plantear una revi-

\footnotetext{
* Universidad de Alicante. alberto.lorrio@ua.es

** Universidad de Alicante.spg3323@gmail.com

***Universidad Complutense.mtorreso@ghis.ucm.es

1 Este trabajo se ha realizado dentro del marco del proyecto del Ministerio de Economía y Competitividad HAR2013-41447$\mathrm{P}$ "El Bronce Final y la Edad del Hierro en el Sureste y el
}

sión del repertorio arqueológico conocido en la actualidad en las tierras del Bajo Segura-Vinalopó y áreas colindantes del Sureste que incorpora, a los ejemplares ya publicados, un buen número de piezas inéditas ${ }^{1}$. Se trata de un tipo arma frecuente en contextos de época

Levante de la Península Ibérica: procesos hacia la urbanización". Las topografías de Peña Negra y El Castellar de Meca han sido realizadas en el marco del proyecto. Por su parte, la topografía de La Fonteta se ha realizado en el marco del proyecto de la Generalitat Valenciana de puesta en valor del yacimiento, agradeciendo la autorización para su uso. 
orientalizante, registrado a partir del hallazgo de puntas metálicas del tipo de doble filo y arpón lateral, sobre todo, con diferentes variantes, un modelo igualmente documentado en yacimientos de cronología posterior, ya plenamente ibérica, aunque siempre en cantidades notablemente inferiores, tema que será igualmente objeto de discusión, toda vez que al menos una parte de las piezas que presentamos pudiera fecharse en ese momento. Se conocen otros tipos de puntas de flecha, cuya presencia es prácticamente testimonial, incluidos igualmente en el trabajo.

El trabajo aborda el estudio de los hallazgos de Peña Negra (Crevillent, Alicante) y La Fonteta (Guardamar del Segura, Alicante), en las tierras meridionales de la provincia de Alicante, así como de El Castellar de Meca (Ayora, Valencia), en los rebordes suroccidentales de la de Valencia ${ }^{2}$, todos ellos asentamientos de carácter urbano (Fig. 1). Al análisis tipoló-

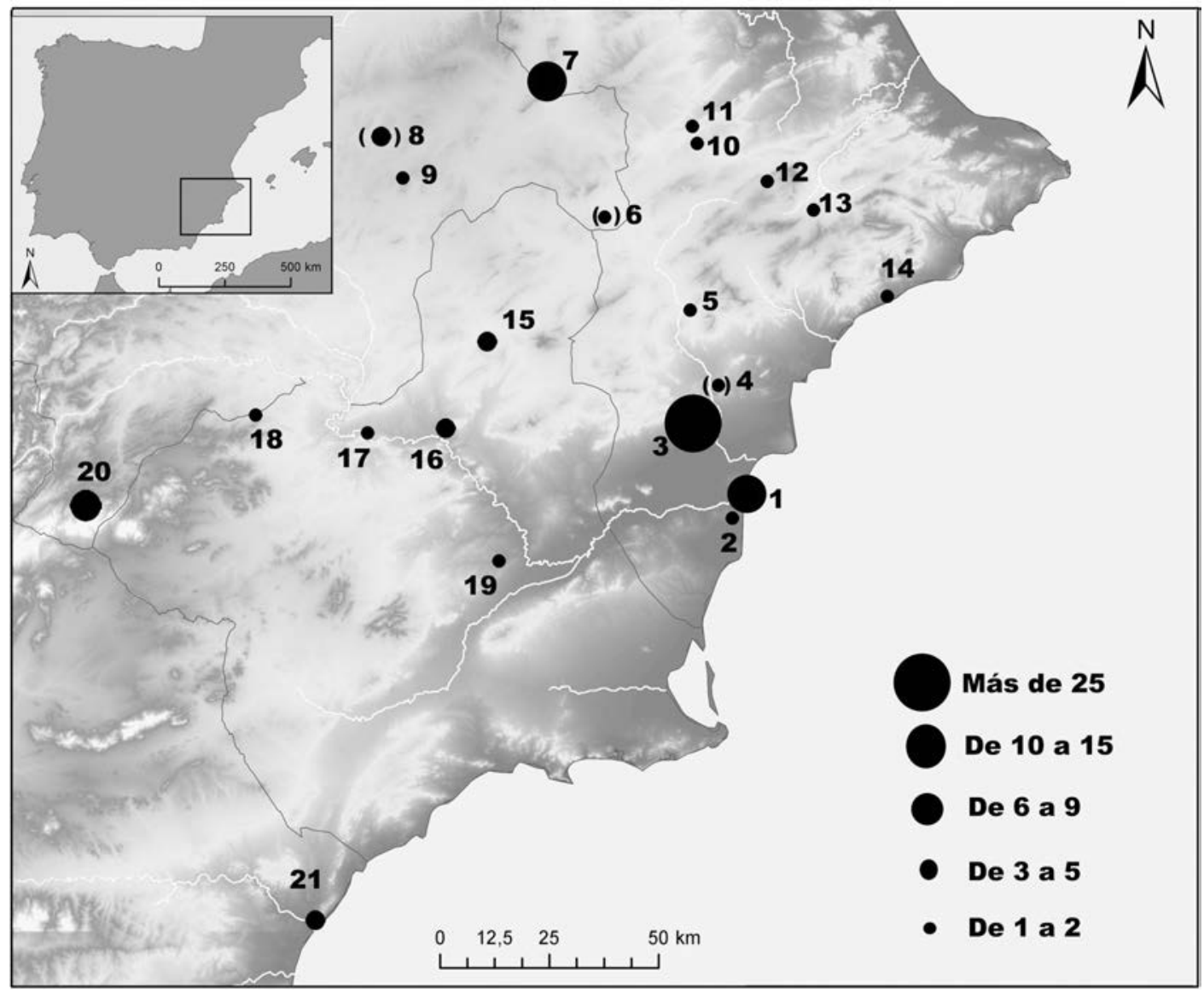

Fig. 1. Localización de los yacimientos del área de estudio y distribución de puntas de flecha con encaje de cubo en el Sureste de la Península Ibérica. 1. La Fonteta (Guardamar del Segura), 2. Castillo de Guardamar, 3. Herna/Peña Negra (Crevillent), 4. El Tabaià-Tabayá (Aspe), 5. El Monastil (Elda), 6. Zona de Caudete, 7. El Castellar de Meca (Ayora),

8. Prov. de Albacete, 9. Hoya de Santa Ana (Chinchilla), 10. La Bastida (Mogente), 11. Corral de Saus (Mogente),

12. Cabeçó de Mariola (Alfafara), 13. La Serreta (Alcoy), 14. Villajoyosa, 15. Coimbra del Barranco Ancho y sus necrópolis (Necrópolis de la Senda y del poblado) (Jumilla), 16. Bolvax (Cieza), 17. El Pericut (Cieza), 18. Cueva del Calor (Cehegín), 19. El Cigarralejo (Mula), 20. El Macalón (Nerpio), 21. Villaricos (Almería).

2 Por lo que respecta a los conjuntos estudiados, agradecemos a D. Julio Trelis Martí, director del Museo Arqueológico Municipal de Crevillent, el facilitarnos el acceso al conjunto de puntas de flecha inéditas de Peña Negra/El Castellar que alberga. Igualmente, a D. Antonio García Menárguez, director del Museo Arqueológico de Guardamar del Segura, quien nos permitió el acceso a las puntas de La Fonteta conservadas en la citada institución. También a D. Alejandro Martínez y a su familia por la información sobre los hallazgos del Castellar de Meca, en la actualidad depositados en el Museo Municipal "Casa Alamanzón" de Utiel (Valencia). Igualmente al M.I. Ayuntamiento de Ayora (Valencia) por la información sobre dos puntas de flecha de la colección arqueológica conservadas en la Casa de Cultura, sin procedencia segura, aunque posi- blemente de Meca o su entorno. Queremos manifestar nuestro agradecimiento igualmente al Dr. Antonio Poveda Navarro, director del Museo de Elda, por facilitarnos el estudio del ejemplar recuperado en El Monastil de Elda y al Dr. Ignacio Grau por la información sobre las piezas del Cabeçó de Mariola. Finalmente, a la Da. Rubí Sanz por facilitarnos la revisión de las piezas de El Macalón (Nerpio, Albacete) y un conjunto sin procedencia relacionado con el decomiso de una colección particular. También al M.I. Ayuntamiento de Caudete (Albacete), por ofrecernos información sobre los materiales conservados en el Centro de Interpretación del Patrimonio Cultural de la localidad. Finalmente, queremos agradecer de manera especial a la Dra. M $^{\mathrm{a}}$ Dolores Sánchez de Prado la realización de los dibujos de los ejemplares estudiados. 
gico de los ejemplares y su integración dentro del catálogo conocido, se añade la revisión de sus contextos arqueológicos y su estudio conjunto con otras áreas del sur peninsular, donde se observa una gran concentración de piezas, generalmente en poblados orientalizantes de cierta entidad del área tartésica (Ferrer, 1994: 36; Quesada, 1997: 448 ss.). Por lo que a las tierras del Sureste se refiere, los datos de mayor interés proceden de dos núcleos urbanos del Bajo Segura-Vinalopó: Peña Negra, identificada con la ciudad orientalizante de Herna, y el asentamiento fenicio de La Fonteta, donde estos objetos suelen identificarse en contextos de ocupación, de fortificación, destrucción y/o abandono, pudiéndose enmarcar la numerosa presencia de puntas de flecha con arpón en estos enclaves dentro del fenómeno histórico de desmantelamiento del modelo urbanístico y poblacional orientalizante. Plantea, por tanto, interesantes reflexiones sobre los patrones de poblamiento orientalizantes en la zona y su vínculo con los procesos de desterritorialización y reterritorialización (Marín-Aguilera, 2015) propios ya del s. VI a.C., y permite realizar una aproximación al fenómeno de desintegración del modelo territorial orientalizante en su etapa más tardía y la eclosión de la cultura ibérica. Un carácter igualmente urbano y una problemática quizás similar presenta El Castellar de Meca (Ayora, Valencia), un asentamiento orientalizante en origen pero que en época ibérica se configurará como uno de los más destacados oppida del Sureste y el Levante peninsular.

El conjunto de piezas recuperadas en el yacimiento de Peña Negra asciende a 26 ejemplares, la mitad de ellas con contexto estratigráfico, correspondiendo el resto a donaciones de particulares, generalmente con referencia aproximada a la zona del hallazgo, algo que como se comprobará tiene un marcado interés, dada la importante extensión que llegó a alcanzar el núcleo urbano orientalizante. Proceden de diversos sectores del yacimiento, incluyendo un conjunto recuperado en El Castellar, la única zona con ocupación en época ibérica, lo que pudiera tener implicaciones cronológicas, como veremos. La Fonteta ha proporcionado 13 ejemplares, todos del Hierro Antiguo, 12 de ellos con procedencia estratigráfica. De Meca, un asentamiento con una larga ocupación a lo largo de la Edad del Hierro, entre el s. VII y, posiblemente, el I a.C., se conocen 9 piezas inéditas, todas sin contexto.

Además de estos hallazgos, se han tenido en cuenta otros aparecidos en yacimientos de la Edad del Hierro de la zona, ya conocidos o inéditos, que proporcionan información complementaria a los repertorios más numerosos, aunque no se hayan incluido en el

3 Las referencias tipológicas para los ejemplares del llamado tipo 'Macalón', con cubo de encaje hueco, según González Prats (1983), Ramon (1983) y Ferrer (1996). Para los de catálogo (Fig. 1), que permiten analizar con una mayor perspectiva el importante desarrollo que llegó a alcanzar esta singular arma en el área septentrional del Sureste Peninsular.

\section{Catálogo ${ }^{3}$}

2.1. Peña Negra (Crevillent, Alicante) (Figs. 2 y 3) - Con contexto estratigráfico:

1. PN1. Punta de flecha de doble filo y arpón lateral, con hoja lanceolada con fuerte nervio central y cañón cilíndrico, en cuya zona de unión entre la hoja y el cañón presenta un saliente destacado y fino a modo de arpón. Sin perforación adicional. Grupo 1. Tipo 11a de Ramon/Ferrer y 1A de González Prats. Procedencia: Peña Negra, Sector IA (1976), Corte 4N, Nivel Ia. Cronología: s. VI a.C. $\mathrm{N}^{\mathrm{o}}$ Inv. C-IA-4N-16. Dimensiones: Long. Máx. 5 cm; Long. Hoja: 3 cm; Anch. Hoja: 0,9 cm; Grosor Hoja: 0,4 cm; Long. Cañón: $2 \mathrm{~cm}$; Diámetro Cañón: 0,5 cm; Índice de Proporcionalidad: 0,6. Peso: sin datos. Bibliografía: González Prats, 1979: 119 n 16, fig. 83,16; Id., 1982a: 257 n 1 , figs. 1,1 y 2a; 1983: fig. 38; Quesada, 1997: 920, nº1375 (Fig. 2, PN1).

2. PN2. Punta de flecha bien conservada de doble filo y arpón lateral, con hoja lanceolada que genera un filo estrecho, del tipo "pseudofenestrada" con extremo de sección romboidal, cuyo nervio central está parcialmente marcado en su mitad inferior gracias a la presencia de dos muescas que generan un corto doble filo. Su cañón es cilíndrico y en su punto de unión con la hoja conserva un fino y pequeño arpón lateral. Grupo 2. Tipo 12a de Ramon/Ferrer y 2A de González Prats. Procedencia: Peña Negra, Sector IB (1978), Corte C1, Nivel Ia. Cronología: s. VI a.C. N ${ }^{o}$ Inv. C-IBC1-603. Dimensiones: Long. Máx. 4,4 cm; Long. Hoja: $3 \mathrm{~cm}$; Anch. Hoja: 0,7 cm; Grosor Hoja: 0,3 cm; Long. Cañón: 1,4cm; Diámetro Cañón: 0,5 $\mathrm{cm}$; Índice de Proporcionalidad: 0,7. Peso: sin datos. Composición: 90,5 \% Cu; 8,6 \% Sn. Bibliografía: González Prats, 1982a: 257 n 2, fig. 1,2 y 2: b; Id., 1983: fig. 38; 1985a: 34, fig. 14:605; Quesada, 1997: 920, nº 1380 (Fig. 2, PN2).

3. PN3. Punta de flecha de bronce que presenta la punta fracturada. Su hoja lanceolada tiene un nervio con arista formando un doble filo muy marcado que en su unión al cañón cilíndrico presenta un pequeño agujero cuadrangular para un posible pasador o remache y en el opuesto un fino y destacado arpón lateral con muescas en los laterales. Sus 


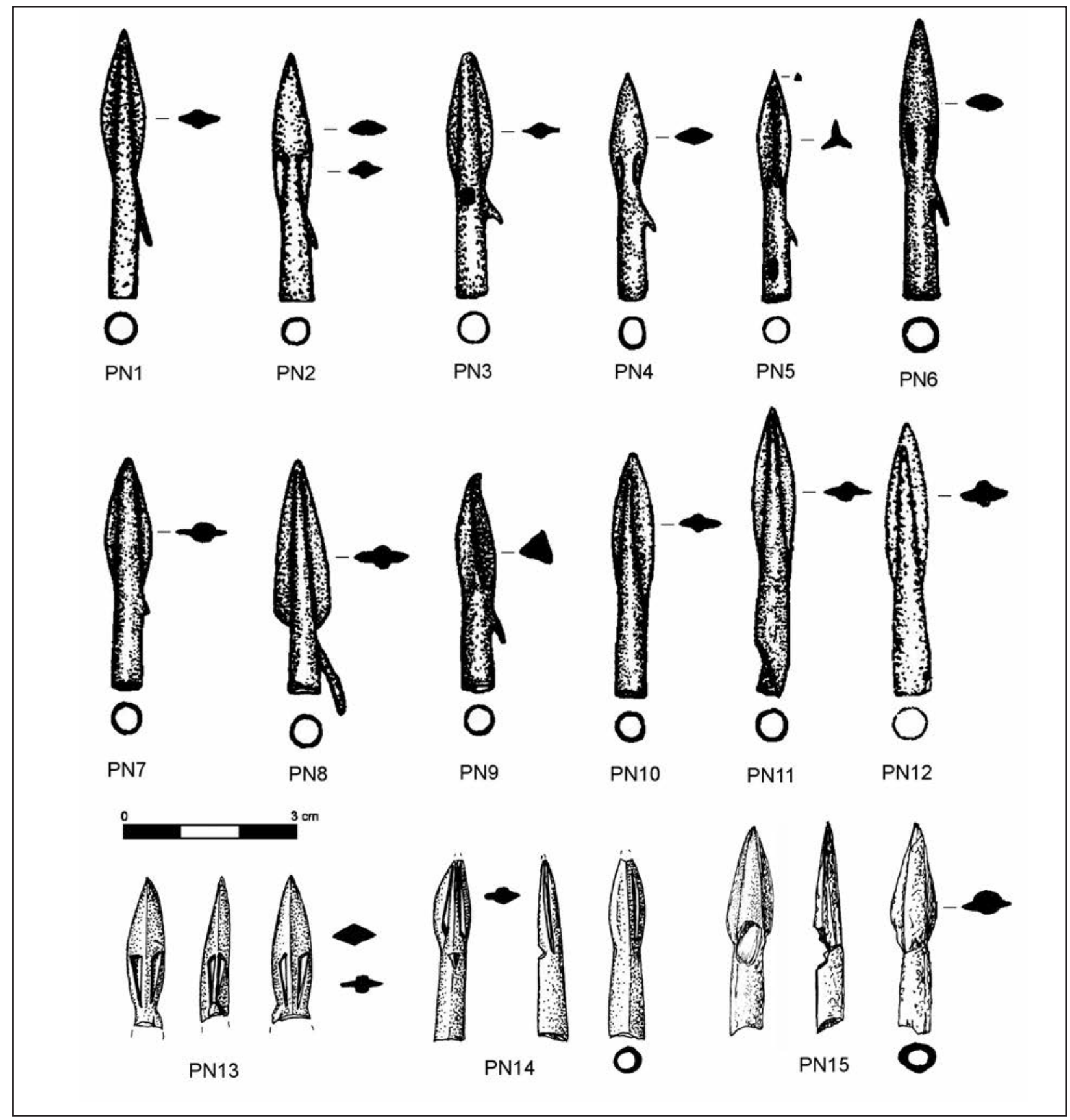

Fig. 2. Peña Negra. Puntas de doble filo con y sin arpón lateral (PN1-15). (PN1-PN12 según González Prats; PN13-PN15, dibujos de Ma D. Sánchez de Prado).

filos estrechos son algo asimétricos respecto al eje de la hoja ya que el nervio central está ligeramente desplazado, dando lugar a un filo más extenso que otro. Grupo 1. Tipo 11a de Ramon/Ferrer y 1A de González Prats. Procedencia: Peña Negra, Sector VII (1980-81), estratos Ic-Id. Cronología: s. VI a.C. $\mathrm{N}^{\mathrm{o}}$ Inv. PN-VII-5816. Dimensiones: Long. Máx. 4,6 cm; Long. Hoja: 2,3 cm; Anch. Hoja: 0,9 cm. Grosor Hoja: 0,3 cm; Long. Cañón: $2 \mathrm{~cm}$; Diámetro Cañón: $0,5 \mathrm{~cm}$; Índice de Proporcionalidad: 0,5. Peso: sin datos. Composición: $90,2 \% \mathrm{Cu} ; 7,5 \% \mathrm{Sn} ; 1,3 \mathrm{~Pb}$. Bibliografía: González Prats, 1982b: 368, fig.
30:5816; Id., 1983: fig. 38; Quesada, 1997: 920, $\mathrm{n}^{\circ}$ 1378 (Fig. 2, PN3).

4. PN4. Punta de flecha de bronce peor conservada que los ejemplares anteriores. De nuevo, no presenta un doble filo como tal, sino un nervio corto en su mitad inferior conformado por la presencia de dos muescas a los lados de la hoja, conformando un falso doble filo. Su hoja lanceolada y de sección romboidal en su tramo inferior se une a un largo cañón cilíndrico. En la zona de unión de hoja y cañón presenta un marcado y fino arpón lateral. Grupo 2. Tipo 12a de Ramon/Ferrer y $3 \mathrm{~A}$ de González Prats. Procedencia: Peña Negra, Sector 


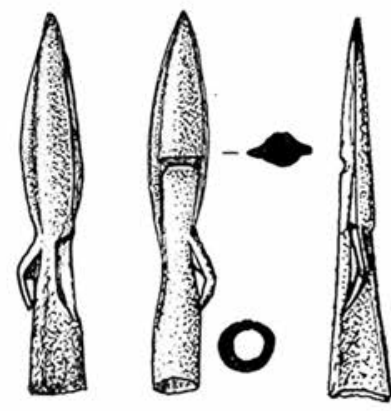

PN16
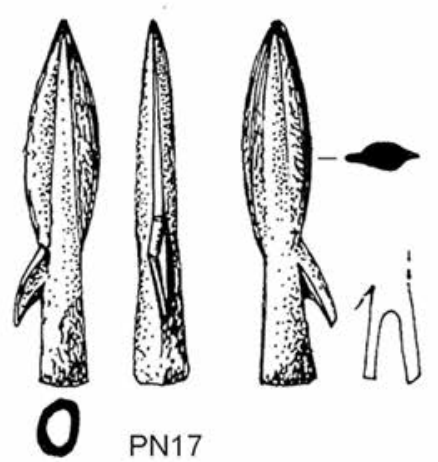

PN17

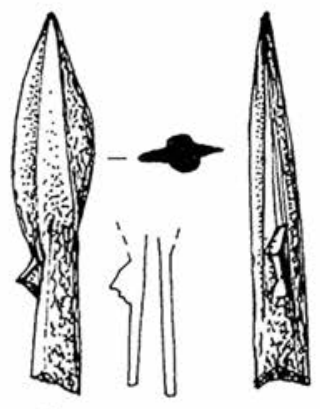

PN18
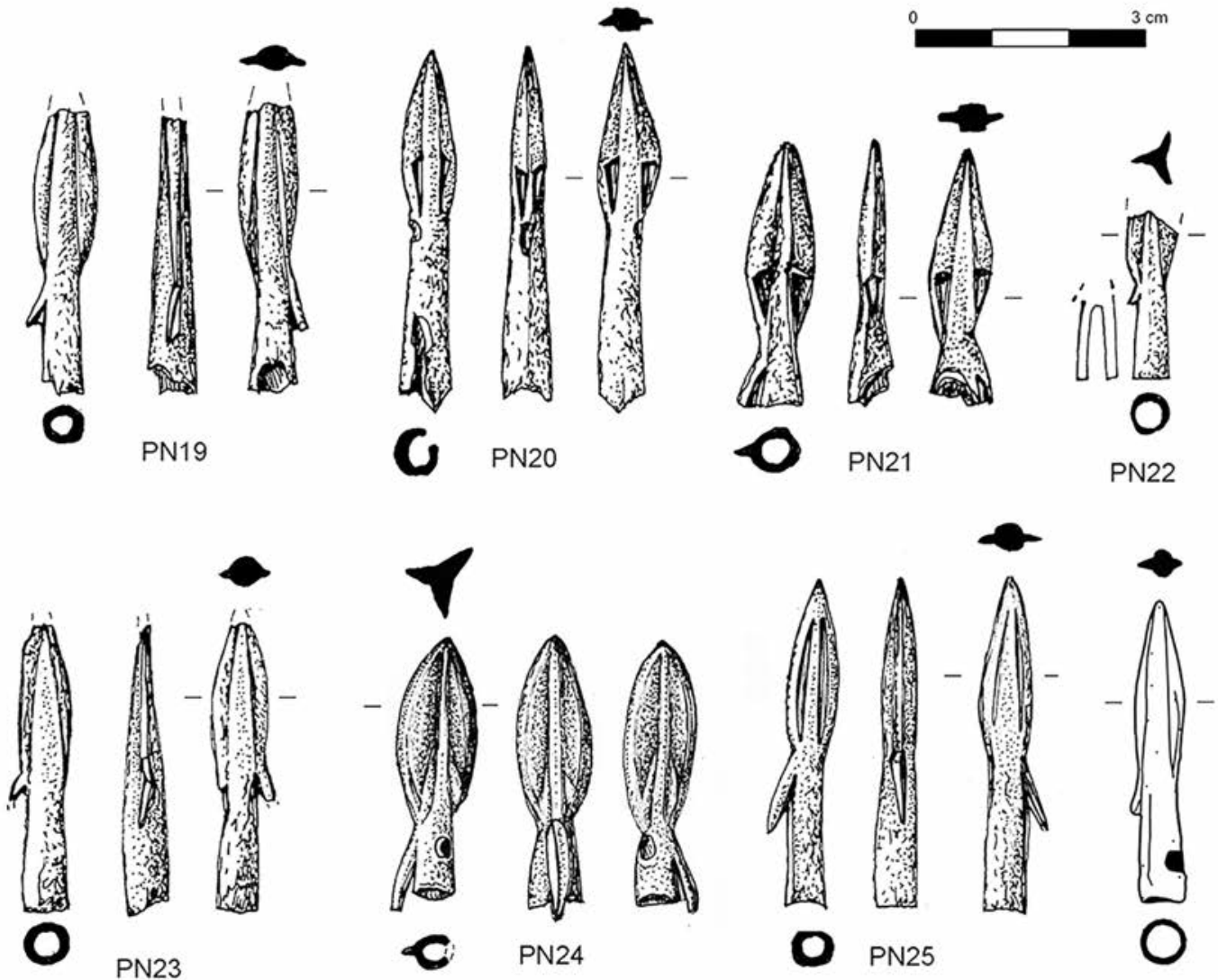

PN26

Fig. 3. Peña Negra. Puntas de doble y triple filo con y sin arpón lateral (PN16-26). (PN16-PN25, dibujos de $\mathrm{M}^{\mathrm{a}} \mathrm{D}$. Sánchez de Prado; PN-26 dibujo de S. Pernas a partir de fotografía).

VII (1980-81), estratos Ic-Id. Cronología: s. VI a.C. $\mathrm{N}^{\mathrm{o}}$ Inv. PN-VII-5817. Dimensiones: Long. Máx. 4,3 cm; Long. Hoja: 2,3 cm; Anch. Hoja: 0,7 cm; Grosor Hoja: 0,3 cm; Long. Cañón: $2 \mathrm{~cm}$; Diámetro Cañón: $0,5 \mathrm{~cm}$; Índice de Proporcionalidad: 0,53. Peso: sin datos. Bibliografía: González Prats, 1982b: 368, fig. 30:5817; Id., 1983: fig. 38; Quesada, 1997: 920, $\mathrm{n}^{\circ}$ 1379 (Fig. 2, PN4).

5. PN5. Punta de flecha de bronce con hoja de sección triangular que forma un triple filo con sus caras rehundidas. Su cañón, cilíndrico está perforado en su tercio inferior por un agujero de un posible pasador o remache de unión a su astil, mientras en el lateral opuesto, pero a una altura ligeramente superior, presenta un pequeño, destacado y fino arpón lateral, que a diferencia de los ejemplares hasta ahora analizados no nace en la zona de unión entre hoja y cañón, sino en la zona central del cubo o cañón, pudiendo marcar un rasgo cronológico. Grupo 4. Tipo 44a de Ramon/Ferrer y 4A de González Prats. Procedencia: Peña Negra, Sector VII (1980-81), Estrato superficial. Cronología: s. VI a.C. $\mathrm{N}^{\mathrm{o}}$ Inv. PN-VII-SUP-s/n. Dimensiones: Long. Máx.: $4.3 \mathrm{~cm}$. Long. Hoja: 2,3 cm; Anch. Hoja: 0,65 cm; Grosor Hoja: 0,3 cm; Long. Cañón: $2 \mathrm{~cm}$; Diámetro Cañón: $0,5 \mathrm{~cm}$. Índice de Proporcionalidad: 0,53. Peso: sin datos. 
Composición: 93,8 \% $\mathrm{Cu} ; 4,9 \% \mathrm{Sn} ; 1,1 \mathrm{~Pb}$. Bibliografía: González Prats, 1982b: 368, fig. 30; Id. 1983: fig. 38; Quesada, 1997: 920, nº1383 (Fig. 2, PN5).

6. PN6. Punta de flecha de estrecha hoja redondeada que presenta un corto nervio central en su tercio inferior, marcado mediante dos pequeñas muescas o hendiduras, presentando el resto de la hoja una sección aplanada. Conforma un falso doble filo o "punta pseudodefenestrada". Conserva el cubo o cañón largo en cuya zona de unión a la hoja destaca un pequeño y fino arpón. Grupo 2. Tipo 12a de Ramon/Ferrer y 3A de González Prats. Procedencia: Peña Negra, Sector VII (1986), Corte A'5. Estrato Ib3. Cronología: s. VI a.C. No Inv. PNVII-A'5-10564. Dimensiones: Long. Máx.: 4 cm; Long. Hoja: 2,3 cm; Anch. Hoja: 0,6 cm; Grosor Hoja: 0,3 cm; Long. Cañón: $1,7 \mathrm{~cm}$; Diámetro Cañón: 0,5 cm. Índice de Proporcionalidad: 0,6. Peso: sin datos. Bibliografía: González Prats y Ruiz Segura, 1990-91: 63, fig. 14: 10564; Quesada, 1997: 920, nº 5150 (Fig. 2, PN6).

7. PN7. Pequeña punta de flecha de bronce de hoja lanceolada dividida por un nervio central cilíndrico que genera un doble filo bastante simétrico. Su cañón, cilíndrico, presenta en la zona de unión con la hoja un pequeño y poco destacado arpón, apenas insinuado. Grupo 1. Tipo 11a de Ramon/Ferrer y $1 \mathrm{~A}$ de González Prats. Procedencia: Peña Negra, Sector VII (1986), Corte A'3-4, Estrato Ia o superior. Cronología: s. VI a.C. $\mathrm{N}^{\mathrm{o}}$ Inv. PN-VII-A'3-49966bis. Dimensiones: Long. Máx: 4/3,8 cm; Long. Hoja: 2,1 cm; Anch. Hoja: 0.8 cm; Grosor Hoja: 0,3 cm; Long. Cañón: 1,7 cm; Diámetro Cañón: 0,5cm; Índice de Proporcionalidad: 0,55. Peso: sin datos. Bibliografía: González Prats y Ruiz Segura, 199091: 76, fig. 14: 9966bis. (Fig. 2, PN7).

8. PN8. Punta de flecha de bronce que supone una variación respecto al conjunto de ejemplares de doble filo hasta ahora identificados. Presenta un nervio muy marcado y robusto que se adelgaza hacia la punta y su hoja es de tendencia triangular de perfiles rectos, conformando por tanto una sección en forma de arista con filos anchos en la parte inferior de la hoja. Su cubo o cañón es corto y cilíndrico, el cual presenta a la altura de su unión a la hoja, el nacimiento de un largo y prolongado arpón que sobrepasa la longitud del cubo. Presenta la punta roma o rota. Grupo 3. Tipo 13a de Ramon, 14a Ferrer ${ }^{4}$. Procedencia: Sector VII (1986), Corte A'5, estrato Ib3. Cronología: s. VI a.C. N ${ }^{o}$ Inv. PN-

4 Respecto a este tipo concreto, mantenemos la propuesta tipológica de Ramon en su tipo 13a, que Ferrer engloba dentro de la variabilidad del tipo 11 (1996: 49 s.). El tipo 14 de Ramon, al ser de hojas triangulares solo incluía ejemplares
VII-A’5-1566. Dimensiones: Long. Máx. conserv.: 3,8 cm; Long. Hoja: 2,8 cm; Anch. Hoja: 0,9 cm; Grosor Hoja: 0,3 cm; Long. Cañón: $1 \mathrm{~cm}$; Diámetro Cañón: 0,5 cm. Long. Arpón: 1,2 cm; Índice de Proporcionalidad: 0,73. Peso: sin datos. Bibliografía: González Prats y Ruiz Segura, 199091: 63-64, fig. 14: 10566; Quesada, 1997: 920, nº 5149 (Fig. 2, PN8).

9. PN9. Punta de flecha de bronce con características singulares. Presenta un triple filo con una hoja se sección triangular con las caras de triedro planas, en las que no se distingue el filo de la hoja, lo que los aproxima al tipo 43b de Ferrer (1996), aunque su hoja es lanceolada y estrecha, como los ejemplares tipo 44a del mismo autor. Su cubo o cañón es corto y cilíndrico, del que nace en su zona de unión con la hoja un estrecho y fino arpón lateral. Como rasgo más característico de la pieza presenta la punta ligeramente modificada, doblada y rota, posiblemente como evidencias de marca de impacto. Grupo 4. Tipo 44a Ramon/Ferrer y 4A de González Prats. Procedencia: Peña Negra, Sector VII (1986), Área A'5, estrato Ib3. Cronología: s. VI a.C. $\mathrm{N}^{\mathrm{o}}$ Inv.: PN-VII-A'5-10565. Dimensiones: Long. Máx. conservada: 3,5 cm; Long. Hoja: 2,1 cm; Anch. Hoja: 0,6 cm; Grosor Hoja: 0,5-0,6 cm; Long. Cañón: 1,4 cm; Diámetro Cañón: 0,5cm; Índice de Proporcionalidad: 0,6. Peso: sin datos. Bibliografía: González Prats y Ruiz Segura, 199091: 63, fig. 14: 10565; Quesada, 1997: 920, nº 1548 (Fig. 2, PN9).

10. PN10. Punta de flecha de bronce de doble filo sin arpón. Presenta la hoja lanceolada con nervio marcado que se adelgaza hacia el extremo de la pieza, y está ligeramente ladeada, provocando filos disimétricos, uno más extenso que el otro. Su cubo o cañón cilíndrico y corto y en su unión con la hoja no presenta ningún agujero o arpón asociado. Son ejemplares sencillos. Grupo 1. Tipo $11 \mathrm{~b}$ de Ramon/Ferrer y 1B de González Prats. Procedencia: Peña Negra, Sector VII (1986), Corte B'10, Dpto. 1, Estrato Ia. Cronología: s. VI a.C. $N^{\circ}$ Inv.: PN-VII-B'10- 9481. Dimensiones: Long. Máx. conserv.: 4,2 cm; Long. Hoja: 2,7 cm; Anch. Hoja: 0,8 cm; Grosor Hoja: 0,3 cm; Long. Cañón: $1,5 \mathrm{~cm}$; Diámetro Cañón: $0,5 \mathrm{~cm}$; Índice de Proporcionalidad: 0,6. Peso: sin datos. Composición: 76,38 \% Cu; 19,37\% Sn; 3,86 Pb. Bibliografía: González Prats y Ruiz Segura, 199091: 76, fig. 14: 9481; Quesada, 1997: 920, nº 5151 (Fig. 2, PN10). con doble arpón o sin arpón, tipos 14a y 14b respectivamente. Dado que nuestro ejemplar posee una hoja romboidal y no triangular, descartamos su adscripción al Tipo 14 reclasificado por Ferrer (1996: 48 s.). 
11. PN11. Punta de flecha de doble filo sin arpón. Se trata del segundo ejemplar que solo presenta hoja lanceolada con nervio de arista marcado que se adelgaza conforme se aproxima a su extremo o punta y que se une al cañón cilíndrico hasta alcanzar su grosor máximo. Su cañón destaca por su longitud. Grupo 1. Tipo 11b de Ramon/Ferrer y $1 \mathrm{~B}$ de González Prats. Procedencia: Peña Negra, Sector VII (1986), Corte B'10, Área 6, Exterior Dpto. 5. Estrato Ia. Cronología: s. VI a.C. N ${ }^{\circ}$ Inv. PN-VIIB'10-Area 6-9654. Dimensiones: Long. Máx.: 5 cm; Long. Hoja: 2,7 cm; Anch. Hoja: 0,8 cm; Grosor Hoja: 0,3 cm; Long. Cañón: 2,3cm; Diámetro Cañón: 0,5 cm; Índice de Proporcionalidad: 0,5. Peso: sin datos. Bibliografía: González Prats y Ruiz Segura, 1990-91: 57, fig. 14: 9654; Quesada, 1997: 920, n⿳0 5152 (Fig. 2, PN11).

12.PN12. Punta de flecha de bronce sin arpón. Presenta hoja lanceolada dividida por un nervio central de morfología cilíndrica que se adelgaza conforme se aproxima a la punta hasta desaparecer antes de ésta, rasgo distintivo de este ejemplar, no identificado hasta ahora en los ejemplares de Peña Negra y que corresponde a la sección tipo 1 de Ferrer (1996) o al cañón tipo III de Sánchez Meseguer (1967), lo que le confiere un aspecto aplanado. El nervio está ligeramente desplazado hacia un lateral respecto al eje de la hoja, formando dos filos disimétricos uno más ancho que otro. El cañón no diferenciado del nervio es cilíndrico y bastante largo. Grupo 1. Tipo 11b de Ramon/Ferrer y 1B de González Prats. Procedencia: El Castellar. Sector V de Peña Negra, Corte Alpha, Nivel Ia. Nivel con intrusiones. Cronología: s. V a.C.? $\mathrm{N}^{\circ}$ Inv.: PN-V-Alpha-3093. Dimensiones: Long. Máx.: 4,8 cm; Long. Hoja: 2,7-2,8 cm; Anch. Hoja: $1 \mathrm{~cm}$; Grosor Hoja: 0,4 cm; Long. Cañón: 2 cm; Diámetro Cañón: $0,5 \mathrm{~cm}$; Índice de Proporcionalidad: 0,6. Peso: sin datos. Bibliografía: González Prats, 1986: 243, fig. 59: 3093; Quesada, 1997: 920, nº 1381 (Fig. 2, PN12).

- Sin contexto estratigráfico:

13. PN13. Punta de flecha de doble filo con hoja lanceolada y nervadura que se prolonga hasta la punta. Parece conservar parte del arranque del arpón lateral, muy deteriorado y roto, al igual que su cañón roto, no conservado. Grupo 1. Tipo $12 \mathrm{a}$ de Ramon/Ferrer A de González Prats. Procedencia: Peña Negra, Sector II W. Superficial, camino del Castellar, Prospección 2014. Cronología: s. VI a.C. $\mathrm{N}^{\circ}$ Inv.: PN'14-SIIW-SUP-12. Dimensiones: Long. Máx. conv.: 2,54 cm; Long. Hoja conserv.: 2,29 cm; Anch. Hoja: 0,7 cm; Long. Cañón: 0,26 cm; Grosor cañón: 0,4 cm; Índice de Proporcionalidad: n/c; Peso: sin datos. Composición: 96,92 \% Cu; 2,75\% Pb. Bibliografía: Inédita (Fig. 2, PN13).
14. PN14. Punta de flecha de doble filo con la punta o extremo fracturado. De hoja lanceolada con nervio central muy marcado por dos aristas y que se adelgaza hacia el extremo, y largo cañón cilíndrico que presenta un orificio o perforación lateral, así como marcas secundarias de rotura o desgaste. Grupo 2. Tipo 12b de Ramon/Ferrer y 3A de González Prats. Procedencia: Peña Negra. Sector IA, Corte 3A, Bancales. Hallazgo de superficie. Prospección 2014. Cronología: s. VI a.C. (?). Nº Inv. PN-14-IAC3A-Bancales. Dimensiones: Long. Máx conv.: 3 cm; Long. Hoja conserv.: 1,2 cm; Anch. Hoja: 0,5 cm; Long. Cañón: 1,6cm; Grosor cañón: 0,6 cm; Índice de Proporcionalidad: 0,4; Peso: 2,56 g. Composición: 91,6 \% Cu; 5,96 \% Sn; 2,43 \% Pb. Bibliografía: Inédita (Fig. 2, PN14).

15. PN15. Punta de flecha de bronce de doble filo con hoja lanceolada ligeramente ojival con nervio central muy marcado que se adelgaza hacia la punta y se une a un corto cañón cilíndrico. La pieza está fracturada en la zona del reverso del cañón, así como en el extremo distal de éste, quizá como evidencias de su uso, marcas de impacto que propiciaron su rotura. Grupo 1. Tipo 11b de Ramon/Ferrer y 1B de González Prats. Procedencia: Peña Negra, Sector II (1979), Cortes A-D, hallazgo superficial. Cronología: s. VI a.C. (?). $\mathrm{N}^{\circ}$ Inv. PN-5. Museo Arqueológico Municipal de Crevillent. Dimensiones: Long. Máx.: 3,4 cm; Long. Hoja: 2 cm; Anch. Hoja: 0,8 cm; Grosor Hoja: 0,4 cm; Long. Cañón: 1,4 cm; Grosor Cañón: 0,6cm; Índice de Proporcionalidad: 0,6. Peso: 3,26 g. Bibliografía: González Prats, 1985a: 76, lám. VIII. (Fig. 2, PN15).

16. PN16. Punta de flecha de bronce. Presenta hoja lanceolada estrecha con un marcado y ancho nervio central que conforma el característico doble filo. El cañón es uniforme y cilíndrico y se une sin distinción a la hoja donde destaca la presencia de un largo arpón, posiblemente doblado por el uso o dispuesto en ángulo. La pieza presenta algunas peculiaridades en su conservación que pueden mostrar su uso o la presencia de marcas de impacto, tal y como parecen indicar la hendidura transversal que cruza el nervio central de la hoja. Grupo 1. Tipo 11a de Ramon/Ferrer y $1 \mathrm{~A}$ de González Prats. Procedencia: Peña Negra, Sector II (1979), Cortes A-D, hallazgo superficial. Cronología: s. VI a.C. (?). $\mathrm{N}^{\circ}$ Inv. C-PN-515. Museo Arqueológico Municipal de Crevillent. Dimensiones: Long. Máx.: 4,5 cm; Long. Hoja: 2,65 cm; Anch. Hoja: 0,7 cm; Grosor Hoja: 0,4 cm; Long. Cañón: 1,85 cm; Grosor Cañón: 0,6 cm; Índice de Proporcionalidad: 0,6; Peso: 5,14 g. Bibliografía: González Prats, 1985a: 76, lám. VIII (Fig. 3, PN16). 
17. PN17. Punta de flecha de bronce con estrecha hoja lanceolada y nervio central que rema su doble filo. Su cañón se adelgaza hacia la punta y se prolonga indiferenciado hasta unirse con el cubo cilíndrico del que nace un arpón lateral muy destacado. El cañón presenta una ligera deformación de su sección cilíndrica debido quizá a la rotura marcada que se abre en su tercio inferior. Grupo 1. Tipo 11a de Ramon/Ferrer y $1 \mathrm{~A}$ de González Prats. Procedencia: Peña Negra, Sector II (1979), hallazgo superficial. Cronología: s. VI a.C. (?). N $\mathrm{N}^{\mathrm{O}}$ Inv. CP-N541. Museo Arqueológico Municipal de Crevillent. Dimensiones: Long. Máx.: 4,4 cm; Long. Hoja: 2,7 cm; Anch. Hoja: 0,8 cm; Grosor Hoja: 0,3 cm; Long. Cañón: 1,7 cm; Grosor Cañón: 0,5 cm; Índice de Proporcionalidad: 0,6; Peso: 4,71 g. Bibliografía: González Prats, 1985a: 76, lám. VIII (Fig. 3, PN17).

18. PN18. Punta de flecha de bronce de ancho doble filo. Tiene la hoja lanceolada, incluso ligeramente trapezoidal, dividida en dos amplios filos por un nervio central marcado que se adelgaza hacia la punta y se une con un cañón corto. En la zona de unión de la hoja y el cubo nace un breve y marcado arpón triangular. Es el ejemplar de doble filo con las alas más anchas localizado hasta el momento. Grupo 1. Tipo 11a de Ramon/Ferrer y 1A de González Prats. Procedencia: El Castellar o Sectores IV-V de Peña Negra, según Gozálvez (1975: 165, lám. 4.c), recogida superficial, aunque González Prats (1977: 674) indica que no se conoce el sector de procedencia ${ }^{5}$. Cronología: s. VI a.C. (?). $\mathrm{N}^{\mathrm{o}}$ Inv. C-PN-134. Museo Arqueológico Municipal de Crevillent. Dimensiones: Long. Máx.: 4,5 cm; Long. Hoja: $3 \mathrm{~cm}$; Anch. Hoja: 1,05 cm; Long. Cañón: 1,5 cm; Grosor Cañón: 0,5cm; Índice de Proporcionalidad: 0,66; Peso: 5,50 g. Bibliografía: Gozálvez, 1975: 165, lám. 4.c; González Prats, 1977: 674, lám. IV: 1; Id., 1982a:

5 Respecto a las piezas conservadas en el Museo Arqueológico Municipal de Crevillent (PN18-PN25), se trata en todos los casos de hallazgos superficiales anteriores a 2014. La dificultad en determinar su procedencia dentro del yacimiento llevó a catalogarlas genéricamente como CPN (Castellar-Peña Negra), mientras que las referencia C o PN estarían remitiendo a su hallazgo ya en El Castellar, ya en el resto del asentamiento, aunque con matizaciones ( $\mathrm{J}$. Trelis, comunicación personal). La pieza PN18 fue dada a conocer en 1975 como un hallazgo de El Castellar (Gozálvez, 1975: 165), aunque González Prats (1977: 674) indica que forma parte de los fondos del Museo Municipal, "sin indicación de sector", lo que explica que se conserve con la referencia C-PN-134. La falta de noticias sobre las piezas PN9 y PN20 es igualmente señalada por González Prats (ibid.), aunque en este caso las referencias del Museo sean algo más concretas en el primer caso ( $\mathrm{n}^{\circ}$ ref. PN-6 y C$\mathrm{PN}-133$, respectivamente). Otro caso similar sería el de la pieza PN24 (C-PN-132). No obstante, la sigla C-PN es
257 n 3 , fig. 1:3 y 2: c; Id., 1983: fig. 38; Quesada, 1997: 920, no 1377 (Fig. 3, PN18).

19. PN19. Punta de flecha de bronce, que presenta la punta rota, provista de marcado cañón o nervio central que se adelgaza ligeramente hacia el extremo y que está ligeramente inclinado respecto al eje de la hoja, desarrollando un doble filo disimétrico, con un ala más extensa que la otra. Del cañón cilíndrico corto nace en su zona de unión con la hoja un arpón lateral fino y alargado con el extremo fracturado. Otras marcas de impacto pueden ser la rotura que presenta su cañón en su extremo distal en la zona de engarce con su astil. Tipología: 11a de Ramon/Ferrer y 1A de González Prats. Procedencia: Sin referencia a sector específico conocida, González Prats lo incluye dentro de los ejemplares recogidos en superficie por aficionados locales (González Prats, 1977: 674; Id., 1982: 17 s., fig. 1.4), hallazgo superficial. Cronología: (?). $\mathrm{N}^{\mathrm{o}}$ Inv. PN-6. Museo Arqueológico Municipal de Crevillent. Dimensiones: Long. Máx. conserv.: 3,7 cm. Long. Hoja conserv.: 2,5 cm; Anch. Hoja: 0,85 cm; Long. Cañón: 1,6 cm; Grosor Cañón: 0,5cm; Long. Arpón: 0,7 cm; Índice de Proporcionalidad: 0,67; Peso: 4,37 g. Bibliografía: González Prats, 1977: 674, lám. IV: 1; Id., 1982a: 257-258 nº 4, fig. 1:4 y 3:b; Id., 1983: fig. 38 (Fig. 3, PN19).

20. PN20. Punta de flecha de bronce de doble filo con hoja lanceolada estrecha con dos caras aplanadas en sus dos tercios superiores y un corto nervio en su tercio inferior con hendiduras en la base de la hoja que le confieren el típico aspecto mencionado de "falso doble filo". Su cañón es sencillo y cilíndrico, destacando su gran longitud respecto a la proporción habitual de hoja/cañón más equilibradas, aunque dentro de los límites del tipo. Está fragmentada en su tercio inferior quizá como evidencia de impacto o uso y de la presencia de un agujero de un pasador o remache o un posible

igualmente utilizada para hallazgos superficiales provenientes del Sector II de Peña Negra (véase en nuestro catálogo los $n^{\circ}$ PN16 y PN17). Por tanto es difícil establecer en estos casos su adscripción precisa a El Castellar. Diferente parece ser el caso de nuestras puntas PN21, PN22 y PN23 que, catalogadas como C-27, C-29 y C-28, respectivamente, procederían de El Castellar, por lo que podrían corresponder a aquellas halladas en superficie relacionables con dicho sector, aunque se trata en todos los casos de hallazgos realizados por aficionados que utilizaban la denominación tradicional de toda la zona de la Sierra como El Castellar (J. Trelis, comunicación personal), lo que no permite confirmar fehacientemente que provengan del sector alto de la muela del Castellar (Sectores IV y V). La PN25 se halló en Les Moreres, también en superficie -Mo(s) 301-, donde se localiza la necrópolis vinculada a Peña Negra y la PN26 (C-PN1997-s/n) de nuevo remite a un ejemplar donado en 1997 del que no se puede determinar procedencia exacta. 
arpón perdido. Destaca ante todo por ser el ejemplar que presenta una desproporción a favor de un largo cañón. Grupo 2. Tipo 12b Ramon/ Ferrer (1996) y 3B de González Prats. Procedencia: Sin referencia a sector específico conocida, González Prats lo incluye dentro de los ejemplares recogidos en superficie por aficionados locales (González Prats, 1977: 674; Id., 1982a: fig. 1:5). Cronología: (?). $\mathrm{N}^{\mathrm{o}}$ Inv. C-PN-133. Museo Arqueológico Municipal de Crevillent. Dimensiones: Long. Máx. $4.8 \mathrm{~cm}$; Long. Hoja: 2,3 cm; Anch. Hoja: 0,7 cm; Grosor Hoja: 0,3 cm; Long. Cañón: 2,5 cm; Grosor Cañón: 0,5 cm; Índice de Proporcionalidad: 0,4 cm; Peso: 5,51 g. Bibliografía: González Prats, 1982a: 258 n $^{\circ}$ 5, fig. 1:5 y 2: c; Id., 1983: fig. 38; Quesada, 1997: 920, nº 1382 (Fig. 3, PN20).

21.PN21. Punta de flecha de bronce de doble filo y hoja lanceolada con fino nervio central, solo remarcado en el tercio inferior de la misma mediante dos muescas o hendiduras que conforman un falso doble filo. Su cañón o cubo es cilíndrico y se ensancha en su base, aunque esté parcialmente roto. Presenta en la zona de unión entre la hoja y el cubo un destacado y largo arpón, también fragmentado, evidencias quizá de marcas de impacto. Grupo 2. Tipo 12a de Ramon/Ferrer y $2 \mathrm{~A}$ de González Prats. Procedencia: posible procedencia superficial de El Castellar, aunque no existen datos precisos (vid. nota 5). Cronología: s. VI a.C. (?). $N^{o}$ Inv. C-27. Museo Arqueológico Municipal de Crevillent. Dimensiones: Long. Máx. 3,5 cm; Long. Hoja: 2,8 cm; Anch. Hoja: 0,8 cm; Grosor Hoja: 0,4 cm; Long. Cañón conserv.: $0,8 \mathrm{~cm}$; Grosor Cañón: 0,6 cm; Índice de Proporcionalidad: 0,8; Peso: 3,34 g. Bibliografía: Inédita (Fig. 3, PN21).

22.PN22. Punta de flecha de bronce de triple filo. Presenta la hoja rota conservando solo su tercio inferior, que permite identificar su triple sección triangular con hendiduras y su conexión a un cañón central cilíndrico del que nace un pequeño arpón fragmentado, evidencias plausibles de marcas de impacto. Grupo 4. Tipo 44a de Ramon/Ferrer y 4A de González Prats. Procedencia: posible procedencia superficial de EI Castellar, aunque no existen datos precisos (vid. nota 5). Cronología: s. VI a.C. (?). No Inv. C-29. Museo Arqueológico Municipal de Crevillent. Dimensiones: Long. Máx. conserv. 2,2 cm; Long. Hoja conserv.: 0,7 cm; Anch. Hoja: 0,7 cm; Grosor Hoja: 0,5 cm; Long. Cañón: 1,5 cm; Grosor Cañón: 0,5 cm; Índice de Proporcionalidad: 0,3; Peso: 2,13 g. Bibliografía: Inédita (Fig. 3, PN22).

23.PN23. Punta de flecha de bronce de doble filo y hoja lanceolada estrecha con nervio central marcado que se adelgaza en la punta, la cual está fragmentada. Su cañón es cilíndrico y presenta un arpón indicado fino y corto fragmentado, así como una rotura que podría pertenecer a un agujero de pasador o remache. Grupo 1. Tipología: 11a de Ramon/Ferrer y $1 \mathrm{~A}$ de González Prats. Procedencia: posible procedencia superficial de El Castellar, aunque no existen datos precisos (vid. nota 5). Cronología: s. VI a.C. (?). $\mathrm{N}^{\circ}$ Inv. C-28. Museo Arqueológico Municipal de Crevillent. Dimensiones: Long. Máx. 3,7 cm; Long. Hoja: 2,4 cm; Anch. Hoja: $0.7 \mathrm{~cm}$; Grosor Hoja: 0,4 cm; Long. Cañón: 1,4 cm; Grosor cañón: 0,5cm; Índice de Proporcionalidad: 0,64; Peso: 3,67 g. Bibliografía: Inédita (Fig. 3, PN23).

24. PN24. Punta de flecha de bronce de triple filo. Presenta la hoja lanceolada o redondeada con nervio central y sección estrellada que presenta tres amplias caras rehundidas. Su cañón es cilíndrico y corto presentando en un lateral una pequeña perforación y en el lado opuesto un fino y largo arpón que sobrepasa la longitud del cañón. Grupo 4. Tipo 44a de Ramon/Ferrer y 4A de González Prats. Procedencia: Sin referencia a sector específico, recogida superficial. Cronología: s. VI a.C. (?). $\mathrm{N}^{\mathrm{o}}$ Inv. C-PN-132. Museo Arqueológico Municipal de Crevillent. Dimensiones: Long. Máx. 3,4 cm; Long. Hoja: 2,3 cm; Anch. Hoja: $0.7 \mathrm{~cm}$; Grosor Hoja: 0,5 cm; Long. Cañón: 1,1 cm; Grosor Cañón: $0,6 \mathrm{~cm}$; Long. Arpón: $0,8 \mathrm{~cm}$; Índice de Proporcionalidad: 0,67; Peso: 4,42 g. Bibliografía: Inédita (Fig. 3, PN24).

25. PN25. Punta de flecha de bronce de doble filo. Presenta la hoja lanceolada muy estrecha con nervio central que se estrecha hacia la punta. Dos finas hendiduras longitudinales individualizan la zona del ala. Su cañón es cilíndrico y largo presentando en un lateral un destacado y largo arpón. Grupo 2. Tipo 12a de Ramon/Ferrer. Procedencia: Les Moreres, Nivel Superficial. Cronología: s. VI a.C. (?). $\mathrm{N}^{\circ}$ Inv. Mo (s) 301. Museo Arqueológico Municipal de Crevillent. Dimensiones: Long. Máx. 4,3 cm. Long. Hoja: 2,5 cm. Anch. Hoja: $0.6 \mathrm{~cm}$; Grosor Hoja: 0,4 cm; Long. Cañón: 1,8 cm; Grosor Cañón: 0,5 cm; Long. Arpón: 1,1 cm; Índice de Proporcionalidad: 0,6; Peso: 4,77 g. Bibliografía: Inédito (Fig. 3, PN25).

26. PN26. Punta de flecha de bronce de doble filo. Presenta la hoja lanceolada estrecha con nervio central muy marcado ligeramente desviado respecto al eje de la hoja que se estrecha hacia la punta. Su cañón es cilíndrico presentando en un lateral un destacado arpón. Presenta la punta redondeada y un agujero o rotura en la parte inferior de la hoja, así como un agujero lateral en el cañón como posibles marcas de impacto. Grupo 1. Tipo 11a de Ramon/Ferrer y 1A de González Prats. Procedencia: Castellar-Peña Negra. Sin determinar sector. Colección Vives-Quesada, 1997. 
Cronología: s. VI a.C. (?). N ${ }^{\circ}$ Inv. C-PN-1997Quesada-Vives-s/n. Museo Arqueológico Municipal de Crevillent. Dimensiones: Long. Máx. $3,8 \mathrm{~cm}$; Long. Hoja: 2,3 cm; Anch. Hoja: 0,7 cm; Grosor Hoja: 0,3 cm; Long. Cañón: 1,5 cm; Grosor Cañón: 0,5 cm; Índice de Proporcionalidad: 0,6; Peso: 2,56 g. Bibliografía: Inédita (Fig. 3, PN26).

\subsection{La Fonteta (Guardamar del Segura)} (Figs. 4-5)

- Con contexto estratigráfico:

27.F1. Punta de flecha de bronce de doble filo con hoja lanceolada y fuerte nervio central que se adel- gaza hacia la punta y está ligeramente desplazado respecto al eje de la hoja, generando dos alas asimétricas, una más grande que otra. Su cañón cilíndrico presenta en la zona de unión con la hoja un destacado y corto arpón. Presenta la punta fragmentada. Grupo 1. Tipo 11a de Ramon/Ferrer y 1A de González Prats. Procedencia: Fonteta, Fase Vb, Estrato 3088. Cronología: Mediados s. VI a.C. N ${ }^{\circ}$ Inv. RG/97-3088-7. Dimensiones: Long. Máx. 4,3 cm; Long. Hoja: 2,6 cm; Anch. Hoja: 0,8 cm; Grosor Hoja: 0,3 cm; Long. Cañón: 1,5 cm; Grosor cañón: 0,5 cm. Índice de Proporcionalidad: 0,6. Peso: sin datos. Bibliografía: Le Meaux y Sánchez de Prado, 2007: 325, fig. 260: 3 (Fig. 4, F1).

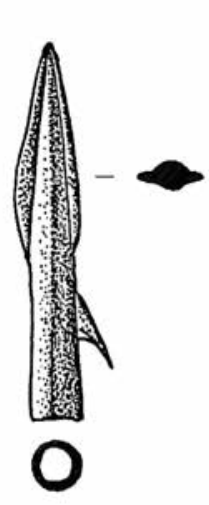

F1

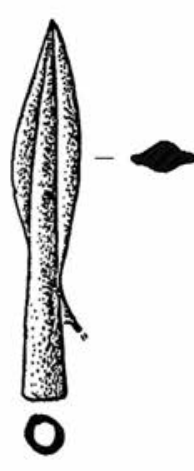

F2

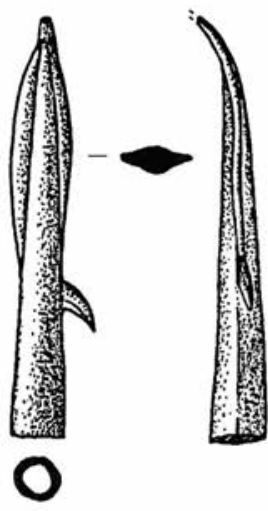

F3

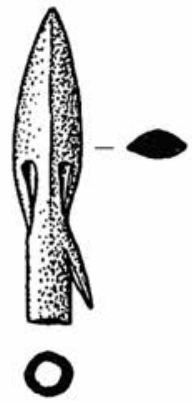

F4

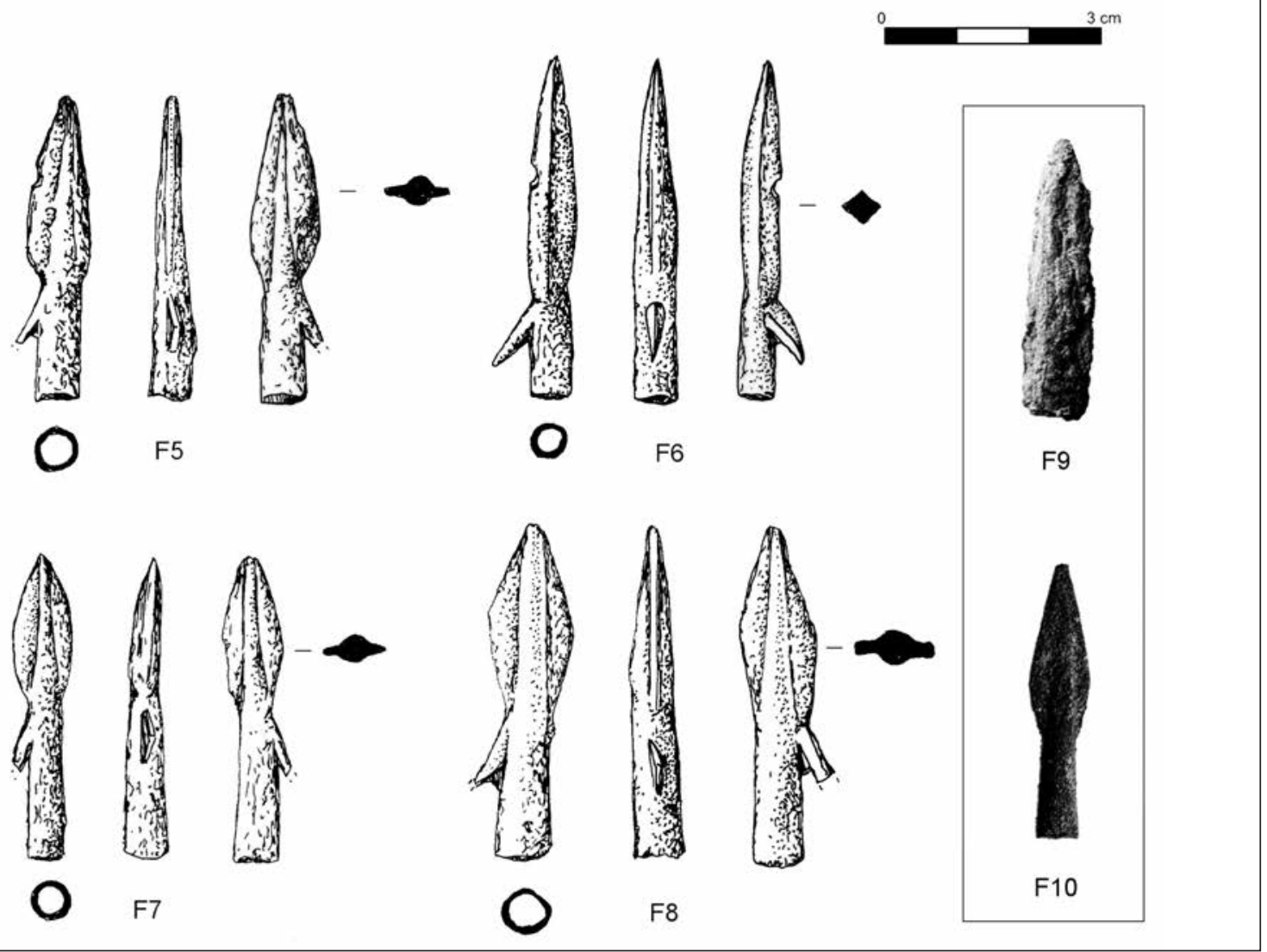

Fig. 4. La Fonteta. Puntas de doble y cuádruple filo con y sin arpón lateral (F1-10). (F1-F4, dibujos de Mª D. Sánchez de Prado; F5-F8, dibujos de S. Pernas; F9-10 según González Prats, 2014a). 


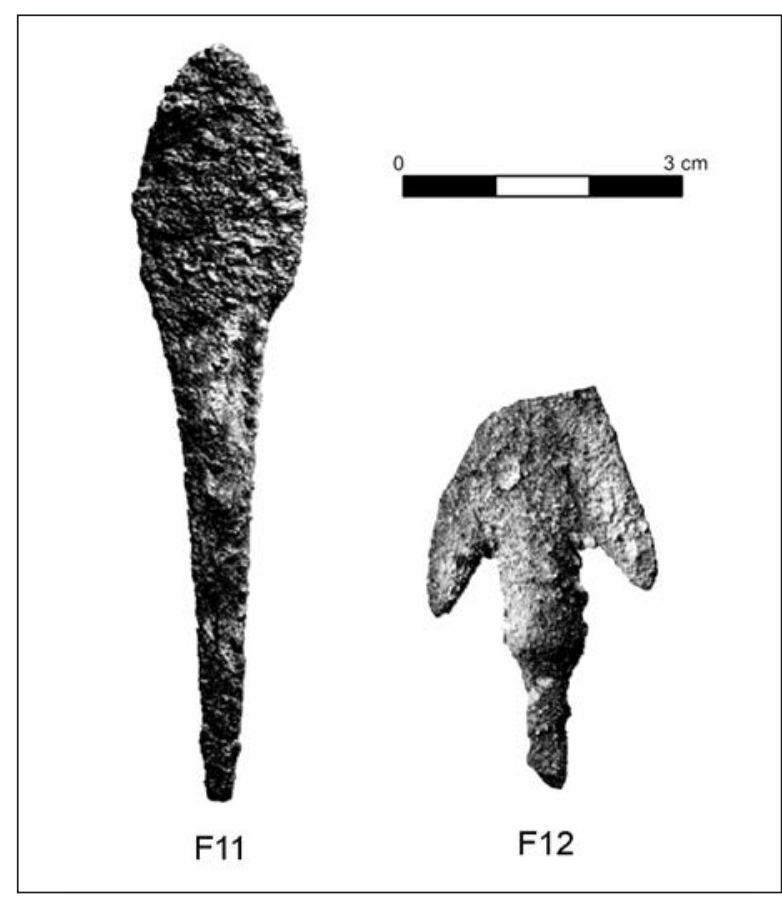

Fig. 5. Otras puntas de flecha de La Fonteta (F11-12). (Según González Prats, 2014a).

28.F2. Punta de flecha de bronce de doble filo bien conservada, con hoja lanceolada, doblada y fragmentada en la punta con un nervio central muy marcado y un cubo cilíndrico. Grupo 1. Tipo 11a de Ramon/Ferrer y 1A de González Prats. Procedencia: Fonteta, Fase Vb, Estrato 3088. Cronología: Mediados s. VI a.C. N ${ }^{\circ}$ Inv. RG/973088-6. Dimensiones: Long. Máx. $5 \mathrm{~cm}$; Long. Hoja: $3 \mathrm{~cm}$; Anch. Hoja: 0,8 cm; Grosor Hoja: 0,3 cm; Long. Cañón: 2 cm; Grosor Cañón: 0,6 cm; Índice de Proporcionalidad: 0,6. Peso: sin datos. Bibliografía: Le Meaux y Sánchez de Prado 2007: 325, fig. 260:4 (Fig. 4, F2).

29.F3. Punta de flecha de bronce de doble filo completa, con hoja lanceolada y nervio central muy marcado y un cubo cilíndrico, en cuya zona de unión con la hoja presenta un destacado y largo arpón lateral. Grupo 1. Tipo 11a de Ramon/Ferrer y 1A de González Prats. Procedencia: Fonteta, Fase Vb, Estrato 3088. Cronología: Mediados s. VI a.C. No Inv. RG/97-3088-8. Dimensiones: Long. Máx. 4,5 cm; Long. Hoja: 2,6 cm; Anch. Hoja: 0,8 cm; Grosor Hoja: 0,3 cm; Long. Cañón: 2 cm; Grosor Cañón: 0,6 cm; Índice de Proporcionalidad: 0.6. Peso: sin datos. Bibliografía: Le Meaux y Sánchez de Prado, 2007: 325, fig. 260: 5 (Fig. 4, F3).

30.F4. Punta de flecha de bronce de doble filo bien conservada, con hoja lanceolada de sección aplanada en los dos tercios superiores de la hoja y un pequeño cañón formado por dos hendiduras laterales en su tercio inferior, formando el característico "falso doble filo". Presenta un corto cañón, en cuya zona de unión con la hoja nace un corto, fino y des- tacado arpón lateral. Grupo 1. Tipo 12a de Ramon/Ferrer y 3A de González Prats. Procedencia: Fonteta, Fase Vb, Estrato 3088. Cronología: Mediados s. VI a.C. N ${ }^{o}$ Inv. RG/973088-9. Dimensiones: Long. Máx. 5 cm; Long. Hoja: $3 \mathrm{~cm}$; Anch. Hoja: 0,8 cm; Grosor Hoja: 0,3 cm; Long. Cañón: 2 cm; Grosor Cañón: 0,6 cm; Índice de Proporcionalidad: 0,6. Peso: sin datos. Bibliografía: Le Meaux y Sánchez de Prado, 2007 : 325, fig. 260: 6 (Fig. 4, F4).

31.F5. Punta de flecha de bronce de doble filo, con hoja romboidal, con sección disimétrica que presenta un nervio central ligeramente ladeado y que genera alas de diferente longitud, entre 0,4 a $0,2 \mathrm{~cm}$ respectivamente. El nervio central se estrecha hacia la punta y en una de sus caras no se une con ella. El cañón cilíndrico ligeramente más ancho en su base del que nace un destacado arpón. Tanto la punta como el arpón están rotos. Como rasgo singular, el cañón de esta pieza es macizo o al menos está colmatado quizá por el óxido y erosión que presentaba antes de su restauración a excepción de su tramo final, en el cual a $0,4 \mathrm{~cm}$ se conserva la morfología original hueca del cañón con apenas un milímetro de grosor en sus paredes. Grupo 1. Tipo 11a de Ramon/Ferrer y $1 \mathrm{~A}$ de González Prats. Procedencia: Fonteta, Cortes intramuros meridionales, 7CA4. Fase V. Cronología: fines s. VII-principios s. VI a.C. $N^{\circ}$ Inv. 10101 (González Prats, 2014a: 272), GUARD-039, Museo Arqueológico de Guardamar. Dimensiones: Long. Máx. 4,2 cm; Long. Hoja: 2,5 cm; Anch. Hoja: 0,9 cm; Grosor Hoja: 0,4 cm; Long. Cañón: 1,7 cm; Grosor cañón: 0,6 cm; Índice de Proporcionalidad: 0,6; Peso: 7,09 g. Bibliografía: González Prats, 2014a: 272, fig. 29.10101 (Fig. 4, F5).

32. F6. Punta de flecha de bronce con hoja romboidal y cuatro filos, no diferenciándose la hoja de los filos. Presenta un cañón cilíndrico que presenta un arpón lateral que arranque de la zona de unión del filo de la hoja y el cañón. El cañón de nuevo es macizo o está colmatado por el óxido de la pieza hasta el último tramo del mismo que conserva su morfología hueca con pared de grosor de un milímetro. Presenta una ligera marca de impacto en uno de sus filos. Su arpón es destacado y largo. Grupo 5. Tipo 54a de Ferrer. Procedencia: Fonteta, Cortes intramuros meridionales, Fase VIb. 5C-A3. Cronología: mediados s. VI a.C. No Inv. 25011 (González Prats, 2014a: 272). GUARD-40. Museo Arqueológico de Guardamar. Dimensiones: Long. Máx. 4,7 cm; Long. Hoja: 3,3 cm; Anch. Hoja: 0,5 cm; Grosor Hoja: 0,5 cm; Long. Cañón: 1,4 cm; Grosor cañón: 0,6 cm; Índice de Proporcionalidad: 0,74; Peso: 5,60 g. Bibliografía: González Prats, 2014a: 273, fig. 30.25011 (Fig. 4, F6). 
33.F7. Punta de flecha de bronce de doble filo con estrecha hoja lanceolada, de sección redondeada, con nervio central que genera don amplias alas y largo cañón del que nace un arpón lateral fragmentado. Presenta la punta rota. El cañón, parcialmente deformado y roto en su extremo lateral, está colmatado o relleno por la oxidación interna de la pieza hasta los últimos 0,5 milímetros que conserva su morfología hueca con paredes de un milímetro de grosor. Grupo 1. Tipo 11a de Ramon/Ferrer y 1A de González Prats. Procedencia: Fonteta, Cortes intramuros meridionales, Fase VI, 5NA3VIb. Cronología: mediados s. VI a.C. $N^{o}$ Inv. 25003 GUARD-038. Museo Arqueológico de Guardamar. Dimensiones: Long. Máx. 4,1 cm; Long. Hoja: $2 \mathrm{~cm}$; Anch. Hoja: 0,7 cm; Grosor Hoja: 0,5 cm; Long. Cañón: 2,1 cm; Grosor cañón: 0,6 cm; Índice de Proporcionalidad: 0,5; Peso: 5,52 g. Bibliografía: González Prats, 2014a: 273, fig. 30.25003 (Fig. 4, F7).

34.F8. Punta de flecha de bronce de doble filo con hoja lanceolada o romboidal, de sección redondeada disimétrica, con nervio central que presenta dos anchos filos laterales marcados. Su largo cañón se ensancha en su base ligeramente y en la zona de unión con la hoja nace un largo arpón lateral que está fragmentado, al igual que la hoja sin punta marcada. Grupo 1. Tipo 11a de Ramon/Ferrer y 1A de González Prats. Procedencia: Fonteta, Cortes intramuros meridionales, Fase VI, 5N-A3. Cronología: mediados s. VI a.C. N $^{\circ}$ Inv. 21143 (González Prats, 2014a: 271). GUARD-041. Museo Arqueológico de Guardamar. Dimensiones: Long. Máx. 4,7 cm; Long. Hoja: 2,7 cm. Anch. Hoja: 1 cm; Grosor Hoja: 0,5cm; Long. Cañón.: 2 cm; Grosor Cañón: 0,6cm; Long. Arpón: 1 cm; Índice de Proporcionalidad: 0,51. Peso: 4,28 g. Bibliografía: González Prats, 2014a: 273, fig. 30.21143 (Fig. 4, F8).

35.F9. Punta de flecha de bronce muy erosionada que no permite una identificación precisa de sus partes, más que intuir su hoja lanceolada de doble filo y un cañón cilíndrico que parece remitir a un ejemplar sin arpón. Grupo 1. Tipo 11b Ramon/Ferrer y 1B de González Prats. Procedencia: Fonteta, Cortes intramuros meridionales, Fase VI, 8BC-A3bcVIb. Cronología: mediados s. VI a.C. N ${ }^{\circ}$ Inv. 13028. Dimensiones $^{6}$ : Long. Máx. 4 cm; Long. Hoja: 1 cm; Anch. Hoja: 0,9 cm; Grosor Hoja: sin datos. Long. Cañón: sin datos; Grosor cañón: sin datos; Índice de proporcionalidad: sin datos. Peso: sin

6 En la revisión realizada a los ejemplares depositados en el Museo arqueológico de Guardamar, solo se localizaron los datos. Bibliografía: González Prats, 2014a: 273. fig. 30.13028 (Fig. 4, F9).

36. F10. Punta de flecha de bronce de doble filo bien conservada, con hoja romboidal con nervio central que se adelgaza hacia la punta y forma dos anchas alas. Su largo cañón se ensancha en su base. Presenta la punta rota. Grupo 1. Tipo 11b Ramon/Ferrer y 1B de González Prats. Procedencia: Fonteta, Cortes intramuros meridionales, Fase VI, 7EB6VIb. Cronología: mediados s. VI a.C. N Inv. 4311. Dimensiones: Long. Máx. 3,6 cm; Long. Hoja: $2 \mathrm{~cm}$; Anch. Hoja: 0,8 cm; Long. Cañón: 1,6 cm; Grosor cañón: 0,5-0,6 cm; Índice de Proporcionalidad: 0,55. Peso: sin datos. Bibliografía: González Prats, 2014a: 273, fig. 30.4311 (Fig. 4, F10).

37. F11. Punta de flecha de bronce de hoja lanceolada y largo pedúnculo macizo de sección cuadrangular. Grupo 7. Tipo I de Simón (1998) y IIPL de Kaiser (2003). Procedencia: Fonteta, Cortes intramuros meridionales, Fase III. Corte 7CB11b. Cronología: s. VII a.C. $\mathrm{N}^{\mathrm{o}}$ Inv. 10099. Dimensiones: Long. Máx. 7,7 cm; Long. Hoja: 2 cm; Anch. Hoja: 1,5 y 0,5 cm. Long. Pedúnculo: 4,7 cm; Grosor pedúnculo: 0,7-0,3 cm. Peso: sin datos. Bibliografía: González Prats, 2014a: 272, fig. 29.10099 (Fig. 5, F11).

38. F12. Punta de flecha de bronce de hoja triangular con aletas y pedúnculo macizo adelgazado tras un engrosamiento, que presenta sección cuadrangular. Grupo 7. Tipo IIIBNPE Kaiser (2003) y VII de Buchholz (1962). Procedencia: Fonteta, Cortes extramuros meridionales, Fase III-IV, Corte 54 A4ab (González Prats, 2011: fig. 37: 69) Cronología: s. VII a.C. $\mathrm{N}^{\circ}$ Inv. 42043. Dimensiones: Long. Máx. 4 cm; Long. Hoja: 1,8 cm; Anch. Hoja: 2,2 cm. Long. Pedúnculo (zona más estrecha): $1,2 \mathrm{~cm}$. Grosor pedúnculo: $0,9 \mathrm{~cm}$; Largo aletas: 0,6 cm; Peso: sin datos. Bibliografía: González Prats, 2014a: 272, fig. 29.42043 (Fig. 5, F12).

Sin contexto estratigráfico:

39.F-13. Punta de flecha de bronce "con pedúnculo", lo que no permite su adscripción tipológica Procedencia: Fonteta, Rabita Islámica. Nivel inferior, Mirhab I Espacio IX. Reutilización de materiales fenicios que incluye betilos funerarios y la punta de flecha. Cronología: s. VII a.C. (?). Dimensiones y peso: sin datos. Bibliografía: Azuar, 2004: 11. 


\subsection{El Castellar de Meca (Ayora, Valencia) (Fig. 6)}

Sin contexto estratigráfico:

40. CM1. Punta de flecha de doble filo y arpón lateral, con hoja lanceolada o romboidal con fuerte nervio central que se adelgaza ligeramente hacia la punta y está ligeramente inclinado respecto al eje de la hoja que presenta sección romboidal. Su hoja presenta en uno de sus laterales el nacimiento de un largo arpón doblado. Su cañón es cilíndrico, se ensancha en su base, probablemente por la rotura que presenta en su parte inferior, evidencias ambas de posibles huellas de impacto. Sin perforación adicional. Grupo 1. Tipo 11a de Ramon/Ferrer y 1A de González Prats. Procedencia: Castellar de Meca, sin contexto. Cronología: s. VI a.C. (?). Dimensiones: Long. Máx. 3, 2 cm. Long. Hoja: 1,8 $\mathrm{cm}$. Anch. Hoja: 0,7 cm. Grosor Hoja: 0,4 cm. Long. Cañón: 1,5 cm. Diámetro Cañón: 0,4-0,6. Índice de proporcionalidad: 0,5. Peso: $3,4 \mathrm{~g}$. Bibliografía: Inédita (Fig. 6, CM1).

41.CM2. Punta de flecha de doble filo y arpón lateral apenas indicado. Presenta una afilada y muy estrecha hoja con amplio nervio central y finos filos laterales. Su cañón cilíndrico se ensancha en su tercio inferior. Presenta la punta doblada como huella principal de impacto. Grupo 1. Tipo 11a de Ramon/Ferrer y 1A de González Prats. Procedencia: Castellar de Meca, sin contexto. Cronología: s. VI a.C. (?). Dimensiones: Long. Máx. $4 \mathrm{~cm}$; Long. Hoja: 2,1 - 2,3 cm; Anch. Nervio: 0,4 cm.; Anch. Hoja: 0,7 cm; Grosor Hoja: $0,3 \mathrm{~cm}$; Long. Cañón: $1,9 \mathrm{~cm}$; Diámetro Cañón: 0,4-0,7 cm; Índice de proporcionalidad: 0,52; Peso: 4,6 g. Bibliografía: Inédita (Fig. 6, CM2).

42. CM3. Punta de flecha de doble filo y arpón lateral, característica de la puntas de "falso doble filo". Presenta una hoja lanceolada, de sección romboidal de sección aplanada en su tercio superior y con un corto nervio central en su tercio inferior realizando mediante dos muescas longitudinales laterales. Su largo cañón cilíndrico presenta un destacado arpón lateral. Grupo 2. Tipo 12a de Ramon/Ferrer y 12d de Lorrio, Pernas y Torres. Procedencia: Castellar de Meca, sin contexto. Cronología: s. VI a.C. (?). Dimensiones: Long. Máx. 4,4 cm; Long. Hoja: 1,9$2 \mathrm{~cm}$; Anch. Hoja: 0,9 cm; Grosor Hoja: 0,4 cm; Long. Cañón: 2,4 cm; Diámetro Cañón: 0,5 cm;

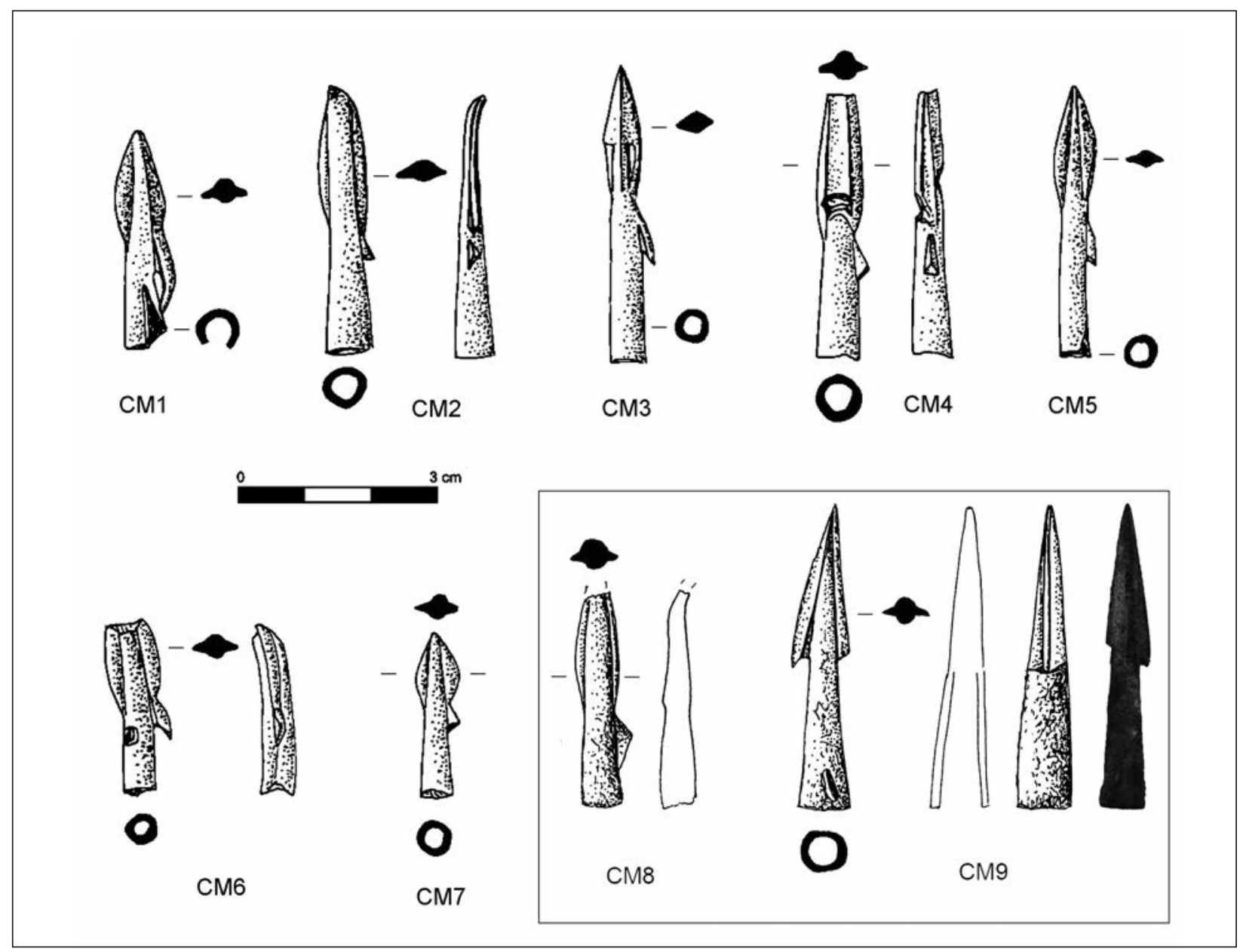

Fig. 6. Puntas de doble filo con y sin arpón lateral de El Castellar de Meca (CM1-7). CM8-CM9, sin procedencia confirmada. (Dibujos de $\mathrm{M}^{\mathrm{a}} \mathrm{D}$. Sánchez de Prado) 
Long. Arpón: 0,8 cm; Índice de proporcionalidad: 0,45; Peso: 4,6 g. Bibliografía: Inédita (Fig. 6, CM3).

43. CM4. Punta de flecha de doble filo y arpón lateral indicado. Presenta una hoja lanceolada, rota en su punta, con nervio central ancho y filos estrechos laterales. Tiene un cañón cilíndrico que se ensancha en su tercio inferior. Presenta la punta rota y una fractura transversal en la hoja, a la altura de la unión de la hoja con el cañón en ambos filos de la pieza como huellas de impacto. Grupo 1. Tipo 11a de Ramon/Ferrer y IA de González Prats. Procedencia: Castellar de Meca, sin contexto. Cronología: s. VI a.C. (?). Dimensiones: Long. Máx. 3,8 cm; Long. Hoja: 2,2 o 2,3 cm; Anch. Hoja: 0,7 cm; Grosor Hoja: 0,4 cm; Long. Cañón: 1,8cm; Diámetro Cañón: 0,5-0,6 cm; Índice de proporcionalidad: 0,55; Peso: 4,6 g. Bibliografía: Inédita (Fig. 6, CM4).

44. CM5. Punta de flecha de doble filo y arpón lateral destacado. Presenta hoja romboidal con nervio central que se estrecha significativamente hacia la punta, Tiene un largo cañón cilíndrico que en la zona de unión con la hoja presenta un destacado arpón lateral. Grupo 1. Tipo 11a de Ramon/Ferrer y 11d de Lorrio, Pernas y Torres. Procedencia: Castellar de Meca, sin contexto. Cronología: s. VI a.C. Dimensiones: Long. Máx. $4 \mathrm{~cm}$. Long. Hoja: 1,8 cm. Anch. Hoja: 0,6 cm. Grosor Hoja: 0,3 cm. Long. Cañón: 3,2 cm. Diámetro Cañón: 0,5 cm; Índice de proporcionalidad: 0,45; Peso: 2,7 g. Bibliografía: Inédita (Fig. 6, CM5).

45. CM6. Punta de flecha de doble filo y arpón lateral destacado. Presenta una hoja lanceolada con amplio nervio central y anchos filos laterales. $\mathrm{Su}$ cañón cilíndrico se ensancha en su tercio inferior. Presenta la punta rota y ligeramente ladeada como huella principal de impacto. Grupo 1. Tipo 11a de Ramon/ Ferrer y 1A de González Prats. Procedencia: Castellar de Meca, sin contexto. Cronología: s. VI a.C. (?). Dimensiones: Long. Máx. Conserv.: 2,4 cm; Long. Hoja conserv.: 1,3 cm; Anch. Hoja: 0,7 cm; Grosor Hoja: 0,3 cm; Long. Cañón: 1,1 cm; Diámetro Cañón: 0,4 cm; Índice de proporcionalidad: 0,54; Peso: 3,2 g. Bibliografía: Inédita (Fig. 6, CM6).

46. CM7. Pequeña punta de flecha de doble filo y arpón lateral destacado. Presenta una hoja romboidal muy marcada con nervio central que se adelgaza hacia la punta y amplios filos laterales. Su cañón cilíndrico se ensancha en su tercio inferior. Presenta la punta rota como huella principal de impacto. Grupo 1. Tipo 11a de Ramon/Ferrer y 11d de Lorrio, Pernas y Torres. Procedencia: Castellar de Meca, sin contexto. Cronología: s. VI a.C. (?). Dimensiones: Long. Máx. 2,4 cm. Long. Hoja: 1,1 cm; Anch. Hoja: 0,7 cm; Grosor Hoja: 0,3 cm;
Long. Cañón: 1,3cm; Diámetro Cañón: 0,5cm; Índice de proporcionalidad: 0,45. Peso: 2,4 g. Bibliografía: Inédita (Fig. 6, CM7).

47. CM8. Punta de flecha de doble filo y arpón lateral apenas indicado. Presenta una afilada y muy estrecha hoja lanceolada con amplio nervio central y finos filos laterales. Su cañón cilíndrico se ensancha muy ligeramente en su tercio inferior. Presenta la punta doblada y rota en su extremo como huella principal de impacto. El interior del cañón está relleno de concreciones y muy deteriorado. Grupo 1. Tipo 11a de Ramon/Ferrer y IA de González Prats. Procedencia: sin datos, se conservan en la Casa de Cultura de Ayora (Valencia). Cronología: s. VI a.C. (?). Dimensiones: Long. Máx. 3,4 cm; Long. Hoja: 1,8-1,9 cm; Anch. Nervio: 0,4 cm; Anch. Hoja: 0,5-0,6 cm; Grosor Hoja: 0,3 cm; Long. Cañón: 1,5 cm; Diámetro Cañón: 0,4-0,5 $\mathrm{cm}$; Índice de proporcionalidad: 0,52; Peso: sin datos. Bibliografía: Inédita (Fig. 6, CM8).

49. CM9. Punta de flecha de doble filo y sin arpón lateral. Presenta una afilada hoja triangular con extremos remarcados a modo de pequeñas aristas o aletas, una de ellas rota como huella de impacto. El nervio central se estrecha hacia la punta y no llega a unirse a ella, generando dos alas estrechas, rectilíneas y muy afiladas que destacan respecto a la forma cilíndrico-cónica del cañón central, cónico en su parte superior en zona de la hoja, mientras que en su tercio inferior se conforma como un cubo cilíndrico recto, que presenta unos agujeros o perforaciones irregulares, posiblemente, nuevas evidencias de impacto o engarce la pieza, al carecer del mencionado arpón lateral. Grupo 4. Tipo 22 de Ramon/Ferrer. Procedencia: sin datos, se conservan en la Casa de Cultura de Ayora (Valencia). Cronología: s. VI a.C. (?). $\mathrm{N}^{\circ}$ Inv. AYO-1. Dimensiones: Long. Máx. 4,6-4,7 cm; Long. Hoja: 2,3 cm; Long. Aletas: 0,3 cm; Anch. Nervio: 0,4 y 0,2 cm.; Anch. Hoja: 0,7 cm; Grosor Hoja: 0,3 cm; Long. Cañón: 2,3-2,4 cm; Diámetro Cañón: 0,6 cm máximo, y 0,4 cm mínimo; Índice de proporcionalidad: 0,56; Peso: sin datos. Bibliografía: Inédita (Fig. 6, CM9).

\section{Estudio Tipológico}

\subsection{Caracterización morfológica de las puntas de flecha del Hierro Antiguo}

Las puntas de flecha orientalizantes, propias del Hierro Antiguo, presentan una cierta variedad de tipos, aunque el más numeroso sea el denominado de "doble filo y arpón lateral", objeto de numerosos estudios y propuestas de clasificación que han abordado su morfología, origen, adscripción cultural y dispersión (García Guinea, 1967; Sánchez Meseguer, 1974; González Prats 1983: 175, 246-247; Ramon, 1983; 
Mancebo y Ferrer, 1988-89; Ferrer, 1994; Id. 1996; Elayi y Planas 1995; Quesada 1997: 441 s.), recibiendo variadas denominaciones, como puntas de tipo "Macalón" -por ser el yacimiento epónimo el primero en aportar contextos estratificados (García Guinea, 1967: 70)-, o “a barbillon", por la presencia de un característico arpón lateral (Sánchez Meseguer, 1974: 71), lo que explica las denominaciones de anzuelo y doble filo o simplemente de anzuelo o con arpón (González Prats, 1982a: 257) 7 .

Estas pequeñas puntas de bronce se caracterizan por la presencia de un encaje tubular con un cubo cilíndrico bastante homogéneo en sus dimensiones, entre 0,4-0,6 cm de grosor, siendo su medida mayoritaria, $0,5 \mathrm{~cm}$, lo que ha sido identificado como un rasgo de la homogeneidad y estandarización de su fabricación (Ferrer, 1996: 49). Otro rasgo característico es su morfología general alargada (Sánchez Meseguer, 1974: 72), gracias a la existencia de una hoja nervada preferentemente estrecha y afilada, que conforma perfiles foliáceos, como pauta más numerosa, y, en algunos ejemplares, más o menos romboidales y triangulares (Ferrer, 1996: 49, fig. 4), con la presencia de un característico doble filo, como mínimo, existiendo también ejemplares con triple o cuádruple filo, lo que se ha marcado como una tendencia de modernidad hacia la multiplicación de filos (Quesada, 2011: 209-210), aunque a menudo todas las variantes sean coetáneas. Un último rasgo, posiblemente al que mayor peso se le concedió en un principio (García Guinea, 1967; Sánchez Meseguer, 1974: 73) y que ha servido para denominar a estos tipos, es la presencia de un arpón o anzuelo lateral, elemento que es mayoritario en las puntas de flecha orientalizantes, aunque existen bastantes ejemplos más sencillos, sin arpón (Ferrer, 1996: fig. 4).

El primer estudio que abordó un intento de aproximación a la clasificación tipológica de estas piezas fue realizado por Sánchez Meseguer (1974: 71 ss.), que si bien identifica sus rasgos básicos, ya apuntados por García Guinea (1967: 73-74), remarca la gran variedad de la morfología de hojas, cañones y arpón, a partir de cuyos rasgos genera una gran diversidad de tipos y subtipos, intentando adscribirles valor cronotipológico (Sánchez Meseguer, 1974: 71 ss.). No obstante, esta alta variabilidad de tipos hace compleja su aplicación, como ya han señalado algunos autores (Elayi y Planas, 1995; Ferrer, 1996: 47-48).

Posteriormente, fueron analizadas por Serge Cleuziou en su estudio sobre las puntas de flecha en el Próximo y Medio Oriente, del que solo se ha publica-

7 Un ejemplar del tipo fue publicado por A. Vives junto con otros modelos recuperados en la necrópolis feno-púnica de Ibiza (Vives, 1917: 58-59 no 227-231, láms. XIV, 1-5, XIX,10). Por su parte, L. Siret había identificado años antes algunas puntas de modelos similares a los recogidos por do un corto trabajo sobre las puntas de flecha escitas y en el que se definen varios tipos fechados en los s. VIIVI a.C., en los que se recogen ejemplos de todos los ejemplares hispanos (Cleuziou 1977: 190-193, fig. 1).

No obstante, para su estudio y clasificación seguimos las propuestas principalmente de J. Ramon (1983) y E. Ferrer (1996), que plantean la necesidad de abordar de manera completa su descripción. De esta forma, debe atenderse no solo a la caracterización de sus atributos principales -hoja, cubo y arpón-, como en las clasificaciones previas (García Guinea, 1967; Sánchez Meseguer, 1974), pues algunos, como por ejemplo la presencia del arpón, se han demostrado que son secundarios (Ramon, 1983: 310-312; Quesada, 1989: 165; Ferrer, 1996: 50), sino identificando patrones dimensionales diversos (diámetro de cañón, anchura de hoja y filo, sección de hoja y filo; longitud de hoja y cubo; etc.) que permitan una caracterización más detallada de sus rasgos específicos (Ferrer, 1996), pudiendo destacar la sección de la hoja y la proporción entre hoja y cañón, este último siempre en forma de cubo. Otros rasgos, como la homogeneidad del diámetro del cubo, habitualmente no mayor de $0,5 \mathrm{~cm}$, pueden considerarse comunes a estas puntas orientalizantes y remarcan el característico sistema de encaje tubular de estas puntas de flecha (Ferrer, 1996: 49). Así mismo, incorporaremos otras propuestas como la realizada para el yacimiento de Peña Negra por González Prats (1983: 146), que individualiza diversos tipos en atención a la morfología de la hoja, el número de filos y la presencia o ausencia de arpón.

Respecto a la propuesta de clasificación planteada por Ramon (1983) y actualizada más tarde por Ferrer (1996), que incorpora además algún tipo nuevo como los ejemplares de cuádruple filo, y elimina otros, como el 13 de Ramon, o de otras como la de González Prats (1983: 175), si bien suponen un salto cualitativo en el estudio y clasificación de estas piezas, también plantean algunas dificultades. La tipología de Ramon combina la valoración morfológica de los componentes principales (hoja, cañón y arpón) de estas puntas de flecha y su disposición, aunque incluye un tipo, el 33, ajeno a esta familia (Ramon, 1983: 310; Ferrer, 1996: 50). Ferrer (1996: 48-49) incorpora una aproximación estadística y suma otros elementos de análisis como la sección de la hoja y la proporción dimensional, a fin de evaluar la variabilidad interna de las categorías establecidas por Ramon, que le llevan a proponer la unificación de algunas de ellas, englobando en el tipo 11a, puntas de doble filo de hoja lanceolada y de hoja rom-

Vives, aunque ninguno del tipo con arpón (Siret, 1891/2001: láms. 80,39-40 -procedentes de contextos domésticos- y 81, 4 y 74; reproducidas en Id. 1909: láms. VI,39-40 y VII,4 y 74; vid. Astruc 1951: lám. XLIX, 1-3 y 12, para los ejemplares recuperados en el cementerio). 
boidal, el 13a de Ramon, y a la propuesta de nuevos subtipos, como el 43c, que incorporan la proporción hoja-cañón en su definición, aunque mantiene en general el esquema de la propuesta anterior. Estas clasificaciones establecen una diferenciación general en grupos o tipos de puntas de flecha muy útil, diferenciando hasta 5 'Formas', definidas a partir del primer dígito: puntas de doble filo (Forma 1), puntas de hojas disimétricas (Forma 2), puntas con aletas (Forma 3), puntas de triple filo (Forma 4) y, solo en la propuesta de Ferrer, puntas de cuádruple filo (Forma 5). Por su parte, en la elaboración de los subtipos se incorporan diversos criterios de identificación: la presencia o ausencia de arpón; la longitud y morfología de las hojas; la combinación de rasgos como la presencia de aletas y la longitud del cañón; y otros como la morfología de la hoja, la presencia de aletas, el número de filos y la longitud del arpón o la sección de las hojas. Las peculiaridades que ofrecen las 'Formas' implica que cada una de ellas presente su propia clasificación, con hasta 4 'Tipos', para los que se reserva el segundo dígito, y numerosos subtipos, definidos a partir de letras $(a, b, c)$, que en la clasificación original de Ramon permitía diferenciar los ejemplares con o sin arpón (a y b) de una misma forma $(11,12,13,14$ y 44), pero que en la de Ferrer se complica al incorporar otros atributos, como la presencia de doble arpón en más de un subtipo (lo que obliga al autor a cambiar alguna denominación previa en los grupos 11 y 14), o la identificación de piezas con largos cañones (grupos 43 y 44).

Aunque estas clasificaciones alfanuméricas destacan por su carácter abierto que permite la incorporación de nuevas variantes, sin duda una de las claves que explican la perduración de su uso por la investigación, la personalidad de cada Forma y los diferentes atributos que la definen, que al menos a priori no se repiten en las restantes, dificulta seguir un mismo criterio al definir cada grupo, así como la incorporación de una mayor variabilidad de subtipos en las formas creadas, atendiendo a la coincidencia de los mismos sistemas alfanuméricos aplicados a diferentes rasgos según el tipo (véase los tipos 11, 43 y 44 por ejemplo). Ello obliga, ante la identificación de nuevos subtipos, a cambiar las denominaciones de las variantes afectadas, como hace Ferrer en la

8 Para intentar corregir estos desajustes Ferrer se vio obligado a cambiar algunas denominaciones para mantener la coherencia interna de la clasificación. De esta forma, la identificación de una punta con arpón simple asimilable al grupo 14 lleva al autor a clasificarla como 14a, siguiendo la lógica seguida en los diferentes grupos, pasando las de doble arpón a incluirse dentro de los subtipos 11c y 14c (antes 14a en Ramon). Por su parte, incorporó como tercera variante en los grupos 43 y 44, las puntas con largos cañones y cortas puntas, al faltar entre las piezas de estos grupos las puntas de doble arpón. El problema viene cuando se producen nuevos hallazgos que combinan rasgos clasificados de forma diferente según los grupos analizados, como la forma 14, añadir un significado diferente a las denominaciones alfabéticas de las variables en cada tipo, o incorporar las variantes identificadas a continuación de las ya establecidas, como hace también Ferrer en los grupos 11, 43 y 44 o como hemos hecho nosotros al añadir las variantes $11 \mathrm{~d}$ y $12 \mathrm{e}^{8}$. A este respecto, uno de los problemas que el estudio de nuestras colecciones plantea ha sido la identificación de una mayor variabilidad de puntas con largo cañón dentro de los grupos de doble filo, no distinguidas por la tipología Ramon-Ferrer. No obstante, dada la versatilidad y amplia aplicación en el ámbito de la investigación de dicha propuesta hemos optado por mantenerla e incorporar dos nuevos subtipos (11d, 12d y 12e), que permitan ampliar los grupos ya conocidos.

\subsection{Tipología}

El conjunto de piezas objeto del presente estudio corresponde a una colección bastante homogénea de puntas de flecha de bronce, asimilables en su gran mayoría a la familia de puntas pequeñas de bronce con cubo de origen oriental, coloquialmente denominada como ‘tipo Macalón', con “anzuelo y doble filo”, aunque se conozcan subtipos o variantes sin arpón o incluso provistas de dos anzuelos y modelos de triple o cuádruple filo.

Este tipo de puntas se caracterizan por presentar encaje tubular, lo que las diferencia de los modelos macizos del Bronce Final (Kaiser, 2003: 84), innovación técnica y armamentística que permite una mejor sujeción de la punta al astil de la flecha. Dicho encaje está a menudo reforzado mediante un pasador o remache lateral (López Palomo, 1981: 255; Mancebo y Ferrer, 1988-89: 328; Quesada, 1989: 164; Ferrer, 1996: 49), que cabría deducir a partir de la presencia de una perforación en el vástago como encaje, documentada en el $24,4 \%$ de los casos estudiados en este trabajo (Fig. 7, A).

Otro rasgo singular es el pequeño arpón lateral, que nace de la zona de unión entre la hoja y el cubo, muy frecuente en el conjunto analizado, aunque también se identifiquen piezas sin este elemento. Es igualmente

identificación de puntas asimilables a los grupos 11 y 12 pero con largos cañones, a su vez con o sin arpón, que son clasificadas por nosotros como $11 \mathrm{~d}$ y $12 \mathrm{~d}-\mathrm{e}$ (en este caso, reservando el 12c para las de doble arpón, sin ejemplares conocidos hasta la fecha), aunque ya sin seguir un orden lógico respecto de los restantes grupos (para lo cual habría que haber modificado de nuevo la terminología de éstos). Estos desajustes obligarán a abordar de nuevo el tema de la clasificación de las puntas orientalizantes, aunque no es nuestra intención hacerlo en este trabajo, donde hemos seguido las tipologías al uso, incorporando las nuevas variantes detectadas. 


\begin{tabular}{|c|c|c|c|c|c|c|c|c|}
\hline \multicolumn{6}{|c|}{$\begin{array}{l}\text { A. Según presencia de arpón y/u orificio para } \\
\text { pasador } 0 \text { remache }\end{array}$} & \multicolumn{3}{|c|}{ B. Según el número de filos } \\
\hline \multicolumn{3}{|c|}{ Puntas con arpón (36) } & \multicolumn{3}{|c|}{ Puntas sin arpón (9) } & \multicolumn{3}{|c|}{ Puntas de doble Filo (40) } \\
\hline \multicolumn{3}{|c|}{$80 \%$ con arpón } & \multicolumn{3}{|c|}{$20 \% \sin$ arpón } & \multicolumn{3}{|c|}{$88,9 \%$ Doble filo } \\
\hline$P N$ & $F$ & $C M$ & $P N$ & $F$ & $C M$ & $P N$ & $F$ & $C M$ \\
\hline 20 & 8 & 8 & 6 & 2 & 1 & 22 & 9 & 9 \\
\hline $56 \%$ & $22,2 \%$ & $22,2 \%$ & $66,7 \%$ & $22,2 \%$ & $11, \%$ & $55 \%$ & $22,5 \%$ & $22,5 \%$ \\
\hline \multicolumn{3}{|c|}{$\begin{array}{l}\text { Puntas con pasador o } \\
\text { remache (11) }\end{array}$} & \multicolumn{3}{|c|}{$\begin{array}{c}\text { Puntas sin pasador o } \\
\text { remache }(34)\end{array}$} & \multicolumn{3}{|c|}{ Puntas de triple Filo (4) } \\
\hline \multicolumn{3}{|c|}{$\begin{array}{c}24,4 \% \text { con pasador } 0 \\
\text { remache }\end{array}$} & \multicolumn{3}{|c|}{$\begin{array}{c}75,56 \% \text { sin pasador o } \\
\text { remache }\end{array}$} & \multicolumn{3}{|c|}{$8,9 \%$ Triple filo } \\
\hline$P N$ & $F$ & $C M$ & $P N$ & $F$ & $C M$ & $P N$ & $F$ & $C M$ \\
\hline 8 & 1 & 2 & 18 & 9 & 7 & 4 & 0 & 0 \\
\hline $\begin{array}{c}72,8 \\
\%\end{array}$ & $9,1 \%$ & $18,1 \%$ & $53 \%$ & $26,5 \%$ & $20,5 \%$ & $100 \%$ & $0 \%$ & $0 \%$ \\
\hline \multicolumn{6}{|c|}{ Puntas con arpón y pasador o remache (8) } & \multicolumn{3}{|c|}{ Puntas de cuádruple Filo (1) } \\
\hline \multicolumn{6}{|c|}{$17,78 \%$ con pasador o remache } & \multicolumn{3}{|c|}{$2,2 \%$ Cuádruple filo } \\
\hline \multicolumn{2}{|c|}{$P N$} & \multicolumn{2}{|c|}{$F$} & \multicolumn{2}{|c|}{$C M$} & $P N$ & $F$ & $C M$ \\
\hline \multicolumn{2}{|c|}{6} & \multicolumn{2}{|c|}{1} & \multicolumn{2}{|c|}{1} & 0 & 1 & 0 \\
\hline \multicolumn{2}{|c|}{$75 \%$} & \multicolumn{2}{|c|}{$12,5 \%$} & \multicolumn{2}{|c|}{$12,5 \%$} & $0 \%$ & $100 \%$ & $0 \%$ \\
\hline \multicolumn{9}{|c|}{ C. Según el diámetro del cañón o cubo } \\
\hline \multicolumn{4}{|c|}{$\varnothing$ Cubo $(\mathrm{cm})$} & \multicolumn{3}{|c|}{$N^{\circ}$ Piezas } & \multicolumn{2}{|c|}{$\%$} \\
\hline \multicolumn{4}{|c|}{0,4} & \multicolumn{3}{|c|}{5} & \multicolumn{2}{|c|}{11,1} \\
\hline & & & & & 28 & & & \\
\hline & & & & & 12 & & & \\
\hline & To & & & & 45 & & & \\
\hline
\end{tabular}

Fig. 7. A. Presencia/ausencia de arpones y pasador o remaches en puntas, B. Hojas de doble o múltiple filo, C. Diámetros de cubo o cañón de la colección estudiada. PN: Peña Negra, F: Fonteta, CM: Castellar de Meca. Muestra: 45 puntas.

característico del tipo la estandarización en su morfología y el equilibrio de sus dimensiones, siendo en general puntas que guardan una canónica proporción entre hoja y cañón, ya señalada por diversos autores -dos tercios la hoja y un tercio el cubo señala Sánchez Meseguer (1974: 73)-, que, en general, corresponde con el patrón más habitual en los ejemplares estudiados, aunque no el único, como veremos. Un rasgo fundamental que ahonda en la "homogeneidad" y "estandarización" del modelo es sin duda el grosor del cañón o cubo, que se encuadra en el intervalo ya señalado entre 0,4 y $0,6 \mathrm{~cm}$ como máximo, siendo $0,5 \mathrm{~cm}$ la medida más frecuente (Ferrer, 1996: 49), lo que igualmente ocurre en la muestra analizada (Fig. 7, C).

Dentro de la aparente homogeneidad del modelo de encaje tubular de estas puntas de flecha podemos distinguir cierta diversidad de tipos y subtipos, atendiendo a la forma de la hoja nervada, el número de filos y la longitud del cañón. El conjunto que estudiamos consta de un total de 45 ejemplares, que incluye todas las de Peña Negra y Meca, así como la mayor parte de las de Fonteta, yacimiento éste que ha proporcionado dos ejemplares de espiga, de morfología muy diferente, que serán estudiados de forma independiente. Predominan los ejemplares de doble filo, que suponen el $88,9 \%$ respecto al total, entre los que se distinguen varios subtipos, presentando el resto entre tres y cuatro filos (Fig. 7, B).

En general la proporción hoja/cañón en los ejemplares de doble filo (Figs. 8, B y 14) sigue el patrón genérico de los dos tercios a favor de la hoja (PN1, PN2), aunque en algunos casos ambas dimensiones se igualan (PN3, PN4, PN5, PN6, PN9, PN10, PN14, PN20, F8, F10, CM2), manteniéndose dentro de la variabilidad de los tipos 11 y 12 de Ramon/Ferrer pero remarcando una tendencia en algunos casos a agrandar la longitud del cañón, como los tipos 11d y 12d, quizá como mejora del sistema de encaje, dado que en algunos de estos casos es común la presencia de perforaciones laterales para insertar un pasador o remache como refuerzo (PN3, PN5, PN20).

Se observa igualmente el predominio de los filos estrechos, de alas poco desarrolladas, lo que incide en su mayor efectividad y potencia de penetración y así lo podría indicar el que en el $55 \%$ de los casos las alas son menores a $0,3 \mathrm{~cm}$, lo que se relaciona a veces con la presencia de potentes nervios centrales (PN3, PN7, PN15, PN 16, CM2, CM4).

Cabe señalar la gran diversidad que presenta la tipología de los arpones identificados (según su sección, longitud y disposición). Esta diversidad, o falta 
de homogeneidad, quizá pudiera sugerir que la presencia de dicho arpón no sea el elemento principal que defina al grupo, a pesar de haber contribuido a definirlo (García Guinea, 1967; Sánchez Meseguer, 1974; Ferrer y Mancebo, 1988-89; Quesada, 1989), como demuestra que falte en muchos casos. La presencia del arpón contribuye a dificultar la extracción de la pieza, produciendo en cualquier caso un mayor desgarro en la herida (Sánchez Meseguer, 1974: 72; Ramon, 1983: 312; Quesada, 1997: 441). En la mayoría de los casos nace en la zona de unión entre hoja y cañón (94\%), y solo en algunas piezas lo hace en el tercio inferior del cañón.

Aunque seguimos las tipologías de Ramon/Ferrer y González Prats, hemos englobado las piezas recopiladas en seis grandes grupos, más otro vario, donde incluimos los dos ejemplares de encaje macizo de La Fonteta. El análisis se centra en los tres grandes conjuntos que justifican el trabajo (Herna/Peña Negra, La Fonteta y El Castellar de Meca), aunque puntualmente hagamos referencia a otros ejemplares conocidos o inéditos de la zona de estudio.

\section{Grupo 1: Puntas de doble filo y hoja fusiforme con o sin arpón (Tipo 11)}

Se trata del grupo más nutrido, con 27 ejemplares (Figs. 8, A, 9, 10 y 11, A). Los provistos de arpón corresponden a los tipos 11a de Ramon/Ferrer (Ramon, 1983; Ferrer, 1996: fig. 4), 1A de González Prats (1983: 175) y E6 de Cleuziou (1977: 190-191, fig. 1), que con 20 ejemplares ${ }^{9}$ es el más numeroso en los yacimientos estudiados, al representar un $44,5 \%$ de las puntas con encaje tubular, al igual que ocurre en los contextos orientalizantes de cronología similar del sur peninsular (Mancebo y Ferrer, 1988-89: 326; Ferrer, 1996: 50; Quesada, 2011: fig. 269) (Fig. 11, B.11a)

Menos numerosas son las puntas carentes de arpón incluidas en los tipos 11b de Ramon/Ferrer, 1B de González Prats y E8 de Cleuziou (1977: 190-191, fig. 1), con 4 ejemplares en Peña Negra y 1 en Fonteta, que suponen el $11 \%$ del total ${ }^{10}$ (Fig. 11, B.11b), lo que concuerda con su menor representación en general respecto al modelo anterior (Quesada, 1997: fig. 270).

9 PN1, PN3, PN7, PN16, PN17, PN18, PN19, PN23, PN26, F1, F2, F3, F5, F6, F8, CM1, CM2, CM4 y CM6.

10 PN10, PN11, PN12, PN15 y F10. El estado de conservación del ejemplar F9 no permite confirmar si también se podría adscribir a este tipo (González Prats, 2014a: fig. 30.13028). En nuestra revisión de los ejemplares del Museo Arqueológico de Guardamar del Segura no pudo ser localizado, con lo que planteamos la posibilidad de que se incluya en este tipo, aunque debemos esperar al análisis directo de la pieza para poder asegurarlo.

11 CM5 y CM7.

12 Este es un buen ejemplo de los problemas que presenta, ante la incorporación de nuevos modelos, su denominación de
El valorar como un rasgo significativo la proporción entre las longitudes de hoja y cañón nos ha permitido identificar dentro de este Grupo un nuevo subtipo, de hoja corta, largo cañón, superior en longitud a la hoja, y provisto de arpón, que denominamos $11 \mathrm{~d}^{11}$, un rasgo ya presente en el subtipo de triple filo y largo cañón, tipo 43c de Ferrer (1996: 49) ${ }^{12}$. Esta tendencia ha sido identificada en un minoritario conjunto de piezas, en el cual la proporción hoja/cañón se rompe a favor de un largo cubo, que siempre supera la longitud de la hoja, como reflejan algunos ejemplares en El Castellar de Meca, CM5, CM7 o CM3, éste último integrado en el siguiente Grupo $2^{13}$. Sin duda estos ejemplos muestran el interés de la variable 'proporción hoja/cañón' apuntada por Ferrer (1996: 47), que se da independientemente del tamaño de la pieza, pues se registra tanto en ejemplares de 4 o $5 \mathrm{~cm}$ de longitud máxima (CM3 y CM5), como en aquellos que apenas superan los $2 \mathrm{~cm}$ (CM7).

Como muestra de la gran variabilidad que incorporan estos tipos del Grupo 1, si acudimos al análisis de la morfología de sus hojas podemos distinguir tendencias, con hojas más estrechas (PN25 o F3), o con las que ofrecen una mayor anchura de ala (PN10, PN17 o $\mathrm{PN} 1$, entre otros). Si analizamos la morfología de los cañones siguiendo las clasificaciones o grupos de Sánchez Meseguer (1974: 75), comprobamos como se documentan ejemplares cuyo nervio finaliza y se estrecha antes de llegar a la punta ${ }^{14}$, aunque sea más habitual que se prolongue hasta dicha punta, al tiempo que si analizamos la anchura del nervio central, distinguimos un conjunto de ejemplares con nervio recto y ancho hasta el extremo ${ }^{15}$.

Por lo que respecta al tamaño, se observa una cierta homogeneidad, con dimensiones de 3 a $5 \mathrm{~cm}$., aunque al menos dos piezas (CM6 y CM7) presenten dimensiones inferiores a $3 \mathrm{~cm}$, una de ellas con el vástago extraordinariamente corto, algo que veremos también entre las piezas de los grupos 2 (PN21) y 5 (PN24).

Por último, si atendemos a los arpones, a pesar de su gran variabilidad, se observa una tendencia hacia los destacados y finos, tipos 1, 2 y 3 de Sánchez Meseguer (1974: 75) ${ }^{16}$, y a los más largos y ligeramen-

acuerdo a unos criterios preestablecidos, por lo que la letra de la variante no siempre remite a un mismo atributo. Hemos intentado, no obstante, mantener un mismo criterio en la Forma 1, donde el atributo c se reserva a la presencia de dos arpones (tipos 11c y 14c), mientras que en la Forma 4 , el referido atributo engloba otras singularidades relacionadas en parte con la pieza que incorporamos (43c y 44c).

13 Aunque siempre en una proporción minoritaria, se ha localizado un ejemplar de largo cubo en Coria del Río (Rodríguez Cordones, 1996: 225-226, fig. 1).

14 PN10, PN12, PN23 y F1.

15 PN16, CM2 y CM4.

16 PN17, PN25, F3, PN3, F1, PN10. 


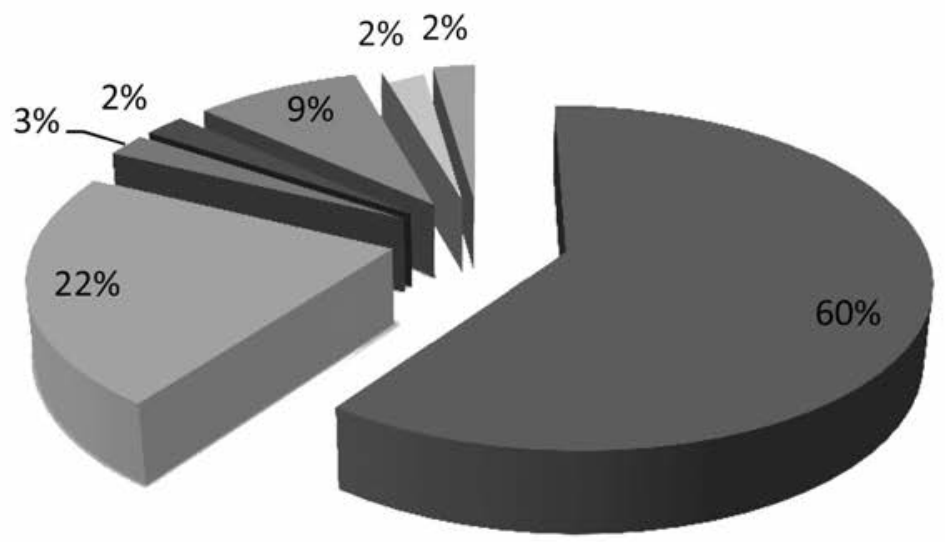

" Grupo 1 a Grupo 2 a Grupo 3 a Grupo 4

घrupo 5 arupo 6 = Indeterminado

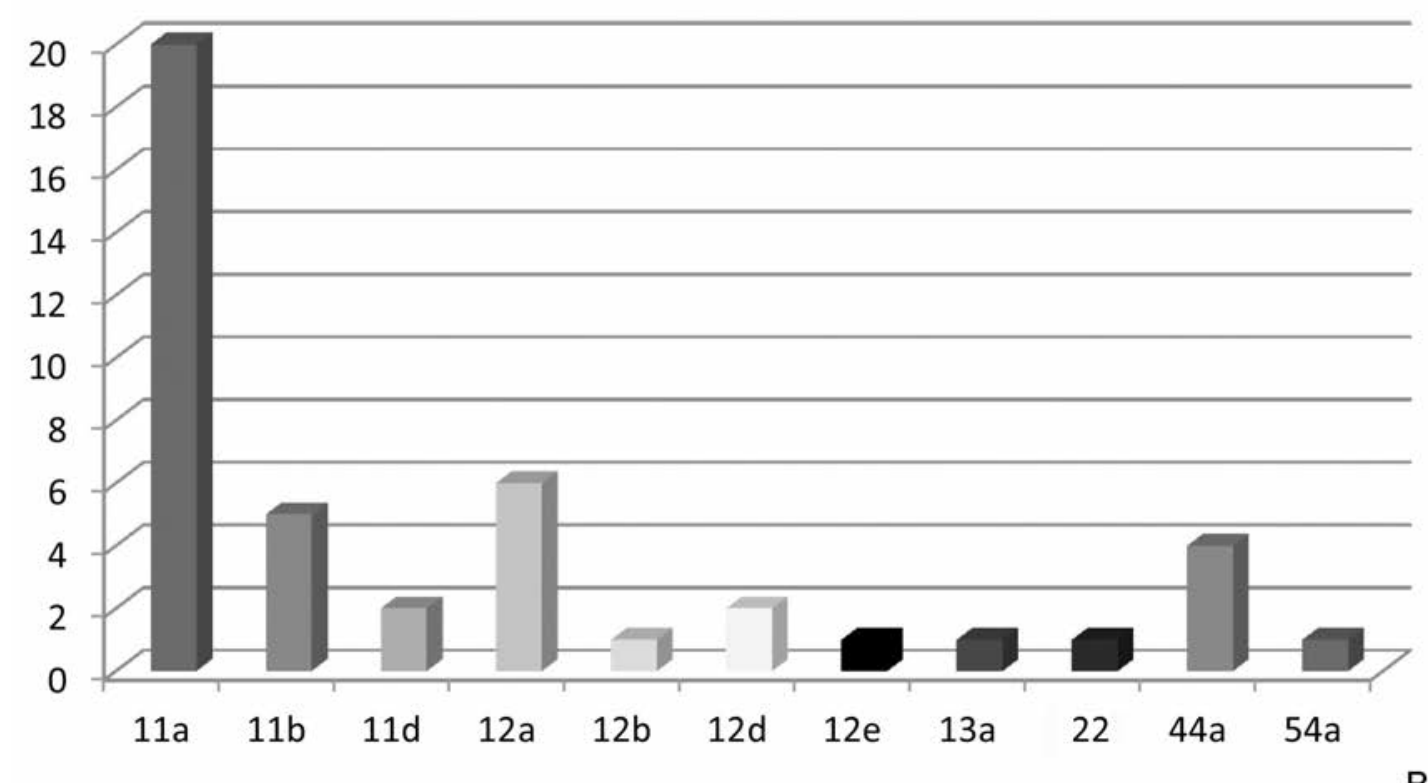

B

Fig. 8. Puntas de flecha con enmangue tubular. Distribución por grupos (A) y tipos (B). Muestra: 44 ejemplares.

te doblados, correspondientes quizá con sus tipos 7 y 8 (CM1, PN16, PN8). Esta variabilidad de hojas, arpones y cañones se repetirá en el resto de grupos establecidos, incluso en los ejemplares con triple filo, entre los que destacamos algún ejemplar con hoja foliácea muy redondeada (PN24). Cabe destacar algunos ejemplares con arpones muy poco desarrollados, con ejemplos en Peña Negra y El Castellar de Meca (PN5, PN26, CM4, C6, CM7) (Fig. 9) ${ }^{17}$.

17 Aunque no ha sido incluido en el catálogo, hemos podido estudiar un ejemplar de El Monastil (Elda, Alicante), que presenta, además, aunque apenas insinuado, el arranque de
Grupo 2: Puntas de doble filo de hoja fusiforme, provista de dos muescas, con o sin arpón lateral (Tipo 12)

También conocidas como puntas con "breve nervadura" o con "pseudo-nervadura" inferior (González Prats, 1983: 175), "pseudofenestradas" (Ramon, 1983: 310), o con "falso doble filo" (Ferrer, 1996: 50), en las que lo característico es la existencia en el tercio inferior de la hoja de un nervio central corto realizado

lo que podría interpretarse como un segundo arpón en posición simétrica al anterior (Fig. 26, A.2), correspondiendo por tanto con el Tipo 11c (Ferrer, 1996: fig. 4). 

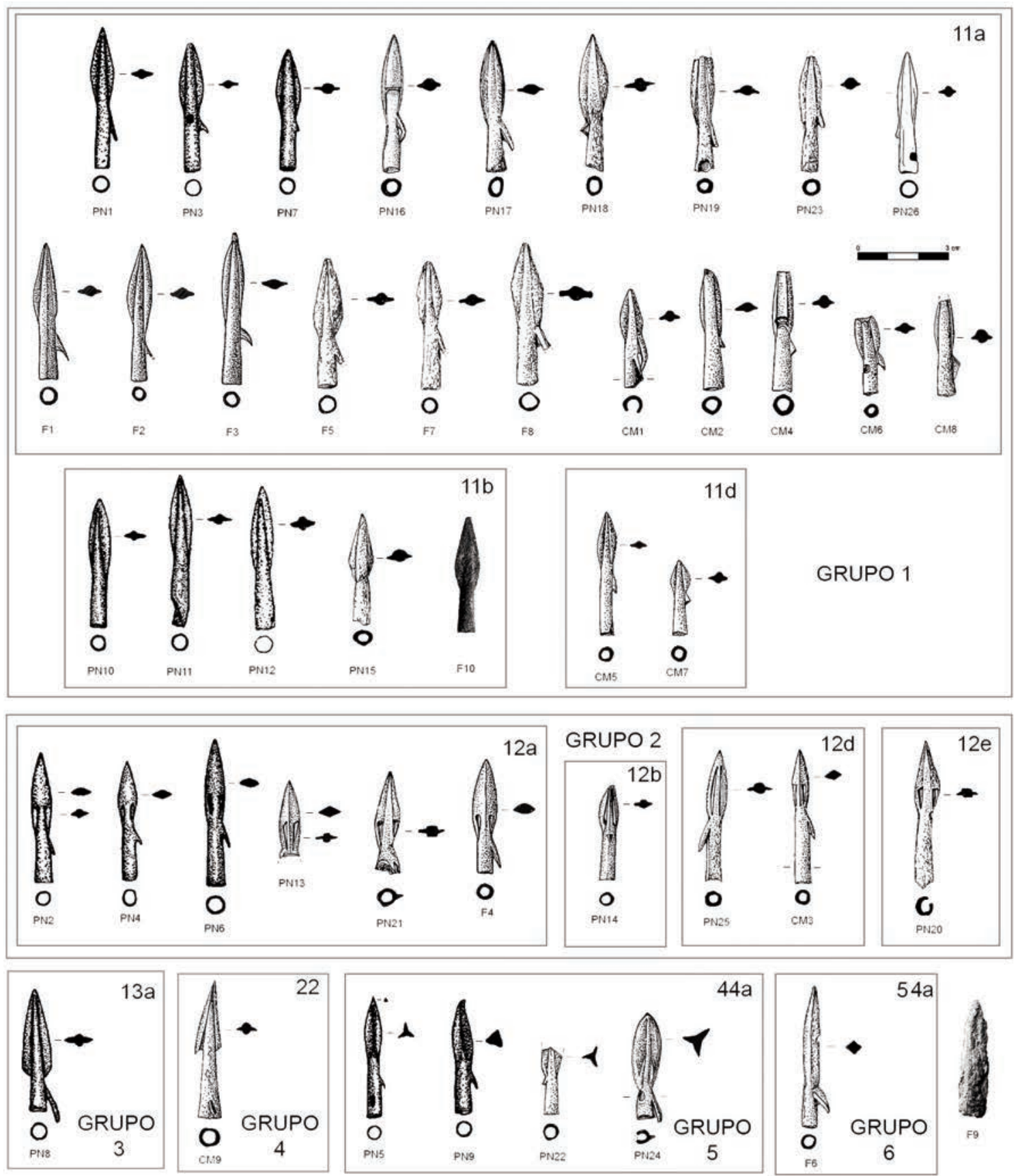

Fig. 9. Propuesta de clasificación tipológica de la colección de puntas de flecha estudiada.

mediante dos hendiduras laterales en la hoja y un tercio superior de la misma con sección aplanada. Se singularizan, de esta forma, por presentar un peculiar sistema para generar el doble filo nervado, gracias a la realización de muescas laterales en su parte inferior, lo que hemos identificado en nuestros ejemplares, aunque con una menor variabilidad tipológica que la identificada en otras áreas (Ferrer, 1996: fig. 2, abajo). Este

18 La diferenciación de dos tipos que hace González Prats (1983: 175, fig. 38), a partir de la presencia de una nervadura inferior en un ejemplar de Peña Negra (Tipo 2A), frente a los ejemplares con "pseudo-nervadura inferior, obteni- grupo, con un número menor de ejemplares que el analizado previamente (vid. Quesada, 1997: 271, en relación a su distribución geográfica), se documenta en los tres yacimientos incluidos en el catálogo, conformando el $22 \%$ de la muestra estudiada. Corresponde a los tipos 12 a-b de Ramon/Ferrer, 2A y 3A-B de González Prats (1983: 175) ${ }^{18}$ y E10 y E11 de Cleuziou (1977: 190, fig. 1), con variantes según tengan presencia o

da mediante muescas" (Tipo 3A-B), creemos que, con los nuevos hallazgos, debe enmarcarse dentro de la variabilidad del modelo. 
ausencia de arpón. En los ejemplares estudiados suele ser habitual la presencia de arpón lateral (PN2, PN4, PN6, PN21, F4, CM3), aunque también localizamos algún ejemplar sin él (PN20) (Figs. 9 y 10).

Estas clasificaciones incluyen puntas que presentan una proporción que remite a las dimensiones canónicas entre puntas y cañón, asimilables al tipo $12 \mathrm{a}^{19}$, aunque entre los nuevos hallazgos hemos identificado, como en el grupo anterior, ejemplares de largo cañón, que siguiendo la nomenclatura de Ramon/Ferrer, pasan a englobar los Tipos 12d (CM3) y 12e (PN20), en función de la presencia o ausencia de arpón, respectivamente, reservando el $12 \mathrm{c}$, no identificado hasta la fecha, para la posible presencia de ejemplares con más de un arpón ${ }^{20}$. Es significativo por otro lado, la presencia de algún ejemplar del tipo 12 a con una marcada gran hoja (PN21 y F4), respecto a su corto cañón, cuyo Índice de proporcionalidad se aproxima a 1 , rasgo identificado en otros grupos, como el 5 y el 6 (vid. infra) (Fig. 10). Destaca la abundancia del tipo 12 en Peña Negra, frente a su carácter excepcional o minoritario en otros contextos peninsulares (Quesada, 1997: 920-922) $)^{21}$.

\section{Grupo 3: Puntas de doble filo, hoja romboidal ner- vada con o sin arpón lateral (Tipo 13)}

La morfología de la hoja en los tipos de doble filo es habitualmente lanceolada o redondeada, incluso marcadamente fusiforme, de filos estrechos, como muestran los tipos 11 y 12 de Ramon/Ferrer. No obstante, también se conocen algunos ejemplares con hojas de tendencia romboidal de base marcada, Forma 13 de Ramon ${ }^{22}$, o de hojas triangulares y bases rectas, Forma 14 de Ramon/Ferrer (vid. Quesada, 1997: figs. 272-273). Igualmente, las puntas de fle-

19 PN2, PN4, PN6, PN21, F4. La proporción entre el largo cañón y la hoja del ejemplar PN20 (sin arpón) nos hace considerarlo como una variante aparte.

20 La presencia en el ejemplar PN16 de una marcada ranura transversal, debe relacionarse con su uso, más que considerarla intencional e interpretarla como una forma singular de "pseudofenestra", lo que llevaría a su inclusión en este Grupo 2, aunque sus divergencias frente a los modelos habituales adscritos al Tipo 12, nos lleva a excluir esta posibilidad. La pieza resulta igualmente singular, pues ofrece otra ranura en el cubo de enmangue opuesto al arranque del arpón, elemento que no modifica su clasificación dentro del tipo 11a.

21 Como ejemplo de este singular rasgo presente en Peña Negra podemos valorar la escasa representatividad de ejemplares $12 \mathrm{a}$ y $12 \mathrm{~b}$ documentados entre los hallazgos del Mediodía peninsular y las Islas Baleares (véase por ejemplo el catálogo recogido en Quesada 1997: 920-922). Frente a este panorama, Peña Negra, supone un caso singular. Se han identificado hasta 7 ejemplares, no solo del tipo habitual cha con hojas de esta forma se incluyen en el tipo E14 de Cleuziou (1977: 191, fig. 1). La punta PN8 podría integrarse sin dificultad en el tipo 13a de Ramon, al presentar una hoja romboidal y una base diferenciada, aunque para Ferrer (1996: 50), este detalle remita a la variabilidad propia del tipo 11 , lo que le lleva a eliminar la forma de su propuesta tipológica. La pieza de Peña Negra destaca, además, por la presencia de un largo arpón que excede la longitud del cañón, algo insólito en el conjunto estudiado, que correspondería con el tipo de arpón 7 y 8 de Sánchez Meseguer (1974: 75), que parece asociarse en muchos casos a ejemplares de hoja romboidal como el nuestro (Id., 1974: 88 ss.) (Fig. 9) $)^{23}$.

\section{Grupo 4: Puntas de doble filo y hoja triangular}

Corresponde con aquellos ejemplares de doble filo que presentan una característica hoja triangular muy marcada con remates rectilíneos, de filos afilados, simétricos o asimétricos, que contrasta con el grupo mayoritario de hojas lanceoladas. Desde la definición de los Grupos y tipos asociados por Ramon (1983) como 22 y 31 respectivamente, y mantenidos por Ferrer (1996: fig. 4), se presenta como una variedad minoritaria poco representada, en la que no se ha localizado ningún ejemplar con arpón lateral (Ramon, 1983: 314; Ferrer, 1996: 50). La punta conservada en la Casa de la Cultura de Ayora (CM9), posiblemente del Castellar de Meca o, en cualquier caso, de sus alrededores, podría corresponder a los modelos asimétricos, tipo 22, en el cual solo uno de sus filos presenta la característica aleta lateral, siendo el otro filo recto (Fig. 9).

Respecto a la identificación de los rasgos formales de la propuesta, Ramon/Ferrer distinguen por un lado los ejemplares asimétricos dentro de su Forma 2,

$12 \mathrm{a}$ y $12 \mathrm{~b}$, pues incluye nuevos modelos, $12 \mathrm{c}, 12 \mathrm{~d}$ y $12 \mathrm{e}$. Solo en un caso de los estudiados por Ramon (1983: 318, fig. 2), se ha recuperado más de un ejemplar del modelo, como las 4 puntas encontradas en Sal Rossa, Ibiza.

22 Es un grupo integrado por un número reducido de ejemplares (en realidad Ramon incluía un ejemplar sin arpón y otro con arpón), cuyo rasgo principal es la tendencia hacia piezas con hojas más triangulares que los grupos anteriores (Ramon, 1983: 314).

23 La revisión de algunas piezas publicadas en Puig des Molins (García Guinea, 1964: 75) y en Pancorvo (Mancebo y Ferrer, 1988-89) permite evidenciar una mayor variabilidad dentro del tipo 13, con ejemplares de doble arpón (García Guinea, 1967: fig. 4.5), otros en los que destaca su largo cañón (Mancebo y Ferrer, 1988-89: fig. 5.47), o uno muy corto (Ibid. fig. 3.20). Así mismo se podría identificar algún ejemplar de largo cañón dentro del tipo 14 de Ramon/Ferrer, lo que permitiría plantear un nuevo subtipo 14e (Mancebo y Ferrer, 1988-89: fig. 5.51) (Fig.10). 


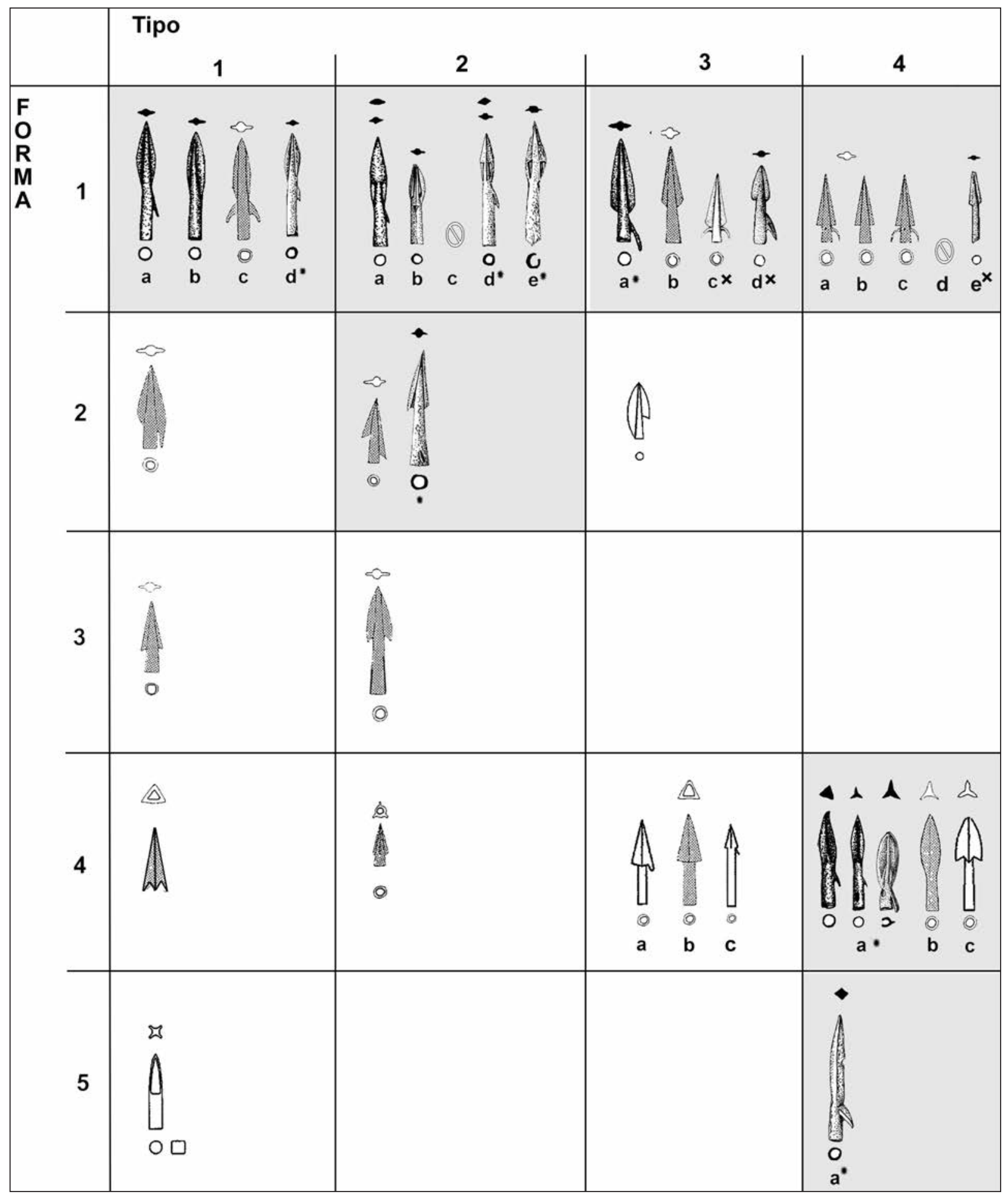

Fig. 10. Tabla tipológica de puntas de flecha según Ramon/Ferrer, reestructurada a partir de los nuevos tipos: * tipos a partir de piezas de nuestro catálogo; $\mathrm{X}$ id. a partir de piezas publicadas y reasignadas; $i d$. no identificados. Gris: Tipos modificados.

tipo 22 de filos rectos; y por otro, en su Forma 3, los ejemplares de su tipo 31 , de hoja triangular con una marcada simetría de sus filos, ambos de igual longitud, así como la presencia de una pequeña prolongación a modo de aletas. Si bien el ejemplar CM9, parece ser asimétrico en sus filos, éstos son bastante equi- librados, lejos del dimorfismo del tipo 22 de Ramon/Ferrer, lo que permitiría señalarlo como un ejemplar de transición entre los tipos simétricos (tipo 31) y los ejemplares marcadamente asimétricos (tipo 22) (Fig. 10). En este sentido, Ramon, ya apuntaba la semejanza entre ambos tipos, dado que "en realidad es 
como el tipo 31, pero con la diferencia de que prolonga una de sus aletas" (Ramon, 1983: 314) ${ }^{24}$. Una cronología del s. IV o posterior se ha planteado para las puntas del tipo 31, de las que se conocen algunos ejemplares en Ibiza, el Noreste o en la necrópolis de Villaricos (Ramon, 1983: 321).

\section{Grupo 5: Puntas de triple filo, hoja fusiforme y arpón lateral (Tipo 44)}

Dentro de las puntas de flecha de cañón tubular, destaca la presencia de un conjunto de ejemplares caracterizados por la multiplicación de sus filos, siendo más frecuente la presencia de puntas de flecha de triple filo, con 4 ejemplares (PN5, PN9, PN22 y PN24), lo que supone el $15 \%$ de los casos de Peña Negra, mientras las provistas de cuatro filos solo tienen un único ejemplar (F6). La solución empleada para generar los filos múltiples permite distinguir las puntas con secciones triangulares de caras planas (PN9 y F6), de otras con filos estrellados, marcados mediante hendiduras (PN5, PN22 y PN24), una peculiaridad que podría incidir en una mayor potencia de penetración, al ser más macizas ${ }^{25}$.

De nuevo, tras el análisis de nuestros ejemplares con triple filo identificamos una mayor variabilidad entre la morfología y la sección de las hojas que la previamente observada. Este es el caso del ejemplar PN9, de hoja de triple filo de sección triangular de lados planos, asimilable al tipo 43a de Ferrer, que modifica la propuesta de Ramon, pero que en nuestro caso presenta hoja fusiforme y no triangular como el resto de los ejemplares asimilables al tipo (Ferrer, 1996: 51, fig. 4) (Fig. 10), por lo que cabría relacionarla, destacando así su carácter híbrido, con

24 No obstante, una vez más, los criterios establecidos para la Forma 2 y la Forma 3 de Ramon/Ferrer, de puntas de doble filo sin arpón y con aletas, incluyen una variedad de hojas, rectas triangulares (tipo 31) o lanceoladas (tipo 32), siempre simétricas, rasgos a los que incorpora la mayor o menor longitud del cañón (tipo 32), y que en definitiva, muestran la amplia asignación de atributos en estas propuestas tipológicas. En este sentido, si comparamos los rasgos principales de este tipo 31, presencia de aletas y hoja triangular recta, vemos que guarda gran semejanza con el tipo 22, cuya única diferencia es la presencia de filos asimétricos. Quizá podría ser factible la integración de esta variabilidad dentro de un gran grupo que representase los ejemplares de hojas triangulares y que podría incluirse en nuestro Grupo 4. No obstante, ante la amplia aplicación de las tipologías existentes, por el momento no planteamos una remodelación de dichas propuestas.

25 Quizás por ello se ha planteado por algunos autores que serían estos tipos específicos los que tendrían una mayor pervivencia, vinculada a la influencia púnica (Mancebo y Ferrer, 1988-89: 327; Ramon, 1983: 312; Quesada, 1989: 165; Id., 2011: 209 ss.; Martínez Hahnmüller, 2012: 39), aunque su los ejemplares de hoja fusiforme, pero de sección estrellada, tipo 44a de Ramon/Ferrer y 4A de González Prats. Entre estas piezas de sección estrellada y hoja fusiforme con arpón, bien registradas en el conjunto estudiado (PN5, PN22 y PN24), incluimos el ejemplar PN24, con un muy corto cubo de encaje, algo ya observado en piezas de otros grupos, como las PN6, asimilable al tipo 11a, y las PN21 y $\mathrm{F} 4$, del 12a, un rasgo que permitiría identificar una poco numerosa variante de puntas aunque, con tan pocos hallazgos, nos limitemos a señalar la presencia de este singular rasgo presente tanto en las Formas 1 , 3 o 4 (Figs. 9 y 10$)^{26}$.

\section{Grupo 6: Puntas de cuádruple filo, hoja fusiforme y arpón lateral (Tipo 54)}

Destaca un único ejemplar localizado en La Fonteta, que presenta hasta cuatro filos (F6) que remite a la forma 5 de Ferrer, que lo incorpora por vez primera a la tipología del modelo, y a la Forma XXI de Elayi-Planas, que encuentra paralelos en contextos fenicio-púnicos y orientalizantes andaluces (Mancebo, 1994: 293-294), de la isla de Ibiza (Elayi y Planas, 1995: fig. 18.96; González Prats, 2014a: 274), el Noreste peninsular (Armada et al., 2005: 145) o el sur de Francia, fechándose en concreto una similar de Pech Maho a mediados del s. VI a.C. (Barroul, 1971: 378), lo que también es el caso de la punta F6. Nuestra propuesta asimila el ejemplar alicantino al tipo 54a, pretendiendo mantener una coherencia respecto al tipo 44 , con hojas fusiformes, presentando la pieza de La Fonteta sección rómbica de lados rectos, detalle que encontramos en algunas de las piezas asimilables al tipo anterior (Fig. 10).

presencia en contextos orientalizantes esté bien documentada, como demuestran los casos de Peña Negra (González Prats, 1983: 175; Ferrer, 1996: 51) o La Fonteta (vid. infra),

26 Este singular rasgo identificado en algunas puntas de muy corto cañón se identifica en varios de los tipos ya conocidos tanto de doble como de múltiple filo. Según la revisión de los ejemplares estudiados en nuestro catálogo así como otros ya publicados podríamos identificar este fenómeno dentro de los tipos 11, como muestra un ejemplar de El Macalón (Fig. 27, D .5) publicado por García Guinea (1967: fig. 3.6); 12, con la punta F4 de nuestro catálogo; 13, con un ejemplar de Pancorvo (Mancebo y Ferrer, 1988-89: fig. 3.20); 31, representado por las puntas del Cerro del Prado y Los Villares de Gilena (Ulreich et al., 1990; Mancebo, 1994: fig. 4.4 y 8); y entre las de múltiple filo, como el tipo 43 , un ejemplar localizado en el interior de la cisterna intramuros en Baria (Siret, 1909: lám. VI.39), y entre las del tipo 44, nuestro ejemplar PN24 (Fig. 10). Aunque siempre con un número reducido, parecen marcar una singularidad respecto a los cánones habituales, que deberá tenerse en consideración en futuros trabajos. 


\section{Grupo 7: Vario}

En este último grupo incorporamos dos ejemplares de La Fonteta (F11 y F12) caracterizados por la presencia de aletas y, sobre todo, un largo pedúnculo macizo o espiga como encaje, en ambos casos recuperados en contextos estratigráficos que remiten a cronologías del Hierro Antiguo.

Por un lado, se identificó un ejemplar de punta de flecha con aletas y pedúnculo engrosado (F12), rasgo de inspiración mediterránea que se asemeja al denominado Tipo Mailhac/IIIBNPE de Kaiser (2003: 82), y que ha sido relacionado con ejemplares localizados en la zona del Languedoc durante el Bronce Final-Hierro Antiguo, como los de Roc de Boussecos (Bize) (Louis, Taffanel y Taffanel, 1955: fig. 57.5) o la gran concentración documentada en el entorno del Golfo de León (Gascó 2006; Guilaine y Verger, 2008: 235), documentándose incluso una docena de ejemplares en el pecio de Rochelongue (Bouscaras y Hugues, 1967: 178, fig. 2:5-6; Gascó, 2006: figs. 2:17 y 21, 4:4-6), que también ha proporcionado fíbulas (Bouscaras y Hugues, 1967: 178, fig. 3:1-2 y 13) y broches de cinturón (ibid:: 180, fig. 3:6) idénticos a los hallados en las fases Fonteta V y VI, aunque la punta de La Fonteta sea algo anterior al proceder de la fase III-IV (vid. infra).
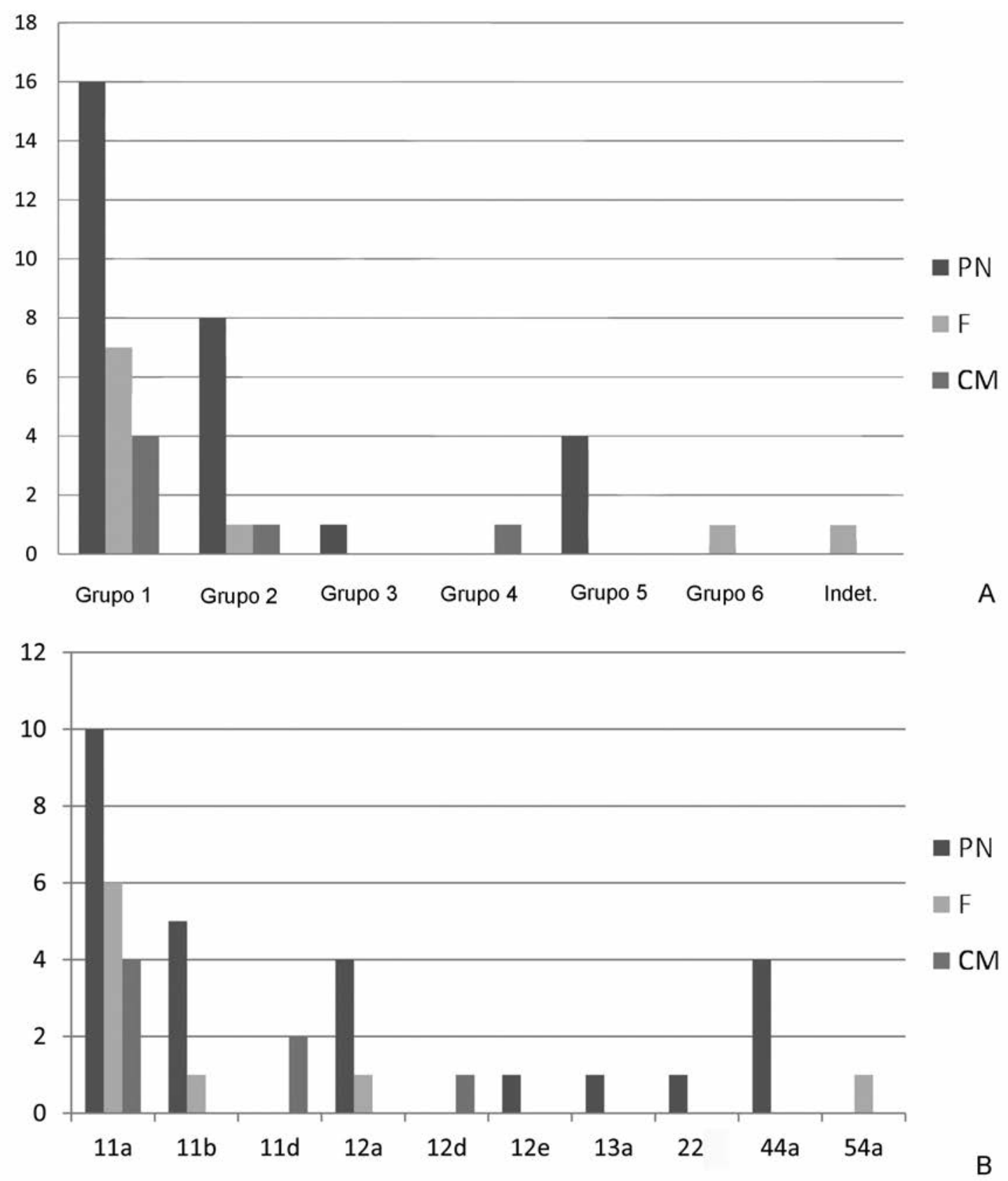

Fig. 11. Puntas de flecha. Distribución por yacimientos según grupo grupo (A) y tipos (B). PN: Peña Negra, F: Fonteta, CM: Castellar de Meca. Tipos según Ramón/Ferrer, Kaiser y propuesta actual. Muestra: 44 ejemplares. 
Así mismo, se documentan en el área del Noreste y el Valle del Ebro en estas cronologías, procedencia que ha sido planteada para la llegada del ejemplar localizado en La Fonteta (González Prats, 2014a: 273-274), Igualmente, puntas muy similares tanto fabricadas en bronce como en hierro, se han hallado en la tumba 1 de la necrópolis tartésica de La Angorrilla (Sevilla) (Quesada, Casado y Ferrer, 2014: 358 s., fig. 4:23-40), que por la tipología de su recipiente cinerario (Fernández Flores, Prados y Rodríguez Azogue, 2014: 87, 91), una urna de tipo Cruz del Negro de tipo 5, puede fecharse hacia el segundo cuarto del s. VI a.C. (Torres, 2008: 649650, fig. 741).

Más singular resulta la presencia de una punta con aletas y largo pedúnculo (F11), que recuerda a tipos de cronología prehistórica (Simón, 1998: 264 s.) y que puede adscribirse al Tipo C2 de Ruiz Zapatero (1985: 930 ss.), que presenta nervio central poco marcado que el autor relacionó con el tipo Mailhac I, para las que plantea una cronología entre los s. VIII-VI a.C. (Ruiz Zapatero, 1985: 936). Semejante a dicho ejemplar se conoce un hallazgo superficial en el Castillo de Guardamar (García Menárguez y Mas, 2010: 260). A pesar de sus rasgos arcaizantes, que lo vinculan con los ejemplares propios de la Edad del Bronce, en Oriente se documentan también en contextos fenicios, conviviendo con ejemplares realizados en hierro, tal y como refleja la Tumba familiar 1 de la necrópolis de Akhziv (Mazar, 2004: fig. 29), un contexto de marcado significado simbólico, lo que ha llevado a relacionar el ejemplar del Castillo de Guardamar con el carácter sacro del lugar (González Prats, 2014a: 273), lo que no parece ser el caso del ejemplar recuperado en La Fonteta (vid. infra).

\subsection{Estudio metalográfico}

Este tipo de puntas responde a un complejo y sofisticado proceso técnico de fabricación (Maryon, 1961; Elayi y Planas, 1995) mediante moldes de varias piezas y para el que se ha planteado su producción local, evidenciada por la gran dispersión peninsular (Sánchez Meseguer, 1974: 101; Quesada, 1989: 164 y 172; Id., 1997: 446-447; Ferrer, 1994: 38), sobre todo de sus tipos más sencillos como el 11a (Mancebo y Ferrer, 1988-89: 328). Lamentablemente, es poca la información directa que poseemos, pues únicamente hay noticias de un molde conservado en el Museo de Barcelona, que pudiera proceder de Emporion o Ibiza (Sánchez Meseguer, 1974: 101; González Prats, 1982a: 260), al tiempo que faltan productos semielaborados que pudieran aportar información al respecto.

27 La ampliación del número de piezas analizadas, prevista para un posterior trabajo, permitirá contrastar si el índice de
Por su parte, existen escasos análisis metalográficos publicados de estas puntas de flecha a nivel peninsular (Mancebo y Ferrer, 1988-89: 94; Quesada, 1989: 172; Id., 1997: 447, fig. 268; Rovira et al. 2005: tabla 1, $\mathrm{n}^{\circ} 33-$ 35; Espinosa et al., 2008: 206), de gran interés, no obstante, pues en ocasiones queda clara su producción local, lo que como destaca Quesada (1997: 446-447) puede deducirse asimismo de su hallazgo en ocasiones en elevado número. Para la zona del Sureste contamos con los de tres piezas de Peña Negra, publicados en los años 80 del s. XX (González Prats, 1982a: 261; Id., 1983: 287289, fig. 56), a las que añadimos alguna más de Peña Negra y un ejemplar de El Monastil (Elda, Alicante) (Fig. 12).

La composición metalográfica de estas piezas evidencia su fabricación en bronce, aunque con composiciones relativamente heterogéneas, frente a modelos más modernos de finales de época orientalizante, como los de la necrópolis de La Angorrilla (Alcalá del Río, Sevilla), o de época ibérica y romana, con algunos ejemplares ya de hierro (Ferrer, 1994; Quesada 1997: 464; Quesada, Casado y Ferrer 2014: 358 s., fig. 4.23-40).

En el caso de las piezas de Peña Negra se observa una cierta variablidad (Fig. 12). Las puntas PN2, PN3, PN5 y PN14 son bronces pobres o muy pobres (ninguna supera el $10 \% \mathrm{Sn}$ ), con baja presencia de $\mathrm{Pb}$ en algunas piezas -en porcentajes cercanos al 1\%-, lo que plantea que su presencia pudiera no ser intencional (Montero, 2008: 502). Estos datos no desentonan con la información disponible para la metalurgia orientalizante, que evidencia una tendencia a la disminución de estaño (González Prats, 1983: 287-289, fig. 56; Rovira, 1995: 481; Montero, 2008: 502; Montero y Murillo, 2014).

Si observamos los datos que ofrecen focos de producción metalúrgica coetáneos cercanos como La Fonteta (Renzi, 2013: 48), estos datos podrían incluirse dentro de las pautas de fabricación fenicia, donde los bronces binarios ofrecen valores medios de 4,21\% Sn y $0,59 \% \mathrm{~Pb}$ (Montero y Murillo, 2014: 243). En el caso de los ejemplares de Peña Negra comentados, las piezas analizadas se sitúan dentro de los valores medios de estaño propios de esta cronología, menores del $9 \%$ y en algún caso próximos al $5 \%$, llegando incluso a estar ausente en el ejemplar PN10 (Fig. 12), que vienen a caracterizar en nuestra colección este "empobrecimiento del bronce" característico de la metalurgia orientalizante, siguiendo pautas similares a asentamientos fenicios del Bajo Segura (Renzi, 2013: 48) y áreas meridionales de la Península (Montero, 2008: 500; Montero y Murillo, 2014: 243 ss.). El bajo porcentaje de estaño utilizado en estas piezas en la Península Ibérica ha sido vinculado con la alta proporción de piezas dobladas y rotas, habitual en los tipos más sencillos 11a y 11b (Ramon, 1983: fig. 2.23-24; Quesada, 1989: 172) ${ }^{27}$.

deformación de las piezas puede ser vinculada al valor medio de la presencia de \% Sn de su composición. 


\begin{tabular}{|c|c|c|c|c|c|c|c|c|c|}
\hline No & Fe & Ni & Cu & Zn & As & Ag & Sn & Sb & Pb \\
\hline${ }^{*}$ PN2 & 0,15 & ND & 90,5 & ND & 0,28 & ND & 8,6 & ND & ND \\
\hline${ }^{*}$ PN3 & 0,42 & ND & 90,2 & ND & ND & ND & 7,5 & ND & 1,3 \\
\hline${ }^{*}$ PN5 & 0,11 & ND & 93,8 & ND & ND & ND & 4,9 & ND & 1,1 \\
\hline PN10 & 0,39 & ND & 76,38 & ND & ND & ND & 19,37 & ND & 3,86 \\
\hline PN13 & 0,33 & ND & 88,91 & ND & ND & ND & ND & ND & 10,76 \\
\hline PN14 & ND & ND & 90,97 & ND & ND & ND & 6,42 & ND & 2,61 \\
\hline EI Monastil & ND & ND & 85,89 & ND & ND & ND & 14,11 & ND & ND \\
\hline **Villajoyosa & ND & ND & 84 & ND & ND & ND & 12 & ND & 3 \\
\hline
\end{tabular}

Fig. 12. Análisis XRF de algunas puntas de Peña Negra y otros yacimientos alicantinos. Valores expresados en $\%$ en peso (ND = no detectado). Fte.: SS-TT y Laboratorio de Química Inorgánica. Universidad de Alicante. *González Prats (1983: 287, fig. 56). **Espinosa et al. (2008: 206).

Diferente es la pieza PN10, un bronce ternario con alto porcentaje en estaño, lo que se registra igualmente en un ejemplar de Villajoyosa (Espinosa et al., 2008: 206) o en una punta de El Monastil, aunque en este caso carente de plomo, con ejemplos en piezas andaluzas (Quesada, 1997: fig. 268).

\subsection{Estandarización o tendencias detectadas}

Los rasgos formales de estas puntas de flecha, analizados anteriormente (vid. supra Apartados 3.1 y 3.2), muestran una gran diversidad reflejada tanto en la morfología de la hoja como en la longitud y forma de sus atributos (hoja, cañón, arpón, etc.), siendo muy útiles a la hora de estudiar las distintas producciones y la distribución de este armamento, aunque son elementos secundarios en su estandarización, identificada principalmente por su encaje en cubo. Si acudimos a un análisis morfométrico, comprobamos cuáles son los rasgos principales que definen a esta familia de puntas: su peso medio, su material, su tamaño y sobre todo su cubo, aspectos que enfatizan el alto grado de estandarización alcanzado en su fabricación (Ramón, 1983: 310-312; Ferrer, 1996: 50; Quesada, 1989: 164-165; Id., 1997: 441), quizá evidenciando "una producción en serie" (Ferrer, 1994; Id., 1995: 94).

Por lo tanto, el principal rasgo morfométrico que permite hablar de una estandarización en la fabricación es el diámetro del cañón o cubo, en torno a 0,5 a 0,6 cm (Ferrer, 1996: 49), que debe ser entendido como un rasgo propio de este tipo de arma, y que vemos reflejada en los ejemplares estudiados (Fig. 17). Tales piezas reproducen las dimensiones generales planteadas para estas puntas: un tamaño que oscila entre 3 a $5 \mathrm{~cm}$ de longitud (Sánchez Meseguer, 1974: 72), mientras que en la mayoría de los casos la longitud del cañón equivale a "un tercio del total de la flecha, correspondiente pues, el resto, dos tercios, a la hoja" (Sánchez Meseguer, 1974: 73), aunque existen otras pautas (Figs. 13 y 15).

Analizaremos a continuación la proporción entre las longitudes de hoja y cañón, así como respecto a su longitud máxima, a fin de identificar patrones comple- mentarios de estandarización, para lo que hemos utilizado dos índices. El Índice de Tamaño, que nos permite identificar tendencias respecto a la longitud máxima de las flechas, con ejemplares mayores de 4 y hasta 5 $\mathrm{cm}$ (Tendencia 1); ejemplares entre 3 a $4 \mathrm{~cm}$ (Tendencia 2) y de reducido tamaño, menores de $3 \mathrm{~cm}$ (Tendencia 3) (Figs. 13 y 15). Por otro lado, el denominado Índice de proporcionalidad, permite identificar las tendencias o valores que fomentan una morfología a favor de la Hoja (Tendencia A y B), equilibrada (Tendencia C) o a favor del cañón (D), señalando la B los tipos canónicos en los cuales la hoja conforma los dos tercio de su tamaño, y la D, la proporción contraria, dos tercios a favor del cañón, que, como ya hemos indicado, hasta la fecha solo se había identificado en piezas del tipo 32 y 43c de Ferrer (1996: 50), habitualmente sin arpón, aunque nuestros ejemplares presenten características que les permiten englobarse en otros modelos como el 11 o el 12, con o sin arpón, lo que ha obligado a plantear la existencia de nuevas variantes, como la 11d (vid. supra) (Figs. 14 y 15).

- La primera variable interesante para su análisis que abordaremos es el tamaño de las puntas. Se observa una amplia variabilidad, propia de esta clase de proyectiles, con unas dimensiones máximas de 5 cm y mínimas de $3 \mathrm{~cm}$, incluso menores, siendo su reducido tamaño uno de sus rasgos característicos (García Guinea, 1967: 72; Ferrer, 1996: 48 ss.) (Fig. 13).

Se diferencian las siguientes tendencias en cuanto al tamaño:

- Tendencia 1. Ejemplares más grandes: presentan tamaños mayores de $4 \mathrm{~cm}$, no superando los $5 \mathrm{~cm}$.

- Tendencia 1A. Ejemplares entre 4,6 y $5 \mathrm{~cm}(=10)$ : PN1, PN3, PN11, PN12, PN20, F2, F4, F5, F6 y CM9.

- Tendencia 1B. Ejemplares entre 4,2 y 4,5 cm (=12): PN2, PN4, PN5, PN10, PN16, PN17, PN18, PN25, F1, F3, F8 у CM3.

- Tendencia 2. Ejemplares medios: presentan tamaños no superiores a $4 \mathrm{~cm}$ ni inferiores a $3 \mathrm{~cm}$, predominando aquellos próximos a $4 \mathrm{~cm}$. 


\begin{tabular}{|c|l|c|}
\hline $\begin{array}{c}\text { Tamaño } \\
(\mathrm{cm})\end{array}$ & \multicolumn{1}{|c|}{ Ejemplares organizados por tamaño } & Totales \\
\hline $\mathbf{2}$ & $\mathbf{2 , 4}$ (CM6) (CM7) (PN22) & 3 \\
& $\mathbf{2 , 5}$ (PN13) & 1 \\
\hline $\mathbf{3}$ & $\mathbf{3 , 0}$ (PN14) & 1 \\
& $\mathbf{3 , 3}(\mathrm{CM} 1)$ & 1 \\
& $\mathbf{3 , 4}$ (PN15) (PN24) (CM8) & 3 \\
& $\mathbf{3 , 5}$ (PN9) (PN21) & 2 \\
& $\mathbf{3 , 6}$ (F10) & 1 \\
& $\mathbf{3 , 7}$ (PN19) (PN23) & 2 \\
& $\mathbf{3 , 8}$ (PN8) (PN26) (PN7) & 3 \\
\hline $\mathbf{4}$ & $\mathbf{4 , 0}$ (PN6) (F7) (F9) (CM2) (CM4) (CM5) & 6 \\
& $\mathbf{4 , 2}$ (PN10) & 1 \\
& $\mathbf{4 , 3}$ (PN4) (PN5) (PN25) (F1) (F8) & 5 \\
& $\mathbf{4 , 4}$ (PN2) (PN17) (CM3) & 3 \\
& $\mathbf{4 , 5}$ (F3) (PN16) (PN18) & 3 \\
& $\mathbf{4 , 6}$ (PN3) & 1 \\
& $\mathbf{4 , 7}$ (F6) & 3 \\
\hline $\mathbf{4 , 8}$ (PN12) (PN20) (CM9) & $\mathbf{4 5}$ \\
\hline & $\mathbf{5 , 0}$ (PN1) (PN11) (F2) (F4) (F5) & \\
\hline & Total & \\
\hline
\end{tabular}

Fig. 13. Tendencias de longitud máxima. Muestra: 45 ejemplares.

- Tendencia 2A. Ejemplares entre 3,6 a $4 \mathrm{~cm}(=12)$ : PN6, PN7, PN8, PN19, PN23, PN26, F7, F9, F10, CM2, CM4 y CM5.

- Tendencia 2B. Ejemplares entre 3,4 a 3,5 cm (=5): PN15, PN24, CM8, PN9 y PN 21.

Tendencia 2C. Ejemplares entre 3 a $3,3 \mathrm{~cm}(=2)$ : CM1 y PN14.

- Tendencia 3. Ejemplares pequeños: presentan tamaño menores de $3 \mathrm{~cm}$, son muy escasos (=4): CM6, CM7, PN22 y PN13.

Respecto al Índice de Proporcionalidad (Figs. $14 \mathrm{y}$ $15)^{28}$, identificamos hasta cuatro grupos o Tendencias, identificadas con letras mayúsculas (A-D). Puntas de hoja larga, cuando presenta valores superiores a 0,6 o cercanos a 1, refleja la tendencia a ejemplares donde la hoja es predominante respecto al cañón (A y B), con puntas de hojas bastante más largas que el cañón (A) y las que siguen el canon o estándar por el cual la hoja ocupa los dos tercios de la longitud total del proyectil

28 Denominamos Índice de proporción al coeficiente resultante del cálculo de la longitud máxima de la hoja y la longitud máxima conservada de la pieza. El uso de la variable longitud máxima del proyectil permite adecuar el índice a los diferentes tamaños que presentan los ejemplares, que suelen oscilar entre 5,4 o $3 \mathrm{~cm}$ de longitud total, incorporando el análisis de la distribución y proporcionalidad de las partes teniendo en cuenta su distribución concreta en cada caso. La variación del índice en cada ejemplar permite conocer la
(B). La tercera tendencia (C), se refiere a las puntas con dimensiones muy próximas o iguales entre la hoja y el cañón, lo que se refleja en un índice igual o ligeramente mayor a 0,5 , habitualmente no por encima de 0,55 , siendo los tipos más equilibrados que guardan una proporción entre las partes. Y por último, las hojas de largo cañón, que supera en longitud a la hoja, con índice menor de 0,5, observándose en los valores que se acercan a 0 una tendencia a la desproporción del cañón (D).

A. Mayores de 0,75 a 1: Ejemplares de hoja destacadamente más larga que el cañón, superando los dos tercios de la longitud total. Tipos 12a, 44a y 54a. Piezas (=3) ${ }^{29}$ : PN21, PN24 y F6.

B. Entre 0,6 a 0,7: Son ejemplares que reproducen el canon o estándar de los dos tercios de longitud a favor de la hoja. Tipos 11a, 12a, 13a, 11b y 44a. Piezas (=18): PN1, PN2, PN6, PN8, PN9, PN10, PN15, PN16, PN17, PN18, PN23, PN25, PN26, F1, F2, F3, F4 y F5.

proporción que representa la hoja o el cañón respecto a la longitud total de la pieza.

29 Los ejemplares PN2 y PN8 podrían incluirse en el límite de este patrón, al obtener como índice un 0,7 y 0,73 respectivamente. El ejemplar PN19, con la punta rota, lo que determinaría una mayor longitud de la hoja que la conservada, podría ampliar su índice actual en torno a 0,67 y situarse también dentro de esta tendencia. 


\begin{tabular}{|l|c|l|l|l|l|l|l|l|l|l|c|}
\hline \multicolumn{10}{|c|}{ Índice de proporcionalidad de puntas } \\
\hline Pieza & I. P. & Pieza & I. P. & Pieza & I. P. & Pieza & I. P. & Pieza & I. P. & Pieza & I. P. \\
\hline PN1 & $(0,6)$ & PN8 & $(0,6)$ & PN16 & $(0,6)$ & PN25 & $(0,6)$ & F6 & $(0,74)$ & CM3 & $(\mathbf{0}, 45)$ \\
\hline PN2 & $(0,68)$ & PN9 & $(0,6)$ & PN17 & $(0,61)$ & PN26 & $(0,6)$ & F7 & $(0,5)$ & CM4 & $(0,55)$ \\
\hline PN3 & $(0,53)$ & PN10 & $(0,64)$ & PN18 & $(0,66)$ & F1 & $(0,6)$ & F8 & $(0,51)$ & CM5 & $(\mathbf{0 , 4 5})$ \\
\hline PN4 & $(0,53)$ & PN11 & $(0,54)$ & PN20 & $(\mathbf{0 , 4 7 )}$ & F2 & $(0,6)$ & F9 & $(\mathbf{0 , 2 5})$ & CM6 & $(0,54)$ \\
\hline PN5 & $(0,53)$ & PN12 & $(0,5)$ & PN21 & $(0,8)$ & F3 & $(0,6)$ & F10 & $(0,55)$ & CM7 & $(\mathbf{0 , 4 5 )}$ \\
\hline PN6 & $(0,6)$ & PN14 & $(\mathbf{0 , 4})$ & PN23 & $(0,6)$ & F4 & $(0,6)$ & CM1 & $(0,5)$ & CM8 & $(0,52)$ \\
\hline PN7 & $(0,5)$ & PN15 & $(0,6)$ & PN24 & $(0,7)$ & F5 & $(0,6)$ & CM2 & $(0,52)$ & CM9 & $(0,56)$ \\
\hline
\end{tabular}

Fig. 14. Índices de Proporcionalidad de las piezas de estudio. Nota: Se han eliminado de tabla los ejemplares que por su rotura de hoja no pueden estimarse la longitud máxima con certeza (PN13, PN19, PN23).

Se marcan en negritas las piezas con marcado cañón o cubo. Muestra: 42 ejemplares.

C. Equilibrado o Igual a 0,5: Son puntas que tienden al equilibrio entre tamaño de hoja y cañón. Tipos 11a, 12a, 22, 44a y 11b. Piezas (=15): PN3, PN4, PN5, PN7, PN11, PN12, F7, F8, F10, CM1, CM2, CM4, CM6, CM8 у CM9.

D. Menores de 0,5 o cercanos a 0: Son puntas que tienen el cañón más largo de la punta, distinguiéndose de manera destacada según se acerca a 0. Puntas de largo cañón. Tipos 11a, 11d, 12b, 12d y 12e. Piezas (=6) ${ }^{30}$ : PN14, PN20, F9, CM3, CM5 y CM7.

Esta variabilidad de proporciones no parece afectar de manera drástica a una identificación estricta en los tipos más sencillos, como el 11a, que es el más numeroso del conjunto y se integra en todas las variantes del Índice (A, B , C , D). Por el contrario, sí podemos señalar una preferencia de los Tipos 13a, 12a y 11b por las piezas con hojas grandes, en equilibrio con la longitud del cañón $(C)$ o superándolo ampliamente $(A, B)$. En esta misma línea, el cálculo de este índice permite identificar los tipos de largo cañón, tipos 11d y 12d, caracterizados los casos estudiados por contar con arpón (D). Los ejemplares de tres y cuatro filos, tipos $44 \mathrm{a}$ y $54 \mathrm{a}$, respectivamente, también presentan una preferencia por puntas grandes, en algún caso de igual longitud que el cañón, pero habitualmente, destacadamente de mayor longitud que éste.

Del estudio de ambos parámetros, Tamaño y Proporción, podemos extraer algunas conclusiones.

Respecto al tamaño, los ejemplares mayoritarios por lo que se refiere a la longitud total del proyectil se sitúan entre 3,5 a $5 \mathrm{~cm}$. lo que permite proponer, al menos a partir de la muestra estudiada, una estandarización en cuanto a la longitud de las puntas, con preferencia por las que miden entre 4 y $5 \mathrm{~cm}$, mayoritarias. Esta pauta está bien representada en las colecciones de Peña Negra y La Fonteta, observándose en éste

30 Del cómputo de esta tendencia hemos desestimado la pieza PN23 dado que presenta la hoja muy rota, apenas conserva el arranque de la misma, descartando la validez de aplicar este índice de proporcionalidad. último caso la preferencia por puntas de mayor longitud (Fig. 13). En los ejemplares de El Castellar de Meca predomina una longitud cercana a $4 \mathrm{~cm}$, presentando similitudes con el grupo de tendencia 3 de Peña Negra, de dimensiones más reducidas. Destaca el ejemplar CM7, el más pequeño del conjunto, único representante de las puntas de longitud menor a $3 \mathrm{~cm}$, en torno a 2,4 cm, caracterizado además por su largo cañón respecto de la punta. Sin duda, es la colección de Peña Negra la de mayor diversidad respecto al tamaño, quedando representadas todas las tendencias identifi$\operatorname{cadas}^{31}$ (Fig. 15).

Respecto a la proporción, predominan las piezas que se insertan dentro de los parámetros canónicos para el tipo (en torno al 42\%), aunque existe un pequeño grupo de puntas de hoja muy larga ( $8,5 \%$ del total). Se observa, además, una tendencia al equilibrio de la hoja y el cañón, con un 36\% (Tendencia C), registrado en los tres yacimientos estudiados. Como ya hemos mencionado, existe un pequeño conjunto de piezas de largo cañón (13,5\% del total), más frecuente en El Castellar de Meca, aunque igualmente se documenten en Peña Negra y, de manera minoritaria, en La Fonteta (Fig. 15).

Si combinamos ambos datos se observa una preferencia clara por la estandarización, reflejada en el predominio de la hoja en dos tercios respecto al cañón en ejemplares de todos los tamaños. Además, se registra la preferencia por puntas de tamaño medio, entre 4 y $5 \mathrm{~cm}$ (en realidad, entre 3,8 y $5 \mathrm{~cm}$ ), que presentan la hoja mucho mayor que el cañón (Tendencia A y B) como primer valor reseñable, rasgo este último propio de los ejemplares de $\mathrm{La}$ Fonteta. Destaca otro grupo de puntas de proporción equilibrada $(\mathrm{C})$, con una longitud algo menor, entre 3,5 y $4,5 \mathrm{~cm}$. Por último, cabe destacar las puntas de largo cañón, menos representadas, pero documenta-

31 El único caso identificado en Peña Negra con menos de 3 $\mathrm{cm}$ de longitud (PN23) es un ejemplar incompleto del que se conserva una longitud de $2,2 \mathrm{~cm}$. 


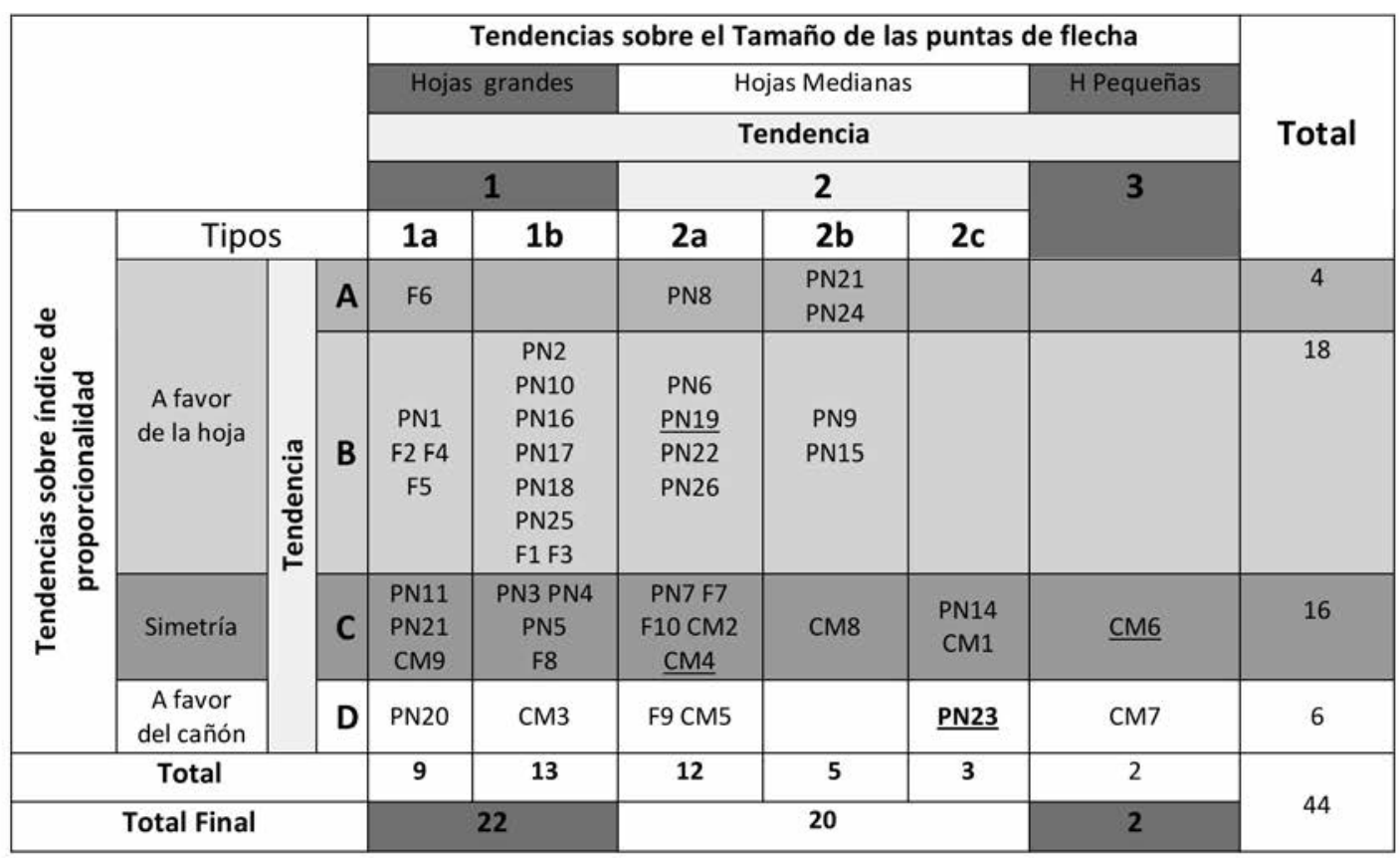

Fig. 15. Variables de Estandarización secundarias. Comparativa de Tendencias de Tamaño y Proporcionalidad (índices). Muestra: 44 ejemplares. El Valor B es el estándar definido para este tipo de puntas 2/3 Hoja / 1/3 Cañón.

Nota: Se han eliminado del cómputo estadístico los ejemplares que por su marcada rotura de hoja no puede estimarse su longitud máxima con certeza (PN19, PN23, CM4, CM6). Muestra: 40 ejemplares.

das en dos formatos: las pequeñas, de $3 \mathrm{~cm}$ o menos, y las mayores de $4 \mathrm{~cm}$ o, incluso, en un caso, de $5 \mathrm{~cm}$ de longitud.

\subsection{Evidencias de uso y huellas de impacto}

El interés por determinar el uso que pudieran haber tenido las puntas de flecha estudiadas nos lleva a analizar la distribución y porcentaje de aparición de huellas de impacto en las mismas, lo que unido al análisis de los contextos de hallazgo nos permitirá inferir su relación con posibles episodios bélicos.

Para tal fin hemos analizado los Índices de Impacto o de Huellas de Impacto, relativos a la cantidad de piezas que presentan evidencias de huellas de uso, ya sea por su rotura, lo que afecta a la punta, la hoja, el cañón o el arpón, o por cualquier tipo de marca o hendidura que desdibuje su morfología original, pudiendo distinguir (Fig. 16):

- Índice de Impacto 1: $\mathrm{n}^{\circ}$ de puntas con impactos de un yacimiento $/ \mathrm{n}^{\circ}$ total de puntas del yacimiento. Se refiere a un cálculo dentro de cada una de las colecciones identificadas, referida a la proporción de piezas que presentan dichas evidencias respecto al total de los hallazgos de un yacimiento.

- Índice de Impacto $2: \mathrm{n}^{\circ}$ de puntas con impactos $/ \mathrm{n}^{\circ}$ de puntas de la colección estudiada, referida al total de la muestra de piezas documentadas en el estudio.

- Índice de Impacto 3: $\mathrm{n}^{\circ}$ de puntas con impactos de un yacimiento $/ \mathrm{n}^{\circ}$ piezas con impacto totales, referi- do a la representatividad de las piezas con huellas de impacto de un yacimiento respecto al conjunto general.

- Índice de Impacto 4: analiza el porcentaje de piezas dentro de la colección de un yacimiento con huellas de impacto, según la zona de localización de la misma (rotura o deformación de la punta y hoja, rotura o perforación del cañón o rotura o deformación del arpón).

Estos índices nos permiten caracterizar las puntas de flecha respecto a su uso, señalando, en aquellas colecciones que superen el $50 \%$ de piezas que presenten huellas de impacto, una tendencia de su alto uso, lo que no puede ser casual, y que dado su contexto de aparición, en relación a obras defensivas o en niveles de abandono, debe estar evidenciando un contexto de uso bélico. Se observa un alto índice de rotura o deformación de la zona de la punta y hoja, seguido de la rotura, perforación o deformación del cañón o cubo de encaje.

\section{Contexto de los hallazgos}

\subsection{Herna/Peña Negra}

Se trata de uno de los principales poblados protohistóricos del Sureste y el Levante de la Península Ibérica. Ha sido identificado con la ciudad de Herna, citada por los fuentes (Avieno, Ora Maritima, vv. 456460), dada la entidad de sus construcciones y la magnitud de su extensión, formando un núcleo urbano de más de 40 ha distribuido por diversas colinas en uno de 


\begin{tabular}{|c|c|c|c|c|c|c|c|c|}
\hline \multicolumn{9}{|c|}{ Índice de Impacto 1: no piezas con impactos/no piezas por yacimiento } \\
\hline \multicolumn{3}{|c|}{ Peña Negra } & \multicolumn{3}{|c|}{ Fonteta } & \multicolumn{3}{|c|}{ Castellar de Meca } \\
\hline \multicolumn{3}{|c|}{$19 / 26: 0,76=76 \%$} & \multicolumn{3}{|c|}{$6 / 10: 0,6=60 \%$} & \multicolumn{3}{|c|}{$7 / 9: 0,78=78 \%$} \\
\hline \multicolumn{9}{|c|}{ Índice de Impacto 2 : no piezas con impactos/ no piezas total } \\
\hline \multicolumn{9}{|c|}{$32 / 44=72 \%$} \\
\hline \multicolumn{9}{|c|}{ Índice de Impacto 3: no piezas impacto en yacimiento/no piezas con impacto totales } \\
\hline \multicolumn{3}{|c|}{ Peña Negra } & \multicolumn{3}{|c|}{ Fonteta } & \multicolumn{3}{|c|}{ Castellar de Meca } \\
\hline \multicolumn{3}{|c|}{$19 / 32=59 \%$} & \multicolumn{3}{|c|}{$6 / 32=19 \%$} & \multicolumn{3}{|c|}{$7 / 32=22 \%$} \\
\hline \multicolumn{9}{|c|}{ Índice de Impacto 4: \% no piezas con impacto según distribución en la pieza } \\
\hline \multicolumn{3}{|c|}{ Peña Negra (19 unidades) } & \multicolumn{3}{|c|}{ Fonteta (6) } & \multicolumn{3}{|c|}{ Castellar de Meca (7) } \\
\hline Punta/H & Cañón & Arpón & Punta/H & Cañón & Arpón & Punta/H & Cañón & Arpón \\
\hline $33 \%$ & $48 \%$ & $18 \%$ & $55 \%$ & - & $44 \%$ & $57 \%$ & $28 \%$ & $14 \%$ \\
\hline \multicolumn{9}{|c|}{ № Piezas con impacto: 32} \\
\hline
\end{tabular}

Fig. 16. Análisis de las huellas de impacto en las puntas de flecha.

los principales pasos intermontanos de la Sierra de Crevillent, a través del que se conecta el área del Bajo Vinalopó-Bajo Segura con el Medio y Alto Vinalopó (González Prats y Ruiz Segura, 1992: 8-10). Ha sido objeto de excavación entre los años 70 y 90 del s. XX (González Prats, 1983: 38-56; Id., 1993, con la bibliografía anterior), incluyendo su necrópolis (González Prats, 2002), lo que permitió documentar una amplia secuencia de ocupación y ofrecer una amplia panorámica de esta zona del Sureste entre los s. IX y VI a.C. Los trabajos en el yacimiento se han reiniciado en 2014, en el marco de un proyecto de investigación del Área de Prehistoria de la Universidad de Alicante, que incluye trabajos de prospección, excavación y musealización en el yacimiento.

Fue durante los primeros siglo de la Edad del Hierro, entre los s. VII y VI a.C., cuando el asentamiento alcanzó su máximo desarrollo, en gran medida por las estrechas relaciones con la ciudad fenicia de La Fonteta, localizada en la desembocadura del río Segura (Rouillard et al., 2007; Rouillard, 2010: 80-89; González Prats, 2010a: 60-69; Id. 2011; Id., 2014 b-c), y que se reflejarán entre otras evidencias en una creciente evolución hacia formas de vida urbana, que finalmente supusieron la transformación social y política de la comunidad instalada en este importante asentamiento, en el que la presencia de fortificaciones y de un sistema de fortines que controlarían las vías de comunicación y el territorio inmediato ponen de manifiesto el papel jerarquizador de Peña Negra en la zona.
Herna/Peña Negra se caracteriza por su emplazamiento estratégico, un entorno interior en la Sierra de Crevillent -aprovechando un altiplano atravesado por varios barrancos que posee importantes colinas y relieves donde se desarrollaría un hábitat aterrazado-, con limitados y controlados pasos de acceso al lugar (Fig. 18): por el sur a través del paso de El Forat-Pic de Les Moreres, hacia el glacis crevillentino meridional y el Bajo Vinalopó; y por el norte, el estrecho paso controlado por las elevaciones de Barricaes y Cantal de la Campana, que conectan con el corredor o Valle de los Hondones, puerta de entrada al Valle de Aspe y el corredor del Vinalopó (González Prats, 1983: 18). A ello deben añadirse sus importantes defensas naturales, reduciendo la necesidad inicial de fortificaciones construidas, o limitando su existencia a aquellas áreas de más fácil acceso o de gran dominio visual, aunque la fuerte erosión del lugar ha transformado de forma importante el asentamiento original (Fig. 18, B y D).

A esta topografía estratégica, aprovechada desde el Bronce Final, se sumará la construcción de fortificaciones al menos desde el Hierro Antiguo, que incluyen una muralla perimetral de la que González Prats (1983: 17-18) identificó algunos lienzos (Fig. 18, C, 3 y 5), a los que deben añadirse otros hallados en 2014 (Fig. 18, C, 4), y una segunda muralla que delimita la zona alta del poblado, en lo que debe considerarse como la ciudadela o acrópolis, descubierta en 2015, aunque en 2016 se haya propuesto su origen en el Bronce Final 


\begin{tabular}{|c|c|c|c|c|c|c|c|c|c|c|c|c|c|c|c|c|c|}
\hline \multirow{2}{*}{$\begin{array}{l}\text { No } \\
\text { Cat. }\end{array}$} & \multirow[t]{2}{*}{ GRUPO } & \multirow[t]{2}{*}{ Tipo } & \multirow{2}{*}{$\begin{array}{l}\text { L. } \\
\text { Máx. }\end{array}$} & \multicolumn{4}{|c|}{ HOJA } & \multirow[b]{2}{*}{6} & \multicolumn{2}{|c|}{ FILO } & \multicolumn{3}{|c|}{ CAÑÓN } & \multirow{2}{*}{$\begin{array}{l}\text { Arpón } \\
\text { (A) } \\
\text { Pasado } \\
\text { ro } \\
\text { remac } \\
\text { he (R) }\end{array}$} & \multirow[t]{2}{*}{ IP } & \multirow{2}{*}{$\begin{array}{c}\text { Peso } \\
\text { g }\end{array}$} & \multirow{2}{*}{$\begin{array}{l}\text { Huellas } \\
\text { Impacto }\end{array}$} \\
\hline & & & & $\mathbf{F}$ & Sección & A & L & & Anc & Tipo & Forma & $\emptyset$ & L & & & & \\
\hline PN1 & 1 & $11 a$ & 5 & La & Nervada & 0,9 & 3 & 0,4 & & Doble & Cilindrica & 0,5 & 2 & $A C$ & 0,6 & - & Cañón roto \\
\hline PN2 & 2 & $12 \mathrm{a}$ & 4,4 & La & $\begin{array}{c}\text { Pseudo } \\
\text { fenestrada }\end{array}$ & 0,7 & 3 & 0,3 & $E$ & $\begin{array}{c}\text { Falso } \\
\text { Doble filo }\end{array}$ & Cilindrica & 0,5 & 1,4 & Al & 0,68 & $\cdot$ & Punta rota \\
\hline PN3 & 1 & $11 \mathrm{a}$ & $4,6^{16}$ & La & $\begin{array}{c}\text { Nervada y } \\
\text { arista }\end{array}$ & 0,9 & $2,3^{1 \mathrm{tc}}$ & 0,3 & & Doble & Cilindrica & 0,5 & 2 & $\begin{array}{l}A C \\
\text { R++ }\end{array}$ & 0,53 & $\cdot$ & $\begin{array}{c}\text { Punta rota } \\
\text { Agujero lateral }\end{array}$ \\
\hline PN4 & 2 & $12 \mathrm{a}$ & 4,3 & La & $\begin{array}{l}\text { Romboidal } \\
\text { pseudo } \\
\text { fenestrada }\end{array}$ & 0,7 & 2,3 & 0,3 & $E$ & $\begin{array}{c}\text { Falso } \\
\text { Doble filo }\end{array}$ & Cilindrica & 0,5 & 2 & $\mathrm{AC}$ & 0,53 & $\cdot$ & Marcas \\
\hline PN5 & 5 & $44 a$ & 4,3 & La & $\begin{array}{l}\text { Estrellada con } \\
\text { caras } \\
\text { rehundidas }\end{array}$ & 0,65 & 2,3 & 0,3 & $E$ & Triple filo & Cilindrica & 0,5 & 2 & $\begin{array}{l}\mathrm{AC}^{*} \\
\mathrm{R+}\end{array}$ & 0,53 & $\cdot$ & - \\
\hline PN6 & 2 & $12 a$ & 4 & $\operatorname{Re}$ & $\begin{array}{c}\text { Pseudo } \\
\text { fenestrada }\end{array}$ & 0,6 & 2,3 & 0,3 & $E$ & $\begin{array}{c}\text { Falso } \\
\text { Doble filo }\end{array}$ & Cilindrica & 0,5 & 1,7 & $A C^{*}$ & 0,6 & $\cdot$ & - \\
\hline PN7 & 1 & $11 a$ & 3,8 & La & $\begin{array}{c}\text { Nervada } \\
\text { Nervio ancho }\end{array}$ & 0,8 & 2,1 & 0,3 & $E$ & Doble filo & Cilindrica & 0,5 & 1,7 & $\mathrm{All}^{*}$ & 0,5 & $\cdot$ & - \\
\hline PN8 & 3 & $13 a$ & $3,8^{1 \mathrm{ct}}$ & $T$ & Nervada & 0,9 & $2,8^{t / 6}$ & 0,3 & - & Doble filo & $\begin{array}{l}\text { Cilindrica } \\
\text { Corto }\end{array}$ & 0,5 & 1 & AML" & 0,6 & $\cdot$ & Punta rota \\
\hline PN9 & 5 & $43 a$ & $3,5^{16}$ & La & $\begin{array}{l}\text { Estrellada con } \\
\text { caras planas }\end{array}$ & 0,6 & $2,1^{16}$ & 0,5 & $E$ & Triple filo & Cilindrica & 0,5 & 1,4 & ACL" & 0,6 & $\cdot$ & $\begin{array}{l}\text { Punta rota y } \\
\text { doblada }\end{array}$ \\
\hline $\begin{array}{l}\mathrm{PN} \\
10\end{array}$ & 1 & $11 \mathrm{~b}$ & 4,2 & La & $\begin{array}{c}\text { Nervada } \\
\text { disimétrica }\end{array}$ & 0,8 & 2,7 & 0,3 & - & Doble filo & Cilindrica & 0,5 & 1,5 & - & 0,64 & $\cdot$ & - \\
\hline $\begin{array}{l}\mathrm{PN} \\
11 \\
1\end{array}$ & 1 & $11 \mathrm{~b}$ & 5 & La & $\begin{array}{c}\text { Nervada y } \\
\text { arista }\end{array}$ & 0,8 & 2,7 & 0,3 & - & Doble filo & $\begin{array}{l}\begin{array}{c}\text { Cilindrica } \\
\text { largo }\end{array} \\
\text { a }\end{array}$ & 0,5 & 2,3 & - & 0,54 & $\cdot$ & Cañón roto \\
\hline $\begin{array}{l}\text { PN } \\
12\end{array}$ & 1 & $11 \mathrm{~b}$ & 4,8 & La & $\begin{array}{c}\text { Nervada } \\
\text { disimétrica }\end{array}$ & 1 & 2,8 & 0,4 & - & Doble filo & $\begin{array}{l}\text { Cilindrica } \\
\text { largo }\end{array}$ & 0,5 & 2 & - & 0,5 & - & - \\
\hline $\begin{array}{l}\mathrm{PN} \\
13\end{array}$ & 2 & $12 \mathrm{a}$ & 2,54 & La & $\begin{array}{c}\text { Pseudo } \\
\text { fenestrada }\end{array}$ & 0,7 & 2,29 & 0,3 & - & Doble filo & Cilindrico & 0,4 & 0,26 & A & - & $\cdot$ & $\begin{array}{l}\text { Deteriorada, rota } \\
\text { punta y cañon }\end{array}$ \\
\hline $\begin{array}{l}\text { PN } \\
14\end{array}$ & 1 & $11 \mathrm{~b}$ & 3 & ta & Nervada & 0,5 & $1,4^{t !}$ & - & - & Doble filo & Gilindrico & 0,4 & 1,6 & $\mathrm{R}+\mathrm{H}$ & 0,4 & 2,56 & $\begin{array}{c}\text { Punta rota,y } \\
\text { marcas }\end{array}$ \\
\hline $\begin{array}{l}\text { PN } \\
15\end{array}$ & 1 & $11 \mathrm{~b}$ & 3,4 & $\begin{array}{l}\text { La/ } \\
0\end{array}$ & $\begin{array}{l}\text { Nervada con } \\
\text { arista }\end{array}$ & 0,8 & 2 & 0,4 & $E$ & Doble filo & $\begin{array}{l}\text { Cilindrico } \\
\text { corto }\end{array}$ & 0,6 & 1,4 & - & 0,6 & 3,26 & $\begin{array}{l}\text { Fractura en } \\
\text { cañón }\end{array}$ \\
\hline $\begin{array}{l}\text { PN } \\
16\end{array}$ & 1 & $11 \mathrm{a}$ & 4,5 & La & $\begin{array}{c}\text { Nervada } \\
\text { amplio nervio }\end{array}$ & 0,7 & 2,65 & 0,4 & $E$ & Doble filo & $\begin{array}{c}\text { Cilindrico } \\
\text { largo }\end{array}$ & 0,6 & 1,85 & $\begin{array}{l}\mathrm{AL} \\
\mathrm{R} ?+\end{array}$ & 0,6 & 5,14 & $\begin{array}{l}\text { Hendidura en } \\
\text { hoja Rotura en } \\
\text { cañón / arpón } \\
\text { doblado }\end{array}$ \\
\hline $\begin{array}{l}\text { PN } \\
17\end{array}$ & 1 & $11 a$ & 4,4 & La & $\begin{array}{c}\text { Nervada } \\
\text { disimétrica }\end{array}$ & 0,8 & 2,7 & 0,3 & $E$ & Doble filo & Cilindrico & 0,5 & 1,7 & $\begin{array}{c}\mathrm{AC}^{*} \\
\mathrm{R}\end{array}$ & 0,61 & 4,71 & Rotura en cañón \\
\hline $\begin{array}{l}\text { PN } \\
18\end{array}$ & 1 & $11 \mathrm{a}$ & 4,5 & $\begin{array}{l}\text { La } \\
\text { /Ro }\end{array}$ & Nervada & 1,05 & 3 & - & A & Doble filo & Cilindrico & 0,5 & 1,5 & $A C^{*}$ & 0,66 & 5,5 & Rotura en cañón \\
\hline $\begin{array}{l}\text { PN } \\
19\end{array}$ & 1 & $11 \mathrm{a}$ & 3,7 & $\begin{array}{l}\text { La } \\
\text { /Ro }\end{array}$ & $\begin{array}{c}\text { Nervada } \\
\text { disimétrica }\end{array}$ & 0,85 & $2,5^{16}$ & - & - & Doble filo & Cilindrico & 0,5 & 1,6 & $A C^{*}$ & 0,6 & 4,37 & $\begin{array}{l}\text { Punta, cañón y } \\
\text { arpón rotos }\end{array}$ \\
\hline $\begin{array}{l}\text { PN } \\
20\end{array}$ & 2 & $12 \mathrm{e}$ & 4,8 & La & $\begin{array}{c}\text { Pseudo } \\
\text { fenestrada }\end{array}$ & 0,7 & 2,3 & 0,3 & $E$ & $\begin{array}{c}\text { Falso } \\
\text { doble filo }\end{array}$ & $\begin{array}{c}\text { Cilindrico } \\
\text { y muy } \\
\text { largo }\end{array}$ & 0,5 & 2,5 & R+t & 0,47 & 5,51 & $\begin{array}{c}\text { Fragmentada en } \\
\text { cañón }\end{array}$ \\
\hline $\begin{array}{l}\text { PN } \\
21\end{array}$ & 2 & $12 \mathrm{a}$ & $3,5^{16}$ & Ro & $\begin{array}{c}\text { Pseudo } \\
\text { fenestrada }\end{array}$ & 0,8 & 2,8 & 0,4 & - & $\begin{array}{c}\text { Falso } \\
\text { doble filo }\end{array}$ & Cilindrico & 0,6 & $0,8^{16}$ & $\mathrm{Al}^{*}$ & 0,8 & 3,34 & $\begin{array}{c}\text { Cañón y arpón } \\
\text { roto }\end{array}$ \\
\hline $\begin{array}{l}\text { PN } \\
22\end{array}$ & 5 & $44 a$ & $2,4^{\pi / C}$ & $\begin{array}{l}\text { La } \\
/ \mathrm{Re}\end{array}$ & $\begin{array}{l}\text { Triangular } \\
\text { estrellada } \\
\text { hendiduras }\end{array}$ & 0,7 & $0,7^{16}$ & 0,5 & $E$ & Triple filo & Gilindrico & 0,5 & 1,7 & $\mathrm{Al}^{*}$ & 0,29 & 2,13 & $\begin{array}{l}\text { Punta, hoja y } \\
\text { arpón rotos }\end{array}$ \\
\hline $\begin{array}{l}\text { PN } \\
23\end{array}$ & 1 & $11 \mathrm{a}$ & 3,7 & La & $\begin{array}{c}\text { Nervada } \\
\text { disimétrica }\end{array}$ & 0,7 & 2,4 & 0,4 & & Doble filo & Cilindrico & 0,5 & 1,4 & $A C^{*}$ & 0,6 & 3,67 & $\begin{array}{l}\text { Arpón roto } \\
\text { Agujero en } \\
\text { cañón }\end{array}$ \\
\hline $\begin{array}{l}\text { PN } \\
24\end{array}$ & 5 & $44 a$ & 3,4 & $\begin{array}{l}\text { OI } \\
\text { la }\end{array}$ & $\begin{array}{l}\text { Triangular } \\
\text { estrellada } \\
\text { hendiduras }\end{array}$ & 0,7 & 2,3 & 0,5 & A & Triple filo & Cilindrico & 0,6 & $1,1^{16}$ & $\begin{array}{l}\mathrm{AL}^{*} \\
\mathrm{R}\end{array}$ & 0,7 & 4,42 & $\begin{array}{l}\text { Arpón y cañón } \\
\text { rotos }\end{array}$ \\
\hline $\begin{array}{l}\mathrm{PN} \\
25\end{array}$ & 1 & $\begin{array}{l}12 \mathrm{~d} \\
11 \mathrm{a}\end{array}$ & 4,3 & $\mathrm{~L}$ & Nervada & 0,6 & 2,5 & 0,4 & $E$ & Doble filo & Gilindrico & 0,5 & 1,8 & AML" & 0,6 & 4,77 & - \\
\hline $\begin{array}{l}\text { PN } \\
26\end{array}$ & 1 & $11 a$ & 3,8 & $\mathrm{~L}$ & Nervada & 0,7 & 2,3 & 0,3 & $E$ & Doble filo & Cilíndrico & 0,5 & 1,5 & $\begin{array}{l}A C^{*} \\
R+\end{array}$ & 0,6 & 2,56 & $\begin{array}{l}\text { Agujero de } \\
\text { pasador o } \\
\text { remache }\end{array}$ \\
\hline
\end{tabular}

Fig. 17. A. Dimensiones y posición estratigráfica de las puntas de flecha estudiadas. Peña Negra.

Claves: ${ }^{\mathrm{LC}}$ Longitud conservada. Filo: A = Ancho; E = Estrecho. Arpón/Remache: *Arpón nace de la zona central del cañón; +Agujero del remache en la zona de unión hoja-cañón; ++Agujero del remache en el cañón; Arpón: AI: Arpón indicado; AC: Arpón corto o destacado. AL: Arpón largo. AML: Arpón muy largo; IP: Índice de proporcionalidad. 1) Redondeada, 2) Romboidal, 3) Nervada. Dimensiones expresadas en cm.

(Fig. 18, C, 6). A ello debe añadirse la construcción de fortines amurallados en aquellas localizaciones más elevadas y con mejor visibilidad de las rutas de acceso y circulación a la sierra, como el Cantal de la Campana o Barricaes (Fig. 18, C, 9-10), a fin de controlar el paso septentrional (Grau y Moratalla, 2001: 191; Moratalla, 2004: 154, 653 ss.; Pernas, 2008: 124-125, 134-165, 144-145; Trelis y Molina, e.p.), o la ocupación de otros relieves destacados, de los cuales no siempre se conservan evidencias constructivas, controlando los accesos meridionales (Fig. 18, C, 1-2, 7).

De esta forma, durante el momento de máximo desarrollo de la ciudad, Herna contaría con dos líneas defensivas, una externa conformada por una red de fortines, y una interna, identificada en algunos secto- res periféricos con una muralla perimetral construida a plomada (Sectores I y VII), pudiendo añadirse una tercera, relacionada con la fortificación de la Peña Negra propiamente dicha, que delimitaría un sector individualizado del poblado, a modo de acrópolis (Sector III), donde pudo localizarse la regia o residencia de los grupos dominantes de Herna. A ello cabe añadir la propia cima de El Castellar (Sector V), con independencia de que los restos de fortificaciones allí conservados pudieran corresponder a una fase más avanzada (Moret, 1996: 478, 480; Moratalla, 2004: 148-150). Los Sectores III y V constituyen zonas elevadas, desde las que se domina visualmente toda la Sierra, los dos accesos a la misma, hacia el norte, Barricaes, y, hacia el sur, la necrópolis de Les 


\begin{tabular}{|c|c|c|c|c|c|c|c|c|c|c|c|c|c|c|c|c|c|}
\hline \multirow{2}{*}{$\begin{array}{l}\text { Ne } \\
\text { Cat. }\end{array}$} & \multirow[t]{2}{*}{ GRUPO } & \multirow[t]{2}{*}{ Tipo } & \multirow{2}{*}{$\begin{array}{c}\text { L. } \\
\text { Máx. }\end{array}$} & \multicolumn{4}{|c|}{ HOJA } & \multirow[b]{2}{*}{ G } & \multicolumn{2}{|r|}{ FILO } & \multicolumn{3}{|c|}{ CAÑÓN } & \multirow{2}{*}{$\begin{array}{l}\text { Arpón (A) } \\
\text { Pasador } \\
0 \\
\text { remache } \\
\text { (R) }\end{array}$} & \multirow[t]{2}{*}{ IP } & \multirow{2}{*}{$\begin{array}{l}\text { Peso } \\
\text { g }\end{array}$} & \multirow{2}{*}{$\begin{array}{l}\text { Huellas } \\
\text { Impacto }\end{array}$} \\
\hline & & & & $\mathrm{F}$ & Sección & A & L & & Anc & Tipo & Forma & $\emptyset$ & L & & & & \\
\hline$F 1$ & 1 & $11 a$ & $\begin{array}{c}4,3 \\
k \mathrm{k}\end{array}$ & La & $\begin{array}{c}\text { Nervada } \\
\text { disimétrica }\end{array}$ & 0,8 & $2,6^{16}$ & 0,3 & $E$ & Doble & Cilindrica & 0,5 & 1,5 & $\mathrm{Al}^{*}$ & $2,6^{11 / 1} / 1,5$ & - & $\begin{array}{c}\text { Punta dobladay } \\
\text { rota }\end{array}$ \\
\hline$F 2$ & 1 & $11 \mathrm{a}$ & 5 & ta & $\begin{array}{l}\text { Nervada } \\
\text { marcada }\end{array}$ & 0,8 & 3 & 0,3 & $E$ & Doble & Clilindrica & 0,6 & 2 & $\begin{array}{l}A C^{*} \\
R+\end{array}$ & $3 / 2$ & $\cdot$ & $\begin{array}{c}\text { Punta doblada y } \\
\text { rota }\end{array}$ \\
\hline$F_{3}$ & 1 & $11 \mathrm{a}$ & 4,5 & La & $\begin{array}{c}\text { Nervada } \\
\text { marcada } \\
\text { disimétrica }\end{array}$ & 0,8 & 2,6 & 0,3 & $E$ & Doble & Cilindrico & 0,6 & 1,9 & $\mathrm{Al}^{\circ}$ & $2,6 / 1,9$ & - & - \\
\hline$F 4$ & 2 & $12 \mathrm{a}$ & 5 & ta & $\begin{array}{c}\text { Pseudo } \\
\text { fenestrada }\end{array}$ & 0,8 & 3 & 0,3 & $E$ & Falso Doble filo & $\begin{array}{l}\text { Gilíndrico } \\
\text { corta }\end{array}$ & 0,6 & 2 & $A C^{\circ}$ & 0,6 & 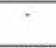 & - \\
\hline F5 & 1 & $11 \mathrm{a}$ & 4,9 & Ro & Nervada & 1,2 & 2,9 & - & A & Doble & $\begin{array}{l}\text { Cilindrica } \\
\text { corta }\end{array}$ & 0,5 & 2 & $A C^{*}$ & $2,9^{16} / 2$ & 7,09 & Punta rota \\
\hline F6 & 6 & $54 a$ & 4,7 & Ro & Nervada & 0,5 & 3,5 & - & $\mathrm{E}$ & Cuádruple filo & $\begin{array}{c}\text { Cuadrada } \\
?\end{array}$ & 0,5 & 1,1 & $A C^{*}$ & 0,74 & 5,6 & - \\
\hline F7 & 1 & $11 \mathrm{a}$ & $4^{4 k}$ & La & Nervada & 0,7 & 2 & - & $\mathrm{E}$ & Doble & Cilindrica & 0,6 & 2 & $\mathrm{Al}^{*}$ & $2^{16 / 2}$ & 5,52 & $\begin{array}{l}\text { Punta y arpón } \\
\text { rotos }\end{array}$ \\
\hline F8 & 1 & 11a & 4,3 & $\begin{array}{l}\text { La } \\
\text { /Ro }\end{array}$ & Nervada & 0,9 & 2,2 & - & A & Doble & Cilindrica & 0,6 & 2,1 & $\mathrm{Al}^{*}$ & $2,2 / 2,1$ & 4,28 & Arpón roto \\
\hline F9 & 1 & $11 \mathrm{~b}$ & 4 & La & Nervada & 0,9 & - & - & - & Doble & Cilindrica & - & - & - & - & - & Erosionada \\
\hline $\mathrm{F} 10$ & 1 & $11 \mathrm{~b}$ & 3,6 & Ro & $\begin{array}{l}\text { Nervada } \\
\text { marcada }\end{array}$ & 0,8 & 2 & - & A & Doble & Cilindrica & 0,5 & 1,6 & - & $2 / 1,6$ & $\cdot$ & Punta \\
\hline CM1 & 1 & $11 \mathrm{a}$ & 3,3 & $\begin{array}{l}\text { La/ } \\
\text { Ro }\end{array}$ & Nervada & 0,7 & 1,8 & 0,4 & $E$ & Doble & Cilindrica & $\begin{array}{l}0,4- \\
0,6\end{array}$ & 1,5 & AML" & 0,5 & 3,4 & $\begin{array}{c}\text { Cahón y arpón } \\
\text { rotos }\end{array}$ \\
\hline CM2 & 1 & $11 \mathrm{a}$ & 4 & La & $\begin{array}{l}\text { Nervada muy } \\
\text { ancha }\end{array}$ & 0,7 & $\begin{array}{l}2,1 * \\
2,3\end{array}$ & 0,3 & $E$ & Doble & Cilindrica & $\begin{array}{l}0,4 . \\
0,7\end{array}$ & 1,9 & $\mathrm{Al}^{*}$ & 0,52 & 4,6 & Punta rota \\
\hline $\mathrm{CM}_{3}$ & 2 & $12 \mathrm{~d}$ & 4,4 & La & $\begin{array}{c}\text { Pseudo- } \\
\text { fenestrada }\end{array}$ & 0,9 & 2 & 0,4 & - & Doble falso filo & $\begin{array}{l}\text { Cilindrica } \\
\text { muy largo }\end{array}$ & 0,5 & 2,4 & $A C^{*}$ & 0,45 & 4,6 & $\begin{array}{l}\text { Punta y arpón } \\
\text { rotos }\end{array}$ \\
\hline CM4 & 1 & $11 \mathrm{a}$ & 4 & La & Nervada ancha & 0,7 & 2,2 & 0,4 & $E$ & Doble & Cilindrica & $\begin{array}{l}0,5-5 \\
0,6\end{array}$ & 1,8 & $\mathrm{AL}^{*}$ & 0,55 & 4,6 & $\begin{array}{l}\text { Punta y hoja } \\
\text { rotas }\end{array}$ \\
\hline CMS & 1 & 11d & 4 & Ro & Nervada & 0,6 & 1,8 & 0,3 & $E$ & Doble & $\begin{array}{c}\text { Cilindrica } \\
\text { largo }\end{array}$ & 0,5 & 3,2 & $A C^{*}$ & 0,45 & 2,7 & - \\
\hline CM6 & 1 & $11 \mathrm{a}$ & 2,4 & La & Nervada & 0,7 & $1,3^{\mathrm{tc}}$ & 0,3 & A & Doble & Cilindrica & 0,4 & 1,1 & $\begin{array}{l}A C^{*} \\
R_{+}\end{array}$ & 0,54 & 3,2 & $\begin{array}{l}\text { Punta rota y } \\
\text { doblada }\end{array}$ \\
\hline CM7 & 1 & $11 \mathrm{~d}$ & 2,4 & Ro & $\begin{array}{l}\text { Nervada } \\
\text { marcada }\end{array}$ & 0,7 & $1,1^{4}$ & 0,3 & A & Doble & Cilindrica & 0,5 & 1,3 & $A C^{\circ}$ & 0,45 & 2,4 & Punta rota \\
\hline CM8 & 1 & $11 a$ & 3,4 & La & $\begin{array}{l}\text { Nervadura } \\
\text { ancha }\end{array}$ & $0,5-0,6$ & $\begin{array}{l}1,8- \\
1,9\end{array}$ & 0,3 & $E$ & Doble & Cilindrica & 0,5 & 1,5 & $A C$ & 0,52 & $\cdot$ & $\begin{array}{l}\text { Punta rota y } \\
\text { doblada }\end{array}$ \\
\hline CM9 & 4 & $22 \mathrm{~b}$ & 4,8 & $T$ & $\begin{array}{l}\text { Nervadura } \\
\text { marcada }\end{array}$ & 0,7 & $\begin{array}{c}2,3+0 \\
, 3\end{array}$ & 0,3 & $E$ & Doble & $\begin{array}{l}\text { Cilindrica- } \\
\text { cónica }\end{array}$ & $\begin{array}{l}0,6 \\
0,4\end{array}$ & $\begin{array}{l}2,3 . \\
2,4\end{array}$ & R+t & 0,56 & . & Arista rota \\
\hline
\end{tabular}

Fig. 17. B. Dimensiones y posición estratigráfica de las puntas de flecha estudiadas. Fonteta y Meca. Claves: ${ }^{\mathrm{LC}}$ Longitud conservada. Filo: A = Ancho; E = Estrecho. Arpón/Remache:

*Arpón nace de la zona central del cañón; +Agujero del remache en la zona de unión hoja-cañón; ++Agujero del remache en el cañón; Arpón: AI: Arpón indicado; AC: Arpón corto o destacado. AL: Arpón largo.

AML: Arpón muy largo; IP: Índice de proporcionalidad.

1) Redondeada, 2) Romboidal, 3) Nervada. Dimensiones expresadas en $\mathrm{cm}$.

Moreres $^{32}$ y las elevaciones meridionales de El Pic de les Moreres, El Forat o Penya Fongua, en primer término, los llanos crevillentinos en el entorno del Hondó, resto de lo que sería en la Antigüedad parte del Sinus ilicitanus (Tent-Mancús y Soria, 2014), a continuación, y finalmente, a una veintena de kilómetros en línea recta, la desembocadura del río Segura y la zona de costa más próxima (Barrier y Montenat, 2007).

En Peña Negra se ha localizado un total de 26 puntas de flecha, aunque haya noticias de otros hallazgos a través de noticias indirectas. De las piezas conocidas, al menos 12 tienen contexto estratigráfico (González Prats, 1982a; González Prats y Ruiz Segura, 1992), mientras las 14 restantes son hallazgos de superficie, solo excepcionalmente recuperados en trabajos de prospección, lo que permite su localización concreta dentro del yacimiento, pues lo habitual es que carezcan de cualquier referencia, más allá de la adscripción genérica a Peña Negra o El Castellar, los dos principales relieves que conforman el yacimiento (Fig. 19).

32 Aquí se localiza, por el momento, el único cementerio en relación directa con Peña Negra (González Prats, 2002), aunque no se debe descartar la existencia de otros núcleos funerarios en la zona. Desde el cerro de Les Moreres se con-
Estos hallazgos hacen de Peña Negra el lugar con mayor número de puntas de flecha de todo el área suroriental de la Península Ibérica (Fig. 1), y el que presenta el más alto porcentaje de huellas de impacto entre las mismas, lo que unido a los patrones de concentración constatados, podrían mostrar posibles escenarios de asedio o asalto, según se deduce de su contexto estratigráfico y localización, ya sea en barrios amurallados en altura (Sector IB), en áreas de hábitat o artesanales en ladera media y baja (Sectores IA, II y VII), o en estratégicos puntos defensivos (Sector V).

Un nutrido conjunto se recuperó en los barrios periféricos de la ladera meridional, los Sectores IB (1 ejemplar), 1A (2) y VII (9), y el resto de la zona central del yacimiento, en el Sector II (IIA-D y IIw), el más próximo a la Peña Negra propiamente dicha o Sector III, con 5 ejemplares, así como de la zona alta de El Castellar (1 punta). Las áreas de concentración de hallazgos corresponden a varios tipos de localizaciones. Por un lado, en las colinas principales en las

trola el paso hacia Peña Negra por el Barranco de la Rambla, lo que podría explicar la presencia en superficie de una punta de flecha en la zona (PN25). 

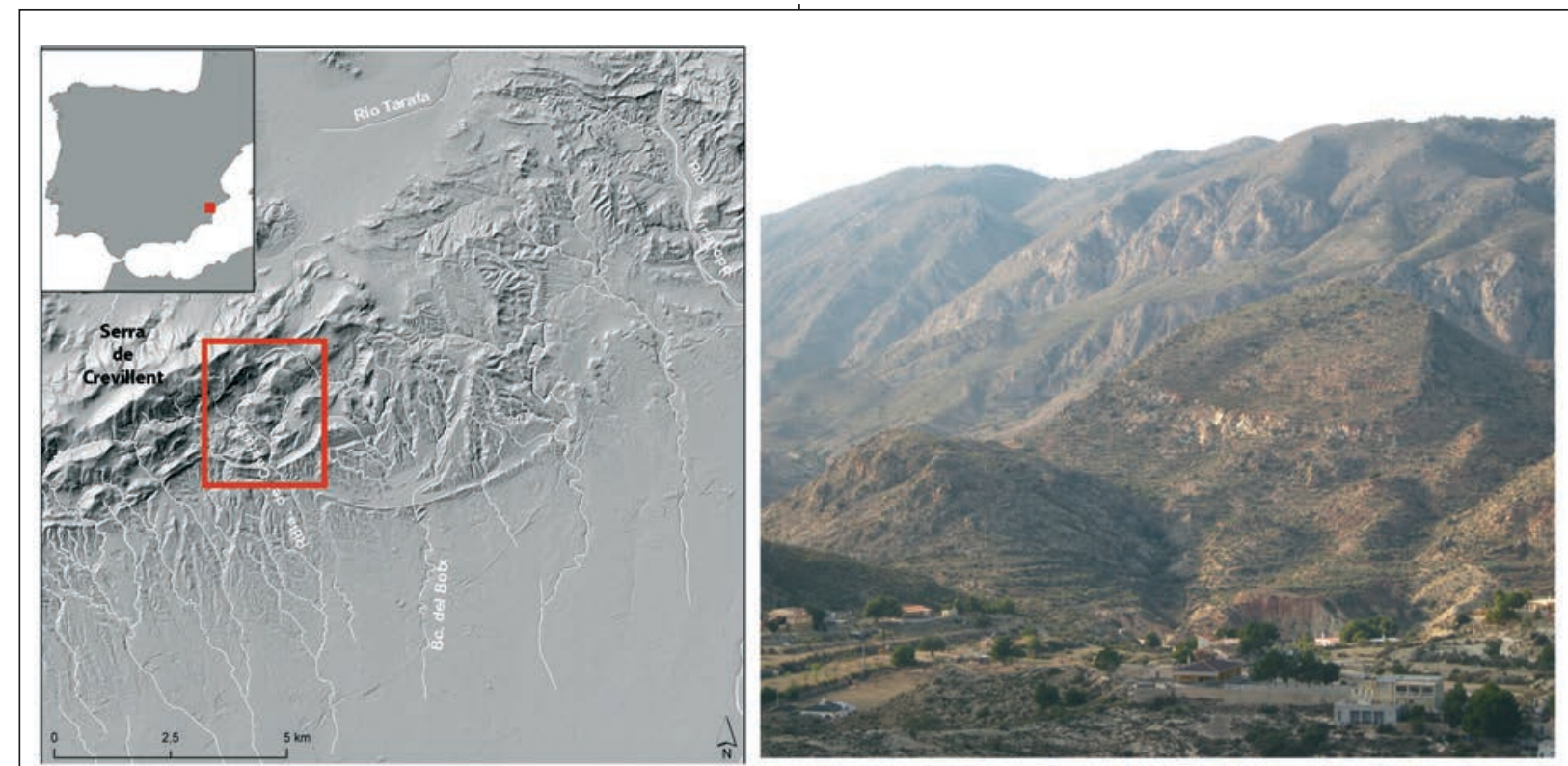

A

B
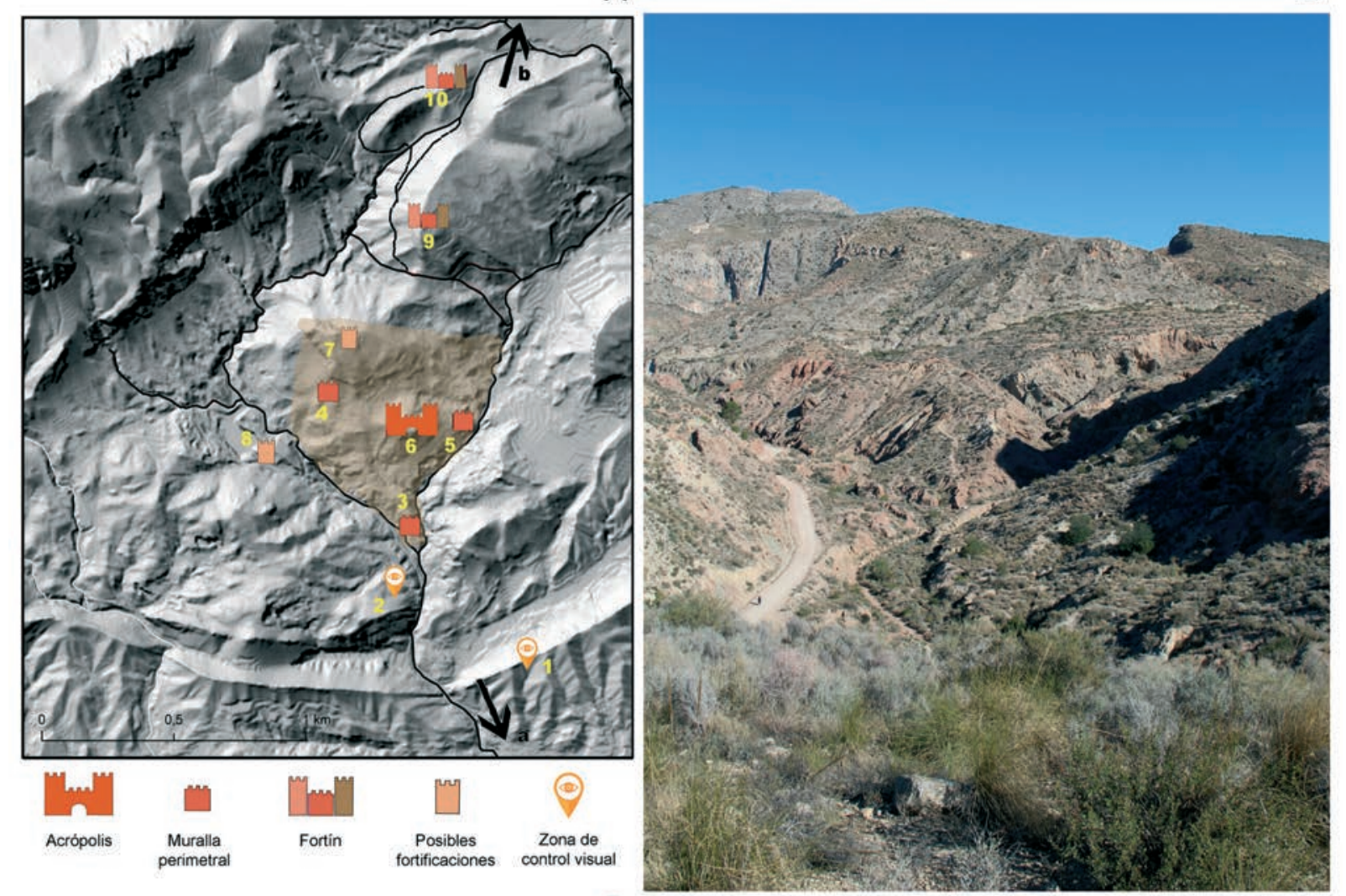

C

Fig. 18. Peña Negra. A. Localización del yacimiento en el paso más oriental de Sierra de Crevillent.

B. Vista de las elevaciones de la Peña Negra y El Castellar desde el sureste.

C. Detalle topográfico y delimitación del poblado de Peña Negra con indicación de líneas defensivas y caminería (hacia el Sur -a-: Glacis crevillentino; hacia el Norte -b-: valle interior de Aspe y Vinalopó).

1. Pic de les Moreres . 2. Lomas de la Penya Fongua. 3. Sector IB "Cerrito".

4. Sector IIw. 5. Sector VII. 6. Muralla acropolitana del Sector III. 7. El Castellar.

8. Sector XIV, 9. Barricaes. 10. Cantal de la Campana.

D. Vista de la Peña Negra y el Castellar desde la entrada a la Rambla del Castellar, desde el sur. Cartografía (A y C) S. Pernas. Fotografías J. Quesada (B) y A. Lorrio (D). 
que se distribuye el urbanismo de la ciudad, en emplazamientos en altura en los cuales se ha identificado la presencia de un lienzo amurallado perimetral (Sector IB y VII Norte) o que gozan de estratégicas ubicaciones defensivas naturales (Sector V). Por otro, las zonas o barrios localizados en la periferia del poblado (Sector IA y VII Sur), cerca de posibles accesos y no muy alejadas de las zonas donde se han identificado posibles líneas de muralla. Finalmente, algunos ejemplares, los menos, proceden de los barrios localizados en la vaguada central de Peña Negra, Sector II A-D y IIw, las primeras en la base del Sector III, un destacado cerro central que estuvo rodeado de una muralla perimetral (Figs. 19 y 20). Analizamos a continuación estos escenarios.

En el Sector IB, conocido como el "cerrito", destaca la localización a extramuros de una punta de flecha (PN2) que presenta la punta rota, asociada al estrato final de destrucción identificado como Nivel Ia del Corte $\mathrm{C} 1$, nivel blanquecino que se interpreta como el derrumbe de adobes o tapial de las paredes de las últimas casas de la secuencia o bien del lienzo identificado como posible muralla (González Prats, 1979; Id., 1985a: 17 y 18) (Figs. 19 y 20, B). No obstante, los niveles de ocupación de la parte superior de la terraza, Cortes A1-B1-C1, están muy arrasados, y no se conserva una asociación estratigráfica clara entre el asiento de la muralla y los niveles de ocupación mejor conservados en la terraza inferior extramuros, lo que dificulta la adscripción cronológica de la muralla. Sin embargo, según los materiales arqueológicos asociados a dicho corte $\mathrm{C} 1$ y sobre todo los identificados en la Trinchera Norte ${ }^{33}$, en las inmediaciones de la muralla, en su cara interna, donde sí se conserva un nivel de uso y un pavimento rojizo a modo de área de circulación, se podría plantear una fecha genérica de principios del s. VI a.C. para la construcción de la fortificación, sino antes, según indican los materiales cerámicos y el fragmento de fíbula de doble resorte que aparecieron sobre este empedrado rojizo, y por tanto correspondiente con la fase PNIIB (González Prats, 1983: 182). La posición de esta punta de flecha, junto a la cara exterior de la muralla, resulta similar al que ofrecen otros ejemplares, como los recuperados en la muralla de

33 En la Trinchera Norte, a intramuros de la muralla, se identifica bajo un nivel blanquecino de derrumbe (Ia), un posible nivel de circulación o uso (Ib), estrato ceniciento situado sobre un suelo rojizo con grava, próximo a la cara interna de uno de los tramos de muralla identificado en esta área.

${ }^{34}$ Este urbanismo guardaría semejanza con el identificado en áreas próximas del Sureste, como El Castellar de Librilla (Murcia) (Ros Sala, 1989). El barrio del Sector IA de Peña Negra se localiza en una pequeña zona amesetada con casas de planta cuadrangular, sin aparente compartimentación y de menores dimensiones que las de fases previas, al igual que parece ocurrir durante la Fase IVa de El
Pancorbo (Montellano, Sevilla), en el Valle del Rio Guadalete (Mancebo y Ferrer, 1988-89: 316).

Por su parte, el Sector IA conforma otro conjunto tardío de casas "dispuestas de forma aislada o en conexión con departamentos adosados" que han sido identificadas como "pertenecientes a la última fase de estructuras del poblado", también asociado a la fase PNIIB y en cuya estratigrafía se identifica un único nivel de ocupación orientalizante o Nivel I (González Prats, 1983: 182) $)^{34}$. En el Corte 4N se localizó una punta con el cañón roto (PN1) en el exterior de una de estas casas cuadrangulares (Fig. 20, A), asociada al nivel estratigráfico Ia, que corresponde con el derrumbe de los adobes pertenecientes a las paredes de la casa, que sepulta los restos materiales arqueológicos vinculados con la ocupación de este espacio doméstico, y que marca el final de la ocupación orientalizante de este sector (González Prats, 1979: 25, 116-119) (35. $^{35}$ Con este mismo contexto de ocupación final del barrio se relaciona una ocultación, el denominado "Tesorillo de Peña Negra", en el interior de una acumulación intencionada de piedras adosada al muro exterior de una de las viviendas. Se trata de un conjunto de objetos suntuarios, que incluye fragmentos de una diadema y un anillo de oro, collares o gargantillas de plata con sus colgantes, un fragmento de torta de plata en bruto, algunas cuentas cilíndricas de vidrio amarillo y un conjunto de escarabeos y una figurilla de halcón de pasta (González Prats 1976-78; Id., 1979: 151-162, fig. 104106; Id., 1983: 179). El conjunto está integrado por objetos cuya fabricación puede situarse hacia finales del s. VII e inicios del VI a.C, como los escarabeos o la diadema y las gargantillas de plata (González Prats, 1983: 261; Padró, 1996). Sobre la fecha de la ocultación, González Prats (1976-78: 359) planteó inicialmente que sería posterior al abandono del poblado, que en un primer momento fechaba hacia el último cuarto del s. VI a.C., aunque el hallazgo en el Sector VII de un troquel de bronce con un motivo similar a uno de los que decoran la diadema áurea le llevaría a plantear la existencia de un taller de orfebre en Peña Negra que estaría fabricando joyas a finales del s. VII o inicios del VI a.C. (González Prats, 1983: 261). Para el autor, el final de la floreciente ciudad habría de situarse hacia el 550-535 a.C., cuando se documentan ocultaciones de

Castellar de Librilla (Ros Sala, 1989: 150).

35 Este nivel I en el exterior del Corte 4N, se asocia a un conjunto de cerámicas a torno (ánforas de importación, cuencos reentrantes y de borde con ala, dos posibles jarros y un soporte anular en cerámica gris), siendo los grupos predominantes la cerámica gris y la naranja de producción local, aunque se constatara la presencia residual de cerámica fina a mano y grosera (tres cazuelitas carenadas de cerámica bruñida, que en algún caso presenta decoración incisa y con incrustaciones y ollas de borde recto) (González Prats, 1979: 25, 116-119). En general, remite de nuevo al horizonte Librilla IV (Ros Sala, 1989: 347, 351-356). 
piezas valiosas, además de saqueos y destrucciones de las casas (González Prats, 1983: 277) ${ }^{36}$.

Durante las prospecciones realizadas en 2014 en la parte meridional de dicho Sector IA se localizó un nuevo ejemplar de punta de flecha (PN14) inmediatamente al oeste del Corte $3 a$, en un área contigua "que en su mayor parte está afectado superficialmente por la tierra de labor de uno de los bancales que aquí comienza", destruyendo mayoritariamente las evidencias de ocupación del Nivel 1 asociado a esta fase identificadas dentro de dicho corte, limitadas a la presencia de fusayolas, cerámica a torno pintada y ollas realizadas a mano, entre otros objetos (González Prats, 1979: 18) (Fig. 20, B).

Otra zona con una elevada concentración de puntas de flecha es el denominado Sector VII (Figs. 19 y 20, C y D), situado en la vaguada y en la terraza inferior de la vertiente septentrional de la Peña Negra. González Prats (1993: 184) identifica en esta zona la existencia de un "barrio artesanal" vinculado con población fenicia, que en su última fase de ocupación presenta de nuevo un urbanismo de casas o espacios organizados en torno a un muro de aterrazamiento (Cortes A'1-A'6), y un pequeño área al sur (Corte B'10) con casas y almacenes de planta cuadrangular, dispuestos de forma aislada, un modelo urbanístico identificado en el Sector IA (González Prats y Ruiz Segura, 1990-91; González Prats, 1982b; Id., 1989).

Así, en la zona más septentrional (Cortes A'1-B1), se localizó una concentración de puntas de flecha con evidentes marcas de impacto (PN3, PN4, PN5), vincu-

36 Posteriormente, propondría el final del asentamiento hacia finales del s. VII o el primer cuarto del s. VI a.C. (González Prats 1993: 187). Este abandono ha querido verse reflejado en la secuencia de la cercana ciudad fenicia de La Fonteta, planteando que "se produce un aumento significativo de cerámica a mano a principios del s. VI en la colonia fenicia (Fonteta VI) que curiosamente coincide con el momento en que PN II perece de modo violento" (vid. González Prats, 2011 y 2014b: 8).

37 Respecto a la cerámica de dicho estrato Ic-Id, mayoritariamente está realizada a torno $(80 \%)$ frente a una reducción clara de la producción a mano $(20 \%)$. La cerámica a mano está principalmente caracterizada por ollas de borde reentrante o rectas, aunque destacan algunos ejemplares de cerámica cuidada, como una botellita con decoración de nervios, que ha sido vinculada a producciones tartésicas (González Prats, 1982b: 325-326), la presencia de un soporte bitroncocónico moldurado, o la singular copa bruñida con decoración geométrica realizada en pintura amarilla (González Prats, 1982b: 326 ss.), técnica decorativa también presente en contextos de cronología avanzada orientalizantes en yacimientos próximos (González Prats, 1982b: 326), como refleja El Castellar de Librilla, Fase IV-V, identificados como perduraciones que pudieran llegar hasta "la primera mitad del s. VI a.C." (Ros Sala, 1989: 372). Vid. la discusión sobre este tipo decorativo en Ros Sala (1989: 372 ss.). Respecto a la cerámica a torno destaca la presencia de ánforas odriformes con marcas postcocción, el predominio de la cerámica gris, principalmente platos de borde reentrante y de borde saliente en forma de ala (González Prats, 1982b: 333), así como jarros de cuello exvasado y perfil bicónico y soportes anulares (González ladas al nivel final de ocupación de un amplio espacio o taller artesanal. En el estrato Ic-Id, nivel anaranjado pálido con bolsadas cenicientas dispersas por todo el área, situado bajo el derrumbe de tapial amarillento de las paredes de la estancia, se localizó el ejemplar PN5, próximo a unas escaleras, mientras que los ejemplares PN3 y PN4 aparecieron algo más alejados. El repertorio material asociado al estrato Ic-Id ha sido relacionada con la Fase PNIIB, para la que se propuso en su momento una cronología en torno al 600-550 a.C. (González Prats, 1983: 182; Id., 1999: 324-326, 333-340, 365$368)^{37}$ (vid. supra, para la discusión cronológica). Destaca la presencia en las inmediaciones de esta zona artesanal central de una nueva ocultación metálica, en este caso un broche de placa romboidal con decoración a molde, que conservaba parte de su correaje, todo ello de bronce, que se ocultó con sumo cuidado en un hoyo, al exterior de la vivienda-taller, al sur del Corte B1' (González Prats, 1999: fig. 31: 371). Esta ocultación, junto con la del Sector IA, se ha interpretado como indicio de la existencia de "un peligro que se cernía sobre los habitantes, al menos de este sector de la ciudad" (González Prats, 1982b: 370).

Por su parte, en el interior del departamento angular localizado en el área suroccidental del Sector VII, Corte A'5, se localizó otra concentración de puntas de flecha en el nivel de ocupación más reciente, fechado en torno a fines del s. VII o principios del s. VI a.C. (González Prats y Ruiz, 1990-91: 53, 58, 65, fig. 14; González Prats, 1999: fig. 18-19, 23, 25-26, 30-31) ${ }^{38}$, Estrato Ib3,

Prats, 1982b: 333-340). También, entre la cerámica clara, tinajas de asas geminadas y urnas tipo Cruz del Negro, algunas de importación como el ejemplar 5414 (González Prats, 1982b: 356-357, fig. 356. 5414), grandes vasos de perfiles muy exvasados y de imitaciones de píxides griegas (González Prats, 1982b: 359 ss.), que nos remiten de nuevo a un horizonte de mediados del s. VI a.C. Así mismo los hallazgos metálicos en este estrato Ic-Id del Corte B1 (González Prats, 1982b: 365 ss.) apuntan a este mismo momento final, tanto los de bronce (fíbulas de doble resorte, troquel, braserillo o chatones con motivos zoomorfos), como los de hierro (cuchillo con encaje de madera o herrajes).

38 Respecto a la cerámica localizada en el estrato Ib3, el predominio del torno es mayoritario (58\%), frente a la presencia de cerámica a mano $(42 \%)$, principalmente ollas de borde reentrante o recto (González Prats, 1999: fig. 18 y 19). Dentro de la cerámica a torno destaca la producción local $(69 \%)$ frente a un $31 \%$ de ejemplares importados: numerosas ánforas odriformes, importadas y locales (González Prats, 1999: fig. 23 y 25), el predominio de la cerámica gris principalmente platos y escudillas de borde reentrante (González Prats, 1999: fig. 26), así como jarros ovoides y soportes anulares o bitroncocónicos y moldurados, una numerosa presencia de cerámica común con diversos tipos, algunos importados como el cuenco-trípode con borde triangular 10495 (González Prats, 1999: fig. 30), similar a los ejemplares de Librilla IV (Ros Sala, 1989: 262); tinajas E13 importadas con decoración pintada (González Prats, 1999: fig. 31), así como ampollas piriformes o jarritas y un conjunto de platos de barniz rojo con ala, tanto locales como importados (González Prats, 1999: fig. 30). 


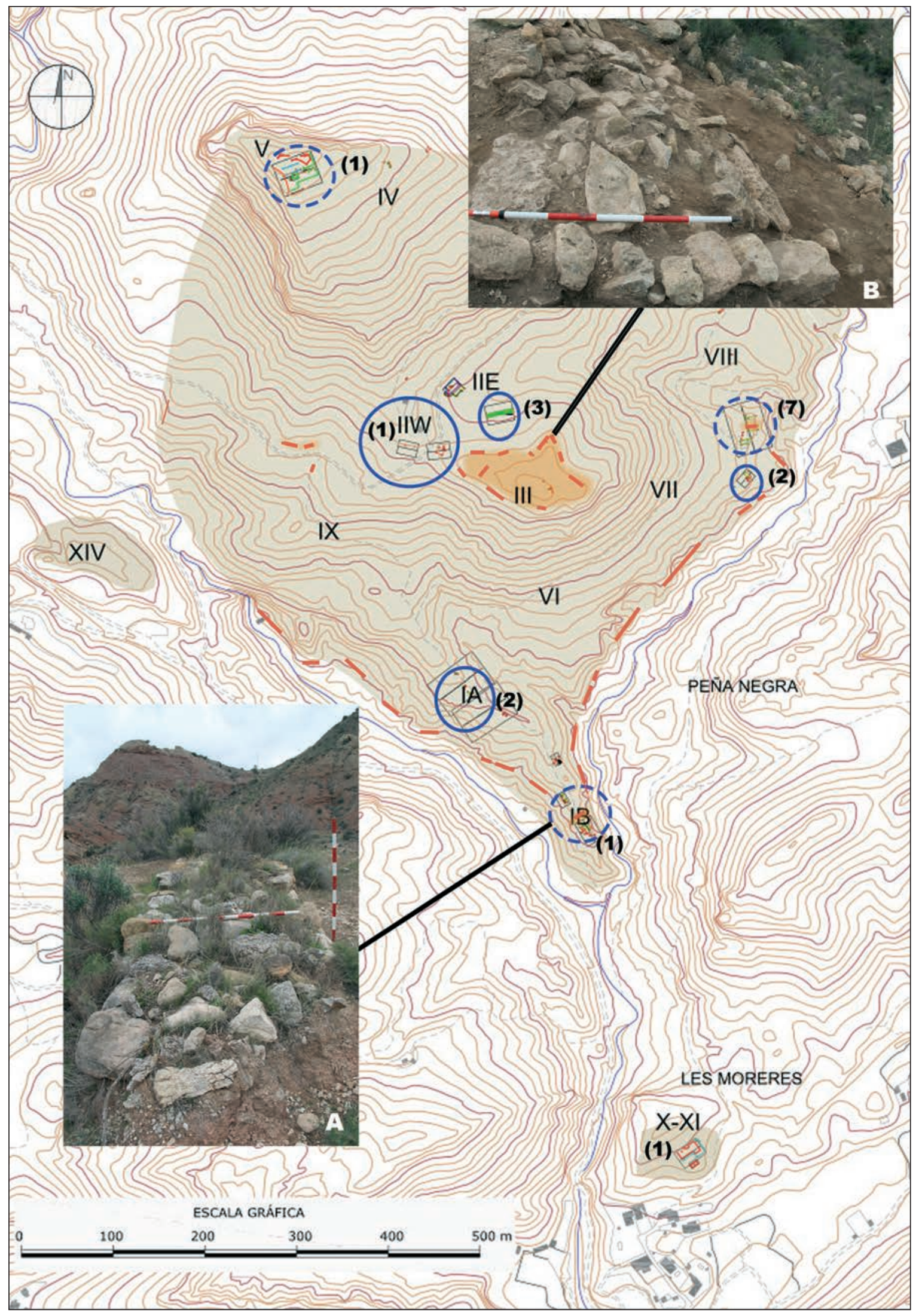

Fig. 19. Plano de Peña Negra con los sectores con localización conocida de puntas de flecha (entre paréntesis el $\mathrm{n}^{\circ}$ de unidades). La línea discontinua marca el teórico perímetro amurallado del lado sur y otras zonas amuralladas, con indicación de los sectores con estructuras defensivas que han proporcionado puntas de flecha (óvalo discontinuo). Los barrios o áreas de hábitat con hallazgos de puntas están indicados mediante óvalos cerrados. A. Vista del tramo de muralla perimetral del Sector IB; B, Vista de la muralla del Sector III descubierta en 2015. Fotografías: A. Lorrio. Topografía: I. Segura. 
inmediatamente debajo de derrumbe del alzado de adobes de las paredes de la casa (Estrato Ia2). Son tres ejemplares (PN6, PN8 y PN9) que muestran gran variabilidad (tipo 12a, 13a y 44a), todos ellos con arpón, uno con marcas de impacto (PN8) y otro con triple filo (PN9) (González Prats y Ruiz, 1990-91: 63, fig.14. 10564, 10566 y 10565; González Prats, 1999: fig. 35. 10564, 10566 y 10565). Además, cabe citar el ejemplar PN7 localizado al exterior de la casa, en el Corte A'3-4, en el pasillo que lo separa del gran espacio de almacén-taller, de nuevo en el nivel de derrumbe de estructuras superior, estrato Ia (González Prats y Ruiz, 1990-91: 52, 57, fig. 14.9966bis). Se ha planteado para esta zona de habitación una cronología entre mediados y finales del s. VII a.C., que plantearía un abandono parcial del área más meridional de esta zona del sector VII, cuya fase final se ha situado a principios del s. VI a.C. (González Prats y Ruiz, 1990-91: 55-57, fig. 2)

Por último, debemos destacar una concentración de hallazgos de puntas de flecha en la parte sur del Sector VII, en el Corte B'10, que comprende un área o "conjunto" de almacén con diversas estancias en esta zona artesanal más meridional del Sector VII y que "corresponden a un único momento de habitación” (González Prats y Ruiz, 1990-91: 58), posiblemente destinada a la producción cerámica y que ha sido fechado en la primera mitad del s. VI a.C., en una fase ligeramente más reciente que la estructura triangular identificada en el Cortes A'5.6 (González Prats y Ruiz, 1990-91: 72; González Prats, 1999: 324 ss.). Las puntas aparecen en dos zonas: en el interior del Departamento 1, área principal de almacén donde aparece el ejemplar PN10 (González Prats y Ruiz, 1990-91: fig. 14. 9481; González Prats, 1999: 324 ss. $)^{39}$ y en una zona exterior del Departamento 5, respectivamente. Al sur de este último departamento, en el Área 6, se localizó otro ejemplar de punta de flecha con el cañón roto (PN11) en el Estrato Ia, relacionado con el derrumbe de las paredes de tapial o adobe de dicho vivienda o Departamento 5 (González Prats, 1999). Ambos corresponden a ejemplares tipo 11b sin arpón (González Prats y Ruiz, 1990-1991: 73, fig. 14.9481 y 9654). La destrucción de este área de

39 La consideración de estar ante la zona principal del almacén cabe deducirse de la presencia de numerosas ánforas completas, algunas con marcas de alfarero, junto con tinajas anforoides, jarros grises y ollas globulares a mano, es decir, predominantemente grandes recipientes de almacenaje, así como en menor número, platillos de engobe rojo entre otros materiales (González Prats, 1999: 324 ss.).

40 Esta esta zona, las excavaciones exhumaron restos constructivos que permiten identificar un urbanismo de casas angulares, probablemente cuadrangulares e individualizadas o con alguna habitación adosada, semejante al identificado en el Sector IA de Peña Negra (González Prats, 1979), del cual las mejores evidencias se conservan en el Corte A (González almacén y dependencias anexas, presumiblemente vinculadas a un nuevo tramo del lienzo perimetral en esta zona meridional, dada la presencia de un "muro de mayor robustez, que emergía con una longitud de 2,60 m en sentido NW-SE" (González Prats y Ruiz, 1990-91: 57), se evidenció por el hundimiento del piso superior del almacén y por el derrumbe de las pared de las dependencias, aunque no fue interpretado en principio como evidencia de una destrucción violenta (González Prats y Ruiz, 1990-91: 58). Quizá la cercanía a un posible tramo del perímetro amurallado y la presencia de ambas puntas de flecha con huellas de impacto pueda hacer valorar la existencia de cierta inestabilidad, detectada en el extremo más meridional del Sector VII en torno a finales del s. VII y principios del VI a.C.

El tercer punto de concentración de puntas de flecha corresponde con la zona central del poblado o Sector II, con tres ejemplares (PN15, PN16 y PN17) localizados en su área oriental, Cortes A, B, C, D, que corresponde con un hábitat en terraza ${ }^{40}$ ubicado en la parte baja de la vertiente septentrional de la cima de la Peña Negra, donde en las campañas de 2014 y 2015 se ha identificado el recinto amurallado acropolitano. Según señala su excavador, esta zona del Sector II está muy afectada por el laboreo contemporáneo, que removió los niveles superiores de la estratigrafía, Ia y Ib (González Prats, 1985a: 65, 69), provocando el afloramiento de numerosas evidencias en superficie, como las puntas de flecha, recogidas a finales de los años 70 (González Prats, 1985a: 76), que podrían remitir a cronologías ya del s. VI a.C. ${ }^{41}$ Durante los trabajos de 2014 y 2015, se ha localizado un nuevo ejemplar de doble filo con arpón (PN13) en la vertiente occidental del sector, el Sector IIw, en el área más próxima al inicio del camino de El Castellar (vid. supra Catálogo ${ }^{42}$.

Por último, el cuarto punto de concentración de puntas de flecha es el que mejor disposición defensiva presenta dentro del complejo urbano de Peña Negra. Nos referimos a la cima amesetada de El Castellar Colorat, ubicada en el monte homónimo que protege en su flanco noroeste la ciudad. Se trata

Prats, 1985a: fig. 40.1), con una larga ocupación que alcanza el momento final del poblado.

41 Estos hallazgos superficiales fueron realizados antes de la excavación de los cortes en 1979, a los que se asocian varios ponderales de plomo, un fragmento de lingote de bronce y un fragmento de fíbula tipo Alcores (González Prats, 1985a: 76).

42 El estudio que hemos realizado ha permitido incorporar un notable conjunto de puntas inéditas, localizadas en recogidas de aficionados o en prospecciones que presentan huellas de impacto en muchos casos (PN18, PN20, PN21, PN22, PN23 y PN24). Si bien desconocemos la ubicación precisa de hallazgo o sector. 


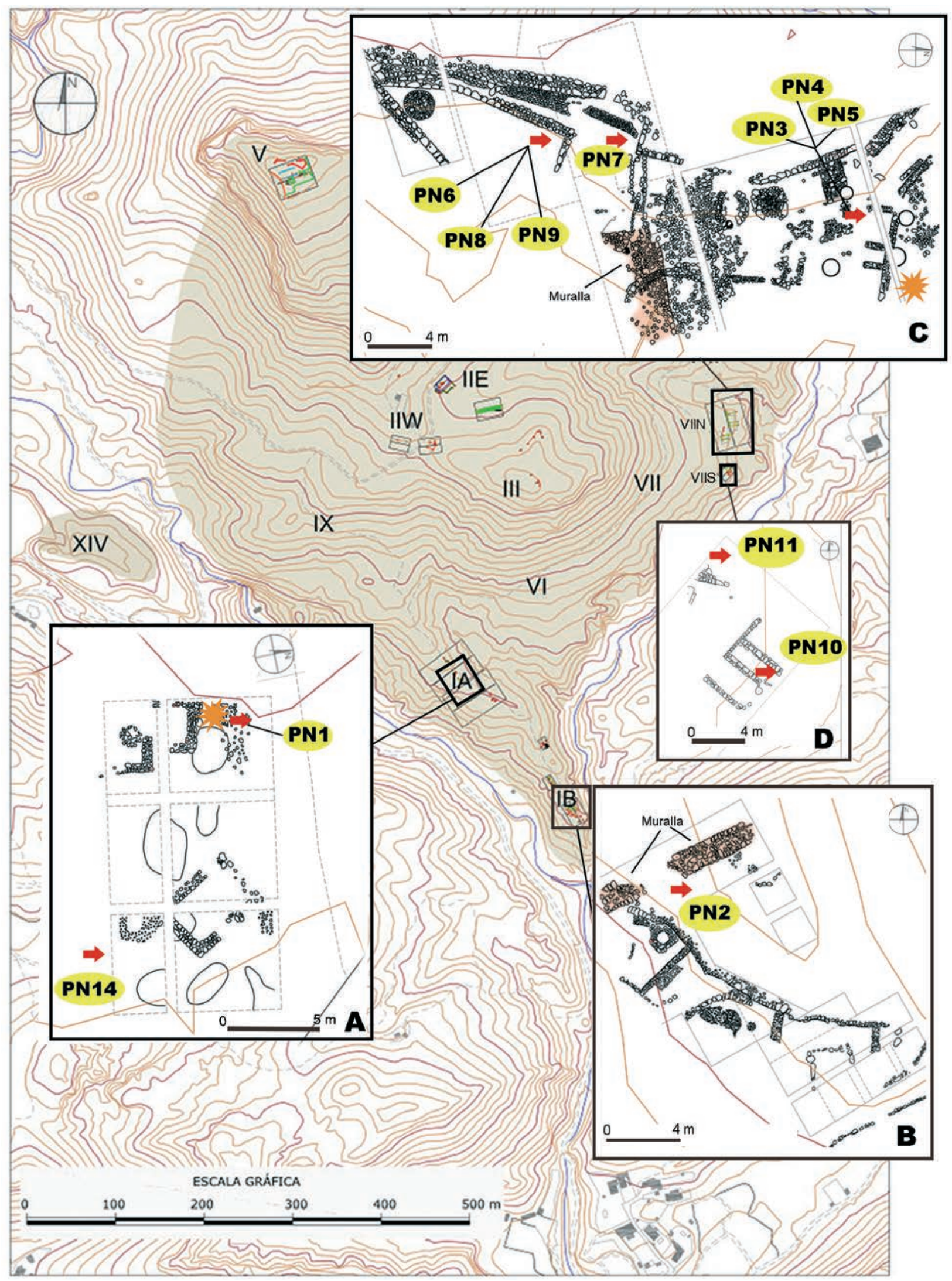

Fig. 20. Principales concentraciones de puntas con contexto estratigráfico en PNIIB. A. Sector IA con localización de puntas y del "tesorillo" en los Cortes 3-4 y 4N/4Na. B. Sector IB con el tramo de la muralla y la localización de la punta asociada. C. Zona septentrional del Sector VII con indicación de hallazgos junto a un tramo de muralla. D. Zona meridional del Sector VII, con almacenes exteriores e indicación de hallazgos. Flecha: puntas. Estrella: ocultaciones.

Según González Prats 1979 (A), 1985a (B), González Prats y Ruiz 1990-91, 1992 y 1999 (C y D). Topografía: I. Segura. 
de un lugar muy visitado, en cuya cima se realizaron excavaciones en 1982, en el denominado Corte Alpha, localizándose en el estrato superior, junto a materiales tanto de época ibérica como orientalizante, un ejemplar de doble filo (PN12) (González Prats, 1986: 231-237). La secuencia de ocupación del sector es muy amplia ${ }^{43}$ : evidencias de hábitat en época orientalizante, un área de ocupación de época ibérica asociada a una importante fortificación en forma de torre defensiva, reutilizada igualmente en época tardorrepublicana para erigir una nueva defensa (González Prats, 1983: 52; Id., 1986: 237; Moratalla, 2004: 148-152). La localización de la punta de flecha (PN12) asociada al estrato superior Ia, relacionado con la vivienda ibérica, ha servido para plantear una cronología tardía para este ejemplar (González Prats, 1986: Quesada, 1989), de finales del s. V a.C.- primera mitad del s. IV a.C. por la mayoritaria presencia de cerámica ibérica ${ }^{44}$, considerando esta punta como un ejemplo de perduración de este tipo de arma durante la Segunda Edad del Hierro (Quesada, 1997: 461-462; Id., 2011: 209). A pesar de que no podemos descartar dicha cronología para nuestro ejemplar, debemos señalar que se trata de estratos muy alterados, como demuestra la presencia de cerámicas a mano (ollas y cazuelitas) y de producciones a torno orientalizante, principalmente bordes de ánfora fenicia y un conjunto de platos orientalizantes grises de tipo B4-B5 (González Prats, 1986), que podrían estar indicando la existencia de niveles más antiguos, fechables los más recientes en torno al s. VI a.C., alterados y removidos por la construcción de la casa ibérica (estratos $\mathrm{Ia}$ y Ib).

Este repaso respecto a los contextos de hallazgo de las puntas de flecha de Peña Negra permite constatar su asociación tanto a niveles de ocupación, como de destrucción y desmantelamiento de las casas situadas en los diferentes sectores o barriadas de la ciudad entre finales del s. VII y mediados del s. VI a.C.

\subsection{La Fonteta}

Se trata de un asentamiento fenicio localizado en el potente entorno dunar conocido como "Las Dunas de Guardamar", en el margen derecho del río Segura,

43 Recientes hallazgos en la ladera de ascenso a la cima de El Castellar, identificada como Sector IV, ha permitido ampliar la secuencia cronológica de ocupación de esta área hasta época romana imperial (Lorrio y Pérez, 2015: 311-313).

44 Entre la cerámica ibérica mayoritaria en este estrato destaca la presencia de bordes de tonelete, un pitorro vertedor, un fragmento de imitación de una crátera de columnas y platos con borde en ala grises (González Prats, 1986).

45 En relación a su fortificación, las evidencias constructivas conocidas hacen referencia a un episodio de profunda remodelación urbanística en su fase más reciente, correspondiente a 'Fonteta Reciente' según la denominación de González Prats (2011), momento en el cual se procedieron a amorti- próximo a su actual desembocadura, aunque en origen ocuparía un pequeño promontorio o península costera junto al paleocauce, con destacadas condiciones como fondeadero o puerto a resguardo, en un paisaje dunar y costero rodeado de humedales muy diferente por tanto a la situación actual (Barrier y Montenat, 2007: 7 ss.) (Fig. 21, A-B). Presenta un carácter protourbano, excepcional dentro de las tierras del Sureste durante el periodo orientalizante, en gran medida debido a su condición de asentamiento fenicio, el único documentado en las costas levantinas. La presencia de La Fonteta explica la importancia del poblamiento orientalizante en el Bajo Vinalopó y Bajo Segura, donde destaca el núcleo urbano de Peña Negra, ya analizado, o el pequeño asentamiento de Los Saladares, en Orihuela. Surgido ex novo, estuvo en uso durante un dilatado espacio de tiempo, que se extiende entre mediados del s. VIII y mediados del s. VI a.C., según González Prats (1998: 202-203; 2011: 14-15), a quien se debe la excavación de la zona más extensa del yacimiento. Una cronología algo más moderna se ha propuesto por parte de Rouillard et al. (2007: 23-98), que fechan el asentamiento entre el último cuarto del s. VIII y finales del VI a.C.

En las intervenciones arqueológicas realizadas desde 1996 a 2002 por Alfredo González Prats (2011) se pudo identificar una primera fase denominada 'Fonteta Arcaica' (=Fonteta I-III), con evidencias muy mal conservadas de construcciones situadas en la parte más meridional, en la que se desarrolla un urbanismo de casas ortogonales pluricelulares de tapial (Corte 25) o con zócalos de mampostería, destacando la intensa actividad artesanal y metalúrgica (Cortes 7 , $8,5,14,5 \mathrm{~N}, 54$ y 1 ), sin que se hayan localizado hasta el momento evidencias de fortificaciones, aunque no deben descartarse. El poblado se caracteriza en su fase más reciente o 'Fonteta Reciente' por su sistema defensivo (Cortes 7, 8, 5, 14, 5N, 54 y 1), en el que destaca su potente muralla perimetral con bastiones adosados, foso y antemural ${ }^{45}$, construida en torno al 635 a.C. (González Prats, 2011) en lo que se denomi-

zar las zonas de producción metalúrgica de Fonteta Arcaica (I a III) a fin de proceder a la construcción de la muralla en torno a finales del s. VII a.C. (González Prats, 1998: 205; Id., 2010a: 68-69), aunque se ha señalado la existencia de remodelaciones en el sector más septentrional, quizá vinculadas al refuerzo de la estructura a partir de mediados del s. VI a.C. (Gailledrat, 2007: 71; Rouillard, 2010: 84). No se descarta la existencia de una muralla perimetral en su fase antigua que siguiese una orientación diferente a la construida con posterioridad, lo que parece lógico si tenemos en cuenta la elevada cronología propuesta para la fortificación del Cabezo Pequeño del Estaño (García Menárguez y Prados, 2014: 126-127), un establecimiento en relación directa con La Fonteta durante sus fases más antiguas. 

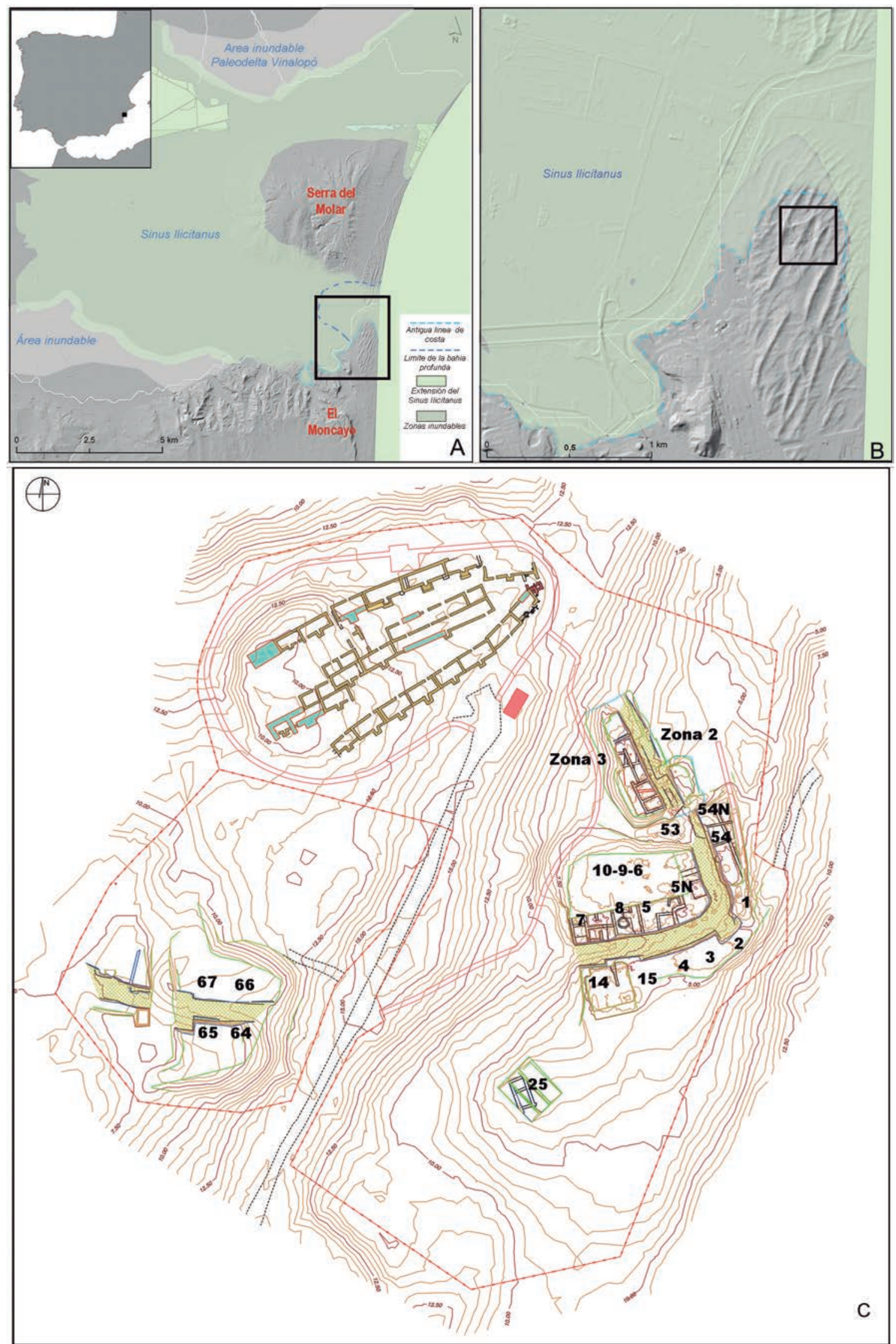

Fig. 21. La Fonteta. A-B. Localización del yacimiento en la desembocadura del río Segura, con la antigua línea de costa y reconstrucción del Sinus Ilicitanus. C. Conjunto arqueológico de Las Dunas de Guardamar, con las zonas de la ciudad protohistórica de La Fonteta objeto de excavación y su denominación. A-B. Cartografía: S. Pernas. C. Topografía: I. Segura. 
na como Fonteta $\mathrm{IV}^{46}$, vinculada a diversas fases de hábitat de viviendas pluricelulares adosadas al paramento interno de la muralla (Fonteta V y VI). Esta secuencia es completada por los resultados de los trabajos realizados en el sector más septentrional del recinto amurallado, o Zona 2-3, por el equipo hispano-francés dirigido por P. Rouillard (Rouillard et al., 2007).

Las puntas de flecha de La Fonteta, todas de bronce o aleación de cobre, provienen de diferentes contextos estratigráficos localizados a lo largo del recinto amurallado de la ciudad, siempre en sus áreas aledañas, aunque no existan excavaciones en otros sectores de la ciudad, lo que relativiza la importancia de este dato (Le Meaux y Sánchez de Prado, 2007: 325 ss.; González Prats, 2014a: 272-275) (Fig. 22). Al menos 9 ejemplares (F1 a F4 y F6 a F10) se asocian a las fases más modernas de la ocupación de 'Fonteta Reciente', en concreto a Fonteta VI. Hacia el segundo cuarto o mediados del s. VI a.C., dependiendo de la propuesta de uno u otro equipo (González Prats, 2011: 14-15; Rouillard et al., 2007 : 23-98), se documenta el desmantelamiento de algunos espacios de hábitat adosados al recinto defensivo, que se transforman en zonas de circulación abiertas, y el desarrollo de otros, así como áreas de vertedero, con evidencias de actividades artesanales (Fonteta VI) ${ }^{47}$, que evidencia una etapa de notoria actividad artesanal o productiva, tras la cual se desarrollan las últimas fases de ocupación de la ciudad (Fonteta VII y VIII) ${ }^{48}$, previas al abandono del lugar y al desmoronamiento de las edificaciones, identificado por potentes derrumbes de la muralla (Fonteta IX). Es en esta fase de reestructuración de la ciudad de Fonteta VI (González Prats, 2011: 14) donde se localiza la mayor concentración de puntas de flecha de doble filo, con evidencias de impacto y rotura en casi todos sus casos (F6 a F10), asociadas a los niveles superiores de los amplios vertederos que identifican la intensa actividad productiva de la ciudad en Fonteta VI, fechada en torno al 580-560 a.C. (González Prats, 2011: 3-4). Por lo que se refiere a la cronología de los

46 En la construcción de este complejo defensivo en la fase Fonteta IV se incluiría un sistema de cajones según propone González Prats (2010a: 69) para la construcción del lienzo de muralla (acerca del uso de los términos "casamatas" y "cajones", vid. Montanero 2008: 96). No obstante, esta identificación de la técnica de cajones para la muralla ha sido discutida (Gailledrat, 2007: 126-127). Destaca además la existencia de tirantes de refuerzo interno de los tramos de muralla interpretados como evidencias de soluciones técnicas frente a peligros sísmicos (González Prats, 1998; 193-194), en un primer momento, que sería paulatinamente modificado, con la incorporación de un barrio de viviendas adosadas al recinto amurallado (Fonteta V).

47 Con ella se relaciona una vivienda con robustos zócalos de piedra en el sector meridional interpretada como un cobertizo (González Prats, 2011: 49-51). ejemplares F1 a F4, debe tenerse en consideración que fueron recuperados en la zona más septentrional del recinto amurallado identificado como Zona 3, en la fase Fonteta $\mathrm{Vb}$, para la que se ha propuesto una fecha de finales del s. VI a.C. (Gailledrat, 2007: 89), más reciente que la establecida por González Prats para niveles equivalentes, unos desajustes que no solo remiten a la cronología y a las fases de ocupación, sino también a la propia interpretación del yacimiento (Figs. 21 y 22).

Un conjunto de 4 ejemplares, todos asimilados al tipo 11a, se recuperaron en la denominada Zona 3 (Sondeo Sur), a intramuros del tramo de muralla más noroccidental de todos los excavados, donde se localizó un espacio artesanal perteneciente a la última fase de ocupación del poblado, situado en concreto en el Espacio A (Azuar et al., 1998:121-122; Gailledrat, 2007: 89-90). En uno de los vertederos próximos a la muralla en su estrato superior (UE 3088$)^{49}$ se localizaron estas 4 puntas de fechas (F1 a F4). Este estrato es adscrito por sus excavadores a su Fase Vb ca. 525/500 a.C. (Gailledrat, 2007: 89-90), a la que se asocian abundantes materiales que incluyen algunos objetos metálicos, como un cuchillo de hierro y fíbulas de los tipos Alcores y Golfo de León (Le Meaux y Sánchez de Prado, 2007: 325), lo que plantearía una datación de finales del s. VI a.C. para esta fase, aunque para González Prats (2011: 14-15) la ocupación final del asentamiento fenicio según los datos del sector meridional sería ligeramente anterior, en torno a mediados del s. VI a.C. Esta concentración de puntas queda sepultada por los niveles de abandono (UE 3087), destrucción y derrumbe de la muralla en su tramo septentrional (UE 3068), lo que permite asociar la presencia de las puntas de flecha a la fase final de la ciudad fenicia (Fig. 23).

Una segunda zona de alta concentración de hallazgos, con 6 ejemplares de doble filo (F5, F7, F8, F9, F10) y una de cuádruple filo (F6), se localiza a intramuros del recinto defensivo más meridional en su ángulo Sureste (Cortes 5N, 5, 7 y 8), mayoritariamen-

48 Identificadas por pequeñas instalaciones artesanales, como cobertizos, hornos o áreas de trabajo al aire libre tanto en el sector meridional como en el sector nororiental (González Prats, 2011: 49-50; Gailledrat, 2007: 89-90)

49 Según los datos publicados (Gailledrat, 2007: 89-90), este estrato 3088 corresponde con la capa superior del vertedero localizado en el área artesanal al aire libre o Espacio A, a cuyas tierras cenicientas y grisáceas propias de un nivel de vertido se asocian también arcillas amarronadas heterogéneas, y que por tanto marcaría el final de la ocupación del sector. Bajo dicho estrato se situaría una primera capa de vertido (UE 3094) de intenso color gris por la abundante presencia de cenizas y carbones la cual sí cubriría directamente el nivel de circulación o suelo arcilloso (UE 3105) de este espacio abierto asimilado con la Fase Vb de la secuencia del sector septentrional intramuros (Gailledrat, 2007: 88). 


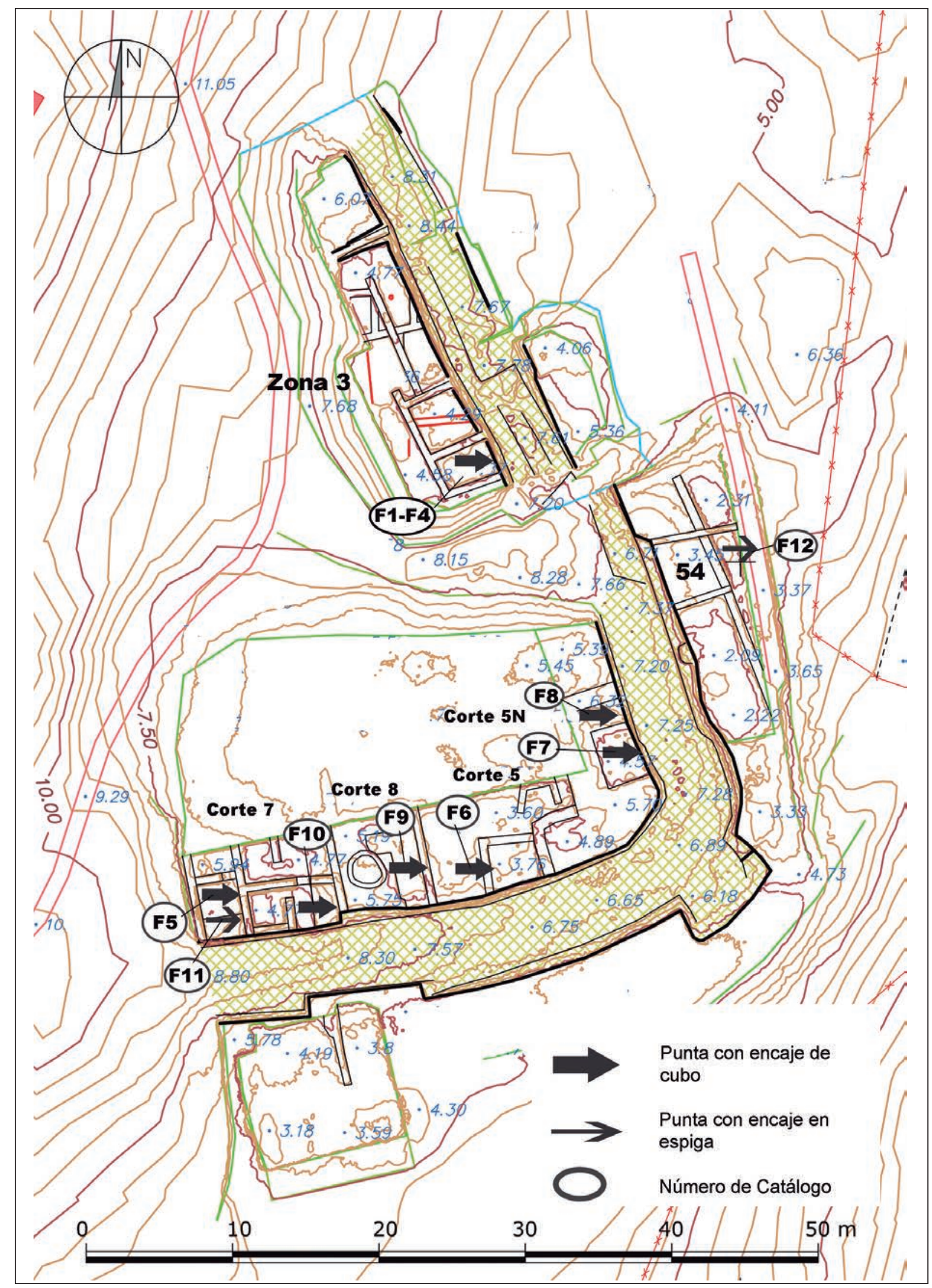

Fig. 22. Puntas de flecha en contextos estratigráficos en torno al recinto defensivo de Fonteta. Sector norte: Zona 3. Capa superior de vertedero intramuros (UE 3088). Sector sur: Corte 54. Nivel de asiento del antemural extramuros (54 A4ab); Corte 5N. Colmatación de la torre interior junto al Bastión SE (5N A3); Corte 5C. Cobertizo artesanal asociado a vertedero (5 C A3); Corte 8. Vertedero bajo derrumbe de muralla (8-BC- A3bc); Corte 7. Depósito que colmata la vivienda (7-E B6 y Corte 7-C-A4). A partir de González Prats 2011 y Rouillard et al., 2007. Topografía: I. Segura. 
te asociados a la fase Fonteta VI. En esta fase se registran potentes depósitos de vertedero (estrato A3) en los espacios abiertos más septentrionales, donde se localiza algún ejemplar en sus capas superiores $5 \mathrm{~N}$ A3VIb (F8) (González Prats, 2011: 23-24, 55), o que cubren los niveles de destrucción de las viviendas más antiguas, tal y como se identifica en el caso del bastión intramuros de Fonteta $\mathrm{V}$, que queda colmatado en esta fase por un nivel de vertido donde se localizó el ejemplar F7. En el frente interior meridional de la muralla, se documentan espacios artesanales a modo de cobertizos aislados realizados con muros de mampostería y espacios abiertos de intensa estratificación de vertidos artesanales, que incluyen un rico y variado repertorio material entre los que destaca el hallazgo de un ejemplar de punta de flecha de triple filo (F6). En su sector más oriental, estos vertidos cubren y colmatan las anteriores viviendas adosadas al lienzo interno de la muralla en el sector oriental, localizándose nuevos ejemplares de puntas de flecha (F9 y F10) siempre en las capas superiores del vertedero identificado como Fonteta VIb (González Prats, 1998; Id., 2011: 14-15, 30, 49, 55, Fig. 14; Id., 2014a: 272, núm. 4311, 21143, 25003, 25011) (Figs. 21 y 22 ).

Se conoce un único ejemplar de doble filo (F5) procedente de Fonteta V, en la zona intramuros del Corte 7C, en los niveles de relleno (estrato A4ab) de las viviendas adosadas a la muralla (Fonteta IV) (González Prats, 2011: 31-32; Id., 2014a: 272, 420425), fechables entre fines del s. VII y el primer cuarto del s. VI a.C. (González Prats, 2011: 14-15; Id., 2014a: 272).

Así mismo, debe mencionarse el hallazgo de 2 ejemplares de puntas de flecha con encajes macizos (F11 y F12) (González Prats, 2014a: 272), minoritarios por tanto respecto a las piezas que analizamos. Es de destacar la recuperación de un ejemplar en el citado Corte 7C (F11), en este caso en relación con la fase de colmatación de las viviendas y áreas artesanales de Fonteta III, y por tanto relacionado con el momento previo a la erección de la muralla (Fonteta IV) (González Prats, 2011: 34; Id., 2014a: 272, 420-425). El hallazgo se localizó en los niveles asociados a la rápida colmatación de las casas o dependencias de Fonteta III (estrato 7C11b), en el estrato que colmata los niveles uso y pavimento de dichas edificaciones previas a la construcción del recinto amurallado, que se han interpretado como un taller metalúrgico (González Prats, 2011: 34-35). De la zona extramuros, junto al antemural (Corte 54) procede una punta de flecha de hoja triangular con aletas y corto pedúnculo macizo engrosado (F12) (González Prats, 2011: 64, fig. 33; Id., 2014a: 272, núm. 42043) (Fig. 22). Su posición estratigráfica y contextual, plantea interesantes reflexiones, ya que procede de los niveles de asiento de la muralla de Fonteta IV y de su antemural exterior que "se asienta sobre la misma capa que la muralla (estratos A4a y b)", pudiendo por tanto relacionarse con la fase de construcción de la fortificación, en concreto de su refuerzo defensivo externo o antemural (González Prats, 2011: 64, fig. 33; Id., 2014a: 272, núm. 42043).

En resumen, se observa una mayor concentración de puntas de flecha de cañón tubular y arpón en los contextos más recientes del poblado, fechados hacia el segundo o el tercer cuarto del s. VI a.C., que identifican contextos de vertido o acumulación de detritus, asociados a la intensa fase de actividad artesanal en la colonia realizada en este momento (Fonteta VI, ca. 580-560 a.C.). Cabe destacar que en todos los casos se sitúan en los niveles superiores correspon-

\begin{tabular}{|c|c|c|c|c|c|c|}
\hline Etapa & Fase & Puntas & Cronología & Sector & UE & Interpretación \\
\hline \multirow{7}{*}{ 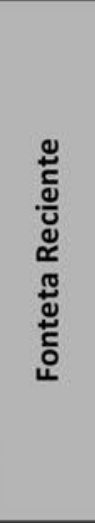 } & Fonteta $\mathbf{V b} * *$ & $\begin{array}{l}\text { F1, F2, } \\
\text { F3, F4 }\end{array}$ & $2^{\mathrm{a}}$ mitad s.VIa.C.** & Zona 3 & 3088 & Nivel de relleno \\
\hline & \multirow[t]{4}{*}{ Fonteta VIb } & F6 & \multirow{4}{*}{$\begin{array}{l}1 \mathrm{a} 1 / 2 \mathrm{s.VI} \text { a.C.* } \\
580-560 \text { a. C. }\end{array}$} & $5 \mathrm{C}$ & A3 & Vertedero meridional \\
\hline & & F7, F8 & & $5 \mathrm{~N}$ & A3 & $\begin{array}{c}\text { Vertedero colmata antigua } \\
\text { torre intramuros }\end{array}$ \\
\hline & & F9 & & $8 \mathrm{BC}$ & A3abc & Áreas de taller y vertedero \\
\hline & & F10 & & $7 E$ & B6 & Áreas de taller y vertedero \\
\hline & Fonteta V & F5 & $\begin{array}{c}\text { Fines s. VII- Prin. s. VI } \\
\text { a.C. }{ }^{*} \\
\text { 625-580 a. C. }\end{array}$ & $7 \mathrm{C}$ & A4 & $\begin{array}{l}\text { Nivel de uso de viviendas } \\
\text { adosadas a muralla }\end{array}$ \\
\hline & Fonteta IV & F12 & $\begin{array}{l}\text { Fines s. VII * } \\
635-625 \text { a.C. }\end{array}$ & 54 & A4ab & $\begin{array}{l}\text { Nivel de asiento de la } \\
\text { muralla y antemural }\end{array}$ \\
\hline $\mathrm{FA}^{+}$ & Fonteta III & F11 & $\begin{array}{l}\text { s. VII a.C. }{ }^{*} \\
670-635 \text { a.C. }\end{array}$ & 7C & B11b & $\begin{array}{l}\text { Colmatación viviendas o } \\
\text { talleres metalúrgicos }\end{array}$ \\
\hline
\end{tabular}

Fig. 23. Correspondencia estratigráfica de las puntas de flecha de Fonteta. Códigos: ${ }^{+}$Fonteta Arcaica. *González Prats (2011) -F5-F11-. **Rouillard et al. (2007) -F1-F4-. 
dientes a la fase más reciente de vertedero, asimilada a la Fase Fonteta VIb por González Prats (2011: 14). Esta ocupación es inmediatamente anterior a las últimas fases de ocupación del poblado (Fonteta VIIVIII), que cabe situar a partir de mediados del s. VI a.C., previas al abandono definitivo del mismo identificado como Fonteta IX (González Prats, 2011: 1415), donde se localiza una última concentración en el sector intramuros septentrional o Zona 3, en su fase Vb datada entre 550-525 a.C. (Gailledrat, 2007: 89) . $^{50}$. Otro elemento de interés a señalar es la documentación de ejemplares tanto de encaje tubular como macizo en otras fases relacionadas de manera directa o indirecta con la construcción y uso de la muralla y su aparato defensivo, que se enmarcarían en un cuadro cronológico entre 635 a 580 a.C. principalmente (González Prats, 2011: 14), así como de otros relacionados durante Fonteta Arcaica con las áreas artesanales de Fonteta III (González Prats, 2011: 34-35) (Fig. 23). Esta lectura estratigráfica de los contextos de La Fonteta asociados a la presencia de puntas de flecha orientalizantes podría reflejar la existencia de episodios de inestabilidad desde finales del s. VII y el s. VI a.C. en el área del entorno de la desembocadura del Segura (vid. infra).

\subsection{El Castellar de Meca}

El Castellar de Meca está situado a 1.046,3 m s.n.m. y ocupa el espolón más occidental de la Sierra del Mugrón (Fig. 24, A-B), un afloramiento rocoso caracterizado por ofrecer una superficie amesetada rodeada por fuertes desniveles que pueden llegar a los $150 \mathrm{~m}$ en la vertiente este y entre 50 a 100 en la oeste (Broncano, 1986: 15 s.). Desde su cumbre se domina un extenso territorio, en los confines de la Meseta y el interior valenciano. Presenta una superficie de unas 15 ha y una forma alargada irregular (Fig. 24, C).

Sus elementos más peculiares son la topografía y el emplazamiento del poblado, su red de caminos, una arquitectura rupestre caracterizada por la presencia de numerosos aljibes y depósitos de almacenaje, y sus fortificaciones, que de forma global corresponden a época ibérica, entre los s. IV y finales del III-inicios del II a.C., momento en que los excavadores sitúan el final violento de la ciudad prerromana (Broncano y Alfaro 1997: 197), aunque algunas de las estructuras pudieran ser algo posteriores (Moret, 1996: 457;

50 Vid. supra la discusión sobre la divergencia cronológica entre la secuencia o fasificación en el área septentrional y la meridional del recinto amurallado planteadas por los diferentes equipos de excavación.

51 Se documentaron escasos fragmentos cerámicos de la Edad del Bronce procedentes de la zona del 'Camino Hondo' y de
Lorrio, 2011: 106-109). El lugar presenta una amplísima secuencia cultural, que se remonta a la Edad del Bronce extendiéndose a lo largo del primer milenio antes de la era ${ }^{51}$, con una ocupación posterior de época romana y otra, más destacada, medieval islámica (Broncano 1986: 159, fig. 118-119).

A pesar de que los restos visibles son principalmente ibéricos, tras las limpiezas efectuadas en la zona del 'Camino Hondo', como popularmente se conoce a la parte final del camino que sube desde el llano o base del cerro, una vez atravesada la puerta principal y antes de alcanzar la zona superior de la meseta (Broncano 1986: 147-149, fig. 110), fueron identificadas ánforas de tipo fenicio (Lorrio, 2011: 108 , figura $2, \mathrm{C}, 1)$, lo que permitiría elevar la cronología inicial del asentamiento al s. VII a.C. (Soria 2000: 525), más adecuada que otras propuestas que situaban su inicio en el s. VIII (Broncano 1986: 140; Broncano y Alfaro 1990: 211-212) o en el VI a.C. (Broncano y Alfaro 1997: 197).

A estos materiales habría que añadir seis ánforas de tipo Ramon 10.1.2.1, un pithos y un cuenco trípode conservados en el Museo de Prehistoria de Valencia (Pla y Bonet 1991: 248, 252 nota 30; VivesFerrándiz 2005: 119, fig. 60-61) y otro trípode conservado en el Museu Arqueològic d'Ontinyent y la Vall d'Albaida (Vives-Ferrándiz 2005: 119, fig. 61). En su conjunto, la presencia de trípodes con una banda pintada por el interior (Broncano 1986: fig. 110:1-2), el tipo de decoración de uno de los pithoi (Ibid.: fig. 110:5), y el perfil del cuello de todos ellos (Broncano 1986: fig. 110:1-2; Vives-Ferrándiz 2005: fig. 60:7-8) sugieren una cronología dentro del s. VI a.C. o, como mucho, muy finales del VII, momento con el que cabe relacionar alguna pieza aislada, como una fíbula de doble resorte (Pla, 1973: 84 s.). Este podría ser igualmente el caso de las puntas que analizamos.

El estudio de los modelos de poblamiento orientalizante en las tierras de la Submeseta Sur, entre las que se incluyen la zona de Chinchilla, Almansa y áreas aledañas donde se ubica el poblado de El Castellar de Meca, han sido objeto de recientes revisiones (Zarzalejos y López Precioso, 2005: 813 ss.), planteando una diferenciación clara respecto al Sureste y el área alicantina y una preeminencia de su carácter estratégico dentro de las principales redes y

las inmediaciones de la poterna este que comunica el oppidum con el Mugrón, fuera ya de la ciudad (Broncano 1986: 147, fig. 109; Broncano y Alfaro 1997: 15), lo que plantearían un emplazamiento ligeramente diferente al ibérico, seguramente en la ladera media y baja del cerro. 

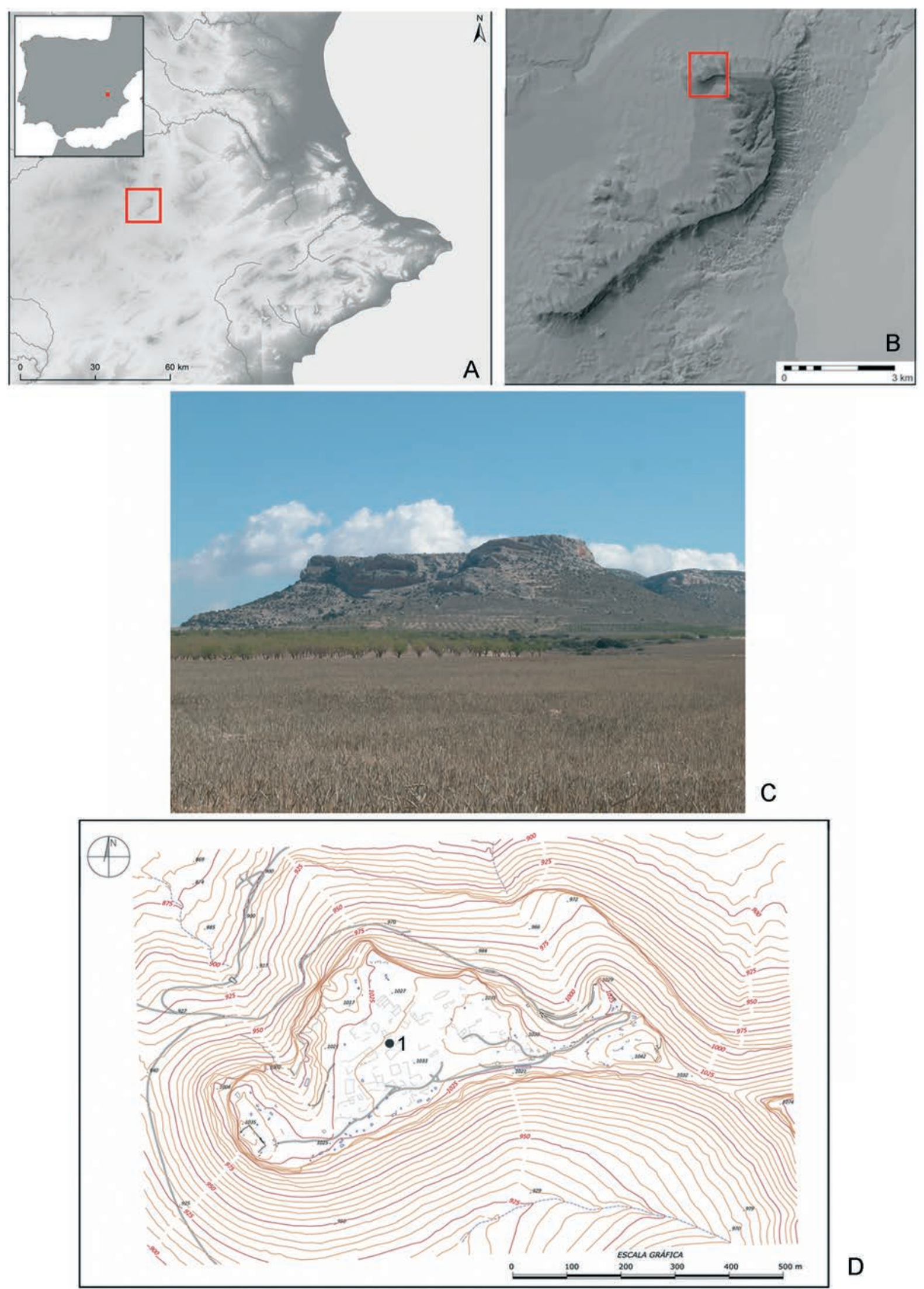

Fig. 24. El Castellar de Meca. A. Localización entre el altiplano manchego y el Valle de Ayora; B. Modelo de sombras y altimétrico del cerro del Mugrón y de su espolón noroccidental; C. vista del oppidum, desde el noroeste; D, plano del yacimiento con la zona de localización de las puntas de flecha (1). (A-B, Cartografía: S. Pernas; C, Fotografía: A. Lorrio; D, Topografía: I. Segura). 
vías de comunicación, que generaría una preferencia por la mononuclearización de centros poblacionales que vertebrarían un amplio territorio.

En el caso de El Castellar de Meca, parece claro su vínculo con un estratégico cruce de caminos interior-costa, que comunica a través del Valle de Fontanars hacia al Este con el núcleo poblacional orientalizante del Valle de Canyoles -en torno al Castillo de Xátiva (Pérez Ballester, 2014)- y la costa valenciana en el entorno de la desembocadura del río Serpis -con el núcleo orientalizante de La Vital (Vives-Ferrándiz y Mata, 2011)-. Hacia el norte, El Castellar conectaría con la cabecera del Valle de Ayora, camino hacia el interior de la Serranía de Cuenca, de fundamental importancia en las redes de comunicación Meseta-Levante, así como con el altiplano valenciano de Requena-Utiel -en el que destaca la presencia de importantes núcleos del Hierro Antiguo en torno al río Magro, como Los Villares (Mata, 1991), y en su acceso a la Serranía de Cuenca, El Molón (Lorrio, 2007)-, la comarca de Los Serranos y el Camp de Llíria -foco de importante poblamiento en torno al Tossal de Sant Miquel (Bonet, 1995)-. Hacia el Sur y Sureste, las tierras de Almansa lo conectarían con el principal corredor interior, puerta de acceso a la Alta Andalucía, el Levante y el Sureste Peninsular, ya sea hacia el Valle del Vinalopó -donde destaca la existencia de poblados orientalizantes a lo largo de este importante corredor como el Castellar de Villena, El Monastil o Camara en Elda-, o hacia el Campo de Hellín-Vega alta del Segura.

La importancia estratégica de El Castellar de Meca como núcleo poblacional destacado ya desde época orientalizante explicaría la concentración de puntas de flecha identificadas -la mayoría localizadas en la zona central sin contar con más información sobre su hallazgo (Figs. 1 y 24, D)-, indicio de su posible papel relevante como núcleo vertebrador de este eje de comunicaciones interior que sufriría en torno a mediados del s. VI a.C. procesos de inestabilidad que conllevarían quizás su temporal declive. Un hecho a destacar es la personalidad tipológica de los hallazgos de Meca, con puntas de largos cañones y hojas cortas, junto a tipos más canónicos, lo que pudiera explicarse por su relación con un taller local, no necesariamente ubicado en el asentamiento, sin

52 Queremos agradecer a D. Antonio García Menárguez las informaciones facilitadas sobre dicho ejemplar que fue objeto de estudio y publicación en los años 90 , conservándose documentación gráfica que permite identificar sus rasgos morfológicos (García Menárguez, 1992/1993: 79, lám. 2). Las posteriores excavaciones en el Castillo confirmaron que tampoco pueda descartarse su cronología más reciente, aunque en los contextos ibéricos cercanos (vid. infra) nunca se encuentran estas puntas en tan elevado número, sin olvidar que el conjunto más numeroso parece proceden de la parte alta del oppi$d u m$, una zona alejada de las potentes fortificaciones de época ibérica, cuyas excavaciones no proporcionaron ejemplar alguno de esta singular arma, quizás en relación con posibles obras defensivas antiguas, no documentadas hasta la fecha por falta de investigación en la plataforma superior del yacimiento.

\subsection{Otros hallazgos}

En este apartado recogemos otros ejemplares localizados en la zona de estudio, pertenecientes en general a hallazgos superficiales, por lo que carecemos de datos claros sobre su cronología. Su perduración en época ibérica es un hecho incuestionable (vid. infra), por lo que no puede descartarse una cronología más moderna para alguno de ellos (Figs. 25 y 26).

En relación muy posiblemente con los hallazgos de La Fonteta cabe referirse a un ejemplar de doble filo (tipo 11a), actualmente desaparecido ${ }^{52}$, y a otro de largo pedúnculo macizo (García Menárguez y Mas, 201: 260) similar al recuperado en Fonteta III (F11), piezas procedentes del Castillo de Guardamar (Guardamar del Segura, Alicante), para el que se ha propuesto un carácter sacro en época ibérica (Abad, 1992: 233; Id., 2010: 132, aunque el hallazgo de materiales del Hierro Antiguo (González Prats y García Menárguez, 2000: 1531-1532) (Menárguez, 2000: 1531-1532), haya llevado a sugerir su consideración ya desde el s. VIII a.C. como un santuario dedicado a Astarté (González Prats y Ruiz, 2000: 46; González Prats, 2010a: 74; Id. 2014a: 273). Estos hallazgos permiten aportar nuevas evidencias que nos remiten a una singular concentración de puntas de flecha en la desembocadura del río Segura, que podrían ser indicio sobre episodios de inestabilidad, de los que tenemos evidencias directas en el núcleo principal que vertebra el poblamiento en la zona.

Otros hallazgos singulares lo constituyen el ejemplar de doble filo con arpón, quizás también doble (tipo 11c), hallado en el poblado de El Monastil (Elda) (Fig. 26, A), por el momento la única punta de

la presencia de este primer horizonte del Hierro Antiguo, con la presencia de cerámicas fenicias junto a materiales indígenas (González Prats y García Menárguez 2000: 1552, fig. 2,14-16) 


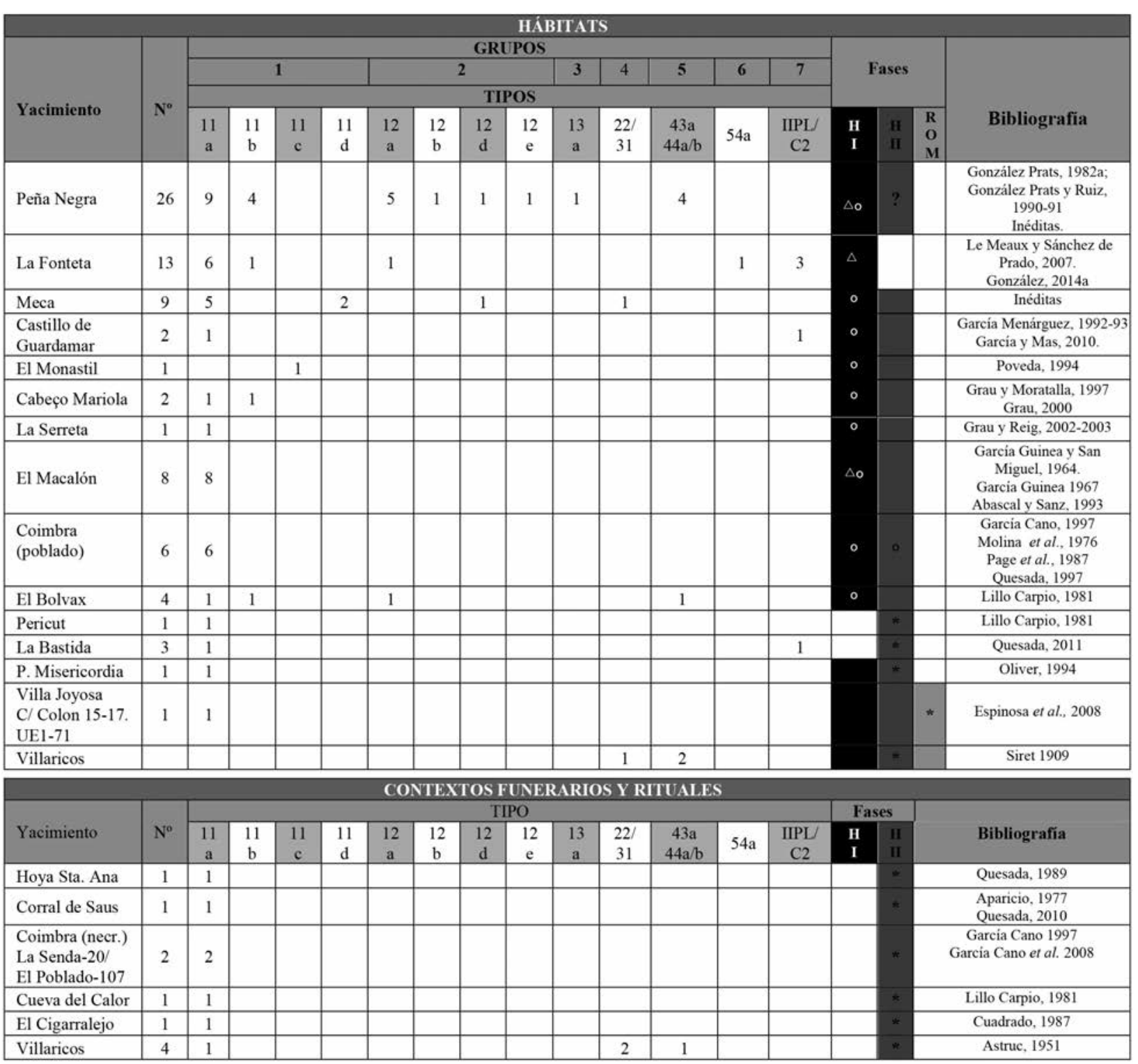

Fig. 25. Puntas de flecha de cubo realizadas en bronce y su tipología, localizadas en el entorno regional de estudio, durante la Edad del Hierro (Hierro I, contextos orientalizantes y coloniales; Hierro II, contextos ibéricos y púnicos; ROM, contextos romanos). ${ }^{r}$ Contextos de los s. VII-VI a.C. ${ }^{\circ}$ Hallazgos sin contexto, en asentamientos con presencia de materiales orientalizantes. ${ }^{*}$ Contextos de hallazgo del s. IV a.C. o posteriores.

esta naturaleza localizada con seguridad en el Valle Medio del Vinalopó, aunque existen noticias no confirmadas de la presencia de varios ejemplares en la Sierra del Tabaià, en Aspe (M. Hernández, comunicación personal), una zona caracterizada por sus estrechas relaciones con la ciudad de Herna/Peña Negra, como evidencian las marcas y grafitos en ánforas y platos de vajilla gris orientalizante, tanto importaciones como producciones locales, la presencia de lingo-

53 En el Valle de Elda, área de importante concentración poblacional orientalizante, además del mencionado poblado de El Monastil, que ocupa la ladera media baja de un cerro próximo al río Vinalopó, se localiza el poblado fortificado en altura de Camara, con igual presencia de grafitos y conco- tes de valor premonetal de cobre y cobre plomado, etc. (Poveda, 1994: 490 s., lám. 1-4; Id. 2000: 1865, fig. 10: 1-4; González Prats, 1985b; Id., 2005: 303 ss.; Renzi, 2010: 138) $)^{53}$ (Fig. 26, A).

En el área del interior de la montaña alicantina, destacamos la presencia de dos ejemplares de encaje tubular con o sin arpón (tipos 11a y 11b) en el poblado del Cabeçó de Mariola (Alfafara) (Grau, 2000: 116-118; Moratalla, 2004: 270, fig. 191), que repre-

mitancias con Peña Negra, cuya ocupación se inicia en torno al s. VII a.C., para abandonarse como éste a mediados del s. VI a.C. (Pernas, 2005), aunque no se conozcan hallazgos de puntas de flecha en las prospecciones realizadas (Poveda y Pernas, e.p.). 
senta otro estratégico foco de poblamiento desde el Bronce Final en la zona (Lorrio, 1996: 197; Pernas, 2005: 381-383, 389-391; Id., 2010-2011; Id., 2012: 68 ss.; Grau, 2002: 173; Grau y Moratalla 1999), y que comunica con los valles valencianos más septentrionales. A este hallazgo cabe añadir otra punta de flecha de La Serreta de Alcoy (tipo 11a), que junto a otros materiales, como cerámicas de origen fenicio y un fragmento de broche de bronce del modelo de escotaduras con decoración a molde similar al recuperado en el Sector VII de Peña Negra, ha permitido plantear una ocupación orientalizante en el lugar (Pla y Bonet, 1991: 247; Grau y Reig 2002-03: 114-116, lám. XI y XIII).

Además cabe citar dos puntas de doble filo y arpón lateral (11a) que se conservan en el Museo de Caudete (Albacete) (Fig. 26, C), que pudieran proceder de este término municipal ${ }^{54} \mathrm{o}$ de la zona colindante de Jumilla, donde se localiza un importante núcleo orientalizante en torno a la Sierra de Santa Ana, en el enclave del Sitio del Maestre-Coimbra del Barranco Ancho, aunque la imposibilidad de concretar el lugar del hallazgo, junto a la aparición de algunas puntas del modelo en sepulturas y poblado de

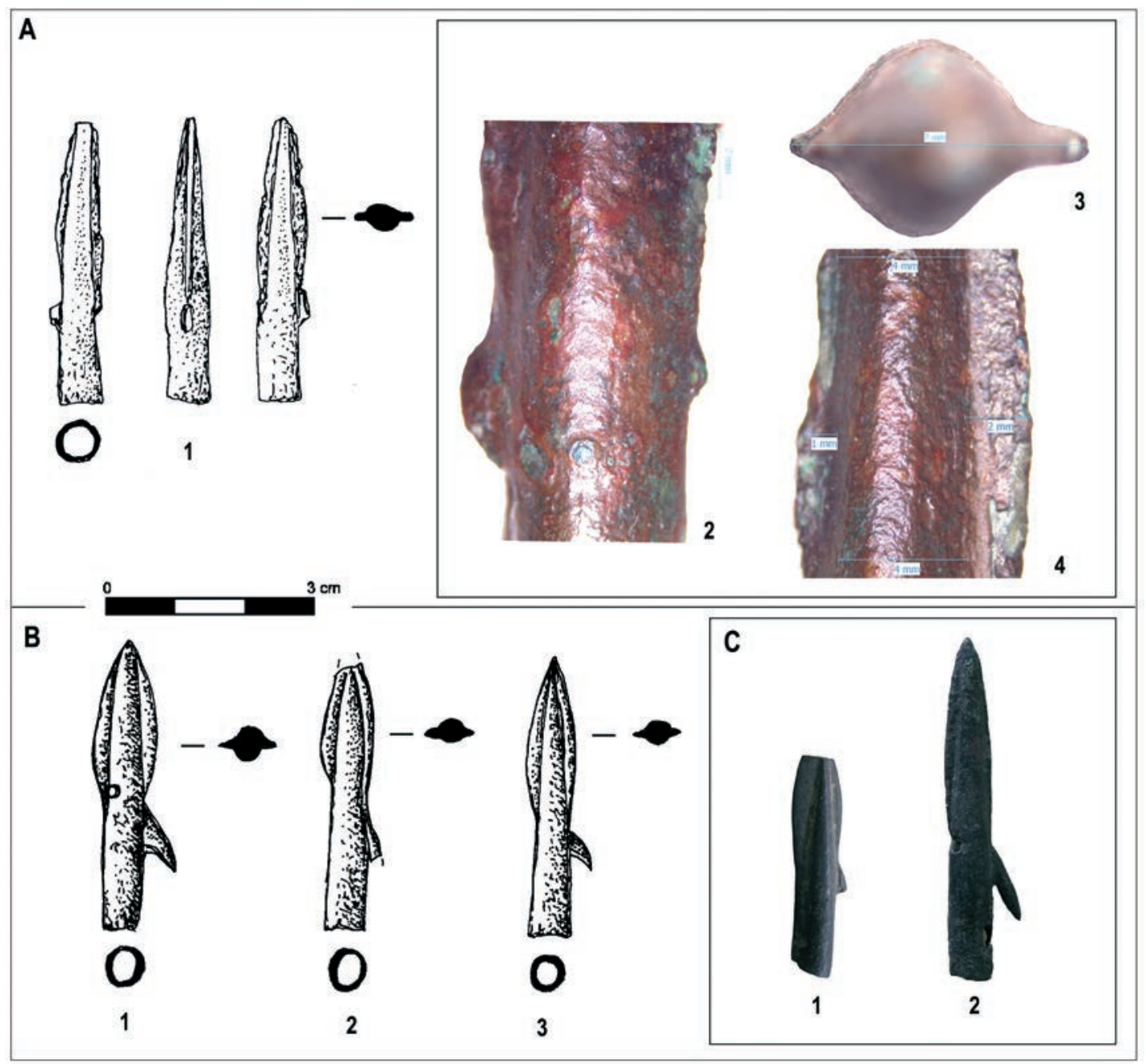

Fig. 26. Otras puntas de flecha de cubo. A. Dibujo y fotografías de la punta de flecha de El Monastil (Elda) Ampliaciones (2-3) 8x y (4) 12,5x. B. Ejemplares del Museo de Albacete procedentes de actuaciones de expolio.

C. Ejemplares conservados en la Casa de Cultura de Caudete (sin escala). (A1, dibujo de S. Pernas; A2-4, fotografías de I. Martínez Mira; B, dibujos de Ma D. Sánchez de Prado; C, fotografías J.L. Simón).

\footnotetext{
54 Se trata de dos piezas procedentes de una colección particular, sin información alguna sobre su procedencia. Si bien los indicios existentes sobre poblamiento orientalizante en el término municipal de Caudete son escasos, el entorno del Valle o Llanos de Caudete destaca por ser un
}

importante nudo de comunicación en época protohistórica y por tanto foco de atracción de poblamiento, como demuestra la densa ocupación de la zona en época ibérica, para el que no cabría descartar la posibilidad de una ocupación anterior (Moratalla, 2004: 769). 
época ibérica de la zona (vid. infra), no nos permitan sacarle mayor partido al hallazgo ${ }^{55}$. Por último, en el extremo suroriental de nuestra zona de estudio, no podemos dejar de mencionar la colección de 8 ejemplares de El Macalón (Nerpio, Albacete) (Fig. 27), yacimiento que fue pionero en aportar los primeros datos estratigráficos de la presencia de estas puntas de cubo con arpón, que apoyaban una cronología centrada en los s. VII-VI a.C. para estos tipos (García Guinea y San Miguel, 1964) ${ }^{56}$.

55 Respecto a la poco conocida ocupación durante el Hierro Antiguo de este importante núcleo protohistórica en la Sierra de Santa Ana en Jumilla, la revisión de los materiales orientalizantes depositados en el Museo Arqueológico de Jumilla que venimos realizando dentro de nuestro proyecto de tesis doctoral (SPG), procedentes de los niveles inferiores de las antiguas excavaciones realizadas en el poblado de Coimbra por A. Muñoz Amilibia y de las prospecciones del entorno del Sitio del Maestre, muestra la existencia de un repertorio cerámico orientalizante a torno, con tinajas E13 y ánforas, entre otros materiales, además de recipientes realizados a mano, semejantes a los ya identificados por Ros Sala (1990). Queremos agradecer al Dr. J. M. García Cano, director de las excavaciones de Coimbra del Barranco Ancho y a D. E. Hernández Carrión, director del Museo Arqueológico de Jumilla el habernos facilitado la posibilidad del estudio de parte de estas colecciones. Estos materiales inéditos vienen a sumarse a otras evidencias ya conocidas sobre las primeras etapas de ocupación del enclave (Iniesta et al., 1987: 150; Ros Sala, 1990: 361; García Cano, 1997: 82, Simón et al., 1999: 31, 33, 35-37, figs. 1.13 y 14; Hernández y Gil, 2001-02). Cabría relacionar con este horizonte antiguo algunas puntas de flecha del tipo que analizamos procedentes de contextos ibéricos (vid. infra), que incluyen algún hallazgo superficial, las recuperadas en el poblado y las procedentes de las áreas funerarias, donde podrían haberse reutilizado quizás como amuletos o adornos, aunque volveremos sobre el tema más adelante.

56 El poblado orientalizante de El Macalón (Nerpio, Albacete) se sitúa sobre un cerro amesetado destacado respecto al paso del rio Taibilla por la Sierra del Segura, en un importante cruce de comunicación que enlaza la cuenca alta del Segura con la comarca del Noroeste murciano y Andalucía Oriental (Fig. 27, A y B). Los distintos sondeos realizados en varios puntos de esta plataforma durante los años 50 y 60 del s. XX, tanto en su flanco suroeste como sureste, en torno al punto más elevado del cerro, por García Guinea (1959; Id., 1960; García Guinea y San Miguel, 1964), permitieron identificar una secuencia que incluía una fase más antigua anclada en cronologías del tránsito del Bronce Final y los inicios del Hierro Antiguo (García Guinea y San Miguel, 1964: 27-33), aunque revisiones recientes y la integración de los nuevos datos procedentes de la excavación de 1986 en el Sector II, correspondientes a sus fases I y II, propongan una fecha de finales del s. VIII a.C., en los inicios del Hierro Antiguo (López Salinas, 2015: 129130). En este sentido, destacan los recientes estudios arqueometalúrgicos sobre escorias de hierro tanto en El Macalón como en yacimientos coetáneos de la Cuenca alta del Segura, que apuntan hacia el inicio de la actividad siderúrgica en torno a los s. VII-VI a.C., que explicaría el papel destacado del enclave, que se convertiría en eje vertebrador del poblamiento de la zona, situándose además en una ruta metalúrgica que conectaría la Alta Andalucía con el Sureste murciano (González Reyero et al., 2015: 134-137, 141-142), donde destacan centros orientalizantes como El Castellar de Librilla (Ros Sala, 1989).
Frente a la variabilidad de tipos de puntas mostrada en núcleos orientalizantes y fenicios destacados, como Peña Negra o La Fonteta, en El Macalón solo se han registrado puntas de tipo 11a que siguen los patrones canónicos de tamaño y proporción, aunque se distinga algún ejemplar con destacada longitud de hoja (García Guinea, 1967: fig. 2 y 3.6), cuya datación remitiría a fechas similares a los contextos que venimos identificando en Peña Negra, La Fonteta o El Castellar de $\mathrm{Meca}^{57}$.

57 Los trabajos de excavación realizados en El Macalón en los años 50 y 60 del s. XX identificaron tres concentraciones estratificadas de puntas de flecha de cubo asociadas a zonas de viviendas de muros rectilíneos, colmatados por potentes niveles de ceniza que cubren estos restos constructivos más antiguos orientalizantes. Así en el denominado $\mathrm{C} 1$ o $\mathrm{CF}$ (Fig. 27, C), excavado en 1958, se identificó un primer ejemplar con arpón (Fig. 27, D.1), en el Nivel II-III, un espacio de hábitat muy degradado, situado en el punto más alto del farallón sureste del cerro (García Guinea, 1959: 136). En las excavaciones del año 1962, la realización de nuevos cortes en el área central y suroeste del cerro, en la denominada "Cata de las flechas" (Fig. 27, C) identificó un nivel de ocupación de estancias cuadrangulares rectilíneas, colmatadas por un potente nivel de cenizas, en cuyas capas superiores se localizaron hasta cuatro puntas del tipo (García Guinea y San Miguel, 1964: 27-33) (Fig. 27, D. 25). Por último, en la intervención realizada en el Corte CB, se identificó un primer nivel de ocupación de casas rectilíneas muy degradado, colmatado por un potente nivel ceniciento que además de numerosos materiales que incluía cerámica a mano y a torno orientalizante, aportó el sexto ejemplar de punta de flecha con arpón (García Guinea y San Miguel, 1964, 27-33; Soria, 2000: 373-374) (Fig. 27, D.6). En los estratos asociados a las tres concentraciones de puntas, el repertorio material remite a cronologías del Hierro Antiguo, entre los s. VII-VI a.C., cuando si bien sigue predominando la cerámica a mano de buena factura, se constata la importante presencia de cerámica a torno fenicia, principalmente ánforas y cerámica de engobe rojo, junto a objetos metálicos orientalizante, entre los que destacan las mencionadas puntas (García Guinea, 1959: 136; Id., 1960: 736-739; García Guinea y San Miguel, 1964: 27 33; Soria Combadeira, 2000: 358-374). Las piezas fueron publicadas por García Guinea (1967: figs. 2 y 3,1-5), añadiendo nosotros ahora los pesos de las piezas: $8,14,8,23$, $5,79,5,5,4,26$ y $5,2 \mathrm{~g}$, respectivamente (Fig. 27, D.1-6), Dos nuevas puntas se publicarían posteriormente, una recuperada en la campaña inédita de 1986, del tipo 11a como todas las anteriormente citadas (Abascal y Sanz, 1993: 116, $\mathrm{n}^{\circ}$ 258) (Fig. 27, D.7) y otra que, aunque fue asimilada al 21a (Abascal y Sanz, 1993: 257), podría incluirse también en el 11a (Fig. 27, D.8); sus pesos son, respectivamente, 4,5 y 4 g. Este ejemplar quiso identificarse con una de las publicadas por García Guinea (Abascal y Sanz, 1993: 115$116, \mathrm{n}^{\circ} 257$ ), aunque en realidad se trate de una pieza diferente, procediendo quizá, como señalan los autores, de las antiguas excavaciones realizadas entre 1941-1943 (Abascal y Sanz, 1993: 116). Además de estas piezas, en el Museo de Albacete se conservan otros tres ejemplares recuperados en el marco de una operación policial $\left(\mathrm{N}^{\circ}\right.$ inv. 17677,17678 y 17679), todas del tipo 11 a, y con un peso de 5,19, 4,35 y 4,65 g, respectivamente (Fig. 26, B.1-3). 

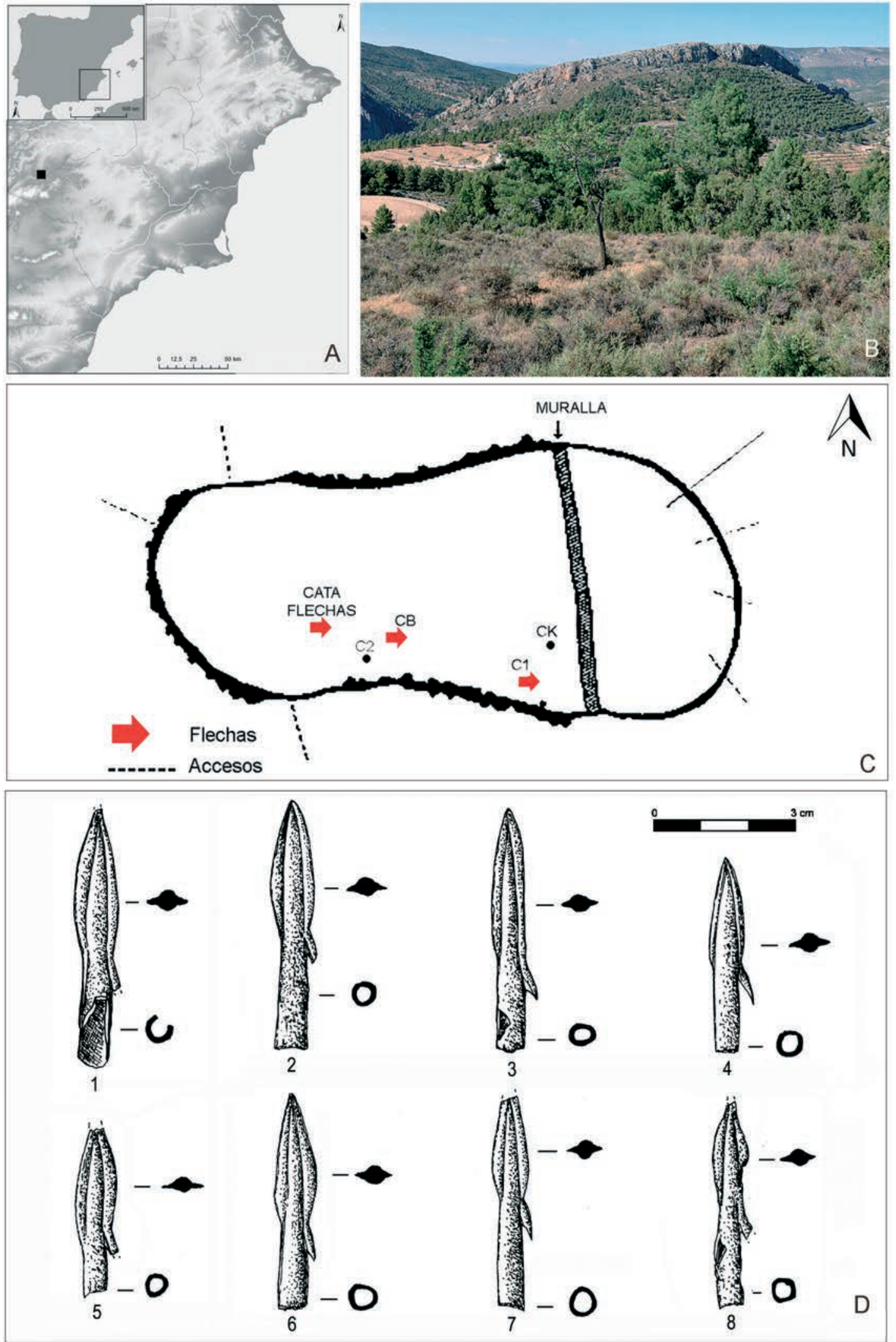

Fig. 27. El poblado orientalizante de El Macalón (Nerpio, Albacete). A-B. Localización y vista del cerro. C. Plano del poblado con indicación de los sondeos realizados por García Guinea.

D. Puntas recuperadas en El Macalón: 1 (Corte 1), 2-5 (Cata de las flechas), 6 (Corte CB), 7 (1986), 8 (Exc. 1941-43) (B, según González Reyero et al., 2015; C, según García Guinea y San Miguel, 1964, modificado; D1-D8, dibujos de M M $^{\mathrm{a}}$. Sánchez de Prado). 
Si valoramos conjuntamente los hallazgos (Fig. 25), la mayor variedad de tipos se registra, como por otro lado parece lógico, en los tres asentamientos de mayor entidad, que son además los que han proporcionado un mayor número de piezas. Destacan las puntas de Grupo 1, las más frecuentes en los yacimientos catalogados, y en el que se engloban la gran mayoría de los ejemplares recuperados en la zona de estudio, destacando sobre todo las del tipo 11a, el más ampliamente representado de todo los modelos de encaje tubular de la Península Ibérica (Quesada, 1997: fig. 269), siendo también el tipo más habitual en el resto de los yacimientos de la zona (Fig. 25), así como los ejemplares del Grupo 1 carentes de arpón (tipo 11b) y, ya entre las integradas en el Grupo 2, las "pseudofenestradas", sobre todo las provistas de arpón (12a), que tienen una significativa presencia o concentración en Peña Negra, donde se documentan también sin dicho elemento ${ }^{58}$. Del resto, destaca el conjunto de puntas de filos múltiples incluidas en nuestro Grupo 5 , sobre todo, con la mayoría de hallazgos procedentes de Peña Negra. Los demás tipos son claramente minoritarios, incorporando formas de largos pedúnculos y hojas muy cortas $(11 \mathrm{~d}, 12 \mathrm{~d}$ y12e), que suponen una novedad en los repertorios conocidos, con hallazgos en Peña Negra y Meca, siendo un modelo mejor representado en el Sureste peninsular, donde son relativamente más numerosos que en otros ámbitos peninsulares, donde su presencia es testimonial (Rodríguez Cordones, 1996: 225, fig. 1). Resulta interesante, por su variedad de tipos, los hallazgos superficiales de Bolvax (Murcia), que incluyen ejemplares de las variantes $11 \mathrm{a}, 11 \mathrm{~b}$ y $12 \mathrm{a}$, además de una pieza de triple filo sin arpón de tipo 44b, un modelo para el que en a menudo suele defenderse una datación más avanzada, cuya contemporaneidad con el resto de los hallazgos encuentra paralelos en el registro de Peña Negra (vid. supra). Sobre la cronología del conjunto, como ya señalara Ramon (1983: 322), si bien el yacimiento presenta una amplia secuencia que llega a época ibérico plena, existen materiales anteriores de época orientalizante como fíbulas de doble resorte, que permiten asimilar los hallazgos a esta temprana fecha. La datación elevada de las puntas de filos múltiples quedaría con-

58 Según la dispersión de ejemplares "pseudofenestrados" conocida (Quesada, 1997: 911-922), su presencia en el área meridional de la Península es muy minoritaria, en general un solo ejemplar del tipo 12a (Quesada, 1997: $\mathrm{n}^{\circ}$ 1654, $1760,2116,5129,5385,5572,5724)$ y en tres casos, del tipo 12b (Quesada, 1997: $\mathrm{n}^{\circ} 5559,5617,5730$ ). Frente a este panorama, Peña Negra destaca por concentrar mayor número y mayor diversidad tipológica (vid. supra), lo que hace pensar en un taller local.

${ }^{59}$ Este hallazgo corresponde con una punta de flecha de hoja firmada por el hallazgo de una pieza de cuádruple filo en La Fonteta, tipo 54, asimilable a nuestro Grupo 6. Del resto de las piezas, cabe referirse al ejemplar de El Monastil, la única pieza que parece presentar el arranque de un segundo arpón (11c), aunque apenas marcado, lo que unido a la alta presencia de estaño en su composición, convierten la pieza en un ejemplar singular.

\section{LAS PUNTAS DE FLECHA ORIENTALIZANTES: SignifiCAdo Y FUNCIÓN}

Las puntas de flecha de bronce son el principal elemento conservado en el registro arqueológico que nos aproxima al uso del arco en contextos protohistóricos del Bronce Final y el Hierro Antiguo. Existe una variedad de puntas de flecha realizadas en bronce en contextos del Bronce Final que nos remiten a las tradiciones propias de la Edad del Bronce en el uso del arco y de las cuales podemos destacar algunos rasgos distintivos respecto a las más tardías orientalizantes. Además de las variaciones en la morfología de su hoja y en la presencia de elementos secundarios como la nervadura central o las aletas laterales, los ejemplares de la Edad del Bronce se distinguen principalmente por presentar el tipo de encaje macizo, que varía según los tipos por la presencia de un pedúnculo más o menos largo o engrosado, que se inserta en el astil o se sujeta a él (Kaiser, 2003). En el Sureste, se conocen en buen número, registrándose su presencia incluso en tumbas, lo que debe relacionarse con el destacado rol social que tendrían las prácticas cinegéticas durante esta etapa (Lorrio, 2008: 294-297). Tanto en Peña Negra como en su entorno se han encontrado algunas de estas puntas, como un ejemplar encontrado de forma casual en la zona conocida como Vall dels Pins ${ }^{59}$, o dos piezas recuperadas en el poblado, una, ya conocida, publicada con dudas como un ejemplar con pedúnculo al estar muy alterada por la corrosión (González Prats, 1983: 77, fig. 19,2001), y otra, de pequeñas dimensiones, con punta nervada y hoja romboidal localizada en 2015 en la ampliación del Corte F del Sector II, posiblemente del tipo IIIA de Kaiser (2003: Tab 2.5).

triangular robusta con nervadura poco marcada con aletas incipientes y posiblemente pedúnculo engrosado roto en su tramo inferior, que podríamos identificar como tipos IIIB2 y IIIB2N de Kaiser (2003: 82), semejante a un ejemplar localizado en el Peñón de la Reina, estrato 14 (Martínez y Botella, 1980), tipo ampliamente difundido en el Sureste (Lorrio, 2008: fig. 171), cuya cronología podría situarse en torno al s. VIII a.C., o quizá en cronologías un poco más tardías ya orientalizantes (Ibid., 296). 
Durante el Bronce Final peninsular la presencia de puntas de flecha de bronce sufriría un paulatino "enrarecimiento" o reducción en el registro arqueológico, que solo se remontaría en los siglos centrales de la etapa siguiente, vinculándose ya al fenómeno orientalizante, lo que ha sido atribuido principalmente a la pérdida progresiva de peso de la actividad cinegética en estas sociedades del final de la Edad de Bronce, conforme se consolidaba un sistema económico y productor ganadero y agrícola autosuficiente, reduciendo, aunque no eliminando, la necesidad de complementariedad de la caza (Kaiser, 2003: 92). En otros contextos mediterráneos coetáneos, como el área griega, se ha considerado como una muestra de que el manejo del arco cayó en desuso, limitándose su presencia a contextos funerarios hasta el s. VIII a.C., ya en cronologías arcaicas (Snodgrass, 1964: 156; Id.:1967: 39; Reboreda, 1998: 90). Además de una función eminentemente práctica, debe destacarse el papel ideológico del arco y el valor simbólico de la caza profusamente reseñados para la protohistoria y el mundo antiguo (Quesada, 1989; Reboreda, 1998), lo que como hemos señalado podría explicar la presencia de puntas de flecha de bronce en tumbas durante el Bronce Final (vid. supra).

La aparición en la Península Ibérica de las puntas de flecha orientalizantes de encaje tubular con o sin arpón se vincula con la presencia fenicia, tratándose por tanto de un tipo surgido ex novo (García Guinea, 1967: 72, 84 s.; Quesada, 1989: 170; Mancebo y Ferrer, 1988-89: 315; Ferrer, 1994: 37; Quesada, 1997: 442), claramente diferente de los tipos tradicionales del final de la Edad del Bronce, que como hemos señalado ofrecen pedúnculo macizo y aletas (Kaiser, 2003). Su origen debe buscarse en las culturas cimerias transcaucásicas y del Mar Negro (Sulimirski 1954; Snodgrass, 1964: 149-150; García Guinea, 1967: 75-85; Cleuziou, 1977: 190-193, fig. 1; Quesada, 1989: 166-167; Elayi y Planas, 1995: 254; Quesada, 1997: 442), aunque su extensión por todo el Mediterráneo les acaba otorgando un carácter marcadamente internacional y pronto serían objeto de producción local (Quesada, 1997: 444), como demostraría la noticia de un molde conservado en Barcelona que pudiera proceder de Emporion o Ibiza (Sánchez Meseguer, 1974: 101).

Se han considerado como un indicio del "influjo oriental directo" (González Wagner, 1988: 427), indicador de las posibles vías de penetración colonial (Mancebo y Ferrer, 1988-89: 316; Quesada, 1989: 160), aunque los hallazgos no se limiten a yacimientos hispano-fenicios, lo que ha llevado a interpretación como evidencias del "fenómeno orientalizante y no solo puramente fenicio" (Ferrer, 1996: 46). De esta forma, el hallazgo de este tipo de puntas en yaci- mientos del valle del Guadalquivir, donde aparecen en gran número, se ha relacionado con la presencia de arqueros en los ejércitos tartésicos (Torres, 2009a: 104), al tiempo que su presencia en asentamientos fenicios evidencian su uso por los colonos semitas, como es bien conocido en Oriente (Torres, 2009b: 153, 155-156). Son objetos relativamente habituales sobre todo en contextos protohistóricos del Sur peninsular, aunque ejemplares del tipo se hayan documentado en las islas de Ibiza (Ramon, 1983; Elayi y Planas, 1995) y Mallorca (Guerrero et al., 2002: 241) o el Noreste (García Guinea, 1967: 74; Sánchez Meseguer, 1974: 97 y 101; Ramon, 1983: 319; Quesada, 2011: 210; Noguera, 2011: 56; Martínez Hahnmüller, 2012: 49).

Respecto a su cronología, se ha señalado para los hallazgos peninsulares una fecha entre los s. VII y VI a.C. (García Guinea, 1967: 87), si bien numerosos hallazgos parecen remarcar un auge de su presencia en contextos orientalizantes tardíos del s. VI a.C. (Ferrer, 1994: 43 ss.; Ferrer y Ruiz, 2000: 134). Como ya planteara García Guinea (1967: 87), “igual que sucede en Oriente, su vida pueda prolongarse bastante", aunque los de doble filo con arpón lateral se fechan en dicha región preferentemente en los s. VII-VI a.C. (Cleuziou 1977: 190-193, fig. 1). La presencia de ejemplares correspondientes a estos tipos en contextos más modernos de la Segunda Edad del Hierro, ya plenamente ibéricos, ha planteado su pervivencia minoritaria, sobre todo la de los ejemplares de triple filo o más, que alcanzarían los s. V y III a.C., proponiéndose una mayor antigüedad para los de doble filo (Quesada, 1989; Id., 2011: 209-210), aunque su hallazgo en escenarios bélicos o en contextos campamentales de finales del s. III a.C., o incluso posteriores, evidencie la larga perduración del tipo, posiblemente asociado en estos casos a contingentes militares cartagineses o baleares (Quesada et al., 2015: 375), discusión que abordaremos más adelante.

Por lo que se refiere a la funcionalidad de estas puntas de flecha, deben ser el estudio técnico de los tipos, que permite un análisis de su diseño y potencialidad, así como del contexto arqueológico de su hallazgo las variables que permitan determinar su uso o función. De acuerdo con esto, su capacidad de penetración como arma arrojadiza, las huellas que denotan su uso, tales como roturas o deformaciones de la punta y sus extremos, o la cercanía o relación directa de puntas de flecha del tipo con estructuras defensivas o fortificaciones, cuando no con escenarios bélicos o contextos campamentales, hace que resulte evidente su consideración como arma de guerra, sin descartar su uso ocasional para la caza (García Guinea, 1967; Ramon, 1983: 309-310; 
Mancebo y Ferrer, 1988-89: 315-316, 328; Quesada, 1989: 162; Ferrer, 1994: 51; Id., 1996: 49; Elayi y Planas 1995: 231 ss. y 255; Torres, 2009a: 104; Quesada et al., 2015: 375), aunque también se hayan relacionado con otras actividades, como la pesca ${ }^{60} ; \mathrm{o}$ incluso se haya interpretado como elemento premonetal (González Wagner, 1988: González Wagner y Alvar, 1989; vid., en contra, Ferrer 1995: 94). Las puntas de flecha metálicas de llamado tipo 'Macalón' resultan especialmente aptas para la guerra por las características específicas de su sistema de encaje en forma de cubo, pensado para mejorar su sujeción al ástil, de su hoja, estrecha y nervada, en relación con aspectos aerodinámicos, en los que debe también valorarse el peso de la punta, pero también de la flecha en su conjunto, o sus dimensiones estándar, que se reproducen de forma rigurosa, en relación con el carácter estandarizado de su producción (Ferrer, 1996: 49), así como su morfología, afilada y estrecha, lo que debe relacionarse con su menor resistencia al aire y una mayor capacidad de penetración. La modalidad de encaje de esta familia de puntas de flecha presenta un origen oriental eminentemente bélico, como flechas diseñadas contra la caballería (Quesada, 1989: 186), siendo además una eficaz arma de asedio (Ferrer, 1995: 95).

La presencia de elementos secundarios como el arpón, reforzaría este aspecto, pues tendría por objeto impedir su sencilla extracción (Sánchez Meseguer, 1974: 73; Ramon 1983: 312; Quesada, 1989: 165).

Si la evolución del uso del arco y las flechas desde finales de la Edad del Bronce promueve una optimización de los proyectiles (Kaiser, 2003: 78), durante el Hierro Antiguo, entre los s. VII y VI a.C., la complejidad de la fabricación y la homogeneidad de los modelos indica una especialización en su uso, que cabe suponer predominantemente bélico, lo que corroboran los contextos aquí analizados (vid. supra), en la línea de lo planteado para explicar las a veces importantes concentraciones de hallazgos en otras áreas peninsulares, con ejemplos como los de

60 Tal interpretación se ha señalado a partir de las piezas recuperadas junto a arpones y pesas de red en contextos costeros gaditanos (García y Bellido, 1952: 318; Sáez Romero, 2005: 122), interpretados como posibles saladeros (Gutiérrez, 2000: 25-26; Gutiérrez y Giles, 2004: 140-141). En el caso de La Fonteta, el único de los aquí analizados que podría aportar algo de luz al tema, la revisión comparada de los contextos de aparición de las puntas de flecha y los numerosos anzuelos y pesas de red identificados a lo largo de toda la secuencia (FI a F-VI y FVb) no parecen evidenciar tal relación (González Prats, 2014a: 249-250, 275-276). De los 68 anzuelos publicados, la mayoría se concentra en
Pancorvo (Mancebo y Ferrer, 1988-89: 315-316, 328), relacionados con episodios de asedio o final violento de los poblados (Ferrer, 1994: 49: Id., 1995: 95).

\section{LA VALORACION DE LOS CONTEXTOS URBANOS Orientalizantes y la PRESEnCia de PUNTAS de FLECHA}

Para el mundo oriental y grecorromano contamos con numerosas fuentes que nos ilustran acerca del desarrollo de conflictos bélicos entre ciudades en época arcaica en el ámbito mediterráneo, y el desarrollo de asedios a ciudades, en un contexto más agitado e inestable que el defendido habitualmente dentro de los marcos interpretativos del mundo colonial peninsular (González Wagner, 2005: 177 ss.). Para la Península Ibérica, las fuentes escritas que nos ilustren o permitan reconstruir episodios bélicos o de inestabilidad y enfrentamiento entre comunidades de época orientalizante son inexistentes, dado que las menciones son más tardías, referidas a los diversos conflictos relacionados con las guerras entre Roma y Cartago y la posterior conquista romana. Para época arcaica (s. VIII-VI a.C.), contamos solo con el registro arqueológico -tanto de la arquitectura defensiva, como de los numerosos hallazgos de puntas de flecha con evidencias de uso e impacto en poblados y fortalezas- para intentar aproximarnos a esta realidad histórica. Estos episodios de inestabilidad latente se vincularían con la presencia fenicia en las ciudades o colonias costeras y su penetración hacia las tierras del interior (García Guinea, 1964: 84-87; Sánchez Meseguer 1974: 101; Mancebo y Ferrer, 1988-89: 327-328), aunque también con los procesos de territorialización desarrollados por los núcleos indígenas durante los siglos centrales del I milenio a.C., en torno al s. VI a.C. (Ibid.: 328).

Claramente vinculado con el desarrollo del proceso urbanizador orientalizante, a partir sobre todo del s. VII a.C., se registra en el Sureste y Sur de la

el horizonte Fonteta Arcaica (FI y FII), mientras que en Fonteta Reciente, su número se reduce drásticamente (González Prats, 2010b: 35). Solo 9 anzuelos se asocian a la fase Fonteta VI (Ibid.: 35), con un solo caso, un anzuelo incompleto ( $\mathrm{N}^{\mathrm{o}}$ 15022), localizado en el mismo estrato de vertedero de Fonteta VI en el que se encontró la punta F9 (8BCA3VIb) (González Prats, 2014a: 421-424). Otro anzuelo más se localizó en la Zona 3 relacionado con la fase $\mathrm{FVb}$, aunque no en el estrato 3088 donde se localizaron las puntas F1 a F4 (Le Meaux y Sánchez, 2007: fig. 260). 
Península Ibérica un fenómeno característico de fortificación del paisaje (Berrocal, 2004), lo que supone un cambio radical en relación al panorama anterior ${ }^{61}$. Este proceso, que afectaría a los enclaves protourbanos y a sus territorios, se observa con nitidez en los casos de la ciudad fenicia de La Fonteta y el núcleo indígena de Herna/Peña Negra ${ }^{62}$. La poliorcética de la Edad del Hierro en la Península Ibérica es en gran medida elemental, al estar basada en "la ocupación de enclaves fácilmente defendibles mediante el control y limitación de sus accesos, como farallones o cerros-testigos, y la construcción de líneas defensivas sencillas" (Berrocal, 2005: 14), con cortinas amuralladas, adaptándose a las curvas de nivel, aprovechando salientes rocosos, como posiblemente sería el caso de la fortificación perimetral de Peña Negra, y la utilización de bastiones y torres macizas regularmente emplazadas como zonas de flanqueo, como se documenta en La Fonteta (vid. supra).

Así, desde finales del s. VIII a.C. se observa la eclosión de fortificaciones, coincidiendo con el desarrollo de la urbanización de los asentamientos. Los rasgos identificados en las fortificaciones del Mediodía y el Sur peninsular (Torres, 2002: 288-296) se repiten en los principales enclaves estudiados en nuestra área de estudio. Por un lado Herna/Peña Negra y su complejo defensivo con fortines o recintos amurallados que presentan bastiones adosados, como Les Barricaes (Grau y Moratalla, 2001: 191; Trelis y Molina, e.p.); por otro, La Fonteta y Cabezo Pequeño del Estaño, con la introducción del uso de técnicas constructivas orientales a modo de casamatas, cajones, refuerzos y tirantes en sus defensas (González Prats, 1998; Id. 2010a: 68-69; Prados y Blánquez,

61 Para momentos anteriores del Bronce Final, en el entorno de los ríos Vinalopó y Segura se ha enfatizado especialmente el carácter no fortificado de los asentamientos (Gil-Mascarell, 1981: 33) y su preferencia por emplazamientos accesibles a las vías de comunicación, reduciendo las estrategias defensivas a la elección, en ocasiones, de lugares fácilmente defendibles de forma natural (Grau y Moratalla, 2001: 189). Durante el Bronce Final, casos como los de Caramoro II, en Elche (González Prats y Ruiz Segura 1992; Moret 1996: 483, fig. 72) o El Castell de Xátiva (Pérez Ballester, 2014: 24-25) evidencian el uso de murallas en la zona, algo ya conocido en otros territorios del Sur peninsular (AlmagroGorbea y Torres 2007: 36-39; Torres 2009a: 103; BerrocalRangel y Silva, 2010: 235 ss.).

62 Los trabajos de topografía, prospección y excavación desarrollados durante las campañas de 2014, 2015 y 2016 han permitido localizar diferentes tramos de muralla, algunos presumiblemente del Bronce Final, aunque posiblemente también en uso durante la etapa orientalizante. Estos hallazgos se suman a los lienzos identificados por González Prats en los sectores IB y VII (González Prats, 1983) asimilables al Hierro Antiguo, a pesar de que en la bibliografía se haya
2007; Bueno, García Menárguez y Prados, 2013: 4952; García Menárguez y Prados, 2014: 118-120) ${ }^{63}$.

Hasta el momento, no existen en la Península Ibérica evidencias del uso de arietes para estas cronologías tempranas, vinculada su introducción a la presencia púnica (Gracia, 2000: 153). De esta forma, las tácticas ofensivas propias del mundo orientalizante primarían la toma o "conquista por asalto" de los poblados, gracias al fuego de cobertura para los atacantes y de barrera para los defensores, tácticas en las cuales el arco tendría un papel fundamental (Gracia, 2000: 139; Quesada, 2009: 112-113) ${ }^{64}$. La importancia de los arqueros sería, por tanto, determinante, al facilitar el asalto de la infantería que utilizaría escalas para asaltar los murallas, tal y como se representa en grabados de la época neoasirios (Hrouda, 1965; Ferrer, 1995: 5; Gracia, 2000: 152; Almagro-Gorbea y Torres, 2007: 45).

Por tanto, la presencia de puntas de flecha de doble o triple filo con arpón en contextos de finales del s. VII y sobre todo el s. VI a.C. nos estaría indicando la incorporación de nuevas formas de combate, con el desarrollo de los primeros asedios a ciudades, modificando antiguas pautas de la guerra arcaica, en las cuales los conflictos entre comunidades se habrían dirimido ya sea mediante pactos entre sus elites dirigentes o mediante una modalidad de guerra aristocrática de base gentilicia, caracterizada por combates singulares o monomachia, en la cual, las estrategias preventivas, entre las que se insertaría la erección de potentes fortificaciones como estrategia disuasoria frente a ataques como una demostración simbólica de control y poder, responderían a una misma idea (Gracia, 2000:139140). Frente a ello, desde mediados del s. VI a.C. -

incidido en su condición de poblado carente de murallas (Moret, 1996: 95; Grau y Moratalla, 2001: 190; Moratalla, 2004: 162). La fortificación identificada en 2015 y 2016 en el Sector III de Peña Negra, que coincide con la cima de la Lloma Negra, a diferencia de las evidencias de los lienzos de la muralla perimetral, se configura como un elemento delimitador del espacio acropolitano de la ciudad, y por tanto de un evidente valor estratégico y simbólico ya desde el Bronce Final.

63 Vid. supra, sobre el uso de la técnica de casamatas y cajones en dichos enclaves del Bajo Segura.

64 Otros indicios de estrategias, tanto defensivas como ofensivas, relacionadas con los asedios a ciudades señalan la reducción y concentración de los puntos de fortificación, toda vez que "la resistencia se prolonga y se optimizan las fuerzas de los defensores al acortarse la longitud de los puntos a cubrir", al tiempo que "también posibilita que el esfuerzo de los sitiadores se concentre en determinados puntos" (Gracia, 2000: 153), que podrían identificarse a través de las concentraciones de puntas de flecha con huellas de impacto, tal y como reflejan los casos de Peña Negra o La Fonteta. 
momento de consolidación de los procesos de urbanización y territorialización entre las comunidades protohistóricas-, las estrategias y tácticas guerreras se modificarían e incluso se implementarían en un contexto generalizado de competitividad entre comunidades y territorios que derivaría en la posibilidad del desarrollo de episodios de asedio a las ciudades. Por tanto, la presencia de puntas de flecha con evidencias claras de impacto en algunos enclaves estratégicos del Hierro Antiguo nos estaría revelando la existencia de una geografía de asentamientos en los que pudo registrarse algún episodio violento, tales como Herna/Peña Negra o La Fonteta, que serían finalmente abandonados, mostrando su ruptura por tanto respecto a la siguiente etapa, el Ibérico Antiguo, un fenómeno que solo puede suponerse en el caso de Meca.

Habitualmente se defiende un modelo poco violento o belicista para explicar el desarrollo del proceso colonial durante el I milenio a.C., vinculando el fenómeno de fortificación patente desde los inicios del Hierro Antiguo al desarrollo de la implantación de las formas de vida y organización urbanas, en las cuales la construcción de recintos fortificados seria uno de los hitos más destacados de tal planificación. Sin menoscabar esta funcionalidad o intencionalidad ideológica en la configuración de los primeros núcleos protourbanos, con la erección de poblados rodeados de potentes fortificaciones, que delimitarían el perímetro urbano frente al hinterland o el territorio no controlado directamente por la comunidad, podemos plantear que el desarrollo del proceso de implantación colonial sí pudo conllevar determinados momentos o contextos de inestabilidad en los cuales se desarrollase una necesidad defensiva o disuasoria que llevase a la construcción de estas potentes fortificaciones.

El análisis de las evidencias conocidas en el área del Bajo Segura-Vinalopó, junto con el estudio de los contextos urbanos de aparición de grandes concentraciones de puntas flecha con marcas de impacto podría evidenciar este pulso, entre momentos en los que la fortificación respondería a razones plenamente disuasorias de reafirmación territorial y otros de necesidades defensivas ante episodios de conflicto e inestabilidad. En el

65 En este modelo arcaico de implantación colonial se identificarían varios núcleos, no del todo coetáneos en el tiempo, que evidencian que se trató de un proceso gradual y complejo. Por un lado, un centro fortificado, el Cabezo Pequeño del Estaño, que denota un interés por la protección de los bienes de prestigio y comercio que comienzan a distribuirse por la zona, y que se ubica como límite de esta implantación colonial. Por otro, un emporio y centro artesanal, $\mathrm{La}$ Fonteta, de marcada vocación costera que contaría con un espacio sacro próximo (González Prats, 2010a: 73).

66 En cualquier caso, en este primer episodio urbanizador del área del Bajo Segura, con potentes construcciones defensi- área de la desembocadura del río Segura, durante el s. VIII a.C., momento en el que según los datos actuales se implanta la presencia fenicia directa, asistimos a este doble proceso de demarcación, fijación y fortificación territorial con la aparición de los primeros asentamientos con contingentes coloniales como el Cabezo Pequeño del Estaño, que ha sido identificado como "un centro fortificado de carácter complejo y urbano" en torno al borde de un antiguo estuario o ensenada, posiblemente navegable, adelantado respecto a los promontorios rocosos costeros, un ejemplo del primer urbanismo sin ciudad o difuso para esta fase arcaica de implantación fenicia (García Menárguez y Prados, 2014: $116)^{65}$. Introduce numerosas novedades técnicas en la construcción del perímetro amurallado y sus torreones, como el uso de casernas (Berrocal y Moret, 2007: 28), además de un programa de monumentalización inspirado en modelos orientales que aúnan la función militar con la monumental, principalmente de carácter persuasivo $^{66}$ (García Menárguez y Prados, 2014: 118-122) (vid. supra). La vida de este enclave parece no extenderse más allá de principios del s. VII a.C. según plantean sus excavadores (García Menárguez y Prados, 2014: 124), y por tanto podría relacionarse con la fase más antigua de la colonia fenicia de La Fonteta, asentada sobre un pequeño promontorio costero en el límite de la propia desembocadura del Segura, en torno a un área de antigua bahía (Barrier y Montenat, 2007: 20; Gailledrat, 2007: 22-89; González Prats, 2010a: 63). Dado que no se han identificado evidencias de inestabilidad que expliquen el abandono y desmantelamiento del asentamiento fortificado, su final ha sido relacionado con los problemas estructurales de sus construcciones, así como con cambios paleoambientales del entorno costero que afectaron a la zona, motivados tanto por problemas sísmicos como por procesos de colmatación y sedimentación en el área de la Rinconada (García Menárguez y Prados, 2014: 126-127). Paralelamente al abandono de este primer enclave colonial en una posición avanzada respecto a la costa, se observa la concentración y permanencia del foco poblacional en el enclave costero de La Fonteta, que en estos momentos podría presentar ya un perímetro amurallado (González Prats, 2010a: $68)^{67}$ y que en este periodo inicial desarrolla un

vas como refleja el Cabezo Pequeño del Estaño, de claro significado ideológico, organizativo y urbanizador que supone, no debemos desdeñar su carácter defensivo y, por tanto, la existencia de cierta inestabilidad en el momento de implantación directa de los primeros asentamientos fenicios en la zona de la desembocadura del Segura.

67 Aunque se ha mencionado la posible existencia de una empalizada con postes de madera (García Menárguez y Prados, 2014: 118, 126, 128), las fortificaciones identificadas en el Cabezo Pequeño del Estaño hacer pensar más bien en una muralla de mampostería de similar entidad. 
modelo de implantación tipo emporio con una importante área artesanal y productiva, un espacio portuario, además de un área sacra de cuya existencia son testimonio los elementos arquitectónicos recuperados en las obras de construcción de la muralla de Fonteta Reciente (González Prats, 2010a: 73).

A lo largo del s. VII a.C., la colonia costera de La Fonteta en su fase arcaica (FI-FIII) vivirá un momento de expansión y primer esplendor con una intensa actividad artesanal que genera áreas de hábitat y producción artesanales que amplían el espacio ocupado, próximo a la misma línea de playa y para el que no se puede descartar la existencia de un perímetro fortificado antiguo con un trazado no conocido por el momento pero que presumiblemente no seguiría el de la muralla posterior de Fonteta Reciente (González Prats, 2010a: 69). El final de este modelo de implantación arcaico, fechable hacia el 635 a.C. (González Prats, 2011: 14-15), parece coincidir con un momento de clara inestabilidad y peligro, cuyas evidencias constructivas hacen referencia a un episodio de profunda remodelación urbanística que conlleva la reducción de los límites del asentamiento y la construcción de un perímetro amurallado con bastiones asociados, evidencia de una marcada necesidad defensiva, que inaugura la etapa de Fonteta Reciente (FIV) en torno a finales del s. VII a.C., según la cronología propuesta por González Prats (1998: 205; Id., 2010a: 68-69; Id., 2011).

Quizás la presencia de puntas de flecha en esta fase previa en Fonteta III, de modelos de espiga, en niveles ya de derrumbe de sus edificaciones y sobre los que se asienta directamente la muralla o sus estructuras defensivas asociadas - como el antemural -, pueda relacionarse con estos momentos de inseguridad e inestabilidad previos y que propiciaron o motivaron la remodelación y fortificación del poblado, como un nuevo indicio relativo a la premura señalada de la construcción del recinto defensivo de Fonteta Reciente. A diferencia del Cabezo Pequeño del Estaño, esta fortificación de Fonteta Reciente levantada a finales del s. VII a.C., sí se ha relacionado con una posible "crisis entre fenicios e indígenas -que no parece reflejarse en el funcionamiento de la factoría instalada en la ciudad orientalizante de Peña Negra II- y que habría obligado a un replanteamiento de la estrategia territorial en la desembocadura del Segura, concentrándose la población fenicia toda en La Fonteta IV y requiriendo un sistema de defensa disuasorio" (González Prats, 1998: 201).

Tras este episodio de inestabilidad, la secuencia conocida del asentamiento de La Fonteta a lo largo ya del s. VI a.C. parece mostrar un nuevo despegue de la ciudad, con la identificación de una primera fase en la que se desarrolla un urbanismo de casas adosadas a la muralla que introducen la presencia numerosa de muros de mampostería, frente al predominio de la arquitectura del barro en las edificaciones de las fases arcaicas (Gailledrat, 2007: 99-105; González Prats, 2010a: 72-73). Esta etapa no parece prolongarse mucho en el tiempo, siendo estos espacios rápidamente amortizados, como evidencian la destrucción del bastión intramuros del Corte $5 \mathrm{~N}$ o la casa multicelular del Corte 7-8 (vid. supra). En relación con los niveles ya de colmatación de las estancias de la casa del Corte 7, se identificó el primer ejemplar de punta de doble filo y cañón tubular (F5), cuyas huellas de impacto quizá podría relacionarse con algún episodio de inestabilidad que motivase una nueva remodelación de la organización interna de la ciudad que conllevaría el traslado del área de hábitat a un área central intramuros y alejada de la muralla.

En un segundo momento, durante la fase Fonteta VI, la ciudad vive un nuevo momento de apogeo de la actividad artesanal y productiva que concentra las áreas de producción artesanal en el espacio intramuros aledaño a la muralla (González Prats, 2011: 4951). Es ahora cuando se identifica la mayor concentración de puntas de flecha de doble filo y encaje de cubo, 5 de los 10 ejemplares conocidos, siendo mayoritaria su presencia en las capas superiores de los distintos espacios de vertido artesanal situados en las inmediaciones de la muralla, documentándose tanto ejemplares de doble filo de tipo 11a como de filo múltiple 54a (vid. supra). Aunque no existan por el momento evidencias claras de una producción o fabricación local de estos tipos, sí parecen existir indicios que marquen esta posibilidad y que explicarían esta concentración como objetos desechados en los niveles de detritus y residuos metalúrgicos de la ciudad. En relación con la fabricación y distribución de las puntas de flecha de doble filo y cubo, el caso evidenciado por la gran concentración de ejemplares en la Fonteta Reciente (Fonteta VI), en niveles asociados a una potente actividad artesanal metalúrgica de base cobre en los que se identifican numerosas instalaciones como hornos, pequeños cobertizos y áreas de trabajo al aire libre asociadas a la presencia de potentes vertederos que denotan una gran actividad en el área intramuros de la ciudad durante la primera mitad del s. VI a.C., podría indicar quizá la existencia de un pequeño taller de producción de estos objetos en la ciudad o, al menos, que pudiera evidenciar su papel como distribuidor de este tipo de armamento por el entorno o territorio inmediato o su comercialización a larga distancia.

Los parámetros analizados en las colecciones estudiadas, sobre todo de los dos centros más próximos de La Fonteta y Peña Negra, permiten corroborar cierta similitud en tendencias de tamaño, tipolo- 
gías y proporcionalidades de los tipos, lo que posibilitaría identificar una distribución regional, como por ejemplo la presencia de los ejemplares de largo arpón o la temprana presencia de una diversidad de tipos de doble y múltiple filo en las mismas concentraciones (vid. supra). A pesar de que los talleres metalúrgicos de Fonteta Reciente han aportado numerosos indicios de la existencia de una fabricación in situ de otros objetos, en el caso de las puntas de flecha no contamos por el momento con moldes o instrumental asociado a dicho labor artesanal, ni con ejemplares semielaborados que permitan aportan mejores indicios. No obstante, la aparición de estos ejemplares (F1-F4, F6-F10) en niveles de vertido o desecho industrial, con roturas o deformaciones, podría evidenciar esta posible actividad productiva.

En concordancia con este proceso de urbanización y fortificación del territorio que se desarrolla en torno a la desembocadura del Segura, en el territorio circundante asistimos, a partir del s. VII a.C., a un fenómeno semejante en destacados poblados de su hinterland, como el de Peña Negra, donde se observa una profunda transformación hacia formas de vida plenamente urbanas para dar lugar a una ciudad orientalizante conocida por las fuentes literarias con el nombre de Herna. Según evidencian los datos conocidos, la ciudad presentaría su perímetro urbano fortificado, solo conservado en algunas zonas, lo que debe relacionase con los importantes procesos erosivos que afectaron las zonas periféricas del asentamiento. Así, los principales restos de la muralla se han identificado en las inmediaciones de lo que debió ser uno de los accesos principales a la ciudad (en torno al Sector VII) y en los barrios de la zona sur (Sector IA y IB), alguno incluso construido a extramuros (IB). Además, un recinto perimetral rodearía la zona acropolitana, identificada en las campañas de 2014 y 2015 (Sector III), y que, según los datos aportados por la campaña de 2016, situaría su origen en cronología previas del Bronce Final, prolongándose su uso en época orientalizante.

A lo largo del s. VII a.C., presumiblemente durante la fase PNIIA, la ciudad de Herna vivirá un fenómeno de fortificación que responde a un proceso urbano de monumentalización y demarcación del perímetro urbano que evidencia los intensos procesos socioculturales que viven las poblaciones orientalizantes locales en su evolución hacia las formas de vida urbanas, pudiendo destacar la aparición de un sistema de fortines que controlarían las principales vías de acceso al territorio circundante. Dentro de este panorama orientalizante indígena, representado por Peña Negra, este desarrollo urbano que, siguiendo los modelos propios del Hierro Antiguo, estable- ce un fuerte vínculo entre fortificación y urbanización, podría reflejar una creciente necesidad defensiva y de control de los espacios urbanos, de sus accesos y de las vías de comunicación desde finales del s. VII y durante el s. VI a.C. En relación con tales necesidades estaría la existencia de posibles arsenales, no detectados, o de equipos personales de armamento en viviendas o edificios asociados a algunas áreas amuralladas de interés estratégico (vid. supra), como la identificada por el Sector VII, una zona donde se ubica una importante zona de talleres y almacenes, que ha sido identificada como una posible "factoría fenicia" (González Prats, 1993: 184), que debió de localizarse en las inmediaciones de uno de los puntos de acceso principal a la ciudad. En la denominada vivienda angular intramuros del Sector VII, se localizó en el último nivel de ocupación, estrato Ib3, una concentración de puntas de flecha de variada tipología (tipos 11a, 12a, 13a y 44a) cuyos rasgos peculiares podrían evidenciar este carácter de equipo militar. De los cuatro ejemplares (PN6-PN9), tres no cuentan con las características huellas de impacto, que denotan su deterioro por su uso, marcando una pauta diferenciada respecto al resto de las puntas localizada en el yacimiento, con 19 de un total de 26 ejemplares identificados que sí tendrían marcas evidentes de impacto (vid. supra). Otro conjunto, también caracterizado por la diversidad de tipos (11a, 44a y 12a) y para el que quizá podría plantearse una interpretación similar, se localiza en el área contigua de este mismo sector VII, en el interior de un gran taller o almacén, cerca de un tramo de escaleras que posiblemente comunicaría este espacio con las edificaciones de la terraza superior; el conjunto incluía un ejemplar sin marcas (PN5), asociado a otros dos que sí parecen presentarlas (PN3-PN4).

A finales de la última fase de ocupación detectada en Peña Negra, PNIIB, se observa un aumento de la inestabilidad, en el que la evidencia de niveles de incendio, destrucción y la presencia de numerosas concentraciones de puntas de flecha de doble filo y cubo con marcas de impacto y roturas en los niveles de destrucción de las edificaciones y sus espacios próximos podrían evidenciar episodios de asedio o asalto a la ciudad que afectarían quizá progresivamente a la reestructuración del perímetro urbano, que se reduce paulatinamente, tal y como parece plantear quizá la destrucción de las edificaciones más meridionales del Sector VII (Área A'5), presumiblemente entre fines del s. VII y principios del s. VI a.C. (vid. supra). Estos episodios antecederían al final de la ciudad, con evidencias de destrucción generalizada, como el desmantelamiento del barrio periférico del Sector IA, un final violento con el que se han asociado acciones de saqueos y ocultaciones, 
como la del conocido tesorillo, y donde aparecen ejemplares de puntas de flecha con marcas de impacto o uso (González Prats, 1983: 277). Otro ejemplo lo tenemos en el Sector IB, en el que el barrio extramuros es abandonado, pudiéndose vislumbrar situaciones semejantes a las comentadas en la presencia de una punta de flecha con marcas de impacto en el nivel de destrucción del alzado de tapial de la muralla. Igualmente, en otras áreas artesanales de la periferia de la ciudad, como el denominado "barrio fenicio” del Sector VII N y S, se identificó en los últimos niveles de ocupación y destrucción de los almacenes y talleres la presencia de puntas de flecha con huellas de impacto, como las localizadas en los niveles de derrumbe del Dpto. 1, así como la realización de nuevas ocultaciones junto al Gran Taller Almacén (González Prats, 1982b: 370; González Prats y Ruiz, 1990-91: 58). Esta inestabilidad se hará presente, al final de la ocupación del poblado, en sus áreas centrales, como el Sector II, donde se registra una alta concentración de puntas de flecha con huellas de impacto en puntos estratégicos, como la base de la elevación que acoge al recinto acropolitano o el camino de subida hacia El Castellar (Sector V), el punto más elevado de la ciudad. Más difícil de valorar es el hallazgo en superficie de una de estas puntas en la zona de Les Moreres, donde se localiza la necrópolis del asentamiento, aunque la posición estratégica de este altozano, en cuya vertiente sur se sitúa el espacio funerario, resulte indiscutible.

Las evidencias aportadas por el estudio de los contextos finales de ocupación de la ciudad orientalizante de Herna/Peña Negra y su contrastación con la dispersión de puntas de flechas con evidencias de impacto muestran el desarrollo de un episodio de inestabilidad generalizado en la ciudad en un momento ubicable en el segundo o tercer cuarto del VI a.C. que marcaría el final de la ciudad. En relación con este final de unos de los núcleos más destacados del poblamiento orientalizante del área del Bajo Segura-Vinalopó, podría apuntarse la continuación de estos episodios de inestabilidad creciente en el área de la propia ciudad fenicia de Guardamar. En una fecha en torno a mediados o segunda mitad del s. VI a.C., difícil de determinar ante la disparidad cronológica de las secuencia de ocupación de las fases finales de La Fonteta propuesta por los dos equipos que han realizado excavaciones en el lugar (Gailledrat, 2007: 22 ss.; González Prats, 2011: 1415), se identifica una última concentración de puntas de flecha de doble filo (F1-F4) que podría relacionarse con las evidencias de un episodio final de inestabilidad que conlleva además una posible necesidad de refuerzo de las estructuras defensivas en su sector septentrional a partir de mediados del s. VI a.C.
(Gailledrat, 2007: 71) y que se vincularía con la presencia de estos ejemplares con marcas de impacto en todos los casos hallados en los niveles finales de ocupación y que serán colmatados por el desplome definitivo de la muralla (vid. supra)

Por tanto, como hemos podido identificar a partir de la dispersión y contextualización de la presencia de concentraciones de puntas de flecha orientalizantes en los poblados estudiados, existen indicios para aproximarnos a estos contextos o episodios de violencia o inestabilidad que podrían motivar bien la necesidad de fortificación del asentamiento, tal y como nos mostraría la ciudad de La Fonteta, en cuya fase IV se levanta un potente sistema defensivo que reduciría el perímetro del asentamiento y para lo cual se desmantelan espacios productivos y sacros, como confirma la reutilización de elementos pétreos como betilos y molduras en la construcción apresurada de la fortificación (vid. supra). El caso de Peña Negra permitiría aproximarnos a un caso de posible asalto a una ciudad entre finales del s. VII y mediados del s. VI a.C., lo que explicaría la mayor concentración de hallazgos en los barrios exteriores, como los sectores IA, IB o VII, el conocido como barrio fenicio (González Prats, 1982b: 380; Id., 1993: 184), en el cual se identifica una posible reestructuración del hábitat a finales del s. VII a.C. con la destrucción de la vivienda angular del Corte A'5 a la que se asocia una de las más numerosas concentraciones de puntas de flecha (González Prats y Ruiz, 1990-91: 63) (vid. supra), mientras la revisión del contexto de hallazgo de otros ejemplares (PN10 y 11) podría plantear un episodio de inestabilidad relativamente posterior que obligue al abandono de un área de almacenes y dependencias anexas al sur del Sector VII en algún momento de la primera mitad del s. VI a.C., tal y como parece evidenciar el desmantelamiento de la barriada de casas del Sector IA, relacionado con la realización de ocultaciones (vid. supra). Estos posibles episodios de inestabilidad marcarán una progresiva remodelación del perímetro urbano en las primeras décadas del s. VI a.C. y, finalmente, supondrán el abandono del asentamiento, un fenómeno identificado en enclaves fortificados en áreas próximas al entorno del Bajo Segura-Vinalopó, como el Valle del Guadalentín (Lomba y Cano, 2002: 171-178), el Valle del Vinalopó (Pernas, 2005; Poveda y Pernas, e.p.) o la Sierra de Mariola (Grau, 2000: 116-118), entre otros (vid. supra).

Planteamos por tanto que, en los casos analizados, la presencia de altas concentraciones de puntas de flecha puede responder en algunos casos al desarrollo de episodios de asedio o ataque a los principales núcleos de población del Bajo Segura y Vinalopó. En relación a los contingentes humanos necesarios para el desarrollo de estos episodios, se ha planteado para el área 
tartésica un cálculo del número de contingentes necesarios para su defensa a partir del tamaño y entidad de las fortificaciones y de los rasgos propios de estos asentamientos que evidenciaría la existencia de "unidades políticas independientes, con milicias gentilicias y ciudadanas y una organización militar en que cada señor con sus clientes formarían parte de un importante ejército" (Almagro-Gorbea y Torres, 2007: 45-46). Si aplicamos este modelo a la zona de estudio, solo los centros mayores, como Herna/Peña Negra ${ }^{68}$, La Fonteta o El Castellar de Meca, con superficies que superan las 10 ha, serían capaces de movilizar un número elevado de guerreros, al menos entre $170 \mathrm{y}$ 350 , y desarrollar estrategias defensivas complejas, siendo necesario para su sometimiento el desarrollo de un ataque de gran envergadura.

\section{LAS PUNTAS DE FLECHA ORIENTALIZANTES Y SU PERDURACIÓN EN LA SEGUNDA EDAD DEL HIERRO}

Como hemos señalado, las puntas de flecha de bronce de doble filo, con y sin arpón lateral, y encaje tubular se fechan a nivel global en torno a los s. VII-VI a.C. (Ferrer, 1996: 46; Quesada, 1997: 447-448; etc.). No obstante, existen ejemplares en cronologías más recientes, en contextos de finales del s. V y el s. IV a.C., o incluso posteriores (Fig. 25), siempre en mucho menor número, que han sido identificados a veces como perduraciones o piezas antiguas reutilizadas (Ferrer, 1994: 47; Quesada, 1997: 447-448) ${ }^{69}$. Algunos hallazgos se han relacionado, no obstante, con episodios militares de finales del s. III a.C., por lo común con presencia púnica, por lo que su uso pudo mantenerse de forma esporádica entre las poblaciones del mediodía peninsular o las Islas Baleares hasta momentos avanzados (Elayi y Planas, 1995; Martínez Hahnmüller, 2012: 48; Quesada et al., 2015: 375).

Los casos más evidentes de la perduración de estos ejemplares son aquellos en los que las puntas de flecha de cubo aparecen en necrópolis ibéricas del Sureste y de la zona meridional del Levante, donde se fechan entre finales del s. V y el IV a.C. (Quesada, 1997: 448, 459-463). Un caso repetidamente citado es el de la punta de tipo 11a de la tumba 282 de El Cigarralejo
(Mula), una sepultura de la primera mitad del s. IV a.C. considerada como perteneciente a una mujer (Cuadrado, 1987: 490-492, fig. 213:18), que cabría interpretar como un posible amuleto o colgante, lo que podría explicar su presencia ocasional en tumbas femeninas (Quesada 1989: 179; Ferrer, 1994: 47), interpretación más plausible que relacionarla, como hizo Cuadrado (1987: 491), con la causa de la muerte de la difunta. Puntas del mismo tipo se han documentado en dos de las áreas funerarias del poblado de Coimbra de Barranco Ancho (Jumilla): un ejemplar en la tumba 20S de La Senda (Iniesta, 1986-91: Cuadro 1. 289 L: 29; García Cano 1997: 49, 246, 339, fig. 36S-6: S288), fechada de forma general en el s. IV a.C., aunque se trate de un ajuar, considerado también como femenino, poco significativo, y otra en la tumba 107 de $E l$ Poblado (García Cano et al., 2008: 135-136, fig. $163,10)$, una sepultura de guerrero fechada $c a$. 375300 a.C. Resulta interesante que en la tumba 32 de esta misma necrópolis (García Cano 1997: 246, fig. 50:10) se encontrara una pequeña punta de hoja lanceolada con pedúnculo macizo que, por su tamaño (14 mm), pudiera tratarse de un juguete, planteando para este tipo de piezas una funcionalidad muy diferente a la que debieron tener en época orientalizante. A estos hallazgos cabría añadir otra punta del tipo 11a que se conserva en el Museo de Albacete como procedente de la necrópolis de Hoya de Santa Ana (Chinchilla) (Quesada, 1989: 179) y dos ejemplares del mismo tipo recuperados en la necrópolis de Corral de Saus (Moixent, Valencia), ambos sin contexto (Aparicio, 1977: 25, fig. 8; Id., 1984: 195, 197; Izquierdo, 1995: 228-229, fig. 6), que ponen de manifiesto su utilización minoritaria como elementos de ajuar en diversas necrópolis de la zona ${ }^{70}$.

También se han recuperado algunos ejemplares en poblados ibéricos, aunque se trate de recogidas superficiales o con niveles revueltos, a menudo en emplazamientos que presentan niveles más antiguos de época orientalizante, lo que podría explicar su presencia en los yacimientos (Fig. 25). Este sería el caso de las puntas recogidas en el sector de Peña Negra conocido como El Castellar, así como de los

68 La ciudad orientalizante de Peña Negra incluiría una organización jerarquizada de fortines y territorios-satélite, entre los que destacaría en el entorno del Valle de Elda, el complejo Monastil-Camara-El Chorrillo, que sería sede de las elites sociales asociadas a su centro político, permitiendo extender el control territorial efectivo fuera de la chora o área territorial de la ciudad de Herna. Con este carácter estratégico podríamos relacionar la presencia de una punta de flecha con arpón en El Monastil y quizás los cuatro ejemplares de los que tenemos noticia en la zona de El Tabayá, en Aspe (M. Hernández, comunicación personal).

69 Resulta significativo a nuestro entender la ausencia de este tipo de armas en las necrópolis orientalizantes peninsulares, aunque sí se hayan recuperado en cementerios de ambiente púnico, como Villaricos o Puig des Molins (vid. infra).

70 Existen otros ejemplos en necrópolis de ambiente púnico como las de Villaricos o Puig des Molins (Ramon, 1983: 317-322). Los ejemplares de la necrópolis de Villaricos/Baria (Siret, 1909, lám VII, no 7 y 74; Astruc, 1951: lám. XLIX) corresponden a modelos con hoja marcadamente triangular, de doble filo asimétrico, tipo 22, o de triple filo, tipo 42, quizás como indicio de su mayor modernidad (Ferrer, 1996: 49; Quesada, 2011: 209-210). 
ejemplares de El Monastil, El Cabeçó de Mariola y La Serreta, ya citados (vid. supra). Otro caso quizás similar sería el de Bolvax (Cieza, Murcia), con cuatro puntas, de los tipos 11a (Lillo, 1981: 278-279 BOL, XIV-5), tipo 11b (Lillo 1981: 278-279 BOL, XIV-7), 12a (Lillo, 1981: 278-279 BOL, XIV-4) y 44b (Ibid.: 279-280 BOL, XIV-14), un enclave que presenta un alta variabilidad de tipos, hecho singular respecto al general predominio de las puntas tipo 11a (Fig. 25), sobre todo teniendo en cuenta que se han documentado en recogidas superficiales otros materiales quizá coetáneos, como una fíbula de doble resorte que podría indicar la existencia de una fase inicial orientalizante, así como un dracma de Lesbos que cabe fechar en el tránsito de los s. VI-V a.C. (Ibid.: 249, 278-279 BOL, XIV-8), además de la fase principal ibérico-romana (Ibid.: 249).

Un número importante de puntas, todas de tipo 11a, se han documentado también en el poblado ibérico de Coimbra del Barranco Ancho (Jumilla, Murcia) (Fig. 25), algunas recuperadas en contexto estratigráfico (Page et al. 1987: 68, n A-110; García Cano, 1997: 246; Quesada, 1997, 914), a la que se añade una hallada sin contexto en sus cercanías (Molina, Molina y Nördstrom, 1976: 67, fig. 43:281, lám. XXV:281), además de las dos recuperadas en las áreas cementeriales del entorno, ya citadas, aunque debe tenerse en cuenta que en torno a la Sierra de Santa Ana, en el Sitio del Maestre-Coimbra del Barranco Ancho se localiza un importante núcleo orientalizante (vid. supra).

En otros casos, la ausencia de niveles orientalizantes no deja lugar a dudas sobre su fecha avanzada, aunque su presencia siempre sea puramente testimonial, lo que ratifica que pudieran tratarse por tanto de perduraciones. Este es el caso de los dos ejemplares de La Bastida de les Alcuses (Moixent, Valencia), de tipo 11a el único conservado, un poblado fechado entre finales del s. V y el tercer cuarto del IV a.C. que ha proporcionado abundantes armas, lo que incide en su carácter excepcional, aunque se haya documentado otra punta más con pedúnculo (Quesada, 2011: 209-210). Testimonial es igualmente su presencia en el Puig de la Misericordia de Vinaròs (Castellón), con una punta de tipo 11a recuperada en el recinto 11000 , en el extremo de una calle probablemente relacionada con el acceso principal del poblado, asociada a materiales ibéricos cuya cronología se fija en época ibérica tardía, ca. s. II a.C., aunque el asentamiento presente niveles igualmente

71 Siete puntas de flecha más de este mismo emplazamiento, pero bajo el topónimo de Cerro del Manantial, formaban parte del Fondo Arqueológico Ricardo Marsal Monzón del s. VII a.C. (Oliver 1994: 86, 127, fig. 75; Quesada, 1997: 462-463).

También se han documentado este tipo de puntas en contextos sacros, lo que podría sugerir su condición de objeto singular, como ocurre en la cueva-santuario de El Calor (Cehegín, Murcia), con un ejemplar de tipo 11a (Lillo 1981: 41-42), aunque parece menos probable tal explicación para los hallazgos del Castillo de Guardamar (vid. supra).

Por último, la identificación de puntas de flecha con arpón, principalmente de ejemplares con más de dos filos, se ha relacionado con la presencia de tropas púnicas en contextos de finales del s. III a.C. relacionados con los episodios de la Segunda Guerra Púnica. Este podría ser el caso de los ejemplares de Villaricos/Baria, localizados por Siret (1909, lám. VI $\left.n^{\circ} 39-40\right)$ en el interior de una cisterna situada en la acrópolis de la ciudad (Martínez Hahnmüller, 2012: 39), junto a otros elementos militares, fechados a finales del s. III a.C. como un casco de bronce de tipo Montefortino de origen itálico, interpretado como botín de guerra (López Castro, 2005: 13). Corresponden a una punta de triple filo, tipo $42 \mathrm{de}$ Ferrer (1996: 51) / 43 de Ramon (1983), introducido por los cartagineses en la Península Ibérica (Martínez Hahnmüller, 2012: 39). Quizá refleje su carácter de frontera cultural la notable ausencia de ejemplares identificada en el Campo de Cartagena y Valle del Guadalentín, ámbito principal de la presencia púnica directa tardía desde la fundación de Qart Hadasth (Noguera et al., 2011: 499).

Igualmente, puntas de flecha del tipo que analizamos se han documentado en las prospecciones llevadas a cabo en el Cerro de las Albahacas (Santo Tomé, Jaén) ${ }^{71}$, escenario de la batalla de Baecula, que enfrentó a los ejércitos de romanos y cartagineses el 208 a.C. Se trata de dos puntas de tipo 11a, una de tipo 12b, otra de tipo 44a y una última relacionada con las puntas de flecha de la familia fenicio-púnica, que habrían sido usadas por el ejército cartaginés, posiblemente por contingentes turdetanos o del área costera entre Almería y Cádiz (Quesada et al. 2015: 371-375, fig. 27-28), donde se registra una fuerte implantación fenicio-púnica desde finales del s. IX a.C.

En otros contextos coetáneos de la Segunda Guerra Púnica se han identificado también puntas de flecha de doble filo y destacado arpón del tipo 11a en campamentos romanos de dichas cronologías como los ejemplares de Nova Classis 1'Aldea, Tarragona, de fines del s. III a.C. (Noguera, 2011: 56; Martínez Hahnmüller, 
2012: 49, lám. 18; Noguera et al. 2015: 67, fig. 4:3-5). Ya en nuestra área de estudio, destaca el hallazgo en Villajoyosa (Alicante), de un ejemplar tipo 11a localizado en un posible campamento cartaginés (Espinosa et al., 2008: 206-208, fig. 4:71). En todos estos casos, su asociación a materiales más antiguos podría indicar una cronología anterior ${ }^{72}$.

\section{Conclusiones}

En este trabajo se han estudiado un total de 46 puntas de flecha de doble filo y cubo pertenecientes a tres importantes enclaves urbanos del Hierro Antiguo en el área del Sureste, lo que nos ha permitido ampliar el conocimiento tipológico y arqueometalúrgico de este tipo de armamento, con evidencias de una mayor variabilidad que la hasta ahora reseñada gracias a la identificación de nuevos tipos de largo cañón con y sin arpón, minoritarios frente a los tipos que responden a los parámetros más estandarizados ampliamente representados tanto en el Sureste como en el resto de la Península Ibérica. Estos tipos singulares evidencian una distribución o fabricación regional, dado su relativo alto número dentro de nuestras colecciones en relación a su reducida identificación en otras zonas peninsulares, reflejada además en la distribución de tendencias morfométricas como plantean los Índices de Tamaño, de Proporcionalidad y de Uso (vid. supra). Así mismo destacamos una gran variabilidad tipológica entre los ejemplares estudiados de la variante puntas "pseudofenestradas", que con los nuevos datos sitúan a Peña Negra como el enclave con mayor número de ejemplares de toda la Península, mostrando de nuevo quizá una lectura regional de la distribución y/o fabricación de estas puntas, que sitúa al área septentrional del Sureste como un punto de referencia. Pero, sin duda, la aportación fundamental del estudio de estas colecciones de puntas orientalizantes de los enclaves de La Fonteta, Peña Negra y El Castellar de Meca ha sido el análisis de sus contextos de hallazgo, que nos aporta información relevante sobre la presencia de este tipo de armamento en ámbitos urbanos del Hierro Antiguo a partir de datos estratigráficos, situando al Sureste como un área de referencia al respecto. En este sentido, hemos podido corroborar la coexistencia en cronologías del s. VII-VI a.C. de los tipos más sencillos de doble filo y aquellos que cuentan con triple o cuádruple filo, lo que evidencia que forman parte

72 Los ejemplares de la desembocadura del Ebro se sitúan sobre niveles de la necrópolis ibérica de Mas de Mussols, fechada en el s. VI a.C. (Quesada, 2011: 210). El estrato donde se localizó el ejemplar de Villajoyosa, perteneciente del repertorio habitual orientalizante, con independencia de su perduración en contextos más modernos, lo que afecta igualmente a las formas más habituales, sobre todo el tipo 11a.

Se ha señalado que la identificación de la presencia de puntas de flecha orientalizantes en entornos urbanos puede ser un indicador en algunos casos de estos episodios de conflicto, sobre todo cuando su alta concentración, las huellas de impacto en los proyectiles y la localización en contextos de destrucción de viviendas, o su presencia en las propias fortificaciones o vaguadas próximas, permita apuntar su presencia no como algo puramente accidental, sino como vestigio de esta inestabilidad. No obstante, en otros casos, puede referirse a indicios de áreas artesanales donde se desarrollaría una producción local de dicho armamento o, incluso, permita reconstruir la distribución de equipos personales de armamento concentrados en entornos urbanos, que desarrollan un programa constructivo de fortificación, monumentalización y defensa de su perímetro urbano.

El estudio de algunos de los contextos de hallazgo denota una alta concentración de puntas de flecha en niveles de ocupación, así como el abandono o destrucción de destacados poblados orientalizantes o fenicios del Sureste peninsular, como podría reflejar Herna/Peña Negra, lo que nos permite analizar el proceso histórico de desmantelamiento de las estructuras poblacionales orientalizantes en la Península Ibérica (Ferrer, 1994: 44 ss.), que habitualmente se identifica con la denominada "crisis del siglo VI a.C." (Frankenstein, 1997: 211; una revisión, en López Castro 2001: 96-100), acompañada en ocasiones por episodios de inseguridad y peligro que explicarían la rápida y acelerada construcción de fortificaciones entre finales del s. VII y el VI a.C., siendo indicios destacados de esta inestabilidad la alta concentración de puntas de flecha y el desarrollo de ocultaciones, como las registradas en Peña Negra (vid. supra).

Este tipo de episodios los tenemos localizados en Pancorvo (Montellano, Sevilla), de donde proviene un importante lote de puntas de flecha halladas en labores agrícolas y por detectoristas en la zona de la muralla, algunas con evidentes señales de impacto (Mancebo y Ferrer 1988-89) y cuya cronología puede fijarse en el s. VI a.C., dada su asociación a un escarabeo, a fíbulas de tipo Alcores y a un ejemplar de tipo Acebuchal

a los tipos más sencillos, se asocia también a la presencia de cerámica ática, lo que podría plantear una cronología del s. V- IV a.C. (Espinosa et al., 2008: 208). 
(Mancebo y Ferrer 1988-89: 328; Mancebo y Ferrer 1992: 328; Mancebo 1996: 40, fig. 3:2). Más dudoso es el caso de Cástulo, donde al exterior de una muralla romana se hallaron una docena de flechas de este tipo (Blázquez 1979: 277-278, fig. 142: 18-29), que quizás deban relacionarse con una posible fortificación de época anterior.

Fuera de la Península Ibérica, el hallazgo de un conjunto de más de 70 puntas con dos, tres y cuatro filos (Barroul 1971: 377-378, fig. 11; Solier 197678: 213) en el área de las defensas del oppidum de Pech Maho (Sigean), atestigua el uso de este elemento armamentístico, tanto por los posibles atacantes, como por los defensores de este importante asentamiento del Midi francés. Las halladas en 1969 y 1970 se asociaban a dos copas jonias de barniz negro de tipo B2, un cántaro etrusco de bucchero nero, una crátera ática y un aríbalo del Corintio Tardío (Barroul 1971: 378), lo que permite fecharlas en el segundo cuarto o mediados del s. VI a.C.

Esta inestabilidad ha sido vinculada con la creciente competición y enfrentamiento entre las poblaciones coloniales, griegos, etruscos y fenicios, en el Mediterráneo Central y Occidental, desde mediados del s. VI a.C. por conseguir la preeminencia en el control de las redes de comercio mediterráneas (Krings 1998; Bernardini 2001) y la desintegración del sistema colonial y comercial fenicio tras la caída de Tiro a manos babilónicas en 573 a.C. y el inicio de una nueva etapa que se caracterizaría desde finales de siglo por el desarrollo incipiente de la influencia de Cartago en el Mediterráneo Occidental y por la irrupción del comercio griego, y que tendría como reflejo la fortificación o destrucción de importantes enclaves urbanos (Ferrer, 1995: 95) ${ }^{73}$. A esta explicación global, podemos contraponer una aproximación a escala regional y local (Ferrer, 1994: 51) que nos permita conocer la evolución de los modelos de poblamiento y territorialización de los poblados orientalizantes de áreas como el Bajo VinalopóSegura durante toda la etapa del Hierro Antiguo (s. VIII-VI a.C.) a fin de contrastar evidencias de un aumento de la inseguridad en el registro arqueológico y los conflictos latentes existentes entre las comunidades orientalizantes dentro de la implantación del modelo territorial orientalizante entre finales del s. VIII y el s. VI a.C.

73 Dado el avance en el conocimiento del registro y evidencias arqueológicas de contextos del s. VI a.C. como una etapa de eclosión y desarrollo, permite dibujar una visión de los procesos históricos acaecidos que matizan esta relación causaefecto entre la caída de Tiro y el desmantelamiento del modelo comercial y colonial fenicio en el Occidente (Aubet, 1987), sino que vienen a poner en relevancia la

\section{Bibliografía}

Abad Casal, L. (1992): "Terracotas ibéricas del Castillo de Guardamar". Estudios de Arqueología Ibérica y Romana. Homenaje a Enrique Pla Ballester. Trabajos varios del SIP, 89. Valencia: 225-238.

Abad Casal, L. (2010): “Terracotas ibéricas del Castillo de Guardamar", en A. García y L. Abad (coords,) Guardamar de Segura. Arqueología y Museo. MARQ. Alicante: 122-133.

Abascal, J. y R. Sanz (1993): Bronces antiguos del Museo de Albacete. Serie I-Estudios 67, Albacete.

Almagro-Gorbea, y M. Torres (2007): "Las fortificaciones tartésicas en el Suroeste peninsular", en L. Berrocal y P. Moret (eds.): Paisajes fortificados de la Edad del Hierro, Bibliotheca Archaeologica Hispana 28, Real Academia de la Historia. Madrid: 35- 56.

Aparicio, J. (1977): Las raíces de Mogente. Prehistoria y Protohistoria. Universidad de Valencia, Valencia.

Aparicio, J. (1984): "Tres monumentos ibéricos valencianos: La Bastida, Meca y el Corral de Saus". Varia III. II Curso de Historia y Cultura Valenciana «La Cultura Ibérica». Homenaje a Domingo Fletcher Valls. Serie Arqueológica 10. Universidad de Valencia. Valencia: 145-205.

Aquilué, X; Castanyer, P.; Santos, M. y J. Tremoleda (2006): "Noves evidencies del comerç fenici amb les comunitats indigenes de l'entorn d'Empuries". Simposi d'Arqueologia d'Alcanar. Alcanar: 171-190.

Armada, L.; Hunt, M.; Tresserras, J.J.; Montero, I.; Rafel, N. y J. Ruiz de Arbulo (2005): "Primeros datos arqueométricos sobre la metalurgia del poblado $\mathrm{y}$ necrópolis de Calvari del Molar (Priorat, Tarragona)". Trabajos de Prehistoria 62 (1): 139-155.

Astruc, M. (1951): La necrópolis de Villaricos. Informes y Memorias, 28, CGEA, Ministerio de Educación Nacional. Madrid.

Aubet, $\mathrm{M}^{\mathrm{a}}$ E. (1987): Tiro y las colonias fenicias de Occidente. Ed. Crítica. Barcelona.

Azuar, R. (2004): "Excavaciones (1984-1992) Espacios, arquitectura y estratigrafía”, en R. Azuar (coord.): El Ribat Califal. Excavaciones y estudios (1984-2002). Casa de Velázquez. Madrid: 7-72.

existencia de un modelo económico y comercial de desarrollo propio en Occidente, el cual vivirá una transformación respecto a las viejas estructuras en torno a mediados y finales del s. VI a.C., coincidiendo con el abandono de algunos poblados, la continuación de otros y el surgimiento de nuevos asentamientos en el cambio de siglo, éstos últimos marcando el nacimiento del mundo ibero. 
Azuar, R., Rouillard, P.; Gailledrat, E.; Moret, P.; Sala, F. y Badie, A. (1998): "El asentamiento orientalizante e ibérico antiguo de la Rabita, Guardamar del Segura (Alicante). Avance de las excavaciones 1996-1998". Trabajos de Prehistoria 55: 111-126. https://doi.org/10.3989/tp.1998.v55.i2.306

Barrier, P. y C. Montenat (2007): "Le paysage de l'époque protohistorique à l'embouchure du Segura", en P. Rouillard; E. Gailledrat y F. Sala (coords.): L'établissement protohistorique de la Fonteta (fin VIIIe - fin VIe siècle av. J.-C. Casa de Velázquez. Madrid: 7-21.

Barroul, G. (1971): "Circonscription de LanguedocRousillon”. Gallia 29: 370-405.

Bernardini, P. (2001): "La battaglia del Mare Sardo: una rilettura”. Rivista di Studi Fenici 29 (2): 135-158.

Berrocal Rangel, L. (2004): "La defensa de la comunidad: Sobre las fundaciones emblemáticas de las murallas protohistóricas en la Península Ibérica". Gladius XXIV: 27-98. https://doi.org/10.3989/gladius 2004.36

Berrocal Rangel, L. (2005): "Las fortalezas de entrada, un elemento de la poliorcética castreña desde el enfoque de la poliorcética romana". Norba 18: 11-25.

Berrocal-Rangel, L. y P. Moret (2007): "Las fortificaciones protohistóricas de la Hispania céltica. Cuestiones a debate", en L. Berrocal y P. Moret (eds.): Paisajes fortificados de la Edad del Hierro, Bibliotheca Archaeologica Hispana 28, Real Academia de la Historia. Madrid: 15-33.

Berrocal-Rangel, L. y A.C. Silva (2010): O Castro dos Ratinhos (Barragem do Alqueva, Moura). Escavações num povoado proto-histórico do Guadiana, 2004-2007. O Arqueólogo Português, Suplemento 6. Lisboa.

Blázquez, J.Mª. (1979): Cástulo II. Excavaciones Arqueológicas en España 105. Ministerio de Cultura. Madrid.

Bonet, T. (1995): El Tossal de Sant Miquel de Llíria: la antigua Edeta y su territorio. SIP. Valencia.

Bouscaras, A. y C. Hugues (1967): "La cargaison des bronzes de Rochelongues (Agde, Hérault) ". Rivista di Studi Liguri 33: 173-183.

Broncano, S. (1986): El Castellar de Meca. Ayora (Valencia). Excavaciones Arqueológicas en España 147. Ministerio de Cultura. Madrid.

Broncano, S. y Mª . M. Alfaro (1990): Los caminos de ruedas de la ciudad ibérica de «El Castellar de Meca» (Ayora, Valencia). Excavaciones Arqueológicas en España, 162. Ministerio de Cultura - Generalitat Valenciana. Madrid.

Broncano, S. y Ma . M. Alfaro (1997): Los accesos a la ciudad ibérica de Meca mediante sus caminos de ruedas. Trabajos Varios del SIP 92. Diputación Provincial de Valencia. Valencia.

Buchholz, H.G. (1962): “Die Pfeilglätter aus dem VI Schachtgrab von Mykene und die helladischen Pfeispitzen". Jahrbuch des Deutschen Archeologischen Instituts 77: 1-58.

Bueno, P.; García Menárguez, C. y F. Prados (2013): "Murallas fenicias de occidente. Una valoración conjunta de Las defensas del Cerro del Castillo (Chiclana, Cádiz) y del Cabezo Pequeño del Estaño (Guardamar, Alicante)". Herakleion 6: 27-75.

Cleuziou, S. (1977): "Les pointes de flèches «scythiques» au Proche et Moyen Orient". Le Plateau Iranien et l'Asie Centrale des origines à la conquête islamique. Leurs relations à la lùmiere des documents archéologiques. Editions du Centre National de la Recherche Scientifique. París: 187-19.

Cuadrado, E. (1987): La necrópolis ibérica de «El Cigarralejo» (Mula, Murcia). Bibliotheca Praehistorica Hispana 23. Consejo Superior de Investigaciones Científicas. Madrid.

Elayi, J. y A. Planas (1995): Les pointes de fléches en bronze d'Ibiza dans le cadre de la colonisation phénico-punique, Gabalda. París.

Espinosa, A; Ruiz Alcalde, D.; Marcos, A. y P. Peña (2008): "Nuevos testimonios romano-republicanos en Villajoyosa: un campamento militar del siglo I a.C.", en J. Uroz; J.M. Noguera y F. Coarelli (coords.): Iberia e Italia: modelos romanos de integración territorial. (Congreso HistóricoArqueológico Hispano-Italiano, 4, 2006. Murcia). Tabularium. Murcia: 199-220.

Fernández Flores, A.; Prados, E. y A. Rodríguez Azogue (2014): "Catálogo de sepulturas", en A. Fernández Flores; A. Rodríguez Azogue; M. Casado y E. Prados (eds.): La necrópolis de Alcalá de época tartésica de La Angorrilla, Alcalá del Río, Sevilla. Universidad de Sevilla. Sevilla: 85-249.

Ferrer Albelda, E. (1994): “Algunas cuestiones sobre cronología y dispersión de las puntas de flecha orientalizantes en la Península Ibérica”. Anales de Arqueología Cordobesa 5: 33-60.

Ferrer Albelda, E. (1995): "Sobre la hipotética función premonetal de las puntas de flecha orientalizantes de la Península Ibérica”. Anejos AEspA, XIV: 91-95.

Ferrer Albelda, E. (1996): "Sistematización de las puntas de flecha orientalizante, aspectos terminológicos y tipológicos". Antiquitas 7: 42-52.

Ferrer Albelda, E. y J. I. Ruiz Cecilia (2000): “Osuna en el periodo orientalizante: nuevos datos". Apuntes 2, $\mathrm{n}^{\mathrm{o}}$ 3: 126-141. 
Frankenstein, S. (1997): Arqueología del colonialismo. El impacto fenicio y griego en el sur de la Península ibérica y el suroeste de Alemania. Ed. Crítica. Barcelona.

Gailledrat, E. (2007): "La stratigraphie", en P. Rouillard; E. Gailledrat y F. Sala (coords.): L'établissement protohistorique de la Fonteta (fin VIIIe - fin VIe siècle av.J.-C.). Casa de Velázquez. Madrid: 23-97.

García y Bellido, A. (1952): "La colonización fenicia desde sus comienzos hasta la fundación de Ibiza (siglo XI hasta el 654)". Historia de España de R. Menéndez Pidal, Tomo I, Vol. II. España protohistórica. Las invasiones celticas y el Mundo de las Colonizaciones. Espasa-Calpe. Madrid: 311-336.

García Cano, J. Mª (1997): Las necrópolis ibéricas de Coimbra del Barranco Ancho (Jumilla. Murcia). I. Las excavaciones y estudio analítico de las excavaciones. Universidad de Murcia. Murcia.

García Cano, J. Mª Page, V.; Gallardo, I; Ramos F.; Hernández, E. y F. Gil (2008): El mundo funerario ibérico en el Altiplano Jumilla-Yecla (Murcia): La necrópolis de El Poblado de Coimbra de Barranco Ancho. Investigaciones de 1995-2004. Vol. II. Las incineraciones y sus ajuares. Proyecto Íberos Murcia. Fundación Adendia. Murcia.

García Guinea, M.A. (1959): "Excavaciones en la Provincia de Albacete. 1958-1959.". Archivo Español de Arqueología 32: 134-142.

García Guinea, M.A. (1960): "Excavaciones y estratigrafías en el poblado ibérico de El Macalón (Nerpio)", Revista de Archivos, Bibliotecas y Museos LXVIII-2: 709-755.

García Guinea, M.A. (1967): "Las puntas de flecha con anzuelo y doble filo y su proyección hacia Occidente". Archivo Español de Arqueología 40: 69-87.

García Guinea, M.A y J.A. San Miguel (1964): Poblado ibérico de El Macalón (Albacete) (Estratigrafías). $2^{\circ}$ Campaña. Excavaciones Arqueológicas en España 25. Madrid.

García Menárguez, A. (1992-93): “El Castillo de Guardamar. Nuevos datos sobre el poblamiento ibérico de la desembocadura del Segura". Alebus 2-3: 67-96.

García Menárguez, A. y B. Mas (2010): “Catálogo de piezas", en A. García y L. Abad (coords.): Guardamar del Segura, arqueología y museo: museos municipales en el MARQ. Exposición celebrada en el MARQ, diciembre 2010-febrero 2011. Alicante: 258-293.

García Menárguez, A. y F. Prados (2014): "La Presencia fenicia en la Península Ibérica: el Cabezo Pequeño del Estany (Guardamar, Alicante)".
Trabajos de Prehistoria 71, 1: 113-133. https://doi.org/10.3989/tp.2014.12127

Gascó, J. (2006): "Les pointes de flèches métalliques à la fin de l'Age du Bronze dans le sud de la France". Cypsela 16: 147-159.

Gil-Mascarell, M. (1981): "Bronce Tardío y Final en el País Valenciano”. El Bronce Final y el comienzo de la Edad del Hierro en el País Valenciano. Valencia: 9-39.

González Prats, A. (1976-78): "El tesorillo de tipo orientalizante de la Sierra de Crevillente". Ampurias 38-40: 349-360.

González Prats, A. (1977): "Nota preliminar sobre el yacimiento protoibérico de Crevillente, provincia de Alicante". XIV Congreso Nacional de Arqueología, Vitoria, 1975. Zaragoza: 671-680.

González Prats, A. (1979): Excavaciones en el yacimiento protohistórico de la Peña Negra, Crevillente (Alicante): ( $1^{a}$ y $2^{a}$ campañas). Ministerio de Cultura. Madrid.

González Prats, A. (1982a): "Las puntas de flecha con arpón de la Sierra de Crevillente" (De Protohistoria Alicantina, I). Ampurias 44: 257-261.

González Prats, A. (1982b): "La Peña Negra IV. Excavaciones en el Sector VII de la ciudad orientalizante de 1980-1981". Noticiario Arqueológico Hispánico 13: 305-418.

González Prats, A. (1983): Estudio arqueológico del poblamiento antiguo de la sierra de Crevillente (Alicante). Alicante.

González Prats, A. (1985a): "La Peña Negra, II-III. Campañas de 1978-1879”. Noticiario Arqueológico Hispánico 21: 7-155.

González Prats, A. (1985b): "Sobre unos elementos materiales del comercio fenicio en tierras del sudeste peninsular". Lucentum IV: 97-106. https://doi.org/10.14198/lvcentvm1985.4.06

González Prats, A. (1986): "La Peña Negra, V. Excavaciones de 1982 en el poblado del Bronce Antiguo y en el recinto fortificado ibérico". Noticiario Arqueológico Hispánico 27: 143-264.

González Prats, A. (1989): "Últimas aportaciones de las excavaciones realizadas en la Peña Negra (1983-1987) al Bronce Final y Hierro Antiguo del Sudeste y País Valenciano". XIX Congreso Arqueológico Nacional, Castellón de la Plana, 1987, Vol. 1: 467-476.

González Prats, A. (1993): “Quince años de excavaciones en la ciudad protohistórica de Herna (La Peña Negra, Crevillente, Alicante)". Saguntum 26: 181-188.

González Prats, A. (1998): "La Fonteta. El asentamiento fenicio de la desembocadura del río Segura 
(Guardamar, Alicante, España). Resultado de las excavaciones de 1996-97'. Rivista di Studi Fenici 26 (2): 191-228.

González Prats, A. (1999): La Peña Negra, VII. Excavaciones de 1986 en el Sector VII de la ciudad orientalizante. Memorias Arqueológicas y paleontológicas de la Comunidad Valenciana, $n^{\circ} 0$. Valencia.

González Prats, A. (2002): La necrópolis de cremación de Les Moreres (Crevillente, Alicante, España) ( $s$. IX-VII AC). Alicante.

González Prats, A. (2005): "El fenómeno orientalizante en el sudeste de la península Ibérica", en J. Jiménez Ávila y S. Celestino Pérez (coords.): $E l$ periodo orientalizante: Actas del III Simposio Internacional de Arqueología de Mérida, Protohistoria del Mediterráneo Occidental, Vol. 2. Mérida: 799-808.

González Prats, A. (2010a): "La colonia Fenicia de la Fonteta", en A. García y L. Abad (coords.): Guardamar del Segura, arqueología y museo: museos municipales en el MARQ. Exposición celebrada en el MARQ, diciembre 2010-febrero 2011. Alicante: 66-79.

González Prats, A. (2010b): “Anzuelos, fíbulas, pendientes y cuchillos: una muestra de la producción de los talleres metalúrgicos de La Fonteta". Lucentum, 29: 33-56. DOI: http://dx.doi.org/10.14198/ LVCENTVM2010.29.03

González Prats, A. (2011). La Fonteta. Excavaciones de 1996-2002 en la colonia fenicia de la actual desembocadura del río Segura (Guardamar del Segura, Alicante). Alicante.

González Prats, A. (2014a): "Útiles y objetos suntuarios", en A. González Prats (ed.) La Fonteta-II. Estudio de los materiales arqueológicos hallados en la colonia fenicia de la actual desembocadura del río Segura (Guardamar del Segura, Alicante). Vol. 1. Alicante: 239-425.

González Prats, A. (2014b y c) (ed.). La Fonteta-II. Estudio de los materiales arqueológicos hallados en la colonia fenicia de la actual desembocadura del río Segura (Guardamar del Segura, Alicante). Vol. 1 y II. Alicante.

González Prats, A. y A. García Menárguez (2000): “El conjunto fenicio de la desembocadura del río Segura (Guardamar del Segura, Alicante)", en M. Barthélemy y M.E. Aubet (coords.): Congreso Internacional de Estudios Fenicios y Púnicos, Cádiz, 1995. Vol. IV. Cádiz: 1527-1537.

González Prats, A. y E. Ruiz Segura (1990-91): "Nuevos datos sobre la urbanística y la cultura material en el Hierro Antiguo del Sudeste (Peña Negra, 1986)". Lucentum 9-10: 51-76.
González Prats, A y E. Ruiz Segura(1992): “Un poblado fortificado del Bronce Final en el Bajo Vinalopó". Homenaje a Enrique Pla Ballester, Trabajos Varios del S.I.P 89: 17-27.

González Prats, A. y E. Ruiz Segura (1999): “Una zona metalúrgica de la primera mitad del siglo VII en la ciudad fenicia de la Fonteta (Guardamar, Alicante)", XXIV Congreso Nacional de Arqueología, Cartagena, 1997, Vol. 3. Cartagena: 355-258.

González Prats, A. y E. Ruiz Segura (2000): El yacimiento fenicio de La Fonteta (Guardamar del Segura, Alicante, Comunitat Valenciana). Serie popular, 4 (Sección de Estudios Arqueológicos Valencianos - SEAV). Valencia.

González Reyero, S.; Renzi, M. y J. Sánchez-Palencia (2015): “Arqueometalurgia en la cuenca alta del río Segura durante la Edad del Hierro. Caracterización y estudio preliminar", en J. M. López Ballesta (coord.): PHICARIA, Minería y metalurgia en el Mediterráneo y su periferia oceánica. Mazarrón: 129-147.

González Wagner, C. (1988): "Gadir y los más antiguos asentamientos fenicios al este del Estrecho". Congreso Internacional El Estrecho de Gibraltar, vol. 1. Madrid: 419-428.

González Wagner, C. (2005): "Fenicios en el Extremo Occidente: conflicto y violencia en el contexto colonial arcaico". Revista Portuguesa de Arqueología 8(2): 177-192.

González Wagner, C. G. y J. Alvar (1989): "Fenicios en Occidente: la colonización agrícola”. Rivista di Studi Fenici XVII, 1: 61-102.

Gozálvez, A. (1975): "Notas sobre el poblamiento antiguo en el término de Crevillente". Archivo de Prehistoria Levantina 14: 161-167.

Gracia, F. (2000): “Análisis táctico de las fortificaciones ibéricas". Gladius 20: 131- 170. https://doi.org/10.3989/gladius.2000.67

Grau, I. (2000): "El poblado de Cabeço de Mariola (Alfafara, Alcoi)", en VV.AA. Catálogo Museu Arqueològic Camil Visedo. Alcoy: 116-118.

Grau, I. (2002): La organización del territorio en el área central de la "Contestania" Ibérica, Universidad de Alicante. Alicante.

Grau, I. y J. Moratalla (1999): "El oppidum ibérico de El Cabeçó de Mariola (Alfafara, Alicante)". XXIV Congreso Nacional de Arqueología, Cartagena, 1997, Vol. 3. Cartagena: 307-316.

Grau, I. y J. Moratalla (2001): “Interpretación socioeconómica del enclave”, en Abad, L y Sala, F. (eds.) El poblamiento ibérico del Bajo Segura. Bibliotheca Archaeologica Hispana 12. Real Academia de la Historia. Madrid: 173-203. 
Grau, I. y C. Reig (2002-03): "Sobre el uso de los metales en la Contestania ibérica: las evidencias de la Serreta". Recerques del Museu d'Alcoi 11-12: 101-150.

Guerrero, V.M.; Calvo, M. y B. Salvà (2002): "La Cultura Talayótica: una sociedad de la Edad del Hierro en la periferia de la colonización fenicia". Complutum 13: 221-258.

Guilaine, J. y S. Verger (2008): "Le Gaule et la Méditerranée (13e -8e siècles avant notre ère)", en S. Celestino; N. Rafel y X. L. Armada (eds.): Contacto cultural entre el Mediterráneo y el Atlántico (siglos XII-VIII ane). La precolonización a debate. CSIC. Roma: 219-237.

Gutiérrez, J. M . (2000): “Aportación a la producción de salazones de Gadir: la factoría púnico-gaditana 'Puerto 19". Revista de Historia de El Puerto 24: 11-46.

Gutiérrez, J. Mª y F. Giles (2004): "Útiles de pesca de la factoría de salazones P-19 (anzuelos, ganchos y punta de arpón tipo Macalón”, en A. Arévalo; D. Bernal y A. Torremocha (eds.): Garum y salazones en el Círculo del Estrecho. Ed. Osuna. Algeciras: 140-141.

Hernández, E. y F. Gil (2001-02): "Encanchados tumulares del Bronce Final y Hierro Antiguo en la necrópolis del Collado y Pinar de Santa Ana (Jumilla, Murcia)". Anales de Prehistoria y Arqueología de Murcia 17-18: 73-94.

Hrouda, B. (1965): Die Kulturgeschichte des assyrischen Flachbildes. Habelt. Saarbrücker Beiträge zur Altertumskunde, 2. Bonn.

Iniesta Sanmartín, A. (1986-1991): "Excavaciones en el poblado ibérico de Coimbra del Barranco Ancho. Campaña septiembre de 1985", Excavaciones y prospecciones arqueológicas en la Región de Murcia, 2 Memorias de Arqueología 1985-1986. Murcia: 131-148.

Iniesta Sanmartín, A., Page del Pozo, V. y J.M. García Cano (1987): Excavaciones arqueológicas en Coimbra del Barranco Ancho. Sepultura 70 de la necrópolis del Poblado. Murcia.

Izquierdo, I. (1995): "El contexto arqueológico de las dos grandes tumbas del Corral del Saus (Moixent, Valencia)". Verdolay 7: 217-237.

Kaiser, J.M. (2003): "Puntas de flecha de del Bronce en Producción, circulación y cronología”. Complutum 14: 73-106.

Krings, V. (1998): Carthage et les Grecs. 580-480 a.C. Textes et histoire. Brill, Leiden - Boston - Colonia.

Le Meaux, H. y M.D. Sánchez de Prado, Ma .D. (2007): "Le mobilier non céramique", en P. Rouillard; E. Gailledrat.y F. Sala (coords.):
L'établissement protohistorique de la Fonteta (fin VIIIe - fin VIe siècle av.J.-C.). Casa de Velázquez. Madrid: 319-337.

Lillo, P. (1981): El poblamiento ibérico en Murcia. Universidad de Murcia. Murcia.

Lomba, J. y M. Cano (2002): "El Cabezo de la Fuente del Murtal (Alhama)". Memorias de Arqueología 11: 165-204.

López Castro, J.L (2001): “Algunos debates en torno a la colonización fenicia en el Extremo Occidente", en J. L. López Castro (coord.): Colonos y comerciantes en el Occidente mediterráneo. Universidad de Almería. Almería: 87-107.

López Castro, J.L. (2005): “Astarté en Baria. Templo y producción entre los fenicios occidentales". Archivo Español de Arqueología 78: 5-21. https://doi.org/10.3989/aespa.2005.v78.71

López Palomo, L.A. (1981): "Bronces y plata tartésicos de Alhonoz y su hinterland". Zephyrus XXXIIXXXIII: 245-261.

López Salinas, I. (2015): "Re-excavando El Macalón (Nerpio, Albacete): panorama y perspectivas para una futura propuesta de estudio". Antesteria 4: 123-145.

Lorrio Alvarado, A.J. (1996): "Materiales cerámicos de la Cova Bolumini (Alfafara, Alicante) en el Museo Camil Visedo de Alcoy". Recerques del Museo d'Alcoi 5: 191-198.

Lorrio Alvarado, A.J. (2007): “El Molón (Camporrobles, Valencia) y su territorio: Fortificaciones y paisaje fortificado de un espacio de frontera", en L. Berrocal y P. Moret (eds.): Paisajes fortificados de la Edad del Hierro, Bibliotheca Archaeologica Hispana 28, Real Academia de la Historia. Madrid: 213-235.

Lorrio Alvarado, A.J. (2008): Qurénima. El Bronce Final del Sureste de la Península Ibérica, Bibliotheca Archaeologica Hispana, 27. Madrid.

Lorrio Alvarado, A.J. (2011): "Castellar de Meca. Anatomía de un oppidum ibérico". Las raíces de Almansa. Desde los orígenes del poblamiento hasta el fin de la Edad Media. XVI Jornadas de Estudio locales (Almansa, 17-21 de mayo de 2010), Jornadas de Estudios locales, 9. Almansa: 95-141.

Lorrio Alvarado, A.J. y M. Pérez Blasco (2015): “La inscripción latina pintada sobre cerámica de El Castellar (Crevillent, Alicante)". Lucentum XXXIV: 311-321. https://doi.org/10.14198/lvcentvm2015.34.14

Louis, M.; Taffanel, O. y J. Taffanel (1955): Le Premier Âge du Fer languedocien. Iere Partie, Les habitats. Inst.Int.d'Ét.Ligures, Monographies Prehistoriques, Bordighera - Montpellier. 
Mancebo, J. (1994): "Nuevos elementos orientalizantes en la Comarca de Gilena". SPAL 3: 291-299.

Mancebo, J. (1996): "El yacimiento protohistórico de Pancorvo (Sevilla)". Boletín de la Asociación de Amigos de la Arqueología 36: 37-46.

Mancebo, J. y E. Ferrer (1988-89): “Aproximación a la problemática de las puntas de flecha en época orientalizante. El yacimiento de Pancorvo (Montellano, Sevilla)". Zephyrus 41-42: 315-330.

Mancebo, J. y E. Ferrer (1992): "El escarabeo de Pancorvo (Montellano, Sevilla)”. SPAL 1: 313-320. https://doi.org/10.12795/spal.1992.i1.15

Marín-Aguilera, B. (2015): "Fronteras en construcción: diferenciación social y desterritorialización en el Sur Ibérico (siglos IX-VI a.C.)". Complutum 26 (1): 189-203. https://doi.org/10.5209/rev_cmpl. 2015.v26.n1.49347

Martínez, C. y M.C. Botella (1980): El Peñón de la Reina (Alboloduy-Almería), Excavaciones Arqueológicas en España 112. Madrid.

Martínez Hahnmüller, V. (2012): Baria II. La conquista romana de Baria. Editorial Universidad de Almería. Almería.

Maryon, H. (1961): "Early Near Eastern Steel Swords”. AJA 65, 2: 173-84. https://doi.org/10.2307/ 502669

Mata, C. (1991): Los Villares, Caudete de las Fuentes, Valencia: origen y evolución de la cultura ibérica. Servicio de Investigación Prehistórica, Diputación Provincial de Valencia. Valencia.

Mazar, E. (2004): The Phoenician family tomb n.l at the Northern cemetery of Achziv $\left(10^{\text {th }}-6^{\text {th }}\right.$ centuries BCE: Sam Turner expedition final report of the excavations. Cuadernos de Arqueología Mediterránea 10. Barcelona.

Molina, J.; Molina, M. de la C. y S. Nordstrom (1976): Coimbra del Barranco Ancho (Jumilla, Murcia). Serie de Trabajos Varios del S.I.P. 52. Diputación Provincial de Valencia. Valencia.

Montanero, D. (2008): "Los sistemas defensivos de origen fenicio-púnico del sureste peninsular (siglos VIII-III a.C.): nuevas interpretaciones", en B. Costa; J. H. Fernández (eds.) XXII Jornadas de Arqueología fenicio-púnica (Eivissa, 2007). Museo Arqueológico de Ibiza y Formentera. Ibiza: 91-144.

Montero Ruiz, I. (2008): “Ajuares metálicos y aspectos tecnológicos en la metalurgia del Bronce FinalHierro en el sudeste de la Península Ibérica l", en A. J. Lorrio, Qurénima. El Bronce Final del Sureste de la Península Ibérica, Bibliotheca Archaeologica Hispana, 27, Anejo a la revista Lucentum 17. Madrid: 499-516.
Montero-Ruiz, I. y M. Murillo-Barroso (2014): "Metales y aleaciones en la necrópolis de Loma del Boliche: nievas valoraciones", en A.J. Lorrio (dir.), La necrópolis orientalizante de Boliche (Cuevas del Almanzora, Almería). Bibliotheca Archaeologica Hispana 43, Studia HispanoPhoenicia 7, Real Academia de la Historia. Madrid: 243-245.

Moratalla, J. (2004): Organización del territorio y modelos de poblamiento en la Contestania Ibérica, Tesis Doctoral, Universidad de Alicante, Alicante. Consultada el 16/09/2015 en http://rua.ua.es/dspace/handle/10045/3751

Moret, P. (1996): Les fortifications ibériques. De la fin de l'Âge du Bronze à la conquête romaine. Collection de la Casa de Velázquez 56, Madrid.

Noguera, J. (2011): La conquesta romana de Catalunya. Institut Català d'Arqueologia Clàssica. Tarragona.

Noguera, J.; Ble, E. y P. Valdes (2015): “El campamento de La Palma-Nova Classis y la Segunda Guerra Púnica en el norte del río Ebro", en J.P. Bellón; A. Ruiz; C. Rueda y F. Gómez (eds.): La Segunda Guerra Púnica en la Península Ibérica. Baecula, Arqueología de una batalla. Universidad de Jaén. Servicio de Publicaciones. Jaén: 63-90.

Noguera Celdrán, J. M., Madrid Balanza, M.J. y V. Velasco Estrada (2011): "Novedades sobre la Arx Hasdrubalis de Qart Hadast (Cartagena): nuevas evidencias arqueológicas de la muralla púnica". CuPAUAM, 37-38: 479-507.

Oliver, A. (1994): El poblado ibérico del Puig de la Misericordia de Vinaròs. Associació Cultural Amics de Vinaròs. Vinaròs.

Page, V.; García Cano, J.M.; Iniesta, A. y M. a J. Ruiz (1987): Coimbra del Barranco Ancho. Diez Años de excavaciones. Murcia.

Padró, J. (1996): "Els escarabeus de la Serra de Crevillent". Fonaments 9: 219-232.

Pérez Ballester, J. (2014): “Entre el Bronce Final y el Hierro Antiguo. Las cerámicas a mano de la Solana del Castell (Xátiva, València)". Lucentum 33: 2339. https://doi.org/10.14198/lvcentvm2014.33.02

Pernas García, S. (2005): La investigación de la protohistoria antigua: el caso de las comarcas centrales y meridionales del Levante Peninsular, Memoria de Licenciatura. Inédito. Depositado en Dpto. Prehistoria e $\mathrm{H}^{\mathrm{a}}$ Antigua de la Universidad de Alicante, 2 vol. Alicante.

Pernas García, S. (2008): "Las formas de intercambio y las estructuras comerciales orientalizantes en la Vega Baja del Segura: dos variables de estudio arqueológico". Panta Rei, Revista de Ciencia y 
Didáctica de la Historia III, $2^{\mathrm{a}}$ época, CEPOAT, Universidad de Murcia: 105-152. https://doi.org/ 10.6018/pantarei/2008/7

Pernas García, S. (2010-2011): El uso funerario y la ocupación de cuevas durante el Bronce Final en las cuencas de los ríos Vinalopó y Segura. Ayudas a la investigación del Instituto de Cultura Juan GilAlbert. Alicante.

Pernas García, S. (2012): Las cuevas de enterramiento en el Bronce Final. Mundo funerario en los valles del Vinalopó y Serpis. Fundación municipal “José María Soler" de Villena. Villena.

Pla, E. (1973): "Castellar de Meca". Gran Enciclopedia de la Región Valenciana. Tomo III. Valencia: 84-85.

Pla, E. y H. Bonet (1991): "Nuevos hallazgos fenicios en yacimientos valencianos", en O. H. Frey; H. Roth y C. Dobiat (eds.): Festschrift für Wilhelm Schüle zum 60. Geburstag überreicht von Schülern und Freunden, Internationale Archäologie 1. Veröffentlichung des vorgeschtichtlichen Seminars Marburg 6. Verlag Marie L. Leidorf. Marburg: 245258.

Poveda, A. (1994): "Primeros datos sobre las influencias fenicio-púnicas en el corredor del Vinalopó (Alicante)", en A. González Blanco; J. L. Cunchillos y M. Molina (eds.): El mundo púnico. Historia, sociedad y cultura. Editorial Regional de Murcia. Murcia: 489-502.

Poveda, A. (2000): "Penetración cultural fenicia en el territorio indígena del valle septentrional del Vinalopó (Alicante)", en $\mathrm{M}^{\mathrm{a}}$.E. Aubet y M. Barthélemy (eds.): Actas del IV Congreso Internacional de Estudios Fenicios y Púnicos, IV. Servicio de Publicaciones de la Universidad de Cádiz. Cádiz: 1863-1874.

Poveda, A. y S. Pernas García (e.p.): "Nuevos datos sobre los enclaves de Camara y El Monastil y la ocupación Orientalizante en el Valle del Vinalopó (Elda, Alicante)". $8^{\circ}$ Coloquio Internacional del Centro de Estudios Fenicios y Púnicos, Guardamar del Segura-Alicante (noviembre, 2013), en prensa.

Prados Martínez F. y J..J. Blánquez Pérez (2007): “Las fortificaciones coloniales en la Península Ibérica: De los modelos orientales a los sistemas púnicohelenísticos", en L. Berrocal y P. Moret (eds.): Paisajes fortificados de la Edad del Hierro, Bibliotheca Archaeologica Hispana 28. Madrid: 57-74.

Quesada, F. (1989): "La utilización del arco y las flechas en la cultura ibérica". Trabajos de Prehistoria 46: 161-201. https://doi.org/10.3989/tp.1989.v46.i0.593

Quesada, F. (1997): El armamento ibérico: estudio tipológico, geográfico, funcional, social y simbóli- co de las armas en la Cultura ibérica (siglos VI-I a C.). Monique Mergoil, Montagnac.

Quesada, F. (2009): "La Guerra en la cultura ibérica", en M. Almagro-Gorbea (ed.). Historia militar de España. Vol. I, Ministerio de Defensa. Madrid: 111-130.

Quesada, F. (2011): “El armamento en un poblado ibérico del siglo IV a.C. Una oportunidad excepcional", en H. Bonet; J. Vives-Ferrándiz (eds.): La Bastida a Bastida de les Alcusses: 1928-2010, Museu de Prehistòria de València. Valencia: 197219.

Quesada, F.; Casado, M. y E. Ferrer (2014): "El armamento", en A. Fernández Flores; A. Rodríguez Azogue; M. Casado y E. Prados (eds.): La necrópolis de Alcalá de época tartésica de La Angorrilla, Alcalá del Río, Sevilla. Universidad de Sevilla. Sevilla: 351-378.

Quesada, F.; Gómez, F. y M. Molinos (2015): “El armamento hallado en el campo de batalla de Las Albahacas-Baecula”, en J.P. Bellón; A. Ruiz; C. Rueda y F. Gómez (coords.): La Segunda Guerra Púnica en la Península Ibérica. Baecula, Arqueología de una batalla. Universidad de Jaén. Servicio de Publicaciones. Jaén: 311-396.

Ramon Torres, J. (1983): "Puntas de flecha de bronce fenicio-púnicas halladas en Ibiza: algunos materiales inéditos". Homenaje al profesor Martín Almagro Basch.Vol.2. Ministerio de Cultura. Madrid: 209-223.

Reboreda, S. (1998): "El arco y las flechas en el Bronce Final y en el Hierro Inicial en Grecia". Gerión 16: 85-99.

Renzi, M. (2010): "La producción de "lingotes-hacha" en el Levante peninsular: nueva valoración a partir de los materiales de La Fonteta (Guardamar del Segura, Alicante)". Revista d'Arqueologia de Ponent 20: 127-144.

Renzi, M. (2013): La metalurgia del yacimiento fenicio de La Fonteta (Guardamar del Segura, Alicante), Biblioteca Praehistorica Hispana XXIX, CSIC. Madrid.

Ros Sala, M. (1989): Dinámica urbanística y cultura material del Hierro Antiguo en el Valle del Guadalentín. Universidad de Murcia. Colegio de Arquitectos de Murcia. Murcia.

Ros Sala, M. (1990): “Datos para una definición del Bronce Final Pleno en el Altiplano Yecla-Jumilla: las cazuelas carenadas de Coimbra del Barranco Ancho (Jumilla)". Trabajos de Prehistoria 47: 351362. https://doi.org/10.3989/tp.1990.v47.i0.580

Rodríguez Cordones, M. ${ }^{a}$ R. (1996): “Dos ejemplares de puntas de flecha de época orientalizante en Coria del Río (Sevilla)". Spal 5: 225-231. https://doi.org/10.12795/spal.1996.i5.12 
Rouillard, P.; Gailledrat, E. y F. Sala (2007): L'établissement protohistorique de la Fonteta (fin VIIIe - fin VIe siècle av.J.-C. Casa de Velázquez. Madrid.

Rouillard, P. (2010): "La Fonteta / Rábita (Guardamar del Segura, Alicante): Las excavaciones hispanofrancesas, 1996-2001", en A. García y L. Abad (coords,): Guardamar del Segura, arqueología y museo: museos municipales en el MARQ. Exposición celebrada en el MARQ, diciembre 2010-febrero 2011. Alicante: 80-89.

Rovira, S. (1995): “De metalurgia tartésica”. Tartessos 25 años después, Actas del Congreso conmemorativo del V Symposium Internacional de Prehistoria Peninsular. Jerez de la Frontera: 475-506.

Rovira, S.; Montero, I.; Ortega, J. y J. Jiménez Ávila (2005): "Bronce y trabajo del bronce en el poblado orientalizante de 'El Palomar' (Oliva de Mérida, Badajoz)", en S. Celestino y J. Jiménez Ávila (eds.): El Período Orientalizante. Actas del III Simposio Internacional de Arqueología de Mérida: Protohistoria del Mediterráneo Occidental. CSIC. Madrid: 1231-1240.

Ruiz Rodríguez, A. (2014): "La Protohistoria en el FARMM". FARMM Fondo Arqueológico Ricardo Marsal Monzón. Consejería de Cultura de la Junta de Andalucía. Sevilla: 119-130.

Ruíz Rodríguez, A. y C. Rueda (2014): “Los exvotos de bronce del FARMM: oppida y santuarios". FARMM Fondo Arqueológico Ricardo Marsal Monzón. Consejería de Educación, Cultura y Deporte de la Junta de Andalucía. Sevilla: 131-144.

Ruiz Zapatero, G. (1985): Los Campos de Urnas del $N E$ de la Península Ibérica. Universidad Complutense. Tesis Doctoral. Madrid.

Sáez Romero, J.M. (2009): “El Templo de Merlkart de Gadir: hito religioso-económico y marítimo. Consideraciones sobre su relación con la industria conservera", en P. Mateos Cruz, S. Celestino Pérez, A. Pizzo, T. Tortosa Rocamora (coords.) Santuarios, oppida y ciudades: Arquitectura sacra en el origen y desarrollo urbano del mediterráneo occidental. Anejos de AEA, XLV. Mérida: 115-130.

Sánchez Meseguer, J. (1974): "Nuevas aportaciones al tema de las puntas “a barbillón”. CupaUAM 1: 71-101.

Simón, J.L. (1998): La metalurgia prehistórica valenciana. Trabajos Varios del SIP 93. Diputación Provincial de Valencia. Valencia.

Simón, J. L., Hernández Carrión, E. y Gil González, F. (1999): La Metalurgia en el Altiplano Jumilla y Yecla: Prehistoria y Protohistoria. CAM. Jumilla.

Siret, L. (1891-2001): España Prehistórica. L'Espagne préhistorique. Almería.
Siret, L. (1909): Villaricos y Herrerías: antigüedades púnicas, romanas, visigóticas y árabes. Real Academia de la Historia. Madrid.

Snodgrass, A.M. (1964): Early Greek armour and weapons from the end of the Bronze Age to 600 B.C. University Press. Edinburgh.

Snodgrass, A.M. (1967): Arms and armour of the Greeks. Thames and Hudson. Londres.

Solier, Y. (1976-78): "La culture ibéro-languedocienne aux VIe-Ve siècles“. Ampurias 38-40: 211-264.

Soria Combadiera, L. (2000): La cultura ibérica en la provincia de Albacete: génesis y evolución a través del estudio del poblamiento. Universidad de Castilla-La Mancha.

Sulimirski, T. (1954): "Scytian antiquities in Western Asia”. Artibus Asiae 17: 282-318. https://doi.org/ 10.2307/3249059

Tent-Mancús, J. E. y J. M. Soria(2014): “Formación y desecación del sinus ilicitanus (Sur de Alicante) en los últimos 15.000 años". Geogaceta 55: 35-38.

Torres, M. (2002): Tartessos. Real Academia de la Historia. Madrid.

Torres, M. (2008): "Urnas de tipo Cruz del Negro", en M. Almagro-Gorbea (dir.) La necrópolis de Medellín. II. El estudio de los hallazgos. Bibliotheca Archaeologica Hispana 26-2. Real Academia de la Historia. Madrid: 631-654.

Torres, M. (2009a): "Tartessos", en M. AlmagroGorbea (coord.) Historia militar de España. I. Prehistoria y Antigüedad. Ministerio de Defensa. Ediciones del Laberinto. Madrid: 99-110.

Torres, M. (2009b): "La guerra en el ámbito hispanofenicio", en M. Almagro-Gorbea (coord.) Historia militar de España. I. Prehistoria y Antigüedad. Ministerio de Defensa. Ediciones del Laberinto. Madrid: 153-159.

Trelis Martí, J. y F.J. Molina Mas (e.p.): “Control y defensa del territorio de la Penya Negra (Crevillent, Alicante): los fortines de "Les Barricaes" y "El Cantal de la Campana"". $8^{\circ}$ Coloquio Internacional del Centro de Estudios Fenicios y Púnicos, Guardamar del Segura-Alicante (noviembre, 2013), en prensa.

Ulreich, H.; Negrete, M. A.; Puch, E. y L. Perdigones (1990): “Cerro del Prado. Die Ausgrabungen 1989 im Schuttang der phönizischen Ansiedlung an der Guadarranque-Mündung". Madrider Mitteilungen 31: 194-250.

Vives Escudero, A. (1917): Estudio de arqueología cartaginesa. La necrópolis de Ibiza. Madrid.

Vives-Ferrándiz, J. (2005): Negociando encuentros. Situaciones coloniales e intercambios en la costa oriental de la Península Ibérica. Cuadernos de Arqueología Mediterránea 12. Barcelona. 
Vives-Ferrándiz, J. y C. Mata (2011): “La ocupación del Hierro antiguo al Ibérico antiguo. La Vital (Gandía, Valencia)", en G. Pérez Jordà; J. Bernabeu; Y. Carrión; O. García Puchol; Ll. Molina y M. Gómez (eds.): Vida y muerte en la desembocadura del Serpis durante el III y el I milenio a.C. Trabajos Varios del SIP 113. Diputación de Valencia.Valencia: 35-52.
Zarzalejos, M. y F.J. López Precioso (2005): "Apuntes para una caracterización de los procesos orientalizantes en la Meseta sur", en S. Celestino y J. Jiménez Ávila (eds.): El Período Orientalizante. Actas del III Simposio Internacional de Arqueología de Mérida: Protohistoria del Mediterráneo Occidental. CSIC. Madrid: 809-842. 